\title{
Safety Analysis of Interchanges
}

\author{
June 2007
}




\section{FOREWORD}

The objectives of this research are to synthesize the current state of knowledge concerning safety assessment of new or modified interchanges; develop a spreadsheet-based computational tool for performing safety assessments of interchanges; and identify gaps in knowledge concerning interchange safety assessment and future research needs to fill those gaps. The primary deliverables of this research are (1) the spreadsheet-based analytical tool [i.e., Interchange Safety Analysis Tool (ISAT)] which provides design and safety engineers with a means for assessing the safety effects of new and existing interchanges, (2) a user manual (FHWA-HRT-07-045) which provides detailed descriptions/instructions on the usage and operation of ISAT, and (3) this final report. This report summarizes the capabilities of ISAT, summarizes safety data related to interchanges, summarizes safety literature related to interchanges, presents results of telephone interviews with key stakeholders to investigate their needs and requirements in safety evaluations of interchanges, and identifies substantive gaps in the current state of knowledge that limit the ability of ISAT to provide all of the capabilities desired by potential users and provides a brief summary of the needed research to address these gaps. The report also contains the detailed algorithms utilized in the calculations of the ISAT program.

Michael Trentacoste

Director, Office of Safety

Research and Development

\section{Notice}

This document is disseminated under the sponsorship of the U.S. Department of Transportation in the interest of information exchange. The U.S. Government assumes no liability for the use of the information contained in this document.

The U.S. Government does not endorse products or manufacturers. Trademarks or manufacturers' names appear in this report only because they are considered essential to the objective of the document.

\section{Quality Assurance Statement}

The Federal Highway Administration (FHWA) provides high-quality information to serve Government, industry, and the public in a manner that promotes public understanding. Standards and policies are used to ensure and maximize the quality, objectivity, utility, and integrity of its information. FHWA periodically reviews quality issues and adjusts its programs and processes to ensure continuous quality improvement. 


\section{TECHNICAL REPORT DOCUMENTATION PAGE}

\begin{tabular}{|c|c|c|c|c|c|c|}
\hline 1. Report No. & \multicolumn{3}{|c|}{ 2. Government Accession No. } & \multicolumn{3}{|c|}{ 3. Recipient's Catalog No. } \\
\hline \multirow{2}{*}{\multicolumn{4}{|c|}{$\begin{array}{l}\text { 4. Title and Subtitle } \\
\text { Safety Analysis of Interchanges }\end{array}$}} & \multicolumn{3}{|c|}{$\begin{array}{l}\text { 5. Report Date } \\
\text { June } 2007\end{array}$} \\
\hline & & & & \multicolumn{3}{|c|}{$\begin{array}{l}\text { 6. Performing Organization Code: } \\
440545878\end{array}$} \\
\hline \multicolumn{4}{|c|}{$\begin{array}{l}\text { 7. Author(s) } \\
\text { D.J. Torbic, D.W. Harwood, D.K. Gilmore, and } \\
\text { K.R Richard }\end{array}$} & \multicolumn{3}{|c|}{$\begin{array}{l}\text { 8. Performing Organization Report No. } \\
110448\end{array}$} \\
\hline \multirow{2}{*}{\multicolumn{4}{|c|}{$\begin{array}{l}\text { 9. Performing Organization Name and Address } \\
\text { Midwest Research Institute } \\
425 \text { Volker Blvd } \\
\text { Kansas City, MO } 64110\end{array}$}} & \multicolumn{3}{|c|}{$\begin{array}{l}\text { 10. Work Unit No. } \\
001\end{array}$} \\
\hline & & & & \multicolumn{3}{|c|}{$\begin{array}{l}\text { 11. Contract or Grant No. } \\
\text { DTFH61-05-P-00302 }\end{array}$} \\
\hline \multirow{2}{*}{\multicolumn{4}{|c|}{$\begin{array}{l}\text { 12. Sponsoring Agency Name and Address } \\
\text { Federal Highway Administration } \\
\text { Turner-Fairbank Highway Research Center } \\
\text { Office of Safety Research and Development } \\
6300 \text { Georgetown Pike } \\
\text { McLean, VA 22101-2296 }\end{array}$}} & \multicolumn{3}{|c|}{$\begin{array}{l}\text { 13. Type of Report and Period Covered } \\
\text { Final Report, (9/7/2005 - 6/31/2007) }\end{array}$} \\
\hline & & & & \multicolumn{3}{|c|}{$\begin{array}{l}\text { 14. Sponsoring Agency Code } \\
\text { HRDS-05 }\end{array}$} \\
\hline \multicolumn{7}{|c|}{$\begin{array}{l}\text { 15. Supplementary Notes } \\
\text { FHWA Contracting Officer's Technical Representative (COTR): Joe G. Bared }\end{array}$} \\
\hline \multicolumn{7}{|c|}{$\begin{array}{l}\text { 16. Abstract } \\
\text { The objectives of this research are to synthesize the current state of knowledge concerning the safety assessment } \\
\text { of new or modified interchanges; develop a spreadsheet-based computational tool for performing safety } \\
\text { assessments of interchanges; and identify gaps in knowledge concerning interchange safety assessment and future } \\
\text { research needs to fill those gaps. This report summarizes the capabilities of the spreadsheet-based Interchange } \\
\text { Safety Analysis Tool (ISAT), summarizes safety data related to interchanges, summarizes safety literature related } \\
\text { to interchanges, presents results of telephone interviews with key stakeholders to investigate their needs and } \\
\text { requirements in safety evaluations of interchanges, and identifies substantive gaps in the current state of } \\
\text { knowledge that limit the ability of ISAT to provide all of the capabilities desired by potential users and provides a } \\
\text { brief summary of the needed research to address these gaps. This report also contains the detailed algorithms } \\
\text { utilized in the calculations of the ISAT program. The other primary deliverables of this research are (1) the } \\
\text { spreadsheet-based analytical tool (i.e., ISAT) and (2) an accompanying user manual (FHWA-HRT-07-045) } \\
\text { which provides detailed descriptions/instructions on the usage and operation of ISAT. }\end{array}$} \\
\hline \multicolumn{3}{|c|}{$\begin{array}{l}\text { 17. Key Words } \\
\text { Interchange, safety, geometric design, safety } \\
\text { performance function }\end{array}$} & \multicolumn{4}{|c|}{$\begin{array}{l}\text { 18. Distribution Statement } \\
\text { No restrictions. This document is available through the } \\
\text { National Technical Information Service, Springfield, VA } \\
22161 \text {. }\end{array}$} \\
\hline \multicolumn{2}{|c|}{$\begin{array}{l}\text { 19. Security Classif. (of this report) } \\
\text { Unclassified }\end{array}$} & \multicolumn{3}{|c|}{$\begin{array}{l}\text { 20. Security Classif. (of this page) } \\
\text { Unclassified }\end{array}$} & $\begin{array}{l}\text { 21. No. of Page } \\
48\end{array}$ & $\begin{array}{l}\text { 22. Price } \\
\text { N/A }\end{array}$ \\
\hline
\end{tabular}

Form DOT F 1700.7 (8-72)

Reproduction of completed page authorized 


\begin{tabular}{|c|c|c|c|c|}
\hline \multicolumn{5}{|c|}{$\begin{array}{c}\text { SI* (MODERN METRIC) CONVERSION FACTORS } \\
\text { APPROXIMATE CONVERSIONS TO SI UNITS }\end{array}$} \\
\hline Symbol & When You Know & Multiply By & To Find & Symbol \\
\hline \multicolumn{5}{|c|}{ LENGTH } \\
\hline in & inches & 25.4 & millimeters & $\mathrm{mm}$ \\
\hline $\mathrm{ft}$ & feet & 0.305 & meters & $\mathrm{m}$ \\
\hline yd & yards & 0.914 & meters & $\mathrm{m}$ \\
\hline $\mathrm{mi}$ & miles & 1.61 & kilometers & $\mathrm{km}$ \\
\hline \multicolumn{5}{|c|}{ AREA } \\
\hline in $^{2}$ & square inches & 645.2 & square millimeters & $\mathrm{mm}^{2}$ \\
\hline $\mathrm{ft}^{2}$ & square feet & 0.093 & square meters & $\mathrm{m}^{2}$ \\
\hline $\mathrm{yd}^{2}$ & square yard & 0.836 & square meters & $\mathrm{m}^{2}$ \\
\hline $\mathrm{ac}$ & acres & 0.405 & hectares & ha \\
\hline $\mathrm{mi}^{2}$ & square miles & 2.59 & square kilometers & $\mathrm{km}^{2}$ \\
\hline \multicolumn{5}{|c|}{ VOLUME } \\
\hline $\mathrm{fl} \mathrm{oz}$ & fluid ounces & 29.57 & milliliters & $\mathrm{mL}$ \\
\hline gal & gallons & 3.785 & liters & $\mathrm{L}$ \\
\hline $\mathrm{ft}^{3}$ & cubic feet & 0.028 & cubic meters & $\mathrm{m}^{3}$ \\
\hline $\mathrm{yd}^{3}$ & cubic yards & 0.765 & cubic meters & $\mathrm{m}^{3}$ \\
\hline \multicolumn{5}{|c|}{ NOTE: volumes greater than $1000 \mathrm{~L}$ shall be shown in $\mathrm{m}^{3}$} \\
\hline \multicolumn{5}{|c|}{ MASS } \\
\hline $\mathrm{OZ}$ & ounces & 28.35 & grams & $\mathrm{g}$ \\
\hline $\mathrm{lb}$ & pounds & 0.454 & kilograms & $\mathrm{kg}$ \\
\hline $\mathrm{T}$ & short tons $(2000 \mathrm{lb})$ & 0.907 & megagrams (or "metric ton") & $\mathrm{Mg}$ (or "t") \\
\hline \multicolumn{5}{|c|}{ TEMPERATURE (exact degrees) } \\
\hline${ }^{\circ} \mathrm{F}$ & Fahrenheit & $\begin{array}{c}5(\mathrm{~F}-32) / 9 \\
\text { or }(\mathrm{F}-32) / 1\end{array}$ & Celsius & ${ }^{\circ} \mathrm{C}$ \\
\hline \multicolumn{5}{|c|}{ ILLUMINATION } \\
\hline fc & foot-candles & 10.76 & $\operatorname{lux}$ & Ix \\
\hline $\mathrm{fl}$ & foot-Lamberts & 3.426 & candela $/ \mathrm{m}^{2}$ & $\mathrm{~cd} / \mathrm{m}^{2}$ \\
\hline \multicolumn{5}{|c|}{ FORCE and PRESSURE or STRESS } \\
\hline & poundforce & 4.45 & newtons & $\mathrm{N}$ \\
\hline $\mathrm{lbf} / \mathrm{in}^{2}$ & poundforce per square inch & 6.89 & kilopascals & $\mathrm{kPa}$ \\
\hline \multicolumn{5}{|c|}{ APPROXIMATE CONVERSIONS FROM SI UNITS } \\
\hline Symbol & When You Know & Multiply By & To Find & Symbol \\
\hline \multicolumn{5}{|c|}{ LENGTH } \\
\hline $\mathrm{mm}$ & millimeters & 0.039 & inches & in \\
\hline $\mathrm{m}$ & meters & 3.28 & feet & $\mathrm{ft}$ \\
\hline $\mathrm{m}$ & meters & 1.09 & yards & yd \\
\hline $\mathrm{km}$ & kilometers & 0.621 & miles & $\mathrm{mi}$ \\
\hline \multicolumn{5}{|c|}{ AREA } \\
\hline $\mathrm{mm}^{2}$ & square millimeters & 0.0016 & square inches & $\mathrm{in}^{2}$ \\
\hline $\mathrm{m}^{2}$ & square meters & 10.764 & square feet & $\mathrm{ft}^{2}$ \\
\hline $\mathrm{m}^{2}$ & square meters & 1.195 & square yards & $y d^{2}$ \\
\hline ha & hectares & 2.47 & acres & ac \\
\hline $\mathrm{km}^{2}$ & square kilometers & 0.386 & square miles & $\mathrm{mi}^{2}$ \\
\hline \multicolumn{5}{|c|}{ VOLUME } \\
\hline $\mathrm{mL}$ & milliliters & 0.034 & fluid ounces & $\mathrm{fl} \mathrm{oz}$ \\
\hline L & liters & 0.264 & gallons & gal \\
\hline $\mathrm{m}^{3}$ & cubic meters & 35.314 & cubic feet & $\mathrm{ft}^{3}$ \\
\hline $\mathrm{m}^{3}$ & cubic meters & 1.307 & cubic yards & $\mathrm{yd}^{3}$ \\
\hline \multicolumn{5}{|c|}{ MASS } \\
\hline g & grams & 0.035 & ounces & $\mathrm{oz}$ \\
\hline & kilograms & 2.202 & pounds & $\mathrm{lb}$ \\
\hline $\mathrm{Mg}$ (or "t") & megagrams (or "metric ton") & 1.103 & short tons $(2000 \mathrm{lb})$ & $\mathrm{T}$ \\
\hline \multicolumn{5}{|c|}{ TEMPERATURE (exact degrees) } \\
\hline${ }^{\circ} \mathrm{C}$ & Celsius & $1.8 \mathrm{C}+32$ & Fahrenheit & ${ }^{\circ} \mathrm{F}$ \\
\hline \multicolumn{5}{|c|}{ ILLUMINATION } \\
\hline $\mathrm{Ix}$ & $\operatorname{lux}$ & 0.0929 & foot-candles & fc \\
\hline $\mathrm{cd} / \mathrm{m}^{2}$ & candela $/ \mathrm{m}^{2}$ & 0.2919 & foot-Lamberts & $\mathrm{fl}$ \\
\hline & FOF & nd PRESSUR & RESS & \\
\hline $\mathrm{N}$ & newtons & 0.225 & poundforce & lbf \\
\hline $\mathrm{kPa}$ & kilopascals & 0.145 & poundforce per square inch & $\mathrm{lbf} / \mathrm{in}^{2}$ \\
\hline
\end{tabular}




\section{TABLE OF CONTENTS}

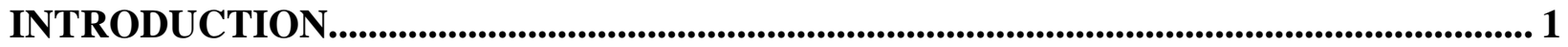

RESEARCH OBJECTIVES AND SCOPE ................................................................ 1

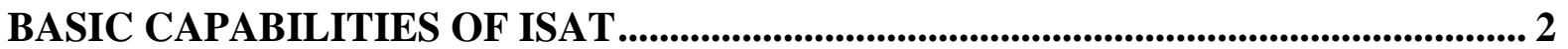

ORGANIZATION OF THIS REPORT......................................................................... 3

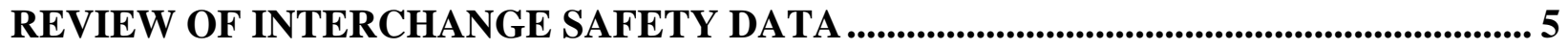

FATALITY ANALYSIS REPORTING SYSTEM (FARS) ...................................... 5

Proportion of Interchange-Related Crashes for the Roadway System as a Whole .... 5

Proportion of Interchange-Related Crashes for the Freeway System ......................... 7

Distribution of Crashes by Portion of Interchange Area ............................................. 7

Distribution of Crashes by Collision Type and Manner of Collision ........................... 7

Distribution of Crashes by Relation to Roadway..................................................... 10

Distribution of Crashes by Traffic Control Device............................................................ 10

Distribution of Crashes by Light Condition.................................................................. 10

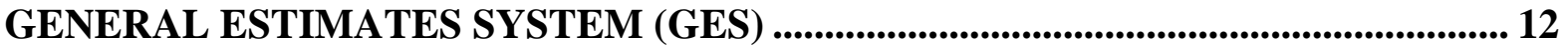

Proportion of Interchange-Related Crashes for the Roadway System as a Whole .. 13

Distribution of Crashes by Portion of Interchange Area ........................................... 13

Distribution of Crashes by Collision Type and Manner of Collision.......................... 13

Distribution of Crashes by Relation to Roadway............................................................... 17

Distribution of Crashes by Traffic Control Device..................................................... 17

Distribution of Crashes by Light Condition............................................................ 19

ESTIMATED NUMBER OF INTERCHANGES IN THE UNITED STATES .............. 20

REVIEW OF SAFETY PERFORMANCE FUNCTIONS FOR INTERCHANGE

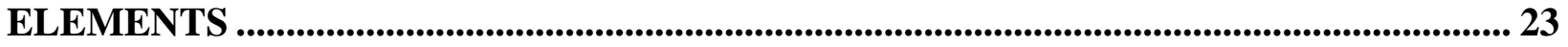

OVERVIEW OF PRIMARY SOURCES ....................................................................... 26

SafetyAnalyst .................................................................................................................... 26

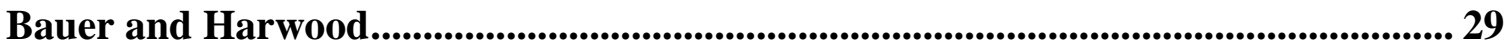

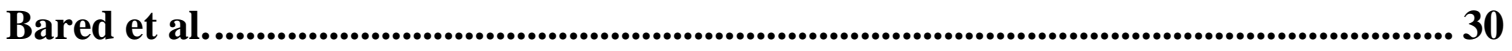

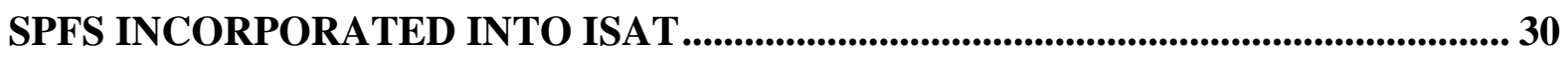

Mainline Freeway Segments ............................................................................................ 31

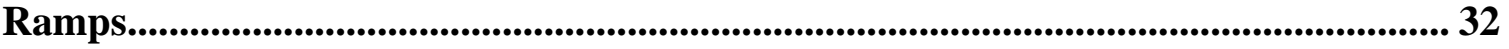

Crossroad Ramp Terminals and Intersections ............................................................. 37 
Crossroad Roadway Segments.................................................................................. 40

INTERVIEWS WITH EXPERIENCED DESIGNERS ...................................................... 45

IDENTIFIED GAPS IN KNOWLEDGE................................................................... 47

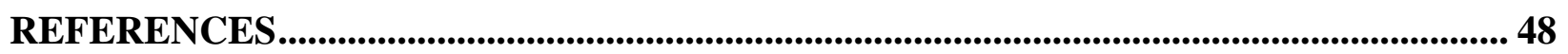

APPENDIX A-RESEARCH PROBLEM STATEMENTS .............................................. 49

APPENDIX B-PROCESSING ALGORITHMS OF ISAT ...............................................8 81 


\section{LIST OF FIGURES}

FIGURE 1. TYPICAL INTERCHANGE CONFIGURATION ${ }^{6}$............................................. 24

FIGURE 2. TYPICAL RAMP CONFIGURATIONS ${ }^{6}$.............................................................. 25

FIGURE 3. TYPICAL GORE AREA CHARACTERISTICS ${ }^{7}$............................................ 31 


\section{LIST OF TABLES}

TABLE 1. FATAL CRASHES FOR ALL ROADWAY TYPES BY RELATIONSHIP TO INTERCHANGES

TABLE 2. FATAL CRASHES FOR FREEWAYS BY RELATIONSHIP TO

INTERCHANGES 8

TABLE 3. FATAL INTERCHANGE-RELATED CRASHES BY PORTION OF INTERCHANGE AREA. 8

TABLE 4. FATAL CRASHES WITHIN INTERCHANGE AREAS BY COLLISION TYPE AND MANNER OF COLLISION. 9

TABLE 5. FATAL CRASHES WITHIN INTERCHANGE AREAS BY RELATION TO ROADWAY 11

TABLE 6. FATAL CRASHES WITHIN INTERCHANGE AREAS BY TYPE OF TRAFFIC CONTROL DEVICE PRESENT.

TABLE 7. FATAL CRASHES WITHIN INTERCHANGE AREAS BY LIGHT CONDITION 12

TABLE 8. CRASHES FOR ALL ROADWAY TYPES BY RELATIONSHIP TO INTERCHANGES 14

TABLE 9. INTERCHANGE-RELATED CRASHES BY SEVERITY FROM 2000 TO 2004.

TABLE 10. CRASHES FOR INTERCHANGE-RELATED ROAD TYPES BY RELATIONSHIP TO INTERCHANGES.

TABLE 11. CRASHES WITHIN INTERCHANGE AREAS BY COLLISION TYPE AND MANNER OF COLLISION.

TABLE 12. CRASHES WITHIN INTERCHANGE AREAS BY RELATION TO ROADWAY

TABLE 13. CRASHES WITHIN INTERCHANGE AREAS BY TYPE OF TRAFFIC CONTROL DEVICE PRESENT

TABLE 14. CRASHES WITHIN INTERCHANGE AREAS BY LIGHT CONDITION

TABLE 15. TYPICAL INTERCHANGE SPACING IN RURAL AND URBAN AREAS

TABLE 16. ESTIMATED NUMBER OF FREEWAY INTERCHANGES IN THE UNITED STATES.

TABLE 17. SPF COEFFICIENTS AND PARAMETERS FOR MAINLINE FREEWAY SEGMENTS.

TABLE 18. DEFINITIONS OF COEFFICIENTS AND PARAMETERS OF SPFS FOR MAINLINE FREEWAY SEGMENTS. 
TABLE 19. SPF COEFFICIENTS AND PARAMETERS FOR RAMPS,

TABLE 20. DEFINITIONS OF COEFFICIENTS AND PARAMETERS OF SPFS FOR RAMPS

TABLE 21. SPF COEFFICIENTS AND PARAMETERS FOR ACCELERATION LANES

TABLE 22. DEFINITIONS OF COEFFICIENTS AND PARAMETERS OF SPFS FOR ACCELERATION LANES 38

TABLE 23. SPF COEFFICIENTS AND PARAMETERS FOR CROSSROAD RAMP TERMINALS AND INTERSECTIONS.

TABLE 24. DEFINITIONS OF COEFFICIENTS AND PARAMETERS OF SPFS FOR CROSSROAD RAMP TERMINALS AND INTERSECTIONS

TABLE 25. SPF COEFFICIENTS AND PARAMETERS FOR CROSSROAD

SEGMENTS .

TABLE 26. DEFINITIONS OF COEFFICIENTS AND PARAMETERS OF SPFS FOR CROSSROAD SEGMENTS....................................................................................... 43

TABLE 27. SUMMARY OF RESEARCH NEEDS............................................................. 47 


\section{INTRODUCTION}

The Interstate highway system and other freeways form the backbone of America's transportation system. Freeways make a remarkable contribution to transportation efficiency and safety, serving over 30 percent of highway travel in the U.S., while operating with the lowest crash rate of any component of the U.S. highway system. One of the reasons for both the efficiency and safety of the freeway system is that access to freeways is permitted only at defined locations where grade-separated interchanges are provided. Nearly every freeway trip begins or ends at a freeway-arterial interchange. In addition, freeway-freeway interchanges (also known as system interchanges) provide connections between intersecting freeways that permit the freeway system to operate as an integrated whole.

The U.S. freeway system is now mature and only limited mileage of new freeways will be constructed in the coming years. However, the freeway system is also aging and becoming more congested; many parts of the freeway system, particularly interchanges, are in need of reconstruction or rehabilitation. In addition, new development and expanding urbanization often require new interchanges to be constructed along existing freeways. Interchange projects are typically among the highest cost projects constructed by highway agencies, so it is important that such large investments be made wisely. Improved safety is a key justification for many interchange improvement projects, but planners and designers lack a suitable analytical tool to examine the safety performance of existing interchanges and to anticipate the safety performance and crash reduction effectiveness of new or rebuilt interchanges.

\section{RESEARCH OBJECTIVES AND SCOPE}

The objectives of this research are to synthesize the current state of knowledge concerning the safety assessment of new and existing interchanges; to develop a spreadsheet-based computational tool for performing safety assessments of interchanges; and to identify gaps in knowledge concerning interchange safety assessment and future research needs to fill those gaps.

The scope of the project includes both freeway-arterial and freeway-freeway interchanges and safety assessment procedures to address both new and existing interchanges. An assessment was made during the performance of the research as to whether the available safety knowledge is sufficient for the computational tool to address arterial-arterial interchanges, as well; there is concern as to whether safety knowledge developed for freeway locations can be directly applied to nonfreeway locations, particularly since existing roadway geometrics are often more restrictive in arterial settings than in freeway settings.

The project scope addresses development of an analytical or computational tool based on existing safety knowledge and predictive relationships from previous and ongoing safety research. New safety modeling or safety evaluations were not performed as part of this research. Thus, the primary value added by this study is organizing existing knowledge into a convenient tool for application by highway agencies. Existing safety relationships are supplemented by an 
analysis of national crash databases maintained by the National Highway Traffic Safety Administration (NHTSA).

In addition to this final project report, the other primary deliverables of this research are as follows:

- Interchange Safety Analysis Tool (ISAT)

This is a spreadsheet-based analytical tool which provides design and safety engineers with a means for assessing the safety effects of geometric design and traffic control features at existing interchanges and adjacent roadway networks. ISAT can also be used to predict the safety performance of design alternatives for new interchanges and prior to reconstruction of existing interchanges. ISAT was developed using Microsoft ${ }^{\circledR}$ Excel ${ }^{\circledR} 2003$ spreadsheet software.

- $\quad$ Interchange Safety Analysis Tool (ISAT): User Manual ${ }^{1}$

The user manual provides detailed descriptions/instructions on the usage and operation of the spreadsheet-based ISAT. The user manual presents basic information for getting started with using ISAT; basic methodology that users will follow when conducting an analysis with ISAT; user input requirements of the program; default data incorporated within the program, and recommendations on when and how the default data should be updated by the user; output reports generated by ISAT; and general information on different applications for which ISAT can be applied. A sample analysis is also provided within the user manual.

\section{BASIC CAPABILITIES OF ISAT}

The basic purpose of ISAT is to provide design and safety engineers with an automated tool to aid in assessing the safety effects of geometric features and traffic control options, along with traffic volumes of an existing interchange, and predicting the safety performance of a new interchange where no interchange previously existed. ISAT was developed to enable a wide range of applications, including but not limited to:

- Estimating crash frequencies, severities, and types for an existing interchange for which crash data are not available

- Estimating the safety performance for a new interchange that has not yet been constructed

- Estimating crash frequencies, severities, and types for a specific proposed design alternative for an existing interchange

ISAT is intended for performing safety assessments of freeway-arterial and freeway-freeway interchanges. ISAT also provides the capability to perform safety assessments of adjoining mainline freeway segments, crossroad ramp terminals and intersections, and arterial roadway segments. It is not recommended to use ISAT to evaluate arterial-arterial interchanges. The interchange/ramp safety performance functions (SPFs) incorporated within ISAT were developed using freeway locations. It is questionable whether the models are sufficient, or directly applicable, for the more restrictive arterial settings. 
Safety assessments can be performed for interchange areas where no crash data are available; and when crash data are available, ISAT can incorporate the information and provide more accurate safety estimates. Thus, ISAT can be used in both situations (i.e., when no crash data exist and when crash data are available).

ISAT uses a building-block approach to assess the safety performance of interchanges. Users input data for the interchange as a whole and for individual components of an interchange and surrounding roadway network. Safety estimates are calculated for the individual components, and these safety estimates are summed to obtain safety performance estimates for the interchange as a whole. The primary interchange elements that can be included in an analysis are:

- Mainline freeway segments (MF)

- Interchange ramps (R) and acceleration lanes (AL)

- Crossroad ramp terminals (RT) and intersections

- Crossroad roadway segments (RS)

ISAT was designed to analyze the interchange elements of a single interchange. ISAT was also designed to analyze a system of interchanges and the elements of the surrounding roadway network. ISAT does have some limitations concerning the number of individual components that can be included in an analysis area, but in many ways it is up to the user to determine the size and/or complexity of the analysis.

The primary outputs from an analysis include:

- Number of predicted crashes for entire interchange area

- Number of predicted crashes by interchange element type

- Number of predicted crashes by year

- Number of predicted crashes by collision type

On the output reports crashes are reported for three severity levels: total (TOT), fatal and injury (FI), and property-damage-only (PDO) crashes.

\section{ORGANIZATION OF THIS REPORT}

The remainder of this report is organized as follows. The Review of Interchange Safety Data section summarizes safety data from the Fatality Analysis Reporting System (FARS) and the General Estimates System (GES) related to interchanges. The Review of Safety Performance Functions for Interchange Elements section summarizes safety literature related to interchanges, focusing on quantitative information that was potentially applicable for use in ISAT, and presents the SPFs incorporated into ISAT. The Interviews with Experienced Designers section presents results of telephone interviews with key stakeholders to investigate their needs and requirements in safety evaluations of interchanges, and the Identified Gaps in Knowledge section identifies substantive gaps in the current state of knowledge that limit the ability of ISAT to 
provide all of the capabilities desired by potential users. A Reference section is also provided along with two appendices. The first appendix provides a brief summary (i.e., similar to research problem statements) of the needed research to address the identified gaps in knowledge. The second appendix contains the detailed algorithms utilized in the calculations of the ISAT program. 


\section{REVIEW OF INTERCHANGE SAFETY DATA}

This section of the report presents a review of interchange safety data from two databases maintained by the National Highway Traffic Safety Administration (NHTSA): the Fatality Analysis Reporting System (FARS) and the General Estimates System (GES).

\section{FATALITY ANALYSIS REPORTING SYSTEM (FARS)}

The FARS database contains data on all fatal traffic crashes reported in the United States. The FARS data provides a means to better understand the magnitude and nature of safety concerns related to interchanges. FARS does not include any traffic volume or exposure data. Therefore, the distribution of crash types can be determined, but crash rates or crash likelihoods cannot be determined. FARS data include only fatal crashes and do not include nonfatal injury or propertydamage-only crashes.

\section{Proportion of Interchange-Related Crashes for the Roadway System as a Whole}

Table 1 shows the distribution of all fatal crashes in the United States from 2000 through 2004, inclusive, based on their relationship to interchanges. The table shows that 3.2 percent of fatal crashes are related to interchanges, while 96.8 percent are not. The table includes roadways of all types, so that many crashes on nonfreeway facilities, where there are not many interchanges, are included.

Table 1 includes a breakdown of the locations within interchange areas where fatal crashes occur. Approximately 1 percent of fatal crashes occur at, or are related to, intersections within an interchange area (probably crossroad ramp terminals, although it is possible that some crashes at frontage road intersections near the ramp terminals are included), 1 percent are related to ramps, and 1 percent occur in "other interchange areas" (which most likely refers to mainline freeway lanes within the interchange areas). The "other interchange area" category could include some crashes on the arterial crossroad near the ramp terminals, but it seems likely that most such crashes would be classified as related to the ramp terminals. A small percentage of interchangerelated crashes occur at driveway/crossover locations (probably near ramp terminals) or at unknown locations within the interchange area. It is presumed that crashes in speed-change lanes along mainline freeways (i.e., acceleration and deceleration lanes) would be included with the "other interchange area" data, since they do not occur on the ramp proper, but this is not known for certain. The remainder of this discussion treats intersection-related crashes within the interchange area as referring primarily to crossroad ramp terminals and other interchange area crashes as referring primarily to mainline freeway crashes, although this cannot be demonstrated from the data itself. 
Table 1. Fatal Crashes for All Roadway Types by Relationship to Interchanges

\begin{tabular}{|c|c|c|c|c|c|c|c|c|c|}
\hline \multirow[b]{2}{*}{$\begin{array}{c}\text { Area } \\
\text { type }\end{array}$} & \multirow{2}{*}{$\begin{array}{c}\text { Not } \\
\text { interchange- } \\
\text { related }^{\mathrm{a}}\end{array}$} & \multicolumn{7}{|c|}{ Interchange-related } & \multirow[b]{2}{*}{ Total } \\
\hline & & $\begin{array}{c}\text { At } \\
\text { intersection }^{\mathbf{b}}\end{array}$ & $\begin{array}{c}\text { Intersection- } \\
\text { related }^{\text {b }}\end{array}$ & $\begin{array}{l}\text { Ramp- } \\
\text { related }\end{array}$ & $\begin{array}{l}\text { Driveway/ } \\
\text { crossover }\end{array}$ & Other $^{c}$ & Unknown & Subtotal & \\
\hline Rural & $108,616(98.1)$ & $905(0.8)$ & $139(0.1)$ & $395(0.4)$ & $62(0.1)$ & $532(0.5)$ & $21(0.0)$ & 2,054 (1.9) & $110,670(100.0)$ \\
\hline Urban & 74,552 (95.1) & $600(0.8)$ & $250(0.3)$ & 1,452 (1.9) & $60(0.1)$ & 1,478 (1.9) & $16(0.0)$ & $3,856 \quad(4.9)$ & $78,408(100.0)$ \\
\hline Unknown & 1,045 (87.3) & $78(6.5)$ & $7(0.6)$ & $29(2.4)$ & $2(0.2)$ & $7(0.6)$ & $29(2.4)$ & $152(12.7)$ & $1,197(100.0)$ \\
\hline Total & 184,213 (96.8) & $1,583(0.8)$ & $396(0.2)$ & $1,876(1.0)$ & $124(0.1)$ & $2,017(1.1)$ & $66(0.0)$ & $6,062 \quad(3.2)$ & $190,275(100.0)$ \\
\hline
\end{tabular}

Source: FARS, 2000-2004

Note: Numbers in parentheses are row percentages.

a Includes crashes on all roadway types.

b Primarily crossroad ramp terminal crashes.

c Primarily mainline freeway crashes. 
The table indicates that approximately 2 percent of rural fatal crashes occur in interchange areas, while 5 percent of urban fatal crashes occur in interchange areas. This clearly suggests the higher volume of traffic on interchanges in urban areas, as opposed to rural areas.

\section{Proportion of Interchange-Related Crashes for the Freeway System}

To put the role in interchange-related crashes in better perspective, Table 2 presents the same data as Table 1 with the not-interchange-related column limited only to freeway crashes. The interchange-related columns in Table 2 include the same crashes as in Table 1, while a few of these crashes may have occurred at arterial-arterial interchanges, most undoubtedly occurred at freeway-freeway or freeway-arterial interchanges, and are thus related to the freeway system. It can be seen in Table 2 that, while interchangerelated fatal crashes constitute only 3.2 percent of all fatal crashes, they constitute 17.9 percent of fatal crashes on, or related to, the freeway system. Thus, interchangerelated fatal crashes represent a substantial percentage of the safety concern on freeways.

\section{Distribution of Crashes by Portion of Interchange Area}

Table 3 shows the distribution of fatal crashes by portion of the interchange area. The crash counts and percentages are also broken down by rural and urban areas. As in the previous tables, it can be seen that intersection, ramp, and mainline freeway crashes constitute nearly equal proportions of interchange crashes. In general, ramp and mainline freeway crashes constitute higher proportions of interchange crashes in urban areas than crossroad ramp terminal crashes, and vice versa in rural areas.

\section{Distribution of Crashes by Collision Type and Manner of Collision}

Table 4 presents the distribution of fatal crashes within interchange areas by collision type and manner of collision. Single-vehicle crashes are classified by object struck and multiple-vehicle crashes are classified by manner of collision. The table shows that fatal multiple-vehicle crashes are more prevalent than single-vehicle crashes at crossroad ramp terminals, while fatal single-vehicle crashes are more prevalent than multiple-vehicle crashes on ramps and mainline freeways. The predominant types of single-vehicle crashes are fixed-object collisions, noncollision events, and collisions with pedestrians. The predominant types of multiple-vehicle crashes are angle, rear-end, and head-on collisions. Same-direction sideswipe collisions are also common in urban areas, particularly on mainline freeways and ramps. 
Table 2. Fatal Crashes for Freeways by Relationship to Interchanges

\begin{tabular}{|c|c|c|c|c|c|c|c|c|c|}
\hline $\begin{array}{l}\text { Area } \\
\text { type }\end{array}$ & $\begin{array}{c}\text { Not interchange- } \\
\text { related }^{\mathrm{a}}\end{array}$ & \multicolumn{7}{|c|}{ Interchange-related } & Total \\
\hline Rural & $10,454(71.8)$ & 905 (6.2) & $139(1.0)$ & $395(2.7)$ & $62(0.4)$ & $532(3.7)$ & $21(0.1)$ & $2,054(14.1)$ & $12,508(100.0)$ \\
\hline Total & $21,232(64.1)$ & $1,505(4.6)$ & $389(1.2)$ & $1,847(5.6)$ & $122(0.4)$ & $2,010(6.1)$ & $37(0.1)$ & $5,910(17.9)$ & $27,142(100.0)$ \\
\hline
\end{tabular}

Source: FARS, 2000-2004

Note: Numbers in parentheses are row percentages.

a Includes crashes on freeways only.

b Primarily crossroad ramp terminal crashes.

c Primarily mainline freeway crashes.

Table 3. Fatal Interchange-Related Crashes by Portion of Interchange Area

\begin{tabular}{|lccccccc|}
\hline \multirow{2}{*}{$\begin{array}{c}\text { Area } \\
\text { type }\end{array}$} & At intersection $^{\mathbf{a}}$ & $\begin{array}{c}\text { Intersection- } \\
\text { related }^{\mathbf{a}}\end{array}$ & Ramp-related & $\begin{array}{c}\text { Driveway/ } \\
\text { crossover }^{-1}\end{array}$ & Other $^{\mathbf{b}}$ & Unknown & Subtotal \\
\hline Rural & $905(44.1)$ & $139(6.8)$ & $395(19.2)$ & $62(3.0)$ & $532(25.9)$ & $21(1.0)$ & $2,054(100.0)$ \\
Urban & $600(15.6)$ & $250(6.5)$ & $1,452(37.7)$ & $60(1.6)$ & $1,478(38.3)$ & $16(0.4)$ & $3,856(100.0)$ \\
Total & $1,505(25.5)$ & $389(6.6)$ & $1,847(31.3)$ & $122(2.1)$ & $2,010(33.9)$ & $37(0.6)$ & $5,910(100.0)$ \\
\hline
\end{tabular}

Source: FARS, 2000-2004

Note: Numbers in parentheses are row percentages.

a Primarily crossroad ramp terminal crashes.

Primarily mainline freeway crashes. 
Table 4. Fatal Crashes Within Interchange Areas by Collision Type and Manner of Collision

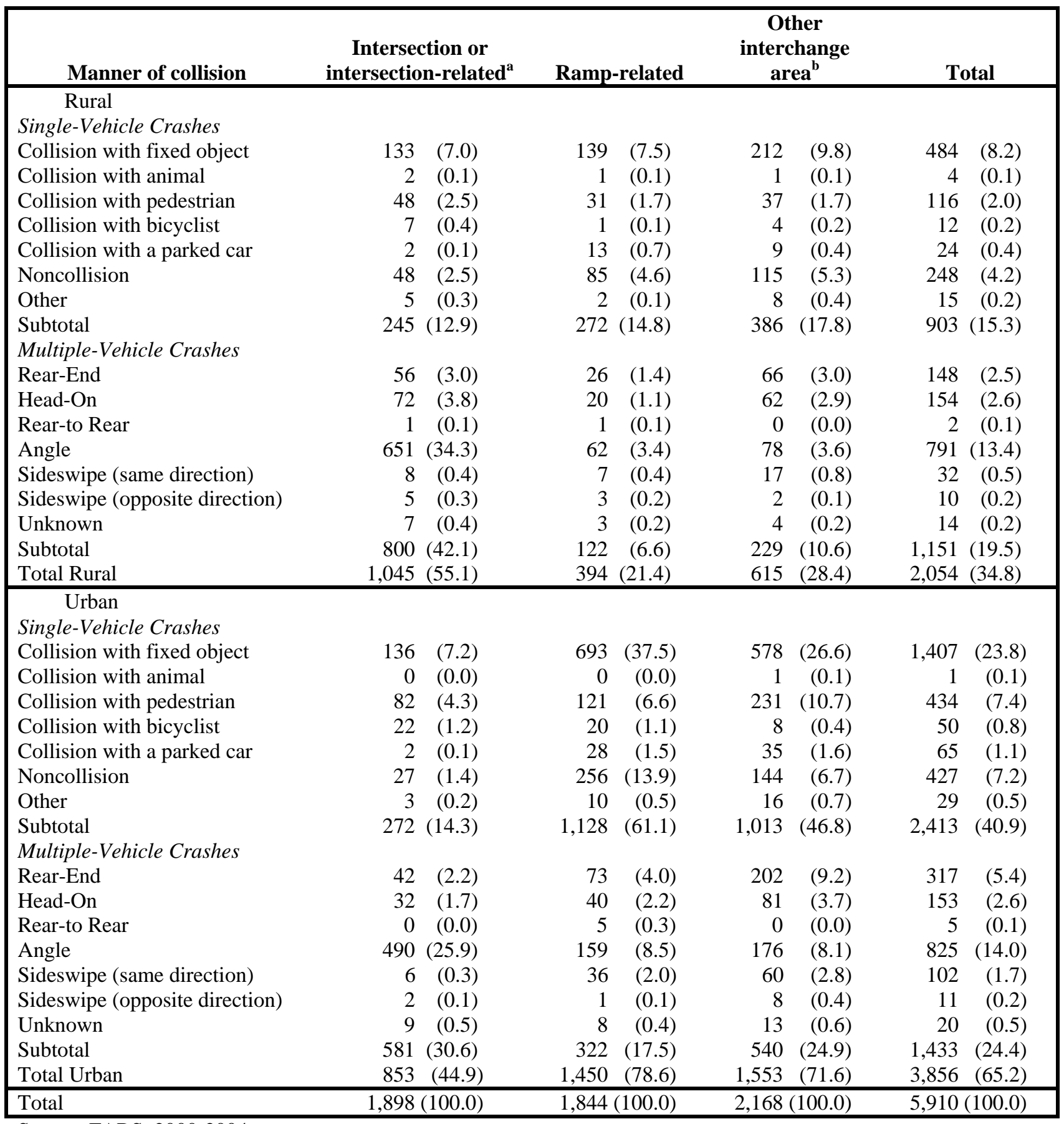

Source: FARS, 2000-2004

Note: Numbers in parentheses are column percentages.

a Primarily crossroad ramp terminal crashes.

b Primarily mainline freeways crashes.

The prevalence of single-vehicle crashes among fatal crashes on ramps and mainline freeways is noteworthy because many observers perceive multiple-vehicle collisions as the primary safety 
issue at interchanges. Overall, single-vehicle crashes constitute over 60 percent of all fatal crashes on ramps and mainline freeways in interchange areas.

\section{Distribution of Crashes by Relation to Roadway}

Table 5 presents the distribution of fatal crashes in interchange areas by the location of the first harmful event in relation to the roadway. The table shows that at crossroad ramp terminals, over 83 percent of crashes occur on the roadway, while 37 and 52 percent of crashes occur on the roadway on ramps and mainline freeways, respectively. For crashes that do not occur on the roadway, for all portions of the interchange area, the predominant location for the first harmful event is on the roadside, rather than the shoulder or median. For other interchange areas, there are a substantial number of median-related crashes, which supports the presumption that these crashes occur on mainline freeways. This corresponds closely to the prevalence of single-vehicle fixed-object collisions noted in Table 4.

The inclusion of gore area crashes in all three interchange area categories in Table 5intersections, ramps, and other interchange areas-calls into question the consistency with which these categories are applied.

\section{Distribution of Crashes by Traffic Control Device}

Table 6 shows the distribution of fatal crashes in interchange areas by the type of traffic control device present. The table shows that, for crossroad ramp terminals, approximately 32 percent of fatal crashes occur at stop signs and approximately 26 percent occur at signalized terminals. The table shows that 36 percent of the fatal crashes at crossroad ramp terminals occur where no traffic control device is present; these are presumably crashes that occur on the crossroad at unsignalized ramp terminals. On ramps and mainline freeways, the vast majority of fatal crashes occur where no traffic control device is present.

\section{Distribution of Crashes by Light Condition}

Table 7 presents the distribution of fatal crashes in interchange areas by light condition. Most fatal crashes in interchange areas occur under daylight conditions, but a substantial proportion of fatal crashes (13 percent in rural areas and 35 percent in urban areas) occur after dark. However, fatal crashes after dark appear more prevalent than during daylight on ramps and mainline freeways in urban areas. In rural areas, the majority of nighttime fatal crashes occur in unlighted areas, while in urban areas the majority occur in lighted areas. This reflects the greater prevalence of highway lighting in urban areas. 
Table 5. Fatal Crashes Within Interchange Areas by Relation to Roadway

\begin{tabular}{|c|c|c|c|c|}
\hline Relation to roadway & $\begin{array}{c}\text { Intersection or } \\
\text { intersection- } \\
\text { related }\end{array}$ & Ramp-related & $\begin{array}{c}\text { Other interchange } \\
\text { area }\end{array}$ & Total \\
\hline On roadway & $1,651 \quad(83.5)$ & 703 (37.4) & $1,142 \quad(51.7)$ & $3,496 \quad(57.6)$ \\
\hline Shoulder & $39 \quad(2.0)$ & 227 (12.1) & $156 \quad(7.1)$ & $(7.0)$ \\
\hline Median & $37 \quad(1.9)$ & $53 \quad(2.8)$ & $243(11.0)$ & (5.5) \\
\hline Roadside & $119 \quad(6.0)$ & 533 (28.4) & 449 (20.3) & 1,101 \\
\hline Outside right-of-way & $23 \quad(1.2)$ & $27 \quad(1.4)$ & $22 \quad(1.0)$ & $(1.2)$ \\
\hline $\begin{array}{l}\text { Unknown) } \\
\text { Introadway }\end{array}$ & $96 \quad(4.9)$ & (4.5) & $(2.8)$ & $(4.0)$ \\
\hline Gore & $5 \quad(0.3)$ & $233(12.4)$ & $112 \quad(5.1)$ & (5.8) \\
\hline Separator & $4 \quad(0.2)$ & $15 \quad(0.8)$ & $19 \quad(0.9)$ & $(0.6)$ \\
\hline Unknown & $(0.2)$ & $3 \quad(0.2)$ & $(0.2)$ & $(0.2)$ \\
\hline Total & $1,978(100.0)$ & $1,879(100.0)$ & 2,209 (100.0) & $6,066(100.0)$ \\
\hline
\end{tabular}

Source: FARS, 2000-2004

Note: Numbers in parentheses represent column percentages.

a Primarily crossroad ramp terminal crashes.

b Primarily mainline freeway crashes.

Table 6. Fatal Crashes Within Interchange Areas by Type of Traffic Control Device Present

\begin{tabular}{|c|c|c|c|c|}
\hline Traffic control device & $\begin{array}{c}\text { Intersection or } \\
\text { intersection- }^{\text {related }}{ }^{\mathrm{a}}\end{array}$ & Ramp-related & $\begin{array}{c}\text { Other interchange }^{\mathrm{b}} \\
\text { area }\end{array}$ & Total \\
\hline $\begin{array}{l}\text { Iraffic signal (ped } \\
\text { control) }\end{array}$ & $22 \quad(1.1)$ & $1 \quad(0.1)$ & $2 \quad(0.1)$ & $25 \quad(0.4)$ \\
\hline $\begin{array}{l}\text { Traffic signal (no ped } \\
\text { control) }\end{array}$ & $44 \quad(2.2)$ & $(0.4)$ & $0 \quad(0.0)$ & $51 \quad(0.8)$ \\
\hline $\begin{array}{l}\text { Traffic signal (unknown } \\
\text { ped control) }\end{array}$ & 441 (22.4) & (3.4) & $(0.6)$ & $517 \quad(8.5)$ \\
\hline Other signals & $12(0.6)$ & $(0.2)$ & $(0.3)$ & $(0.4)$ \\
\hline Flashing signal & $24 \quad(1.2)$ & $(0.4)$ & $(0.1)$ & $(0.6)$ \\
\hline Stop sign & $633(32.1)$ & (4.7) & $(0.7)$ & 736 (12.1) \\
\hline Yield sign & $33 \quad(1.7)$ & (1.8) & $(0.2)$ & $71 \quad(1.2)$ \\
\hline Other signs & $45 \quad(2.3)$ & (7.1) & $(4.0)$ & (4.4) \\
\hline No traffic control device & 719 (36.4) & $1,543 \quad(82.1)$ & $2,076(94.0)$ & 4,338 (71.6) \\
\hline Total & $1,973(100.0)$ & $1,879(100.0)$ & 2,209 (100.0) & 6,061 (100.0) \\
\hline
\end{tabular}

Source: FARS, 2000-2004

Note: Numbers in parentheses represent column percentages.

a Primarily crossroad ramp terminal crashes.

b Primarily mainline freeway crashes. 
Table 7. Fatal Crashes Within Interchange Areas by Light Condition

\begin{tabular}{|c|c|c|c|c|}
\hline Light condition & $\begin{array}{c}\begin{array}{c}\text { Intersection or } \\
\text { intersection- } \\
\text { related }\end{array} \\
\end{array}$ & Ramp-related & $\begin{array}{c}\text { Other interchange } \\
\text { area }\end{array}$ & Total \\
\hline \multicolumn{5}{|l|}{ Rural } \\
\hline Daylight & 682 (36.1) & $186 \quad(10.1)$ & 339 (15.6) & 1,207 \\
\hline Dark & 236 (12.5) & (6.7) & $195 \quad(9.0)$ & $555 \quad(9.4)$ \\
\hline Dark but Lighted & $99 \quad(5.2)$ & (3.8) & $49 \quad(2.3)$ & 218 \\
\hline Dawn & $13 \quad(0.7)$ & $(0.4)$ & $17 \quad(0.8)$ & $38 \quad(0.6)$ \\
\hline Dusk & $12 \quad(0.6)$ & $(0.2)$ & $13 \quad(0.6)$ & $29 \quad(0.5)$ \\
\hline Unknown & $2 \quad(0.1)$ & $(0.2)$ & $2 \quad(0.1)$ & $7 \quad(0.1)$ \\
\hline Subtotal & $1,044 \quad(55.2)$ & $395 \quad(21.4)$ & $615 \quad(28.4)$ & $2,054 \quad(34.7)$ \\
\hline \multicolumn{5}{|l|}{ Urban } \\
\hline Daylight & $463 \quad(24.4)$ & $582 \quad(31.6)$ & 618 (28.4) & $1,663 \quad(28.2)$ \\
\hline Dark & $76 \quad(4.0)$ & 261 & 321 (14.8) & 658 (11.1) \\
\hline Dark but Lighted & 281 (14.8) & $566 \quad(30.7)$ & 555 (25.6) & $1,402 \quad(23.8)$ \\
\hline Dawn & $10 \quad(0.5)$ & $17 \quad(0.9)$ & $39 \quad(1.8)$ & $66 \quad(1.1)$ \\
\hline Dusk & $18 \quad(1.0)$ & (1.1) & $20 \quad(0.9)$ & $59 \quad(1.0)$ \\
\hline Unknown & $2 \quad(0.1)$ & $(0.2)$ & $1 \quad(0.1)$ & $8 \quad(0.1)$ \\
\hline Subtotal & $850 \quad(44.8)$ & $1,452 \quad(78.6)$ & $1,554 \quad(71.6)$ & $3,856 \quad(65.3)$ \\
\hline Total & $1,894(100.0)$ & $1,847(100.0)$ & $2,169(100.0)$ & $5,910(100.0)$ \\
\hline $\begin{array}{l}\text { Source: FARS, 20 } \\
\text { Note: Numbers in } \\
\text { a } \quad \text { Primarily cros } \\
\text { b } \\
\end{array}$ & $\begin{array}{l}\text { eses represent c } \\
\text { amp terminal cr } \\
\text { eeway crashes. }\end{array}$ & ercentages. & & \\
\hline
\end{tabular}

\section{GENERAL ESTIMATES SYSTEM (GES)}

The GES database includes a sample of crashes of all severity levels, not just fatal crashes as is the case in FARS. The crash characteristics included in the GES data are similar, but not identical to FARS. The GES data also provide a means to better understand the magnitude and nature of safety concerns related to interchanges. GES does not include any traffic volume or exposure data. Therefore, the distribution of crash types can be determined, but crash rates or crash likelihoods cannot be determined.

The GES data represent a sample of crashes. Each crash has attached to it a weight that can be used to scale up the sample to make national estimates. These weights have been used to generate the tables presented below. Thus, while GES contains data for a total of 287,767 crashes during the years 2000 to 2004, application of weights provides a total estimate of $31,463,923$ crashes during that five-year period. However, there is some concern as to whether the weighted data provides a complete estimate. The weighted GES data indicate a total of 139,662 fatal crashes during the five-year period from 2000 through 2004 (or 27,932 fatal crashes per year), while FARS data for that same period indicate over 40,000 crashes per year. Given the uncertainty of the weighting process, the tables presented below should be used to gain insights into the distribution of crash characteristics, not to estimate absolute numbers of crashes. 
The tables prepared from GES data omit crashes in which the victim died prior to the crash and crashes in which no person was involved; these are not normally considered traffic crashes.

\section{Proportion of Interchange-Related Crashes for the Roadway System as a Whole}

Table 8 shows the distribution of crashes from 2000 to 2004, inclusive, based on their relationship to interchanges. The table shows that 3.5 percent of crashes of all severity levels are related to interchanges, which shows good agreement with the 3.2 percent shown in table 1 fatal crashes that occur in interchange areas. The table includes roadways of all types, so that many crashes on nonfreeway facilities, where there are not many interchanges, are included. Unlike FARS, GES data cannot be classified by freeway vs. nonfreeway facilities, so no equivalent of table 2 can be constructed with GES data. (It is possible in GES to identify crashes on the Interstate highway system, but not for freeways as a whole.)

Table 8 shows that there is a greater proportion of ramp-related crashes than crossroad ramp terminal or mainline freeway crashes in the GES data. In the FARS data, the proportions of crashes in these portions of interchange area were about even. This suggests that ramp-related crashes are less severe than crossroad ramp terminal or mainline freeway crashes, which is confirmed by the data in table 9 .

Tables 8 and 9 present data for rural and urban areas separately. No explicit rural/urban identifier was available in GES, so the rural/urban breakdown in these tables is based on a population size variable. All areas with population size over 25,000 were classified as urban, while other areas were classified as rural. By contrast, FARS data have an explicit rural/urban identified that is based on the FHWA urban area designations which include towns with populations of 5,000 or more. Thus, the rural vs. urban data shown in the FARS and GES tables may differ.

\section{Distribution of Crashes by Portion of Interchange Area}

Table 10 shows the distribution of interchange-related crashes by portion of the interchange area. As in table 8, it can be seen that ramp-related crashes constitute a higher proportion of all interchange-related crashes than cross-ramp-terminal or mainline-freeway crashes.

\section{Distribution of Crashes by Collision Type and Manner of Collision}

Table 11 presents the distribution of crashes within interchange areas by collision type and manner of collision. Single-vehicle crashes are classified by object struck, and multiple-vehicle crashes are classified by manner of collision. The table shows that multiple-vehicle crashes are far more prevalent than single-vehicle crashes for all portions of the interchange area. This finding is in contrast to table 4, which showed that single-vehicle fatal crashes were more 
Table 8. Crashes for All Roadway Types by Relationship to Interchanges

\begin{tabular}{|c|c|c|c|c|c|c|c|c|c|c|c|c|c|c|c|c|c|c|}
\hline \multirow[b]{2}{*}{$\begin{array}{c}\text { Area } \\
\text { type }\end{array}$} & \multicolumn{16}{|c|}{ Interchange-related } & \multirow[b]{2}{*}{$\begin{array}{l}\text { Unknown if } \\
\text { interchange }\end{array}$} & \multirow[b]{2}{*}{ Total } \\
\hline & \multicolumn{2}{|c|}{$\begin{array}{c}\text { Non-interchange- } \\
\text { related }^{\mathrm{a}}\end{array}$} & \multicolumn{2}{|c|}{ Intersection $^{\mathrm{b}}$} & \multicolumn{2}{|c|}{$\begin{array}{l}\text { Intersection- } \\
\text { related }^{\mathbf{b}}\end{array}$} & \multicolumn{2}{|c|}{ Ramp-related } & \multicolumn{2}{|c|}{$\begin{array}{l}\text { Driveway/ } \\
\text { crossover }\end{array}$} & \multicolumn{2}{|c|}{ Other $^{c}$} & \multicolumn{2}{|c|}{$\begin{array}{c}\text { Unknown, } \\
\text { interchange } \\
\text { area } \\
\end{array}$} & \multicolumn{2}{|c|}{ Subtotal } & & \\
\hline Rural & $9,731,217$ & $(96.5)$ & 29,309 & $(0.3)$ & 15,766 & $(0.2)$ & 216,777 & $(2.1)$ & 1,376 & $(0.0)$ & 68,758 & $(0.7)$ & 1,955 & $(0.0)$ & 333,940 & (3.3) & $19,345 \quad(0.2)$ & $10,084,502 \quad(100.0)$ \\
\hline Urban & $20,570,009$ & $(96.2)$ & 77,705 & $(0.4)$ & 55,308 & $(0.3)$ & 504,039 & $(2.4)$ & 3,869 & $(0.0)$ & 126,032 & $(0.6)$ & 4,466 & $(0.0)$ & 771,420 & (3.6) & $34,676 \quad(0.2)$ & 21,376,104 (100.0) \\
\hline Unknown & 3,316 & $(100.0)$ & 0 & $(0.0)$ & 0 & $(0.0)$ & 0 & $(0.0)$ & 0 & $(0.0)$ & 0 & $(0.0)$ & 0 & $(0.0)$ & 0 & $(0.0)$ & $0 \quad(0.0)$ & $3,316 \quad(100.0)$ \\
\hline Total & $30,304,542$ & $(96.3)$ & 107,013 & $(0.3)$ & 71,074 & $(0.2)$ & 720,817 & $(2.3)$ & 5,246 & $(0.0)$ & 194,790 & $(0.6)$ & 6,420 & $(0.0)$ & $1,105,360$ & (3.5) & $54,021 \quad(0.2)$ & $31,463,923 \quad(100.0)$ \\
\hline
\end{tabular}

Source: GES, 2000-2004

Note: Numbers in parentheses represent row percentages.

Includes crashes on all roadway types.

b Primarily crossroad ramp terminal crashes.

c Primarily mainline freeway crashes. 
Table 9. Interchange-Related Crashes by Severity From 2000 to 2004

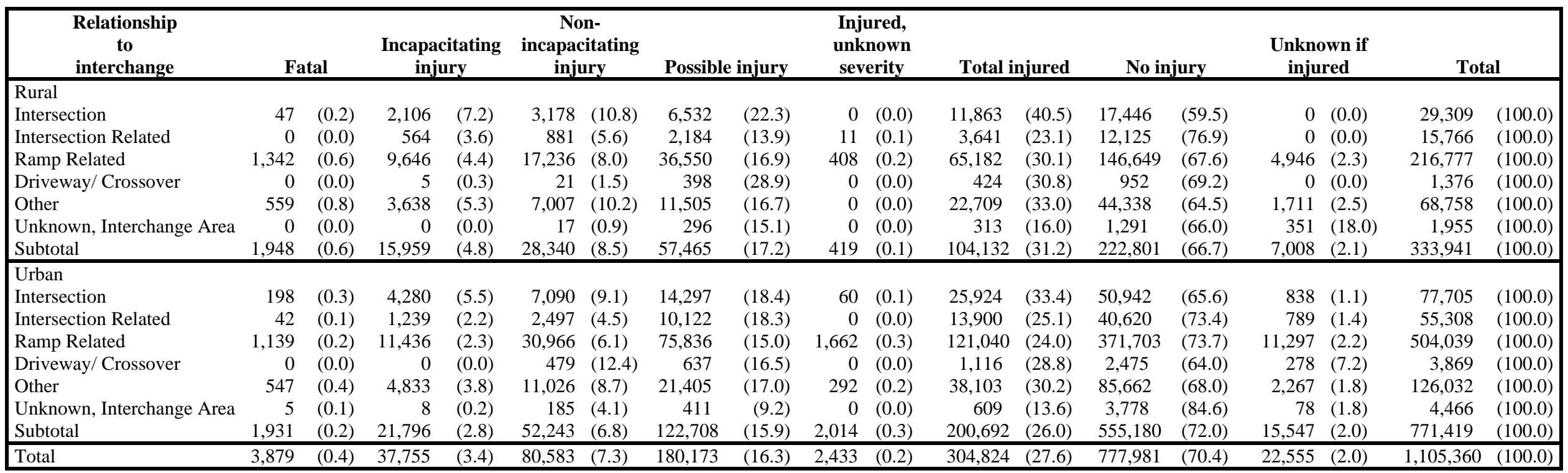

Source: GES, 2000-2004

Note: Numbers in parentheses represent row percentages. 
Table 10. Crashes for Interchange-Related Road Types by Relationship to Interchanges

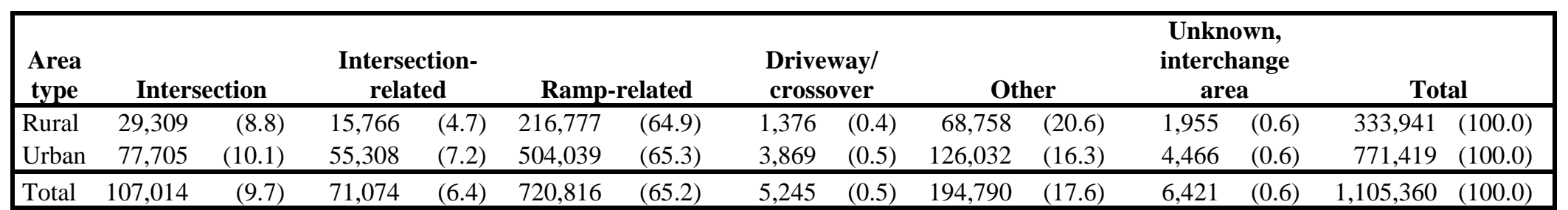

Source: GES, 2000-2004

Note: Numbers in parentheses represent row percentages. 
prevalent than multiple-vehicle fatal crashes on ramps and mainline freeways and are generally more severe than multiple-vehicle crashes. The predominant type of single-vehicle crashes are fixed-object collisions and, to a lesser extent, noncollision events. The predominant types of multiple-vehicle crashes are rear-end, angle collisions, and same-direction sideswipe collisions. Single-vehicle collisions with pedestrians and multiple-vehicle head-on collisions were present in relatively high proportions in the fatal crash data and are present in smaller proportions in the crash data for all severity levels. This finding clearly implies that collisions of these types have high severity levels.

One anomaly in the GES data shown in table 11 is the inclusion of multiple-vehicle noncollision crashes. Approximately 1.4 percent of the interchange-related crashes in the GES data were classified as involving more than one vehicle, but were classified as "not a collision with a motor vehicle in transport.” This is not consistent with normal crash criteria, so it is not clear what these crashes mean. However, they have a relatively small impact on the overall crash type distribution.

\section{Distribution of Crashes by Relation to Roadway}

Table 12 presents the distribution of crashes by the location of the first harmful event in relation to the roadway. The table shows that over 95 percent of crashes at crossroad ramp terminals occurred on the roadway (in comparison to 83 percent for fatal crashes). On-roadway crashes for all severity levels combined constitute 72 percent of ramp-related crashes and 76 percent of mainline freeway crashes, in comparison to 37 and 52 percent, respectively, for fatal crashes. These comparisons indicate that off-roadway crashes are generally more severe than on-roadway crashes.

\section{Distribution of Crashes by Traffic Control Device}

Table 13 shows the distribution of crashes in interchange areas by the type of traffic control present. The table shows that, for crossroad ramp terminals, approximately 59 percent of crashes occur at signalized ramp terminals, 13 percent at stop signs, and 15 percent where no traffic control device is present (presumably on the crossroad at stop-controlled ramp terminals). For ramps and mainline freeways, 54 and 76 percent of crashes, respectively, occur at locations where no traffic control device is present.

An inconsistency noted in the data is that 14 percent of ramp-related crashes are stated to occur where a traffic signal is present; these crashes should presumably be classified as intersectionrelated rather than ramp-related. In addition, 15 percent of ramp-related crashes are classified as occurring at yield signs; these crashes could involve channelized right turns at crossroad ramp terminals or acceleration lanes where a ramp joins a crossroad or mainline freeway. 
Table 11. Crashes Within Interchange Areas by Collision Type and Manner of Collision

\begin{tabular}{|c|c|c|c|c|c|c|c|c|}
\hline $\begin{array}{l}\text { Manner of collision } \\
\text { Rural } \\
\text { Sinale-Vehicle Crashes }\end{array}$ & \multicolumn{2}{|c|}{$\begin{array}{l}\text { Intersection or } \\
\text { intersection- }^{\text {related }} \\
\text { rel }^{\mathrm{a}}\end{array}$} & \multicolumn{2}{|c|}{ Ramp-related } & \multicolumn{2}{|c|}{$\begin{array}{c}\text { Other } \\
\text { interchange } \\
\text { area }^{b}\end{array}$} & \multicolumn{2}{|c|}{ Total } \\
\hline Collision with fixed object & 1.539 & $(0.9)$ & 58,996 & (8.2) & 18,095 & (8.8) & 78,631 & (7.1) \\
\hline Collision with animal & 0 & $(0.0)$ & 2,413 & $(0.3)$ & 2,269 & (1.1) & 4,682 & $(0.4)$ \\
\hline Collision with pedestrian & 25 & $(0.0)$ & 663 & $(0.1)$ & 110 & $(0.1)$ & 798 & $(0.1)$ \\
\hline Collision with bicyclist & 107 & $(0.1)$ & 658 & $(0.1)$ & 43 & $(0.0)$ & 807 & $(0.1)$ \\
\hline Collision with parked car & 0 & $(0.0)$ & 826 & $(0.1)$ & 304 & $(0.1)$ & 1,129 & $(0.1)$ \\
\hline Noncollision & 402 & $(0.2)$ & 10,032 & (1.4) & 2,929 & (1.4) & 13,363 & (1.2) \\
\hline Other & 0 & $(0.0)$ & 1,950 & $(0.3)$ & 1,703 & $(0.8)$ & 3,652 & $(0.3)$ \\
\hline Unknown & 0 & $(0.0)$ & 111 & $(0.0)$ & 0 & $(0.0)$ & 111 & $(0.0)$ \\
\hline Subtotal & 2,074 & (1.2) & 75,647 & $(10.5)$ & 25,452 & (12.3) & 103,173 & (9.3) \\
\hline Multiple-Vehicle Crashes & & & & & & & & \\
\hline Rear-End & 13,775 & (7.7) & 94,534 & $(13.1)$ & 27,745 & (13.4) & 136,054 & (12.3) \\
\hline Head-On & 894 & $(0.5)$ & 780 & $(0.1)$ & 309 & $(0.1)$ & 1,983 & $(0.2)$ \\
\hline Angle & 25,921 & $(14.6)$ & 22,457 & (3.1) & 4,266 & (2.1) & 52,645 & (4.8) \\
\hline Sideswipe, same direction & 1,918 & $(1.1)$ & 19,748 & $(2.7)$ & 11,483 & (5.6) & 33,148 & (3.0) \\
\hline Sideswipe, opposite direction & 84 & $(0.0)$ & 0 & $(0.0)$ & 123 & $(0.1)$ & 207 & $(0.0)$ \\
\hline Non-collision & 20 & $(0.0)$ & 3,250 & $(0.5)$ & 2,274 & (1.1) & 5,544 & $(0.5)$ \\
\hline Unknown & 389 & $(0.2)$ & 362 & $(0.1)$ & 436 & $(0.2)$ & 1,186 & $(0.1)$ \\
\hline Subtotal & 42,981 & $(24.1)$ & 141,130 & (19.6) & 46,637 & (22.6) & 230,767 & (20.9) \\
\hline Total Rural & 45,055 & $(25.3)$ & 216,777 & $(30.1)$ & 72,088 & (34.9) & 333,940 & (30.2) \\
\hline $\begin{array}{l}\text { Urban } \\
\text { Single-Vehicle Crashes }\end{array}$ & & & & & & & & \\
\hline Collision with fixed object & 6,292 & (3.5) & 111,186 & $(15.4)$ & 23,015 & (11.1) & 140,493 & (12.7) \\
\hline Collision with animal & 0 & $(0.0)$ & 3,262 & $(0.5)$ & 641 & $(0.3)$ & 3,904 & $(0.4)$ \\
\hline Collision with pedestrian & 497 & $(0.3)$ & 751 & $(0.1)$ & 99 & $(0.0)$ & 1,347 & $(0.1)$ \\
\hline Collision with bicyclist & 718 & $(0.4)$ & 1,007 & $(0.1)$ & 183 & $(0.1)$ & 1,909 & $(0.2)$ \\
\hline Collision with parked car & 0 & $(0.0)$ & 1,490 & $(0.2)$ & 1,430 & $(0.7)$ & 2,920 & $(0.3)$ \\
\hline Noncollision & 770 & $(0.4)$ & 21,132 & (2.9) & 3,340 & (1.6) & 25,241 & (2.3) \\
\hline Other & 22 & $(0.0)$ & 2,109 & $(0.3)$ & 1,448 & $(0.7)$ & 3,579 & $(0.3)$ \\
\hline Unknown & 0 & $(0.0)$ & 308 & $(0.0)$ & 3 & $(0.0)$ & 311 & $(0.0)$ \\
\hline $\begin{array}{l}\text { Subtotal } \\
\text { Multiple-Vehicle Crashes }\end{array}$ & 8,300 & (4.7) & 141,245 & (19.6) & 30,160 & $(14.6)$ & 179,705 & (16.3) \\
\hline Rear-End & 46,163 & (25.9) & 240,628 & $(33.4)$ & 66,178 & (32.1) & 352,969 & (31.9) \\
\hline Head-On & 2,492 & (1.4) & 2,056 & $(0.3)$ & 1,021 & $(0.5)$ & 5,568 & $(0.5)$ \\
\hline Angle & 67,216 & $(37.7)$ & 60,176 & (8.3) & 10,268 & (5.0) & 137,661 & (12.5) \\
\hline Sideswipe, same direction & 7,749 & $(4.4)$ & 52,350 & (7.3) & 22,941 & (11.1) & 83,041 & (7.5) \\
\hline Sideswipe, opposite direction & 2 & $(0.0)$ & 497 & $(0.1)$ & 473 & $(0.2)$ & 973 & $(0.1)$ \\
\hline Noncollision & 518 & $(0.3)$ & 6,422 & (0.9) & 3,261 & (1.6) & 10,201 & (0.9) \\
\hline Unknown & 571 & (0.3) & 666 & $(0.1)$ & 66 & $(0.0)$ & 1,303 & $(0.1)$ \\
\hline Subtotal & 124,713 & $(70.0)$ & 362,794 & (50.3) & 104,208 & (50.5) & 591,715 & (53.5) \\
\hline Total Urban & 133,013 & $(74.7)$ & 504,039 & (69.9) & 134,367 & (65.1) & 771,420 & (69.8) \\
\hline Total & 178,068 & $(100.0)$ & 720,817 & $(100.0)$ & 206,456 & $\overline{(100.0)}$ & $1,105,360$ & $(100.0)$ \\
\hline
\end{tabular}

Source: GES, 2000-2004

Note: Numbers in parentheses represent column percentages.

a Primarily crossroad ramp terminal crashes.

b Primarily mainline freeway crashes. 
Table 12. Crashes Within Interchange Areas by Relation to Roadway

\begin{tabular}{|lrrrrrrrr|}
\hline \multicolumn{1}{c}{$\begin{array}{c}\text { Relation to } \\
\text { roadway }\end{array}$} & \multicolumn{2}{c}{$\begin{array}{c}\text { Intersection or } \\
\text { intersection- } \\
\text { related }^{\mathbf{a}}\end{array}$} & \multicolumn{2}{c}{ Ramp-related } & $\begin{array}{c}\text { Other interchange } \\
\text { area }^{\mathbf{b}}\end{array}$ & Total \\
\hline On Roadway & 169,858 & $(95.4)$ & 517,721 & $(71.8)$ & 155,865 & $(75.5)$ & 843,444 & $(76.3)$ \\
On Shoulder & 82 & $(0.0)$ & 17,670 & $(2.5)$ & 2,105 & $(1.0)$ & 19,857 & $(1.8)$ \\
On Median & 2,779 & $(1.6)$ & 18,364 & $(2.5)$ & 13,026 & $(6.3)$ & 34,170 & $(3.1)$ \\
On Roadside & 4,101 & $(2.3)$ & 105,215 & $(14.6)$ & 20,979 & $(10.2)$ & 130,295 & $(11.8)$ \\
Outside Trafficway & 0 & $(0.0)$ & 6,461 & $(0.9)$ & 1,964 & $(1.0)$ & 8,424 & $(0.8)$ \\
Off Roadway- & & & & & & & & \\
Location Unknown & 261 & $(0.1)$ & 20,709 & $(2.9)$ & 1,820 & $(0.9)$ & 22,790 & $(2.1)$ \\
In Parking Lane & 0 & $(0.0)$ & 189 & $(0.0)$ & 263 & $(0.1)$ & 452 & $(0.0)$ \\
Gore & 477 & $(0.3)$ & 30,682 & $(4.3)$ & 8,432 & $(4.1)$ & 39,591 & $(3.6)$ \\
Separator & 158 & $(0.1)$ & 2,173 & $(0.3)$ & 1,207 & $(0.6)$ & 3,538 & $(0.3)$ \\
Unknown & 371 & $(0.2)$ & 1,633 & $(0.2)$ & 797 & $(0.4)$ & 2,801 & $(0.3)$ \\
\hline Total & 178,087 & $(100.0)$ & 720,817 & $(100.0)$ & 206,456 & $(100.0)$ & $1,105,360$ & $(100.0)$ \\
\hline
\end{tabular}

Source: GES, 2000-2004

Note: Numbers in parentheses represent column percentages.

a Primarily crossroad ramp terminal crashes.

b Primarily mainline freeway crashes.

Table 13. Crashes Within Interchange Areas by Type of Traffic Control Device Present

\begin{tabular}{|lrrrrrrrr|}
\hline \multicolumn{1}{c}{$\begin{array}{c}\text { Traffic control } \\
\text { device }\end{array}$} & \multicolumn{2}{c}{$\begin{array}{c}\text { Intersection or } \\
\text { intersection- } \\
\text { related }^{\mathbf{a}}\end{array}$} & \multicolumn{7}{c|}{ Ramp-related } & $\begin{array}{c}\text { Other interchange } \\
\text { area }^{\mathbf{b}}\end{array}$ & Total \\
\hline Traffic Signal & 105,331 & $(59.1)$ & 103,174 & $(14.3)$ & 5,086 & $(2.5)$ & 213,591 & $(19.3)$ \\
Flashing Signal & 648 & $(0.4)$ & 1,994 & $(0.3)$ & 537 & $(0.3)$ & 3,179 & $(0.3)$ \\
Other Signal & 129 & $(0.1)$ & 3,176 & $(0.4)$ & 489 & $(0.2)$ & 3,794 & $(0.3)$ \\
Stop Sign & 23,098 & $(13.0)$ & 70,856 & $(9.8)$ & 1,458 & $(0.7)$ & 95,411 & $(8.6)$ \\
Yield Sign & 11,244 & $(6.3)$ & 103,629 & $(14.4)$ & 16,909 & $(8.2)$ & 131,783 & $(11.9)$ \\
Other Sign & 772 & $(0.4)$ & 18,397 & $(2.6)$ & 6,049 & $(2.9)$ & 25,219 & $(2.3)$ \\
Unknown/Other & 10,165 & $(5.7)$ & 30,483 & $(4.2)$ & 19,093 & $(9.2)$ & 59,741 & $(5.4)$ \\
No Traffic Control & & & & & & & & \\
Device & 26,701 & $(15.0)$ & 389,107 & $(54.0)$ & 156,83 & $(76.0)$ & 572,643 & $(51.8)$ \\
\hline Total & 178,087 & $(100.0)$ & 720,817 & $(100.0)$ & 206,456 & $(100.0)$ & $1,105,360$ & $(100.0)$ \\
\hline
\end{tabular}

Source: GES, 2000-2004

Note: Numbers in parentheses represent column percentages.

a Primarily crossroad ramp terminal crashes.

b Primarily mainline freeway crashes.

\section{Distribution of Crashes by Light Condition}

Table 14 presents the distribution of crashes in interchange areas by light condition. Most crashes in interchange areas occur in daylight, but a substantial proportion of crashes occurs after dark (28 percent in rural areas and 25 percent in urban areas). FARS data show that fatal crashes after dark appear more prevalent than during daylight on ramps and mainline freeways in urban areas. GES data do not show a similar pattern for crashes of all severity levels. 
Table 14. Crashes Within Interchange Areas by Light Condition

\begin{tabular}{|c|c|c|c|c|c|c|c|c|}
\hline \multirow{2}{*}{$\begin{array}{c}\begin{array}{c}\text { Light } \\
\text { condition }\end{array} \\
\text { Rural } \\
\text { Davlight }\end{array}$} & \multicolumn{2}{|c|}{$\begin{array}{l}\text { Intersection or } \\
\text { intersection- }^{\text {related }}{ }^{\mathrm{a}}\end{array}$} & \multicolumn{2}{|c|}{ Ramp-related } & \multicolumn{2}{|c|}{$\begin{array}{c}\text { Other } \\
\text { interchange area }\end{array}$} & \multicolumn{2}{|c|}{ Total } \\
\hline & 34,810 & (19.5) & 138,662 & (20.2) & 50,570 & $(21.0)$ & 224,041 & $(20.3)$ \\
\hline Dark & 2,204 & $(1.2)$ & 29,343 & $(4.3)$ & 8,228 & $(3.4)$ & 39,774 & $(3.6)$ \\
\hline Dark but & & & & & & & & \\
\hline lighted & 6,368 & (3.6) & 38,584 & (5.6) & 10,251 & (4.3) & 55,203 & $(5.0)$ \\
\hline Dawn & 563 & $(0.3)$ & 4,217 & $(0.6)$ & 513 & $(0.2)$ & 5,293 & $(0.5)$ \\
\hline Dusk & 1,130 & $(0.6)$ & 4,522 & $(0.7)$ & 668 & $(0.3)$ & 6,321 & $(0.6)$ \\
\hline Unknown & 0 & $(0.0)$ & 1,449 & $(0.2)$ & 1,859 & $(0.8)$ & 3,308 & $(0.3)$ \\
\hline Subtotal & 45,074 & (25.3) & 216,777 & (31.6) & 72,088 & $(30.0)$ & 333,940 & $(30.2)$ \\
\hline \multicolumn{9}{|l|}{ Urban } \\
\hline Daylight & 97,483 & (54.7) & 350,302 & (51.0) & 90,858 & (37.8) & 538,642 & (48.7) \\
\hline Dark & 4,555 & (2.6) & 9,808 & (1.4) & 43,868 & (18.2) & 58,232 & (5.3) \\
\hline Dark but & & & & & & & & \\
\hline lighted & 27,083 & $(15.2)$ & 82,536 & $(12.0)$ & 27,242 & (11.3) & 136,861 & $(12.4)$ \\
\hline Dawn & 1,810 & $(1.0)$ & 10,382 & $(1.5)$ & 2,505 & $(1.0)$ & 14,698 & (1.3) \\
\hline Dusk & 2,082 & $(1.2)$ & 13,134 & (1.9) & 2,887 & $(1.2)$ & 18,103 & (1.6) \\
\hline Unknown & 0 & $(0.0)$ & 3,817 & $(0.6)$ & 1,067 & $(0.4)$ & 4,884 & $(0.4)$ \\
\hline Subtotal & 133,013 & (74.7) & 469,980 & (68.4) & 168,427 & $(70.0)$ & 771,420 & (69.8) \\
\hline Total & 178,087 & $(100.0)$ & 686,757 & $(100.0)$ & 240,516 & $(100.0)$ & $1,105,360$ & $(100.0)$ \\
\hline
\end{tabular}

\section{ESTIMATED NUMBER OF INTERCHANGES IN THE UNITED STATES}

There are no published data on the number of interchanges in the United States. An estimate has been prepared for this report to put the interchange safety data derived from FARS and GES in perspective.

Estimates of the average interchange spacing in several states were obtained from a review of maps. Two or three typical freeway routes were selected in each of four states. The states selected were California, Illinois, Pennsylvania, and Washington. These states were chosen because the same four states were used by Harwood et al. to make similar estimates for the FHWA truck size and weight study. ${ }^{2}$ Table 15 summarizes the length of freeway on the selected routes, the number of interchanges on those routes, and the average interchange spacing for both rural and urban portion of those routes. 
Table 15. Typical Interchange Spacing in Rural and Urban Areas

\begin{tabular}{|c|c|c|c|c|c|c|c|c|}
\hline \multirow[b]{2}{*}{ State } & \multirow[b]{2}{*}{$\begin{array}{c}\text { Selected } \\
\text { routes }\end{array}$} & \multirow[b]{2}{*}{$\begin{array}{c}\text { Total } \\
\text { length } \\
\text { (mi) }\end{array}$} & \multicolumn{3}{|c|}{ Number of interchanges } & \multirow{2}{*}{$\begin{array}{c}\text { Average } \\
\text { interchange } \\
\text { spacing } \\
\text { (mi) }\end{array}$} & \multicolumn{2}{|c|}{$\begin{array}{c}\text { Percentage of } \\
\text { interchanges }\end{array}$} \\
\hline & & & $\begin{array}{c}\text { Freeway/ } \\
\text { freeway }\end{array}$ & $\begin{array}{c}\text { Freeway/ } \\
\text { arterial }\end{array}$ & Total & & $\begin{array}{c}\text { Freeway/ } \\
\text { freeway }\end{array}$ & $\begin{array}{c}\text { Freeway/ } \\
\text { arterial }\end{array}$ \\
\hline \multicolumn{9}{|l|}{ Rural Areas } \\
\hline California & I-5, I-80 & 735 & 10 & 220 & 230 & 3.2 & 4.3 & 95.7 \\
\hline Illinois & I-55, I-70 & 332 & 3 & 59 & 62 & 5.4 & 4.8 & 95.2 \\
\hline Pennsylvania & I-80, I-81 & 477 & 9 & 80 & 89 & 5.4 & 10.1 & 89.9 \\
\hline Washington & I-5, I-90 & 399 & 2 & 107 & 109 & 3.7 & 1.8 & 98.2 \\
\hline Combined & & 1,943 & 24 & 466 & 490 & 4.4 & 5.3 & 94.7 \\
\hline \multicolumn{9}{|l|}{ Urban Areas } \\
\hline California & I-5, I-80 & 275 & 43 & 229 & 272 & 1.0 & 15.8 & 84.2 \\
\hline Illinois & $\mathrm{I}-55, \mathrm{I}-70$ & 95 & 12 & 38 & 50 & 1.9 & 24.0 & 76.0 \\
\hline Pennsylvania & $\begin{array}{l}\mathrm{I}-76^{\mathrm{a}}, \\
\mathrm{I}-80, \mathrm{I}-81\end{array}$ & 90 & 11 & 51 & 62 & 1.5 & 17.7 & 82.3 \\
\hline Washington & I-5, I-90 & 176 & 15 & 103 & 118 & 1.5 & 12.7 & 87.3 \\
\hline Combined & & 636 & 81 & 421 & 502 & 1.5 & 17.6 & 82.4 \\
\hline
\end{tabular}

Only non-toll portions of this route were used.

Table 15 shows that the average interchange spacing, giving equal weight to the data from each state, is $4.4 \mathrm{mi}$ in rural areas and $1.5 \mathrm{mi}$ in urban areas. Recent work by Bared et al. found that safety is influenced with adjacent interchanges within $3 \mathrm{mi}^{3}$ Thus, the safety of urban interchanges is typically influenced by adjacent interchanges, while the safety of rural interchanges is not.

Table 16 uses data on total freeway mileage from Highway Statistics and the estimates of interchange spacing developed in table 15 to estimate the total number of freeway interchanges in the United States. ${ }^{4}$ The divided access-controlled facilities on both the Interstate highway system and on similar roads classified in Highway Statistics as other freeways and expressways and other principal arterials were included in this estimate. Undivided roadways and roadways without full control of access were excluded even if they are part of the Interstate highway system. Other principal arterials with a divided cross section and full control of access were included because certain access-controlled parkways might not be classified as freeways but still have interchanges.

Table 16 shows the estimate that there are approximately 22,800 freeway interchanges in the United States, of which approximately 3,000 are freeway/freeway interchanges and approximately 19,800 are freeway/arterial interchanges. Thus, approximately 13 percent of interchanges are freeway/freeway interchanges and 87 percent are freeway/arterial interchanges. No estimate of the number of arterial/arterial interchanges is available, but there are also interchanges of this type. Overall, it is estimated that approximately 36 percent of freeway interchanges are located in rural areas and 64 percent are located in urban areas. 
Table 16. Estimated Number of Freeway Interchanges in the United States

\begin{tabular}{|c|c|c|c|}
\hline & Rural & Urban & Total \\
\hline \multicolumn{4}{|l|}{${\text { Freeway length }(\mathrm{mi})^{\mathrm{a}}}$} \\
\hline Interstate system & 30,937 & 14,388 & 45,325 \\
\hline Non-Interstate freeways ${ }^{\mathrm{b}}$ & 5,015 & 7,618 & 12,633 \\
\hline Total freeway length & 35,952 & 22,006 & 57,958 \\
\hline \multicolumn{4}{|l|}{ Estimates from Table 15} \\
\hline Average interchange spacing (mi) & 4.4 & 1.5 & \\
\hline$\%$ Freeway/freeway interchanges & 5.3 & 17.6 & \\
\hline \multicolumn{4}{|l|}{ Estimated number of interchanges ${ }^{c}$} \\
\hline No. of interchanges & 8,171 & 14,671 & 22,842 \\
\hline No. of freeway/freeway interchanges & 433 & 2,582 & 3,015 \\
\hline No. of freeway/arterial interchanges & 7,738 & 12,089 & 19,827 \\
\hline
\end{tabular}

Data from Highway Statistics for 2003.

b Includes "Other Freeways and Expressways” and "Other Principal Arterials” with full control of access.

c Estimates do not include arterial/arterial interchanges.

The data in table 16, combined with those in table 3, suggest that there are approximately 0.05 fatal crashes per interchange per year, which implies that interchanges in the United States generally operate very safely. Table 9 shows that, overall, fatal crashes constitute 0.4 percent of total interchange-related crashes. The estimated 0.05 fatal crashes per interchange per year and fatal crashes constituting 0.4 percent of interchange-related crashes for all severity levels imply that the average interchange experiences 12.5 crashes per year for all severity levels combined. 


\section{REVIEW OF SAFETY PERFORMANCE FUNCTIONS FOR INTERCHANGE ELEMENTS}

A review of the technical literature on safety assessment of freeway interchanges was conducted, focusing on quantitative information that was potentially applicable for incorporation in ISAT. The review included both engineering and statistical considerations. In particular, interchangesafety-related literature was evaluated to identify safety performance functions (SPFs) for primary interchange components or elements, as follows:

Primary Components of Interchanges:

- Mainline freeway segments

o Segments within interchange areas

o Segments outside of interchange areas

- Ramps

o Freeway mainline ramp terminals (i.e., speed change lanes)

o Ramp propers

o Crossroad ramp terminals

- Arterial roadways

For clarity purposes, Figure 1 illustrates a number of typical interchange configurations, and Figure 2 illustrates a number of typical ramp configurations.

The primary sources of information that contained SPFs for potential incorporation into ISAT included:

- Development of Safety Performance Functions for SafetyAnalyst Interim Tools ${ }^{5}$

- $\quad$ Statistical Models for Interchange Ramps and Speed-Change Lanes ${ }^{6}$

- Safety Impact of Interchange Spacing on Urban Freeways ${ }^{3}$

A brief review of these primary sources is provided, followed by the individual SPFs from the respective sources. 


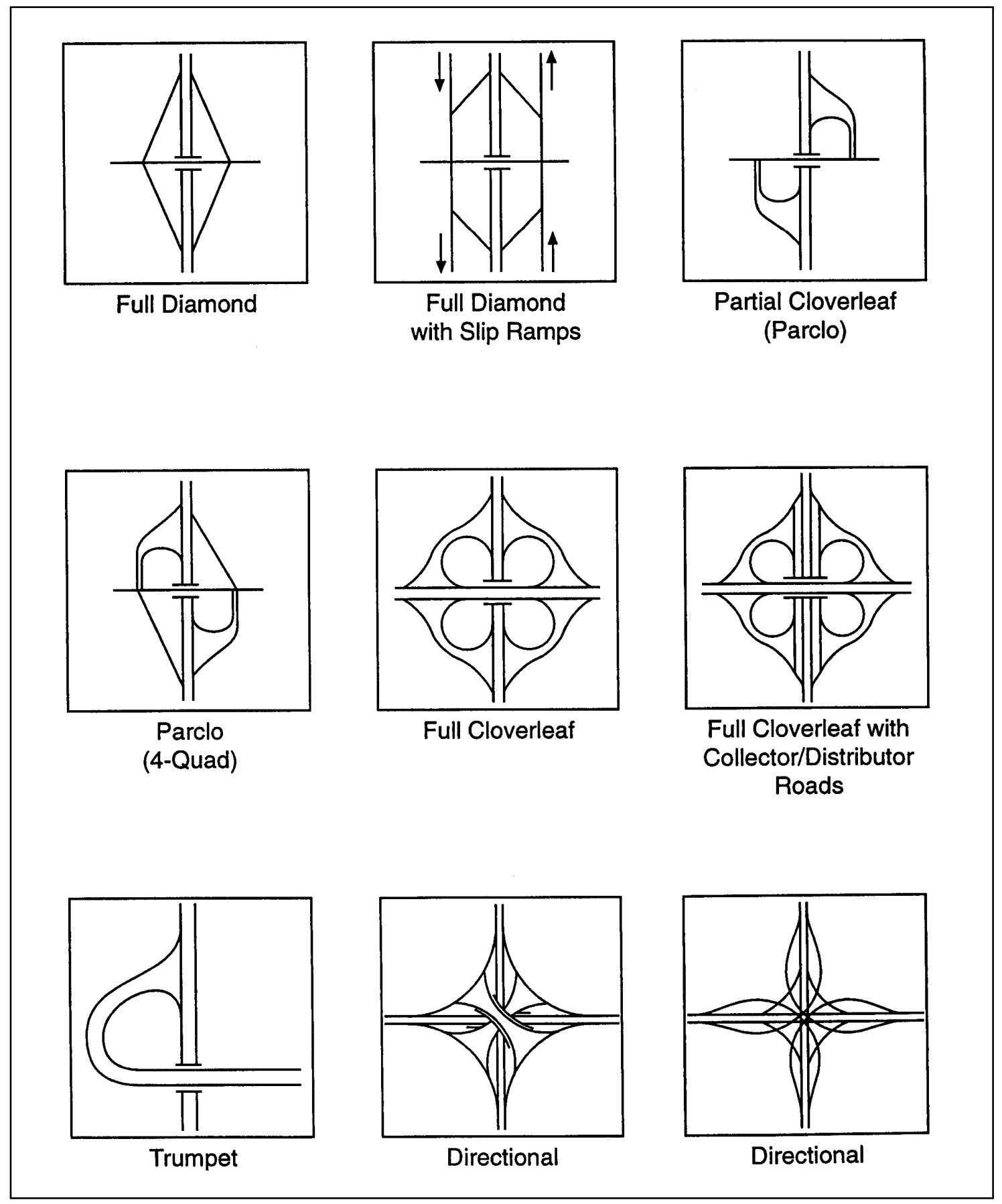

Figure 1. Typical Interchange Configuration ${ }^{6}$ 


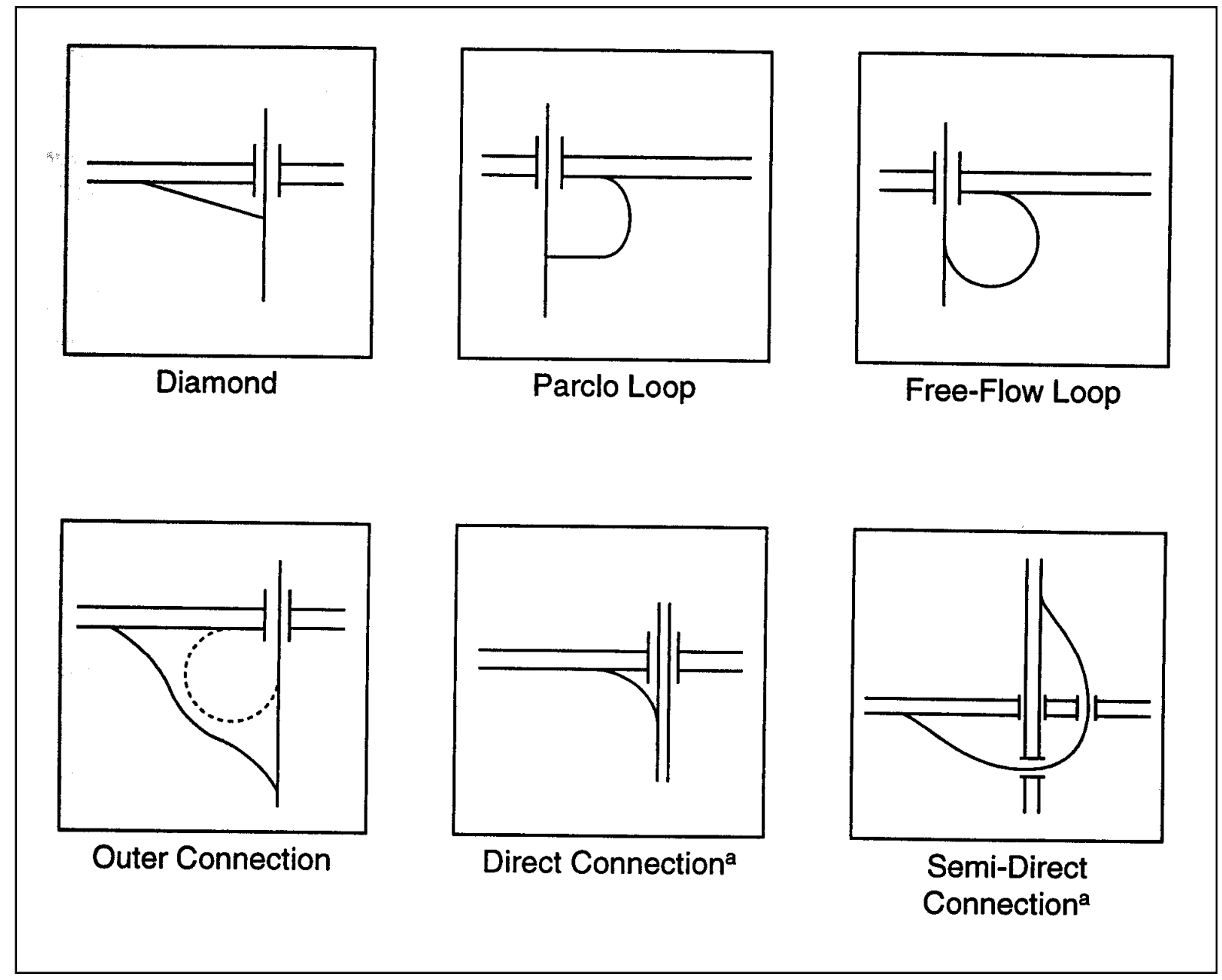

${ }^{\mathrm{a}}$ When used in directional interchanges.

Figure 2. Typical Ramp Configurations ${ }^{6}$ 


\section{OVERVIEW OF PRIMARY SOURCES}

\section{SafetyAnalyst}

The Federal Highway Administration (FHWA) has undertaken a major effort to develop a set of software tools for safety management of specific highway sites, known as SafetyAnalyst. The SafetyAnalyst software will consist of a series of analytical tools, including the four primary analytical modules as follows:

- Module 1-Network screening to identify sites with potential for safety improvement

- Module 2-Diagnosis of safety concerns at particular sites and selection of appropriate countermeasures

- Module 3-Economic analysis and priority ranking of countermeasures

- Module 4-Effectiveness evaluation of implemented countermeasures

All of the SafetyAnalyst modules will incorporate SPFs.

SPFs have been developed for SafetyAnalyst for three types of sites (i.e., roadway segments, intersections, and ramps) and for several subtypes. ${ }^{5}$ The types of sites for which SPFs have been developed are as follows:

\section{$\underline{\text { Roadway Segments }}$}

- Rural two-lane highway segments

- Rural multilane undivided highway segments

- Rural multilane divided highway segments

- Rural freeway segments-4 lanes

- Rural freeway segments-6+ lanes

- Rural freeway segments within an interchange area-4 lanes

- Rural freeway segments within an interchange area-6+ lanes

- Urban two-lane arterial segments

- Urban multilane undivided arterial segments

- Urban multilane divided arterial segments

- Urban one-way arterial segments

- Urban freeway segments-4 lanes

- Urban freeway segments -6 lanes

- Urban freeway segments-8+ lanes

- Urban freeway segments within an interchange area-4 lanes

- Urban freeway segments within an interchange area-6 lanes

- Urban freeway segments within an interchange area-8+ lanes 


\section{$\underline{\text { Intersections }}$}

- Rural three-leg intersections with minor-road STOP control

- Rural three-leg intersections with signal control

- Rural four-leg intersections with minor-road STOP control

- Rural four-leg intersections with all-way STOP control

- Rural four-leg intersections with signal control

- Urban three-leg intersections with minor-road STOP control

- Urban three-leg intersections with signal control

- Urban four-leg intersections with minor-road STOP control

- Urban four-leg intersections with all-way STOP control

- Urban four-leg intersections with signal control

$\underline{\text { Ramps }}$

- Rural diamond off-ramps

- Rural diamond on-ramps

- Rural parclo loop off-ramps

- Rural parclo loop on-ramps

- Rural free-flow loop off-ramps

- Rural free-flow loop on-ramps

- Rural direct or semi direct connection ramps

- Urban diamond off-ramps

- Urban diamond on-ramps

- Urban parclo loop off-ramps

- Urban parclo loop on-ramps

- Urban free-flow loop off-ramps

- Urban free-flow loop on-ramps

- Urban direct or semi direct connection ramps

Many of the individual site subtypes are pertinent to this research.

The SPFs developed to date for SafetyAnalyst predict crash frequency as a function of annual average daily traffic volume alone. (Note: Throughout this report, all traffic volumes are making reference to annual average daily traffic volumes. For simplicity purposes, annual average daily traffic is being abbreviated ADT.) For roadway segments and ramps, the independent variable representing traffic volume is the ADT of the roadway segment or ramp. For intersections, two independent variables represent traffic volume, the ADTs of the two intersecting roads classified as the major and minor roads, where the major road is typically the road with the higher ADT. For roadway segments and ramps, the length of the roadway segment or ramp is also included in the model. 
For the SPFs developed to date, the dependent variable (i.e., the variable whose value is predicted by the model) is crash frequency per year on the roadway segment, intersection, or ramp of interest. SPFs have been developed both for total (TOT) crash frequency (i.e.., all crash severity levels combined) and for fatal and injury (FI) crashes. Fatal and injury crashes include all crashes in which a fatality occurred and all crashes in which a personal injury of any severity level occurred (i.e., FI crashes include fatal crashes and crashes involving injuries of the A, B, and $\mathrm{C}$ severity levels). No SPFs have been developed to estimate the frequency of propertydamage-only (PDO) crashes.

The functional form for roadway segment SPFs from SafetyAnalyst is as follows:

$$
\mathrm{N}=\mathrm{e}^{\mathrm{a}} \times \mathrm{ADT}^{\mathrm{b}} \times \mathrm{SL}
$$

where: $\mathrm{N}=$ predicted crash frequency per mile per year

$\mathrm{ADT}=$ annual average daily traffic (veh/day)

$\mathrm{SL}=$ segment length $(\mathrm{mi})$

The functional form for intersection SPFs from SafetyAnalyst is as follows:

$$
\mathrm{N}=\mathrm{e}^{\mathrm{a}} \times \mathrm{ADT}_{\text {major rd }}^{\mathrm{b}} \times \mathrm{ADT}_{\text {minor rd }}^{\mathrm{c}}
$$

where: $\mathrm{N}=$ predicted crash frequency per intersection per year

$\mathrm{ADT}_{\text {major-rd }}=$ annual average daily traffic on the major road (veh/day)

$\mathrm{ADT}_{\text {minor-rd }}=$ annual average daily traffic on the minor road (veh/day)

The functional form for ramp SPFs from SafetyAnalyst is as follows:

$$
\mathrm{N}=\mathrm{e}^{\mathrm{a}} \times \mathrm{ADT}^{b} \times R L^{c}
$$

where: $\mathrm{N} \quad=$ predicted crash frequency per mile per year

$\mathrm{ADT}=$ annual average daily traffic (veh/day)

$\mathrm{RL} \quad=$ ramp length $(\mathrm{mi})$

In all three equations, a, b, and c represent the regression parameters estimated from the available data.

The SPFs have been developed with negative binomial (NB) regression using the SAS GENMOD software package. NB regression has been used because it is appropriate for data with low-frequency observations, like crash data, and data that are overdispersed (i.e., data for which the variance exceeds the mean). For each data set used in modeling, a dispersion parameter (k) has been quantified, indicating the extent to which the mean crash frequency is exceeded by the 
variance of crash frequency. The goodness of fit of the NB regression models has been represented by the Freeman-Tukey $\mathrm{R}^{2}$ coefficient $\left(\mathrm{R}_{\mathrm{FT}}{ }^{2}\right)$.

SPFs were developed using available data for four states from the FHWA Highway Safety Information System (HSIS). The states whose data files were used and the years of data used for each state are as follows:

- California (1997-2001)

- Minnesota (1995-1999)

- Ohio (1997-1999)

- Washington (1993-1996)

The HSIS data files from these states that were used, when available, include roadway segment characteristics, intersection characteristics, ramp characteristics, and crash data.

The factors considered in selecting a particular SPF for use in SafetyAnalyst were (1) the statistical significance of the model; (2) the goodness of fit of the model as represented by the Freeman-Tukey $\mathrm{R}^{2}$ parameter $\left(\mathrm{R}_{\mathrm{FT}}^{2}\right)$; and (3) the shape of the curve in comparison to the expected shape based on other research. For some site subtypes, there were several acceptable SPFs developed from data for different states. For other site subtypes, only one SPF was available or only one SPF fit the data well. Finally, in limited cases, no SPF was found that explained a sufficient proportion of the variance in crash frequency to be statistically significant. Only those models recommended for use in SafetyAnalyst for the respective site subtype are provided in this document.

The document that presents the majority of SPFs developed to date for SafetyAnalyst is Development of Safety Performance Functions for SafetyAnalyst Interim Tools. ${ }^{5}$ SafetyAnalyst is an ongoing research project. Some of the SPFs that are incorporated into ISAT have been developed subsequent to the referenced document and are not available in other SafetyAnalyst reports.

\section{Bauer and Harwood}

The objective of this research was to develop statistical models for defining the relationship between traffic crashes, highway geometric design elements, and traffic volumes for interchange ramps and speed-change lanes. ${ }^{6}$ The database used to develop the models consisted of data for interchange ramps and speed-change lanes in the State of Washington and was obtained from HSIS. Additional geometric design features were obtained from a review of interchange diagrams, aerial photographs, and other existing highway agency files. 
The statistical modeling approaches used in this research included Poisson and negative binomial regression. Regression models to determine relationships between crashes and the geometric design and traffic volume characteristics of ramps were difficult to develop because the observed crash frequencies for most of the ramps and speed-change lanes were very low. The negative binomial regression provided a better fit to the data. Most of the variability in the data was explained by ramp ADT but other significant variables also included mainline freeway ADT, area type, ramp type (on/off), ramp configuration, and combined length of ramp and speedchange lane. The best models for predicting crash frequencies where those models that estimated the crash frequency for the entire ramp, together with its adjacent speed-change lane. Models were developed to predict both total and fatal and injury crashes.

\section{Bared et al.}

In an effort to approach the issue of interchange spacing from a safety perspective, this research was undertaken using crash data for three California urban freeways. ${ }^{3}$ Bared et al. developed negative binomial regression models for correlating crash frequencies with interchange spacing for both total and fatal and injury crashes. For their research, the authors defined interchange spacing as the shortest distance between successive interchange gore points and used HSIS crash data from 1998 to 2002 (inclusive). A special effort was made to exclude any area from the data set in which construction activity was present that would have changed the basic geometric design of the interchange area. In total, 53 sample segments representing $58.5 \mathrm{mi}$ of freeway were used to develop the models for total and fatal and injury crashes. A separate data set of 40 sample segments representing $34 \mathrm{mi}$ of freeway was used later in the process to validate the resulting models.

In addition to crash counts and ADT values, the following road geometry variables were considered for inclusion in the predictive model: interchange spacing; divided/ undivided; left shoulder width; right shoulder width; median type; median width; and number of lanes. The authors stated that the data were insufficient to test other explanatory factors. To this end, it is possible that omitted variables may introduce a bias if they are correlated with the variables that were ultimately included in the models.

\section{SPFs INCORPORATED INTO ISAT}

The SPFs provided within ISAT were selected for incorporation in the tool based primarily on the following reasons:

- Statistical validity of the models

- Criticality of the components based upon engineering judgment

- Methodological consistency 


\section{Mainline Freeway Segments}

The SPFs for mainline freeway segments provided within ISAT were developed for use within SafetyAnalyst. These SPFs predict the number of crashes that may occur on mainline freeway segments. SPFs are provided for two unique types of mainline freeway segments:

- Mainline freeway segments within an interchange area

- Mainline freeway segments outside an interchange area

The SPFs for mainline freeway segments within interchange areas attempt to account for the increased level of weaving, lane changing, and acceleration/deceleration that takes place immediately upstream, downstream, and between interchange ramps. The SPFs for mainline freeway segments outside an interchange area model the safety experience of basic mainline freeway segments having homogenous characteristics. In these homogeneous segments, the number of through lanes remains the same, the traffic volume remains the same throughout the segment because there are no ramps associated with the segment, and the primary movements include lane changes between through lanes.

The limits of mainline freeway segments within interchange areas are defined in general terms to extend approximately $0.3 \mathrm{mi}$ upstream from the gore (i.e., painted nose) of the first ramp of a particular interchange to approximately $0.3 \mathrm{mi}$ downstream from the gore (i.e., painted nose) of the last ramp of the given interchange (figure 3). All mainline freeway segments beyond these boundaries are by definition mainline freeway segments outside an interchange area.

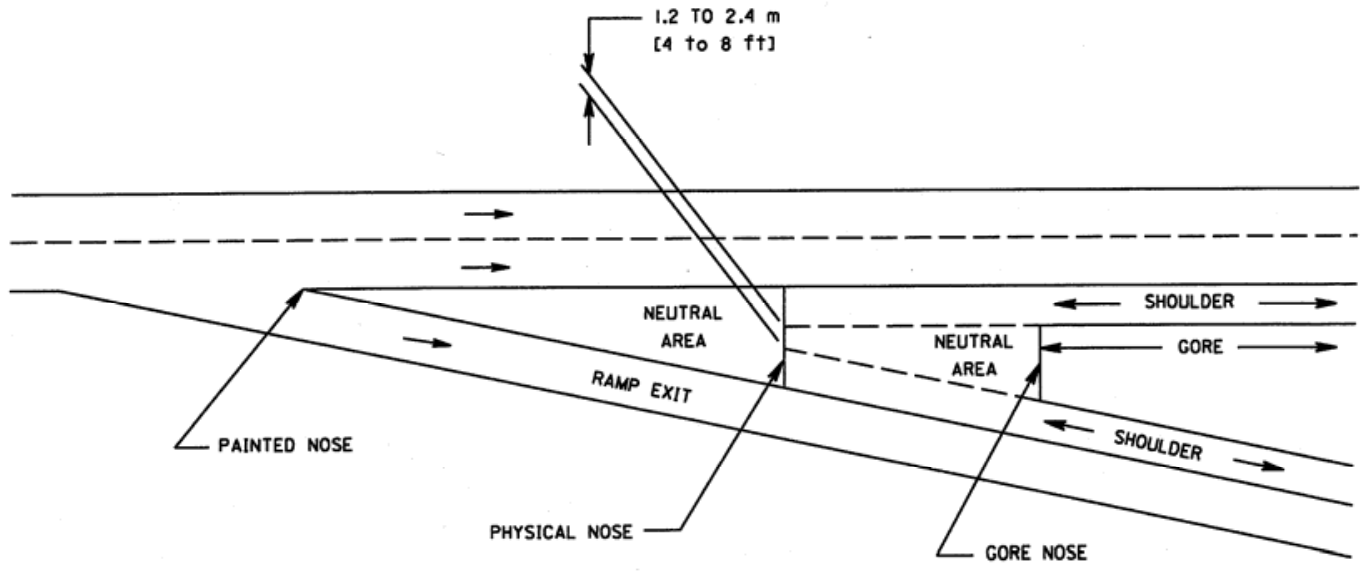

Figure 3. Typical Gore Area Characteristics ${ }^{7}$ 
The SPFs for mainline freeway segments within interchange areas predict crashes that occur on mainline freeway segments and the adjacent roadside and speed-change lanes (i.e., deceleration and acceleration lanes) adjacent to the mainline freeway segment through lanes. The SPFs do not predict crashes that occur on the ramp proper (i.e., downstream from the gore point for off-ramps and upstream from the gore point for on-ramps). Because the SPFs for mainline freeway segments within interchange areas predict crashes that occur on speed-change lanes, certain methodological assumptions are made within ISAT so that crashes are not double counted on mainline freeway segments and acceleration lanes.

Table 17 presents the coefficients and parameters of the SPFs for mainline freeway segments provided within ISAT. Table 17 also shows the functional form of the models. In general, all models included in ISAT were developed using NB regression. Table 18 defines the coefficients and parameters of the SPFs. Twenty SPFs for mainline freeway segments are provided within ISAT and are a function of the following:

- Area type

- Interchange area (i.e., within or outside interchange area)

- Number of lanes

- Severity level

\section{Ramps}

Two sets of SPFs associated with ramps are provided within ISAT:

- SPFs that predict the safety performance along the ramp proper

- SPFs that predict the safety performance along acceleration lanes

The SPFs for the ramp proper were developed for use within SafetyAnalyst, and the SPFs for acceleration lanes were developed by Bauer and Harwood. ${ }^{6}$

Table 19 presents the coefficients and parameters of the SPFs for ramps (i.e., ramp proper) provided within ISAT. Table 19 also shows the functional form of the models. Table 20 defines the coefficients and parameters of these SPFs. Twenty-eight SPFs for ramps (i.e., ramp proper) are provided within ISAT and are a function of the following:

- Area type

- Ramp type

- Ramp configuration

- Severity level 
Table 17. SPF Coefficients and Parameters for Mainline Freeway Segments

\begin{tabular}{|c|c|c|c|c|c|c|c|c|}
\hline SPF No. & $\begin{array}{l}\text { Area } \\
\text { type }\end{array}$ & $\begin{array}{c}\text { Interchange } \\
\text { area }\end{array}$ & $\begin{array}{c}\text { Number of } \\
\text { through lanes } \\
\text { (directional) }\end{array}$ & $\begin{array}{c}\text { Severity } \\
\text { level }\end{array}$ & $\begin{array}{c}\log \\
\text { intercept (a) }\end{array}$ & $\begin{array}{l}\text { Coeff of log } \\
\text { ADT (b) }\end{array}$ & $\begin{array}{l}\text { Dispersion } \\
\text { parameter }\end{array}$ & $\begin{array}{l}\text { Max } \\
\text { ADT }\end{array}$ \\
\hline numeric & $(\mathrm{U}, \mathbf{R})$ & $(\mathrm{Y}, \mathrm{N})$ & $(2,3,4)$ & (TOT, FI) & numeric & numeric & numeric & (veh/day) \\
\hline \multicolumn{9}{|c|}{$\begin{array}{l}\text { SafetyAnalyst Roadway Segment SPF } \\
N=\mathrm{e}^{\mathrm{a}} \times \mathrm{ADT}^{\mathrm{b}} \times \mathrm{SL}\end{array}$} \\
\hline 1 & $\mathrm{R}$ & $\mathrm{Y}$ & 2 & TOT & -7.28 & 0.92 & 0.45 & 60,621 \\
\hline 2 & $\mathrm{R}$ & Y & 3 & TOT & -10.05 & 1.14 & 0.42 & 197,798 \\
\hline 3 & U & $\mathrm{Y}$ & 2 & TOT & -11.23 & 1.3 & 0.81 & 241,255 \\
\hline 4 & $\mathrm{U}$ & $\mathrm{Y}$ & 3 & TOT & -11.25 & 1.28 & 0.60 & 255,154 \\
\hline 5 & $\mathrm{U}$ & $\mathrm{Y}$ & 4 & TOT & -26.76 & 2.58 & 0.52 & 233,323 \\
\hline 6 & $\bar{R}$ & $\bar{Y}$ & 2 & FI & $\begin{array}{l}-8.68 \\
\end{array}$ & 0.94 & 0.58 & 60,621 \\
\hline 7 & $\mathrm{R}$ & $\mathrm{Y}$ & 3 & FI & -12.07 & 1.22 & 0.39 & 197,798 \\
\hline 8 & U & Y & 2 & FI & -12.89 & 1.38 & 0.79 & 241,255 \\
\hline 9 & $\mathrm{U}$ & $\mathrm{Y}$ & 3 & FI & -13.62 & 1.42 & 0.55 & 255,154 \\
\hline 10 & $\mathrm{U}$ & $\mathrm{Y}$ & 4 & FI & -25.63 & 2.42 & 0.53 & 233,323 \\
\hline 11 & $\mathrm{R}$ & $\mathrm{N}$ & 2 & TOT & -6.46 & 0.79 & 0.17 & 60,621 \\
\hline 12 & $\mathrm{R}$ & $\mathrm{N}$ & 3 & TOT & -9.67 & 1.07 & 0.24 & 190,403 \\
\hline 13 & $\mathrm{U}$ & $\mathrm{N}$ & 2 & TOT & -7.85 & 1 & 0.99 & 151,038 \\
\hline 14 & $\mathrm{U}$ & $\mathrm{N}$ & 3 & TOT & -5.96 & 0.78 & 0.48 & 241,255 \\
\hline 15 & $\mathrm{U}$ & $\mathrm{N}$ & 4 & TOT & -16.24 & 1.67 & 0.45 & 223,088 \\
\hline 16 & $\mathrm{R}$ & $\mathrm{N}$ & 2 & FI & -8.86 & 0.9 & 0.10 & 60,621 \\
\hline 17 & $\mathrm{R}$ & $\mathrm{N}$ & 3 & FI & -11.67 & 1.17 & 0.21 & 190,403 \\
\hline 18 & U & $\mathrm{N}$ & 2 & FI & -8.82 & 1.02 & 1.15 & 151,038 \\
\hline 19 & U & $\mathrm{N}$ & 3 & FI & -7.60 & 0.85 & 0.54 & 241,255 \\
\hline 20 & U & $\mathrm{N}$ & 4 & FI & -19.16 & 1.85 & 0.52 & 223,088 \\
\hline
\end{tabular}


Table 18. Definitions of Coefficients and Parameters of SPFs for Mainline Freeway Segments

\begin{tabular}{|c|c|c|}
\hline Variable Name & Format & Definition \\
\hline SPF No. & Numeric & $\begin{array}{l}\text { Each SPF is identified by a sequential integer, starting with } 1 \text {; } \\
\text { this variable is not used in calculations but is useful for } \\
\text { organization. }\end{array}$ \\
\hline Area type & $\begin{array}{l}\text { Character } \\
(\mathrm{U}, \mathrm{R})\end{array}$ & $\begin{array}{l}\text { General character of land use surrounding the interchange, } \\
\text { preferably based on FHWA urban area boundaries: } \\
\text { U = Urban } \\
\text { R = Rural }\end{array}$ \\
\hline Interchange area & $\begin{array}{l}\text { Character } \\
(\mathrm{Y}, \mathrm{N})\end{array}$ & $\begin{array}{l}\text { A code identifying whether the segment is located within the } \\
\text { interchange area: } \\
\mathrm{Y}=\text { yes, segment is located within the interchange area } \\
\mathrm{N}=\text { no, segment is not located within the interchange area }\end{array}$ \\
\hline $\begin{array}{l}\text { Number of } \\
\text { through lanes } \\
\text { (directional) }\end{array}$ & $\begin{array}{l}\text { Numeric } \\
(2,3,4)\end{array}$ & $\begin{array}{l}\text { This field includes all lanes on the segment in a given } \\
\text { direction that are used by through traffic; it does not include } \\
\text { auxiliary lanes. }\end{array}$ \\
\hline Severity level & $\begin{array}{l}\text { Character } \\
\text { (TOT, FI) }\end{array}$ & $\begin{array}{l}\text { A code identifying the crash severity level: } \\
\text { TOT = total crashes } \\
\text { FI = fatal and injury crashes }\end{array}$ \\
\hline Log intercept (a) & Numeric & Intercept of SPF. \\
\hline $\begin{array}{l}\text { Coefficient of log } \\
\text { ADT (b) }\end{array}$ & Numeric & Coefficient of log ADT parameter. \\
\hline $\begin{array}{l}\text { Dispersion } \\
\text { parameter }\end{array}$ & Numeric & $\begin{array}{l}\text { Dispersion parameter associated with negative binomial } \\
\text { regression. }\end{array}$ \\
\hline Max ADT & $\begin{array}{l}\text { Numeric } \\
\text { (veh/day) }\end{array}$ & $\begin{array}{l}\text { The maximum traffic volume for which the coefficients of the } \\
\text { SPF were calibrated/calculated. }\end{array}$ \\
\hline
\end{tabular}


Table 19. SPF Coefficients and Parameters for Ramps

\begin{tabular}{|c|c|c|c|c|c|c|c|c|c|}
\hline $\begin{array}{l}\text { SPF No. } \\
\text { numeric }\end{array}$ & $\begin{array}{c}\begin{array}{c}\text { Area } \\
\text { type }\end{array} \\
(R, U)\end{array}$ & $\begin{array}{c}\text { Ramp type } \\
\text { (ON, OFF, } \\
\text { FWY) }\end{array}$ & $\begin{array}{c}\text { Ramp } \\
\text { configuration } \\
\text { (D, PL, FFL, } \\
\text { DIR) }\end{array}$ & $\begin{array}{c}\begin{array}{c}\text { Severity } \\
\text { level }\end{array} \\
\text { (TOT, FI) }\end{array}$ & $\begin{array}{c}\log \\
\text { intercept (a) } \\
\text { numeric }\end{array}$ & $\begin{array}{c}\text { Coeff of } \\
\operatorname{ADT}_{\text {Ramp }}(\mathbf{b}) \\
\text { numeric }\end{array}$ & $\begin{array}{c}\text { Coeff of ramp } \\
\text { length (e) } \\
\text { numeric }\end{array}$ & $\begin{array}{c}\begin{array}{c}\text { Dispersion } \\
\text { parameter } \\
\text { numeric }\end{array} \\
\end{array}$ & $\begin{array}{c}\text { Max } \\
\text { ADT } \\
\text { (veh/day) }\end{array}$ \\
\hline \multicolumn{10}{|c|}{$\begin{array}{c}\text { SafetyAnalyst Ramp Proper SPF } \\
\mathrm{N}=\mathrm{e}^{\mathrm{a}} \times \mathrm{ADT}_{\mathrm{Ramp}} \times \mathrm{RL}^{\mathrm{e}}\end{array}$} \\
\hline 1 & $\mathrm{R}$ & OFF & $\mathrm{D}$ & TOT & -3.17 & 0.45 & 1.0 & 1.49 & 22,566 \\
\hline 2 & $\mathrm{R}$ & ON & D & TOT & -8.28 & 1.03 & 1.0 & 2.57 & 24,966 \\
\hline 3 & $\mathrm{R}$ & OFF & PL & TOT & -4.50 & 0.73 & 1.0 & 1.17 & 22,538 \\
\hline 4 & $\mathrm{R}$ & ON & PL & TOT & -2.11 & 0.43 & 1.0 & 1.77 & 20,403 \\
\hline 5 & $\mathrm{R}$ & OFF & FFL & TOT & -4.50 & 0.73 & 1.0 & 1.17 & 22,538 \\
\hline 6 & $\mathrm{R}$ & ON & FFL & TOT & -2.11 & 0.43 & 1.0 & 1.77 & 20,403 \\
\hline 7 & $\mathrm{R}$ & FWY & DIR & TOT & -1.80 & 0.45 & 1.0 & 1.67 & 37,474 \\
\hline 8 & $\mathrm{U}$ & OFF & $\mathrm{D}$ & TOT & -3.17 & 0.45 & 1.0 & 1.49 & 22,566 \\
\hline 9 & $\mathrm{U}$ & ON & D & TOT & -8.28 & 1.03 & 1.0 & 2.57 & 24,966 \\
\hline 10 & U & OFF & PL & TOT & -4.50 & 0.73 & 1.0 & 1.17 & 22,538 \\
\hline 11 & $\mathrm{U}$ & ON & PL & TOT & -2.11 & 0.43 & 1.0 & 1.77 & 20,403 \\
\hline 12 & $\mathrm{U}$ & OFF & FFL & TOT & -4.50 & 0.73 & 1.0 & 1.17 & 22,538 \\
\hline 13 & U & ON & FFL & TOT & -2.11 & 0.43 & 1.0 & 1.77 & 20,403 \\
\hline 14 & $\mathrm{U}$ & FWY & DIR & TOT & -1.80 & 0.45 & 1.0 & 1.67 & 37,474 \\
\hline 15 & $\mathrm{R}$ & OFF & $\mathrm{D}$ & FI & -6.88 & 0.78 & 1.0 & 2.21 & 22,566 \\
\hline 16 & $\mathrm{R}$ & ON & $\mathrm{D}$ & FI & -14.40 & 1.61 & 1.0 & 3.44 & 24,966 \\
\hline 17 & $\mathrm{R}$ & OFF & PL & FI & -3.63 & 0.53 & 1.0 & 1.71 & 22,538 \\
\hline 18 & $\mathrm{R}$ & ON & PL & FI & -3.37 & 0.44 & 1.0 & 0.82 & 20,403 \\
\hline 19 & $\mathrm{R}$ & OFF & FFL & FI & -3.63 & 0.53 & 1.0 & 1.71 & 22,538 \\
\hline 20 & $\mathrm{R}$ & ON & FFL & FI & -3.37 & 0.44 & 1.0 & 0.82 & 20,403 \\
\hline 21 & $\mathrm{R}$ & FWY & DIR & FI & -2.80 & 0.46 & 1.0 & 1.89 & 37,474 \\
\hline 22 & $\mathrm{U}$ & OFF & $\mathrm{D}$ & FI & -6.88 & 0.78 & 1.0 & 2.21 & 22,566 \\
\hline 23 & U & ON & D & FI & -14.40 & 1.61 & 1.0 & 3.44 & 24,966 \\
\hline 24 & U & OFF & PL & FI & -3.63 & 0.53 & 1.0 & 1.71 & 22,538 \\
\hline 25 & $\mathrm{U}$ & ON & PL & FI & -3.37 & 0.44 & 1.0 & 0.82 & 20,403 \\
\hline 26 & $\mathrm{U}$ & OFF & FFL & FI & -3.63 & 0.53 & 1.0 & 1.71 & 22,538 \\
\hline 27 & U & ON & FFL & FI & -3.37 & 0.44 & 1.0 & 0.82 & 20,403 \\
\hline 28 & $\mathrm{U}$ & FWY & DIR & FI & -2.80 & 0.46 & 1.0 & 1.89 & 37,474 \\
\hline
\end{tabular}


Table 20. Definitions of Coefficients and Parameters of SPFs for Ramps

\begin{tabular}{|c|c|c|}
\hline Variable Name & Format & Definition \\
\hline SPF No. & Numeric & $\begin{array}{l}\text { Each SPF included in the analysis must be identified by a sequential } \\
\text { integer, starting with } 1 \text {; this variable is not used in calculations but is useful } \\
\text { for organization. }\end{array}$ \\
\hline Area type & $\begin{array}{l}\text { Character } \\
(\mathrm{U}, \mathrm{R})\end{array}$ & $\begin{array}{l}\text { General character of land use surrounding the interchange, preferably based } \\
\text { on FHWA urban area boundaries: } \\
\text { U = Urban } \\
\text { R = Rural }\end{array}$ \\
\hline Ramp type & $\begin{array}{l}\text { Character } \\
\text { (ON, OFF, } \\
\text { FWY) }\end{array}$ & $\begin{array}{l}\text { The type of ramps are distinguished by the following codes: } \\
\text { ON = on-ramp } \\
\text { OFF = off-ramp } \\
\text { FWY = freeway-to-freeway ramp }\end{array}$ \\
\hline $\begin{array}{l}\text { Ramp } \\
\text { configuration }\end{array}$ & $\begin{array}{l}\text { Character } \\
\text { (D, PL, FFL, } \\
\text { DIR) }\end{array}$ & $\begin{array}{l}\text { This variable defines the basic geometric design of the ramp; the } \\
\text { abbreviated codes correspond as follows: } \\
\mathrm{D} \text { = diamond ramp } \\
\mathrm{PL} \text { = parclo loop ramp } \\
\text { FFL = free-flow loop ramp } \\
\text { DIR = directional ramp }\end{array}$ \\
\hline Severity level & $\begin{array}{l}\text { Character } \\
\text { (TOT, FI) }\end{array}$ & $\begin{array}{l}\text { This variable identifies the crash severity level: } \\
\text { TOT = total crashes } \\
\text { FI = fatal and injury crashes }\end{array}$ \\
\hline Log intercept (a) & Numeric & Intercept of SPF. \\
\hline $\begin{array}{l}\text { Coefficient of } \\
\log \text { ADT (b) }\end{array}$ & Numeric & Coefficient of log ADT (ramp) parameter. \\
\hline $\begin{array}{l}\text { Coefficient of } \\
\text { ramp length (e) }\end{array}$ & Numeric & Coefficient of ramp length parameter. \\
\hline $\begin{array}{l}\text { Dispersion } \\
\text { parameter }\end{array}$ & Numeric & Dispersion parameter associated with negative binomial regression. \\
\hline Max ADT & $\begin{array}{l}\text { Numeric } \\
\text { (veh/day) }\end{array}$ & $\begin{array}{l}\text { The maximum traffic volume of the ramp for which the coefficients of the } \\
\text { SPF apply. }\end{array}$ \\
\hline
\end{tabular}


The ramp SPFs within SafetyAnalyst were developed by combining data for rural and urban areas; thus, separate models are not available for rural and urban areas. For consistency the SPFs are presented by area type, but the coefficients and parameters are the same for both area types.

Table 21 presents the coefficients and parameters of the SPFs for acceleration lanes provided within ISAT. Table 21 also shows the functional form of the models. Table 22 defines the coefficients and parameters of these SPFs. Four SPFs for acceleration lanes are provided within ISAT and are a function of the following:

- Area type

- Severity level

The acceleration lane SPFs are based upon models from Bauer and Harwood ${ }^{6}$ for the entire ramp (i.e., ramp proper) and adjacent speed-change lane (i.e., acceleration or deceleration lane). A constant term is provided with the SPF because the original SPFs were developed to predict crashes for a 3-yr period. The constant term scales the prediction to an annual basis. The constant term also accounts for a ramp length term (i.e., the length of the ramp proper) in the original form of the SPF. A constant ramp length of $0.176 \mathrm{mi}$ (i.e., the average length of the ramp proper from the data used in creating the original model) was assumed for determining the value of the constant. Finally, the values of the log intercept term are reflective of diamond on-ramps for both total crashes (at 20 percent significance) and fatal and injury crashes (at 10 percent significance).

ISAT does not include SPFs for deceleration lanes because no models were found that reflect actual safety benefits of incremental changes in deceleration lane lengths without being confounded with other parameters of the model.

\section{Crossroad Ramp Terminals and Intersections}

The SPFs for crossroad ramp terminals and intersections were developed for use within SafetyAnalyst. These SPFs were developed using data for conventional at-grade intersections, but due to the lack of any suitable safety prediction models developed specifically for crossroad ramp terminals, these models are used to predict crashes at both crossroad ramp terminals and conventional intersections defined as part of an analysis area. Table 23 presents the coefficients and parameters of these SPFs. Table 23 also shows the functional form of the models. Table 24 defines the coefficients and parameters. Sixteen SPFs for crossroad ramp terminals and intersections are provided within ISAT and are a function of the following:

- Area type

- Type of traffic control

- Number of legs

- Severity level 
Table 21. SPF Coefficients and Parameters for Acceleration Lanes

\begin{tabular}{|c|c|c|c|c|c|c|c|c|c|}
\hline $\begin{array}{l}\text { SPF No. } \\
\text { Numeric }\end{array}$ & $\begin{array}{l}\text { Area } \\
\text { type } \\
(\mathrm{R}, \mathrm{U}) \\
\end{array}$ & $\begin{array}{c}\text { Severity } \\
\text { level } \\
\text { (TOT, } \\
\text { FI) }\end{array}$ & $\begin{array}{l}\text { Constant } \\
\text { (C) } \\
\text { numeric }\end{array}$ & $\begin{array}{c}\text { Log } \\
\text { intercept } \\
\text { (a) } \\
\text { numeric }\end{array}$ & $\begin{array}{c}\begin{array}{c}\text { Coeff } \\
\text { of }\end{array} \\
\text { ADT }_{\text {Ramp }} \\
\text { (b) } \\
\text { numeric }\end{array}$ & $\begin{array}{c}\begin{array}{c}\text { Coeff } \\
\text { of length } \\
\text { (c) }\end{array} \\
\text { numeric }\end{array}$ & $\begin{array}{c}\begin{array}{c}\text { Coeff } \\
\text { of }\end{array} \\
\text { ADT }_{\text {Freeway }} \\
\text { (d) } \\
\text { numeric }\end{array}$ & $\begin{array}{c}\text { Dispersion } \\
\text { parameter } \\
\text { numeric }\end{array}$ & $\begin{array}{c}\text { Mean } \\
\text { length } \\
\text { (mi) }\end{array}$ \\
\hline \multicolumn{10}{|c|}{ Bauer and Harwood Acceleration Lane SPF } \\
\hline \multicolumn{10}{|c|}{$\mathbf{N}=\mathbf{C} \times \mathbf{e}^{\mathrm{a}} \times \mathbf{A D T}_{\text {Ramp }}{ }^{\mathbf{b}} \times \mathbf{e}^{\mathrm{c} \times \mathrm{ALL}} \times \mathbf{A D T}_{\text {Freeway }}{ }^{\mathrm{d}}$} \\
\hline 1 & $\mathrm{R}$ & TOT & 0.44 & -7.19 & 0.78 & -2.59 & 0.13 & 0.66 & 0.1 \\
\hline 2 & $\mathrm{U}$ & TOT & 0.44 & -6.82 & 0.78 & -2.59 & 0.13 & 0.66 & 0.1 \\
\hline 3 & $\mathrm{R}$ & FI & 0.55 & -10.68 & 0.91 & -4.55 & 0.29 & 0.52 & 0.1 \\
\hline 4 & $\mathrm{U}$ & FI & 0.55 & -10.68 & 0.91 & -4.55 & 0.29 & 0.52 & 0.1 \\
\hline
\end{tabular}

Table 22. Definitions of Coefficients and Parameters of SPFs for Acceleration Lanes

\begin{tabular}{|c|c|c|}
\hline Variable Name & Format & Definition \\
\hline SPF No. & Numeric & $\begin{array}{l}\text { Each SPF in the analysis must be identified by a sequential integer, starting } \\
\text { with 1; this variable is not used in calculations but is useful for organization. }\end{array}$ \\
\hline Area type & $\begin{array}{l}\text { Character } \\
(\mathrm{U}, \mathrm{R})\end{array}$ & $\begin{array}{l}\text { General character of land use surrounding the interchange, preferably based on } \\
\text { FHWA urban area boundaries: } \\
\text { U = Urban } \\
\text { R = Rural }\end{array}$ \\
\hline Severity level & $\begin{array}{l}\text { Character } \\
\text { (TOT, FI) }\end{array}$ & $\begin{array}{l}\text { This variable identifies the crash severity level: } \\
\text { TOT = total crashes } \\
\text { FI = fatal and injury crashes }\end{array}$ \\
\hline Constant (C) & Numeric & $\begin{array}{l}\text { This constant is provided because the SPFs were developed to predict crashes } \\
\text { for a 3-year period. A value of } 0.33 \text { scales the prediction to an annual basis. } \\
\text { The constant also accounts for a ramp length term (i.e., the length of the ramp } \\
\text { proper) in the original form of the SPF. }\end{array}$ \\
\hline Log intercept (a) & Numeric & Intercept of SPF. \\
\hline $\begin{array}{l}\text { Coefficient of } \\
\log \mathrm{ADT}_{\text {Ramp }}(\mathrm{b})\end{array}$ & Numeric & Coefficient of log ADT (ramp) parameter. \\
\hline $\begin{array}{l}\text { Coefficient of } \\
\text { length (c) }\end{array}$ & Numeric & Coefficient of acceleration lane length (ALL) parameter. \\
\hline $\begin{array}{l}\text { Coefficient of } \\
\log \mathrm{ADT}_{\text {Freeway }} \\
\text { (d) }\end{array}$ & Numeric & Coefficient of log ADT (freeway) parameter. \\
\hline $\begin{array}{l}\text { Dispersion } \\
\text { parameter }\end{array}$ & Numeric & Dispersion parameter associated with negative binomial regression. \\
\hline Mean length & $\begin{array}{l}\text { Numeric } \\
\text { (mi) }\end{array}$ & Mean length of acceleration lanes used to develop SPFs. \\
\hline
\end{tabular}


Table 23. SPF Coefficients and Parameters for

Crossroad Ramp Terminals and Intersections

\begin{tabular}{|c|c|c|c|c|c|c|c|c|c|c|}
\hline $\begin{array}{l}\text { SPF No. } \\
\text { numeric }\end{array}$ & $\begin{array}{c}\text { Area } \\
\text { type } \\
(\mathrm{U}, \mathbf{R})\end{array}$ & $\begin{array}{c}\text { Type of traffic } \\
\text { control } \\
\text { (SG, ST) }\end{array}$ & $\begin{array}{c}\text { Number of } \\
\text { legs } \\
(3,4)\end{array}$ & $\begin{array}{c}\text { Severity } \\
\text { level } \\
\text { (TOT, FI) }\end{array}$ & $\begin{array}{c}\text { Log intercept } \\
\text { (a) } \\
\text { numeric } \\
\end{array}$ & $\begin{array}{c}\text { Coeff of } \text { ADT }_{\text {major rd }} \\
\text { (b) } \\
\text { numeric }\end{array}$ & $\begin{array}{c}\text { Coeff of } \\
\text { ADT }_{\text {off-ramp }} \\
\text { (c) } \\
\text { numeric }\end{array}$ & $\begin{array}{c}\text { Dispersion } \\
\text { parameter } \\
\text { numeric }\end{array}$ & $\begin{array}{c}\text { Max } \\
\text { ADT }_{\text {major rd }} \\
\text { (veh/day) }\end{array}$ & $\begin{array}{c}\text { Max } \\
\text { ADT }_{\text {off-ramp }} \\
\text { (veh/day) }\end{array}$ \\
\hline \multicolumn{11}{|c|}{ SafetyAnalyst Ramp Terminal SPF } \\
\hline \multicolumn{11}{|c|}{$\mathbf{N}=\mathbf{e}^{\mathrm{a}} \times \mathbf{A D T}_{\text {major rd }} \mathbf{b} \times \mathbf{A D T}_{\text {off-ramp }}{ }^{\mathrm{c}}$} \\
\hline 1 & $\mathrm{R}$ & ST & 3 & TOT & -8.78 & 0.71 & 0.24 & 1.07 & 28,500 & 27,000 \\
\hline 2 & $\mathrm{R}$ & SG & 3 & TOT & -6.57 & 0.66 & 0.20 & 0.33 & 36,400 & 11,500 \\
\hline 3 & $\mathrm{R}$ & ST & 4 & TOT & -8.96 & 0.65 & 0.47 & 0.70 & 35,500 & 26,700 \\
\hline 4 & $\mathrm{R}$ & SG & 4 & TOT & -6.57 & 0.66 & 0.20 & 0.33 & 36,400 & 11,500 \\
\hline 5 & $\mathrm{U}$ & ST & 3 & TOT & -5.35 & 0.34 & 0.28 & 1.28 & 68,000 & 18,900 \\
\hline 6 & $\mathrm{U}$ & SG & 3 & TOT & -9.85 & 0.97 & 0.18 & 0.23 & 50,000 & 25,807 \\
\hline 7 & $\mathrm{U}$ & $\mathrm{ST}$ & 4 & TOT & -3.12 & 0.27 & 0.16 & 0.86 & 58,870 & 81,000 \\
\hline 8 & $\mathrm{U}$ & SG & 4 & TOT & -3.47 & 0.42 & 0.14 & 0.32 & 75,000 & 81,000 \\
\hline 9 & $\mathrm{R}$ & ST & 3 & $\overline{\text { FI }}$ & -9.35 & 0.71 & 0.21 & 1.23 & 28,500 & 27,000 \\
\hline 10 & $\mathrm{R}$ & SG & 3 & FI & -7.83 & 0.75 & 0.14 & 0.50 & 36,400 & 11,500 \\
\hline 11 & $\mathrm{R}$ & $\mathrm{ST}$ & 4 & FI & -9.36 & 0.66 & 0.40 & 0.00 & 35,500 & 26,700 \\
\hline 12 & $\mathrm{R}$ & SG & 4 & FI & -7.83 & 0.75 & 0.14 & 0.50 & 36,400 & 11,500 \\
\hline 13 & $\mathrm{U}$ & $\mathrm{ST}$ & 3 & FI & -8.45 & 0.49 & 0.39 & 1.23 & 68,000 & 18,900 \\
\hline 14 & $\mathrm{U}$ & SG & 3 & FI & -10.22 & 0.91 & 0.21 & 0.27 & 50,000 & 25,807 \\
\hline 15 & $\mathrm{U}$ & $\mathrm{ST}$ & 4 & FI & -4.35 & 0.29 & 0.19 & 0.99 & 58,870 & 81,000 \\
\hline 16 & $\mathrm{U}$ & SG & 4 & FI & -5.11 & 0.49 & 0.16 & 0.30 & 75,000 & 81,000 \\
\hline
\end{tabular}


Table 24. Definitions of Coefficients and Parameters of SPFs for Crossroad Ramp Terminals and Intersections

\begin{tabular}{|c|c|c|}
\hline Variable Name & Format & Definition \\
\hline SPF no. & Numeric & $\begin{array}{l}\text { Each SPF included in the analysis must be identified by a sequential integer, } \\
\text { starting with 1; this variable is not used in calculations but is useful for } \\
\text { organization. }\end{array}$ \\
\hline Area type & $\begin{array}{l}\text { Character } \\
(\mathrm{U}, \mathrm{R})\end{array}$ & $\begin{array}{l}\text { General character of land use surrounding the interchange, preferably based on } \\
\text { FHWA urban area boundaries: } \\
\text { U = Urban } \\
\text { R = Rural }\end{array}$ \\
\hline $\begin{array}{l}\text { Type of traffic } \\
\text { control }\end{array}$ & $\begin{array}{l}\text { Character } \\
\text { (SG, ST) }\end{array}$ & $\begin{array}{l}\text { A code identifying the type of traffic control for the crossroad ramp terminal or } \\
\text { intersection: } \\
\text { SG = signalized intersection } \\
\text { ST = STOP-control on the ramp or minor roadway; no control on the major } \\
\text { crossroad }\end{array}$ \\
\hline Number of legs & $\begin{array}{l}\text { Numeric } \\
(3,4)\end{array}$ & $\begin{array}{l}\text { A code identifying the number of legs of the crossroad ramp terminal or } \\
\text { intersection: } \\
3 \text { = three legs } \\
4 \text { = four legs } \\
\text { NoTE: In determining the number of legs, the user should consider whether it is } \\
\text { most appropriate to treat each ramp served by the terminal as an individual leg. }\end{array}$ \\
\hline Severity level & $\begin{array}{l}\text { Character } \\
\text { (TOT, FI) }\end{array}$ & $\begin{array}{l}\text { A code identifying the crash severity level: } \\
\text { TOT = total crashes } \\
\text { FI = fatal and injury crashes }\end{array}$ \\
\hline Log intercept (a) & Numeric & Intercept of SPF. \\
\hline $\begin{array}{l}\text { Coefficient of log } \\
\mathrm{ADT}_{\text {major rd }}(\mathrm{b})\end{array}$ & Numeric & $\begin{array}{l}\text { Coefficient of log ADT (major rd) (bi-directional) }\left(\mathrm{ADT}_{\text {major rd }} \text { is calculated }\right. \\
2 \times \text { major rd ADT). }\end{array}$ \\
\hline $\begin{array}{l}\text { Coefficient of log } \\
\text { ADT }_{\text {off-ramp }}(\mathrm{c})\end{array}$ & Numeric & $\begin{array}{l}\text { Coefficient of log } \mathrm{ADT} \text { (off-ramp) ( } \mathrm{ADT}_{\text {off-ramp }} \text { is minor rd or ramp ADT when } \\
\text { terminal type is } \mathrm{RT} \text {. } \mathrm{ADT}_{\text {off-ramp }} \text { is } 2 \times \text { minor rd or ramp ADT when terminal type } \\
\text { is CI.) }\end{array}$ \\
\hline $\begin{array}{l}\text { Dispersion } \\
\text { parameter }\end{array}$ & Numeric & Dispersion parameter associated with negative bionomial regression. \\
\hline $\mathrm{Max}_{\mathrm{ADT}}$ major rd & $\begin{array}{l}\text { Numeric } \\
\text { (veh/day) }\end{array}$ & $\begin{array}{l}\text { The maximum traffic volume on the crossroad for which the coefficients of the } \\
\text { SPF apply. }\end{array}$ \\
\hline Max $\mathrm{ADT}_{\text {off-amp }}$ & $\begin{array}{l}\text { Numeric } \\
\text { (veh/day) }\end{array}$ & $\begin{array}{l}\text { The maximum traffic volume on the ramp for which the coefficients of the SPF } \\
\text { apply. }\end{array}$ \\
\hline
\end{tabular}

\section{Crossroad Roadway Segments}

The SPFs for arterial crossroad segments provided within ISAT were developed for use within SafetyAnalyst. These SPFs predict the number of crashes that may occur on urban and rural 
arterial streets. These predictions include crashes that occur at intersections located on the crossroad roadway segments and are not related to the operation of the intersections; however the predictions do not include crashes that occur at intersections located on the crossroad roadway segments and are related to the operation of the intersections (i.e., these intersection related crashes are included in the predictions for crossroad ramp terminals and intersections).

Table 25 presents the coefficients and parameters of the SPFs for arterial crossroad segments provided within ISAT. Table 25 also shows the functional form of the models. Table 26 defines the coefficients and parameters of these SPFs. Twenty SPFs for crossroad roadway segments are provided within ISAT and are a function of the following:

- Area type

- Number of through lanes

- Median type

- Severity level 
Table 25. SPF Coefficients and Parameters for Crossroad Segments

\begin{tabular}{|c|c|c|c|c|c|c|c|c|}
\hline $\begin{array}{l}\text { SPF No. } \\
\text { numeric }\end{array}$ & $\begin{array}{c}\text { Area } \\
\text { type } \\
(\mathrm{U}, \mathrm{R}) \\
\end{array}$ & $\begin{array}{c}\text { Number of } \\
\text { through } \\
\text { lanes } \\
\text { (directional) } \\
(1,2,3) \\
\end{array}$ & $\begin{array}{l}\text { Median } \\
(\mathrm{D}, \mathrm{U})\end{array}$ & $\begin{array}{c}\text { Severity } \\
\text { level } \\
\text { (TOT, FI) }\end{array}$ & $\begin{array}{c}\text { Log } \\
\text { intercept } \\
\text { (a) } \\
\text { numeric } \\
\end{array}$ & $\begin{array}{c}\text { Coeff of } \\
\text { Log ADT } \\
\text { (b) } \\
\text { numeric }\end{array}$ & $\begin{array}{c}\text { Dispersion } \\
\text { parameter } \\
\text { numeric }\end{array}$ & $\begin{array}{c}\text { Max } \\
\text { ADT } \\
\text { (veh/day) }\end{array}$ \\
\hline \multicolumn{9}{|c|}{$\begin{array}{l}\text { SafetyAnalyst Crossroad Segment SPF } \\
\qquad \mathbf{N}=\mathbf{e}^{\mathbf{a}} \times \mathbf{A D T}^{\mathbf{b}} \times \mathrm{SL} \\
\end{array}$} \\
\hline 1 & $\mathrm{R}$ & 1 & U & TOT & -3.63 & 0.53 & 0.50 & 30,025 \\
\hline 2 & $\mathrm{R}$ & 2 & $\mathrm{U}$ & TOT & -3.17 & 0.49 & 0.53 & 42,638 \\
\hline 3 & $\mathrm{R}$ & 3 & U & TOT & -3.17 & 0.49 & 0.53 & 42,638 \\
\hline 4 & $\mathrm{R}$ & 2 & D & TOT & -5.05 & 0.66 & 0.32 & 31,188 \\
\hline 5 & $\mathrm{R}$ & 3 & D & TOT & -5.05 & 0.66 & 0.32 & 31,188 \\
\hline 6 & U & 1 & U & TOT & -7.16 & 0.84 & 4.40 & 29,850 \\
\hline 7 & $\mathrm{U}$ & 2 & $\mathrm{U}$ & TOT & -10.24 & 1.29 & 0.85 & 57,901 \\
\hline 8 & U & 3 & U & TOT & -10.24 & 1.29 & 0.85 & 57,901 \\
\hline 9 & $\mathrm{U}$ & 2 & D & TOT & -11.85 & 1.34 & 5.91 & 77,735 \\
\hline 10 & $\mathrm{U}$ & 3 & $\mathrm{D}$ & TOT & -11.85 & 1.34 & 5.91 & 77,735 \\
\hline 11 & $\mathrm{R}$ & 1 & $\mathrm{U}$ & FI & -4.86 & 0.53 & 0.67 & 30,025 \\
\hline 12 & $\mathrm{R}$ & 2 & $\mathrm{U}$ & FI & -4.20 & 0.50 & 0.53 & 42,638 \\
\hline 13 & $\mathrm{R}$ & 3 & U & FI & -4.20 & 0.50 & 0.53 & 42,638 \\
\hline 14 & $\mathrm{R}$ & 2 & D & FI & -7.46 & 0.72 & 0.09 & 31,188 \\
\hline 15 & $\mathrm{R}$ & 3 & D & FI & -7.46 & 0.72 & 0.09 & 31,188 \\
\hline 16 & $\mathrm{U}$ & 1 & $\mathrm{U}$ & FI & -8.84 & 0.89 & 4.54 & 29,850 \\
\hline 17 & $\mathrm{U}$ & 2 & $\mathrm{U}$ & FI & -12.07 & 1.39 & 0.81 & 57,901 \\
\hline 18 & U & 3 & U & FI & -12.07 & 1.39 & 0.81 & 57,901 \\
\hline 19 & $\mathrm{U}$ & 2 & D & FI & -14.87 & 1.52 & 5.81 & 77,735 \\
\hline 20 & U & 3 & D & FI & -14.87 & 1.52 & 5.81 & 77,735 \\
\hline
\end{tabular}




\section{Table 26. Definitions of Coefficients and Parameters of SPFs for Crossroad Segments}

\begin{tabular}{|c|c|c|}
\hline Variable Name & Format & Definition \\
\hline SPF No. & Numeric & $\begin{array}{l}\text { Each SPF in the analysis must be identified by a sequential integer, } \\
\text { starting with 1; this variable is not used in calculations but is useful } \\
\text { for organization. }\end{array}$ \\
\hline Area type & $\begin{array}{l}\text { Character } \\
(\mathrm{U}, \mathrm{R})\end{array}$ & $\begin{array}{l}\text { General character of land use surrounding the interchange, } \\
\text { preferably based on FHWA urban area boundaries: } \\
\text { U = Urban } \\
\text { R = Rural }\end{array}$ \\
\hline $\begin{array}{l}\text { Number of through } \\
\text { lanes }\end{array}$ & $\begin{array}{l}\text { Numeric } \\
(1,2,3)\end{array}$ & $\begin{array}{l}\text { A code identifying the number of through lanes in a given direction } \\
\text { on the crossroad segment. }\end{array}$ \\
\hline Median & $\begin{array}{l}\text { Character } \\
\text { (U, D) }\end{array}$ & $\begin{array}{l}\text { A code identifying whether a median is present on the crossroad } \\
\text { segment: } \\
\mathrm{U}=\text { the segment is undivided } \\
\mathrm{D}=\text { the segment is divided }\end{array}$ \\
\hline Severity level & $\begin{array}{l}\text { Character } \\
\text { (TOT, FI) }\end{array}$ & $\begin{array}{l}\text { A code identifying the crash severity level: } \\
\text { TOT = total crashes } \\
\text { FI = fatal and injury crashes }\end{array}$ \\
\hline Log intercept (a) & Numeric & Intercept of SPF. \\
\hline $\begin{array}{l}\text { Coefficient of log } \\
\text { ADT (b) }\end{array}$ & Numeric & Coefficient of log ADT parameter (this ADT is directional). \\
\hline Dispersion parameter & Numeric & Dispersion parameter with negative binomial regression. \\
\hline Max ADT & $\begin{array}{l}\text { Numeric } \\
\text { (veh/day) }\end{array}$ & $\begin{array}{l}\text { The maximum traffic volume on the crossroad for which the } \\
\text { coefficients of the SPF apply. }\end{array}$ \\
\hline
\end{tabular}





\section{INTERVIEWS WITH EXPERIENCED DESIGNERS}

Interviews were conducted with several experienced highway designers about their need for, and potential uses of, an ISAT. The interviews were conducted to guide the development of ISAT. Interviews were conducted with members of Kansas and New York State Departments of Transportation.

The interviews were conducted in a free-form approach centering around five specific questions. The questions posed in the interviews were:

1. Would a safety prediction tool for interchange elements assist your agency in planning and designing interchange projects?

2. At what stages of the project development process would a safety prediction tool be of greatest assistance? Planning? Alternatives development? Preliminary design? Final design?

3. How should such a tool be used to examine safety concerns at an existing interchange? To analyze design alternatives for an existing interchange? To predict the safety performance of a new interchange where no interchange previously existed?

4. Should the tool address the mainline freeway roadway within the interchange area? Speedchange lanes? Ramps? Crossroad ramp terminals? Crossroad roadways near ramp terminals? All of the above?

5. Should the tool address the safety benefits of improving the interchange as a whole? Safety benefits for improving specific design elements within the interchange? Determining dimensions for specific design elements within the interchange?

The overall assessment of the interviews was that the ISAT is very much needed and interest is high. A summary of the responses to each question is presented below.

Would ISAT assist your agency in planning and designing interchange projects?

- The interviews indicated that ISAT would be useful to assist highway agencies in planning and design of interchange projects. One respondent indicated that ISAT would be used when circumstances allowed it. An agency probably would not use the tool if it did not help to prove a particular point that the agency wanted to make about particular design alternatives. Another respondent indicated that ISAT would be useful when reconstructing interchanges, especially when assessing nonconforming features or seeking approval for design exceptions. One respondent suggested the output of the ISAT carry a disclaimer like "for estimating purposes only" to provide some protection for highway agencies in case they made a necessary decision for non-safety reasons that differed from the alternative suggested by the safety analysis. 
At what stages of the project development process would ISAT be of greatest assistance? Planning? Alternatives development? Preliminary design? Final design?

- The interviews indicated that ISAT would most likely be used in the early stages of the design process, especially when design concepts or design alternatives are being developed and assessed. ISAT appears most applicable at the early stage of the design process when different ramp configurations are being sketched and compared because ISAT should be applicable to assessment of ramp form and ramp length. Details addressed at the final design stage, such as dimensions of particular geometric elements, appear less suited to consideration by ISAT, because the state of knowledge about the effects of specific design dimensions on safety is limited.

How should an ISAT be used to examine safety concerns at an existing interchange? To analyze design alternatives for an existing interchange? To predict the safety performance of a new interchange where no interchange previously existed?

- The interviews indicated that both analyses of existing interchanges and analyses of new interchanges are important.

Should ISAT address the mainline freeway roadway within the interchange area? Speed-change lanes? Ramps? Crossroad ramp terminals? Crossroad roadways near ramp terminals? All of the above?

- The interviews indicated that all portions of the interchange area are important. One respondent indicated that two key considerations are, first, crossroad ramp terminals and, second, entrance ramp configuration and its affect on mainline traffic.

Should ISAT address the safety benefits of improving the interchange as a whole? Safety benefits for improving specific design elements within the interchange? Determining dimensions for specific design elements within the interchange?

- The interviews indicated that both overall interchange safety performance and the safety of individual interchange elements are important. One respondent indicated that overall safety performance measures will be most valuable for communicating the benefits of the design to the public, while the results for individual elements of the design will be most valuable to the engineers involved in the design. Another respondent indicated that ISAT should focus on the more serious crashes, suggesting the willingness to accept a higher number of less severe crashes if the number of severe crashes is reduced. 


\section{IDENTIFIED GAPS IN KNOWLEDGE}

ISAT is based on existing safety knowledge. No modeling efforts were conducted as part of this research to develop new SPFs. All SPFs incorporated into ISAT are from previous and ongoing research. As such, it is important to recognize that the accuracy of ISAT is only as good as the safety knowledge on which it is based. This section identifies substantive gaps in the current state of knowledge that limit the ability of ISAT to provide capabilities desired by potential users. The gaps in knowledge are first summarized below in table 27. For each gap in knowledge, Appendix A presents a brief summary of the needed research, equivalent to a research problem statement, designed to address the issue.

Table 27 presents a summary of issues intended to address the gaps in current knowledge concerning the capability to conduct reliable interchange safety assessments. The issues are categorized by interchange elements (i.e., mainline freeways, ramps, crossroad ramp terminals, and crossroad roadway segments). Table 27 also provides the recommended funding level and duration period to complete the research. The funding and time requirements for each research topic have been estimated assuming that only one topic was being studied. There should be substantial economies of scale in terms of both cost and time in performing research on several topics simultaneously. In other words, the funding and time requirements in Table 27 are not necessarily additive.

Table 27. Summary of Research Needs

\begin{tabular}{|l|c|c|}
\hline \multicolumn{1}{|c|}{ Research topic } & $\begin{array}{c}\text { Recommended } \\
\text { funding }\end{array}$ & $\begin{array}{c}\text { Research } \\
\text { period } \\
\text { (months) }\end{array}$ \\
\hline Mainline Freeways & $\$ 15,000$ & 2 \\
\hline Develop improved SPFs for several types of freeway segments & $\$ 25,000$ & 4 \\
\hline Develop methodology to account for spacing between interchanges & $\$ 25,000$ & 4 \\
\hline Ramps & $\$ 10,000$ & 2 \\
\hline Develop improved SPFs for several ramp configurations & $\$ 10,000$ & 2 \\
\hline $\begin{array}{l}\text { Develop improved methodology for estimating safety effect of acceleration } \\
\text { lane length }\end{array}$ & $\$ 25,000$ & 4 \\
\hline Develop SPFs for additional ramp configurations & & \\
\hline $\begin{array}{l}\text { Determine impact of deceleration lane length on safety at freeway ramp } \\
\text { junctions (and if necessary, develop models for deceleration lanes which } \\
\text { account for length) }\end{array}$ & $\$ 20,000$ & 4 \\
\hline Determine difference in safety effectiveness between right- and left-side ramps & $\$ 10,000$ & 2 \\
\hline Develop SPFs for weaving areas between freeway on- and off-ramps & $\$ 10,000$ to & 4 \\
\hline Develop SPFs for collector-distributor roads & $\$ 25,000$ & \\
\hline Crossroad Ramp Terminals & $\$ 20,000$ & 4 \\
\hline Develop improved SPFs for at-grade crossroad ramp terminals & $\$ 25,000$ & 4 \\
\hline Develop SPFs for acceleration lanes and weaving areas on arterial crossroads & $\$ 20,000$ & 4 \\
\hline Crossroad Roadway Segments & & \\
\hline Develop improved SPFs for crossroad roadway segments & \\
\hline
\end{tabular}




\section{REFERENCES}

1. Torbic, D.J., D.W. Harwood, D.K. Gilmore, and K.R. Richard, Interchange Safety Analysis Tool (ISAT): User Manual, Report No. FHWA-HRT-07-045, Federal Highway Administration, June, 2007.

2. Harwood, D. W., W. D. Glauz, L. Elefteriadou, D. J. Torbic, and J. McFadden, "Distribution of Roadway Geometric Design Features Critical to Accommodation of Large Trucks," Transportation Research Record 1658, Transportation Research Board, 1999.

3. Bared, J. G., P. K. Edara, and T. Kim, Safety Impact of Interchange Spacing on Urban Freeways, TRB 2006 Annual Meeting CD-ROM, Transportation Research Board, January 2006.

4. Federal Highway Administration. Highway Statistic 2003, U.S. Department of Transportation, Washington, D.C., 2004.

5. Harwood, D. W., K. M. Bauer, K. R. Richard, D. K. Gilmore, B. Persaud, and C. Lyon, Development of SPFs for SafetyAnalyst Interim Tools-Technical Memorandum, Prepared by Midwest Research Institute for the Federal Highway Administration. September 2004.

6. Bauer, K. M., and D. W. Harwood, Statistical Models of Accidents on Interchange Ramps and Speed-Change Lanes, Report No. FHWA-RD-97-106, Federal Highway Administration, June 1998.

7. American Association of State Highway and Transportation Officials (AASHTO). A Policy on Geometric Design of Highways and Streets, Washington, D.C., 2004.

8. Twomey, J.M., M.L. Heckman, and J.C. Hayward. Safety Effectiveness of Highway Design Features - Interchanges, Volume IV, FHWA-RD-91-047. Washington, D.C., 1992.

9. Worral, R.D., J.S. Drake, J.H. Buhr, and T.J. Soltman. Study of Operational Characteristics of Left-Hand Entrance and Exit Ramps on Urban Freeways, Highway Research Record 99, Transportation Research Board, Washington, D.C., 1965. 
APPENDIX A-RESEARCH PROBLEM STATEMENTS 


\section{RESEARCH PROBLEM STATEMENTS FOR MAINLINE FREEWAY SEGMENTS}




\section{Develop Improved SPFs For Several Types of Freeway Segments}

\section{Research Problem Statement}

For many years statistical techniques have been applied to predict the crash experience along roadway segments and at intersections. These statistical models are developed using crash and inventory databases, selecting appropriate functional forms for the models, and using regression techniques to estimate the values of the coefficients and parameters in the models. Historically; these models, often referred to as safety performance functions (SPFs), were developed with multiple regression techniques. More recently, Possion and negative binomial (NB) analyses have been used because theoretically they are better suited to crash data with low-frequency observations.

ISAT makes use of SPFs for predicting and/or estimating crash frequencies for individual components of an interchange and the surrounding roadway network. Safety estimates are calculated for the individual components, and these safety estimates are summed to obtain safety performance estimates for the interchange as a whole. The primary interchange components that can be included in an analysis are:

- Mainline freeway segments

- Interchange ramps and acceleration lanes

- Crossroad ramp terminals and intersections

- Crossroad roadway segments

ISAT was developed using SPFs from previous and ongoing research projects. It is important to recognize that the accuracy of output results from ISAT is only as good as the safety knowledge on which it is based.

\section{Literature Search Summary}

During the development of ISAT, a review of the technical literature on safety assessment of freeway interchanges was conducted. This review focused on quantitative information that was potentially applicable for use in ISAT. Specifically, interchange-safety-related literature was reviewed to identify quantitative SPFs which could potentially be incorporated into ISAT. The review included both engineering and statistical considerations. The primary sources of information that contained SPFs for potential incorporation in ISAT included:

- Development of Safety Performance Functions for SafetyAnalyst Interim Tools ${ }^{5}$

- $\quad$ Statistical Models for Interchange Ramps and Speed-Change Lanes ${ }^{6}$

- Safety Impact of Interchange Spacing on Urban Freeways ${ }^{3}$ 


\section{Research Objective}

The objective of this research is to develop improved SPFs for four types of mainline freeway segments. ISAT incorporates 20 unique SPFs for mainline freeway segments. Total and fatal and injury crashes are predicted for the following 10 mainline freeway segment types:

- Rural freeway segments outside an interchange area -4 lanes (2 lanes each direction)

- Rural freeway segments outside an interchange area-6+ lanes (3+ lanes each direction)

- Rural freeway segments within an interchange area-4 lanes (2 lanes each direction)

- Rural freeway segments within an interchange area-6+ lanes (3+ lanes each direction)

- Urban freeway segments outside an interchange area—4 lanes (2 lanes each direction)

- Urban freeway segments outside an interchange area -6 lanes (3 lanes each direction)

- Urban freeway segments outside an interchange area-8+ lanes (4+ lanes each direction)

- Urban freeway segments within an interchange area-4 lanes (2 lanes each direction)

- Urban freeway segments within an interchange area -6 lanes (3 lanes each direction)

- Urban freeway segments within an interchange area-8+ lanes (4+ lanes each direction)

The SPFs for mainline freeway segments were developed initially for use within SafetyAnalyst. For most of these models, the goodness of fit as represented by the Freeman-Tukey $\mathrm{R}^{2}$ coefficient is reasonably high (i.e., most of the models explain approximately 40 to 85 percent of the variability in the data). However, the models for total and fatal and injury crashes for rural freeway segments within an interchange area (6+ lanes) and urban freeway segments outside an interchange area (4 lanes) do not fit the data as well (i.e., the models explain only approximately 10 to 20 percent of the variability in the data); therefore, the objective of this research is to develop improved models for these two types of mainline freeway segments for both total and fatal and injury crashes for use in ISAT.

\section{Estimate of Problem Funding and Research Period}

Recommended Funding

$\$ 15,000$

Research Period

2 months

\section{Urgency, Payoff Potential, and Implementation}

ISAT currently uses SPFs developed for SafetyAnalyst for each of the mainline freeway segment types of interest [i.e., rural freeway segments within an interchange area (6+ lanes) and urban freeway segments outside an interchange area (4 lanes)], so the ISAT performs calculations for each of these facility types. ISAT does not "crash" nor provide incorrect answers when these types of freeway segments are part of the specified analysis area. In this respect, there is no major urgency to perform this research; however, it should be recognized that the accuracy of 
ISAT is only as good as the safety knowledge on which it is based. Incorporating improved SPFs for rural freeway segments within an interchange area (6+ lanes) and urban freeway segments outside an interchange area (4 lanes) which fit the data better will improve the accuracy of the output results when these facility types are included in the analysis.

ISAT was programmed in such a way that it will be easy in the future to include new improved SPFs in place of the SPFs in this first version of the program. 


\section{Interchange Spacing}

\section{Research Problem Statement}

The issue of interchange spacing is a complex issue. The American Association of State Highway and Transportation Officials' (AASHTO) Policy on Geometric Design of Highways and Streets (i.e., Green Book) provides guidelines on the distance between successive ramp terminals. The general rule of thumb for minimum spacing between interchanges is $1 \mathrm{mi}$ in urban areas and $2 \mathrm{mi}$ in rural areas. These guidelines are based primarily on operational considerations such as the potential for weaving.

Limited research has investigated the issue of interchange spacing from a safety perspective. Recent research indicates crashes increase with decreasing spacing between interchanges on the urban freeway network. Additional research is necessary to gain a better understanding concerning the safety implications of interchange spacing.

\section{Literature Review Summary}

Little research has been conducted in the area of interchange spacing and its affect on safety. Twomey et al. conducted a study to critically review, summarize, and document past safety research that associates crashes and safety with interchange features. ${ }^{8}$ They concluded that interchange crash rates increased as interchange spacing decreased in urban areas. More recently, Bared et al. investigated the interchange spacing problem from a safety perspective. ${ }^{3}$ Using data from three freeways in California, Bared et al. developed regression models to relate crash frequencies to highway characteristics and specifically interchange spacing. Bared et al. found similar results as Twomey et al. in that crash frequencies increase as interchange spacing decreases in urban areas. Bared et al. also found that crash rates level off when interchange spacing extends beyond $3 \mathrm{mi}$.

\section{Research Objective}

The objective of this research is to develop a model or methodology for implementation in ISAT that can account for the safety implications of interchange spacing. Currently ISAT utilizes SPFs for mainline freeway segments within interchange areas that attempt to account for increased levels of weaving, lane changing, and acceleration/deceleration that takes place immediately upstream, downstream, and between interchange ramps. These SPFs were developed for use within SafetyAnalyst. Bared et al. developed a regression model that includes interchange spacing as a significant variable for predicting crashes on urban freeways which accounts for the extra turbulence experienced between interchanges, extending up to $3 \mathrm{mi}$ in length. The two methodologies were developed as part of separate research efforts and are incompatible with one another. A combined model which would account for the safety experience immediately upstream and downstream of interchanges ramps (i.e., using SafetyAnalyst principles) and extends up to $3 \mathrm{mi}$ in length between interchanges (i.e., using Bared et al. principles) would be desirable for incorporating in ISAT. 


\section{Estimate of Problem Funding and Research Period}

Recommended Funding

$\$ 25,000$

Research Period

4 months

\section{Urgency, Payoff Potential, and Implementation}

ISAT currently accounts for the extra weaving that occurs near on- and off-ramps by utilizing separate models for mainline freeway segments outside of interchange areas and segments within interchange areas. However, these models do not directly incorporate a spacing term, so in that respect, ISAT currently does not directly account for interchange spacing. On the other hand, the Bared et al. model includes interchange spacing as one of the key predictor variables for estimating crash frequency along urban freeways. A methodology that combines the strengths of the models developed for SafetyAnalyst and those by Bared et al. that could be directly implemented within ISAT would be desirable to provide more accurate estimation capabilities. 


\section{RESEARCH PROBLEM STATEMENTS FOR RAMPS}




\section{Develop Improved SPFs For Several Ramp Configurations}

\section{Research Problem Statement}

For many years statistical techniques have been applied to predict the crash experience along roadway segments and at intersections. These statistical models are developed using crash and inventory databases, selecting appropriate functional forms for the models, and using regression techniques to estimate the values of the coefficients and parameters in the models. Historically; these models, often referred to as safety performance functions (SPFs), were developed with multiple regression techniques. More recently, Possion and negative binomial (NB) analyses have been used because theoretically they are better suited to crash data with low-frequency observations.

ISAT makes use of SPFs for predicting and/or estimating crash frequencies for individual components of an interchange and the surrounding roadway network. Safety estimates are calculated for the individual components, and these safety estimates are summed to obtain safety performance estimates for the interchange as a whole. The primary interchange components that can be included in an analysis are:

- Mainline freeway segments

- Interchange ramps and acceleration lanes

- Crossroad ramp terminals and intersections

- Crossroad roadway segments

ISAT was developed using SPFs from previous and ongoing research projects. It is important to recognize that the accuracy of output results from ISAT is only as good as the safety knowledge on which it is based.

\section{Literature Search Summary}

During the development of ISAT, a review of the technical literature on safety assessment of freeway interchanges was conducted. This review focused on quantitative information that was potentially applicable for use in ISAT. Specifically, interchange-safety-related literature was reviewed to identify quantitative SPFs which could potentially be incorporated into ISAT. The review included both engineering and statistical considerations. The primary sources of information that contained SPFs for potential incorporation in ISAT included:

- Development of Safety Performance Functions for SafetyAnalyst Interim Tools ${ }^{5}$

- Statistical Models for Interchange Ramps and Speed-Change Lanes ${ }^{6}$

- Safety Impact of Interchange Spacing on Urban Freeways ${ }^{3}$ 


\section{Research Objective}

The objective of this research is to develop improved SPFs for several ramp configurations. ISAT incorporates 10 unique SPFs for different ramp configurations. Total and fatal and injury crashes are predicted for the following 7 ramp configurations:

- Diamond off-ramps

- Diamond on-ramps

- Parclo loop off-ramps

- Parclo loop on-ramps

- Free-flow loop off-ramps

- Free-flow loop on-ramps

- Freeway-to-freeway directional ramps

These ramp SPFs were developed initially for use within SafetyAnalyst. For most of these models, the goodness of fit as represented by the Freeman-Tukey $\mathrm{R}^{2}$ coefficient was reasonably high (i.e., most of the models explain approximately 20 to 60 percent of the variability in the data). The models for diamond off-ramps, diamond on-ramps, and freeway-to-freeway ramps did not fit the data as well (i.e., the models explain only approximately 7 to 18 percent of the variability in the data): therefore, the objective of this research is to develop improved models for these three ramp configurations for use in ISAT.

\section{Estimate of Problem Funding and Research Period}

Recommended Funding

$\$ 25,000$

Research Period

4 months

\section{Urgency, Payoff Potential, and Implementation}

ISAT currently uses the ramp SPFs developed for SafetyAnalyst, so ISAT performs calculations for all of the ramp configurations specified above. ISAT does not "crash" nor provide incorrect answers when these ramp configurations are part of the specified analysis area. In this respect, there is no major urgency to perform this research; however, the accuracy of ISAT is only as good as the safety knowledge on which it is based. Incorporating improved ramp SPFs for three ramp configurations will improve the accuracy of the output results when these facility types are included in the analysis.

ISAT was programmed in such a way that it will be easy in the future to include new improved SPFs in place of the SPFs in this first version of the program. 


\section{Develop Improved Methodology for Estimating the Safety Effect of Acceleration Lane Length}

\section{Research Problem Statement}

When a driver enters a freeway from an on-ramp, the entry maneuver places increased demand and workload on the driver associated with navigational decision-making, speed changing, and tracking. The combination of these demands results in an increased likelihood of driver error. An acceleration lane should provide sufficient length for a driver to accelerate to the desired speed of the freeway and to position oneself opposite a gap in the through traffic stream and maneuver into it before reaching the end of the acceleration lane. The AASHTO Green Book provides guidance on the minimum lengths of acceleration distances for entrance terminals.

Research has shown the safety importance of acceleration lane lengths. In an era of high construction costs and constrained right-of-way, it is important for designers to understand the relative safety impacts of providing longer acceleration lanes.

\section{Literature Search Summary}

Prior research has revealed the safety importance of acceleration lane lengths. Twomey et al. concluded the safety of on-ramps is enhanced when acceleration lane lengths are at least $800 \mathrm{ft}$ or longer. ${ }^{8}$ Bauer and Harwood developed statistical models using Highway Safety Information System (HSIS) data to define relationships between traffic crashes, traffic volume, and geometric design elements for speed-change lanes. ${ }^{6}$ Key variables identified that contributed to the safety performance of on-ramps included freeway traffic, ramp traffic, area type (urban or rural), ramp length (i.e., length of ramp proper) and length of speed-change lane (i.e., acceleration lane length).

\section{Research Objective}

The objective of this research is to develop an improved methodology for calculating the safety performance of acceleration lanes within ISAT. The current methodology makes use of SPFs for mainline freeway segments within interchange areas, developed for use in SafetyAnalyst, and SPFs for entire ramps and adjacent speed-change lanes developed by Bauer and Harwood. ${ }^{6}$ Because the SPFs for mainline freeway segments within interchange areas include crashes that occur in speed-change lanes adjacent to the mainline through lanes, these crashes must be subtracted from the mainline freeway segments through a series of steps and assumptions before determining the number of crashes attributable to the acceleration lane. An improved methodology would eliminate these series of steps and assumptions. One possible approach would be to develop SPFs for mainline freeway segments within interchange areas that only included crashes on the mainline through lanes and did not include crashes on the adjacent speed-change lanes. This approach, which is recommended, would be relatively inexpensive. 
Other alternative approaches (i.e., requiring the development of new databases) would be more expensive.

\section{Estimate of Problem Funding and Research Period}

Recommended Funding

$\$ 10,000$

Research Period

2 months

\section{Urgency, Payoff Potential, and Implementation}

When the analysis area includes an on-ramp, one of the input variables to be provided by the user is acceleration lane length. ISAT utilizes this information and provides an estimate of the number of crashes that would be expected to occur on the acceleration lane. ISAT does not "crash" nor provide incorrect answers when assigning crashes to acceleration lanes. In this respect, there is no major urgency to perform this research; however, the accuracy of the estimation tool is only as good as the safety knowledge on which it is based. It is recognized that, with some effort, more accurate results could be provided, eliminating some of the necessary assumptions that were made due to the nature of the SPFs used in this processing.

ISAT was programmed in such a way that it will be easy in the future to improve the methodology for estimating the safety effect of acceleration lane length. 


\section{Develop SPFs for Additional Ramp Configurations}

\section{Research Problem Statement}

For many years statistical techniques have been applied to predict the crash experience along roadway segments and at intersections. These statistical models are developed using crash and inventory databases, selecting appropriate functional forms for the models, and using regression techniques to estimate the values of the coefficients and parameters in the models. Historically; these models, often referred to as safety performance functions (SPFs), were developed with multiple regression techniques. More recently, Possion and negative binomial (NB) analyses have been used because theoretically they are better suited to crash data with low-frequency observations.

ISAT makes use of SPFs for predicting and/or estimating crash frequencies for individual components of an interchange and the surrounding roadway network. Safety estimates are calculated for the individual components, and these safety estimates are summed to obtain safety performance estimates for the interchange as a whole. The primary interchange components that can be included in an analysis are:

- Mainline freeway segments

- Interchange ramps and acceleration lanes

- Crossroad ramp terminals and intersections

- Crossroad roadway segments

ISAT was developed using SPFs from previous and ongoing research projects. It is important to recognize that the accuracy of output results from ISAT is only as good as the safety knowledge on which it is based.

\section{Literature Search Summary}

During the development of ISAT, a review of the technical literature on safety assessment of freeway interchanges was conducted. This review focused on quantitative information that was potentially applicable for use in ISAT. Specifically, interchange-safety-related literature was reviewed to identify quantitative SPFs which could potentially be incorporated into ISAT. The review included both engineering and statistical considerations. The primary sources of information that contained SPFs for potential incorporation in ISAT included:

- Development of Safety Performance Functions for SafetyAnalyst Interim Tools ${ }^{5}$

- Statistical Models for Interchange Ramps and Speed-Change Lanes ${ }^{6}$

- Safety Impact of Interchange Spacing on Urban Freeways ${ }^{3}$ 


\section{Research Objective}

The objective of this research is to develop new SPFs for more types of ramp configurations than are currently considered in ISAT. ISAT currently includes SPFs for the following ramp configurations:

- Diamond off-ramps

- Diamond on-ramps

- Parclo loop off-ramps

- Parclo loop on-ramps

- Free-flow loop off-ramps

- Free-flow loop on-ramps

- Freeway-to-freeway ramps

These ramp SPFs were developed initially for use within SafetyAnalyst. It is recognized that other ramp configurations are being designed and exist on our nation's highways, for example slip ramps, buttonhook ramps, and outer-connection ramps. It is desirable to develop new SPFs for a wider range of ramp configurations than are currently considered in ISAT.

\section{Estimate of Problem Funding and Research Period}

Recommended Funding

$\$ 10,000$

Research Period

2 months

\section{Urgency, Payoff Potential, and Implementation}

ISAT provides the capability to assess the safety performance of the most common types of ramp configurations. However, other types of ramps configuration exist, and the user of ISAT has several options for how to proceed in these situations. One option for analyzing a ramp configuration that is not currently incorporated into ISAT is to select the ramp configuration that operates in the most similar fashion to it and analyze the ramp in this way, recognizing the safety assessment for the given ramp is limited because the calculations are not based on SPFs developed for the specific ramp configuration. The other alternative is to not use ISAT for analyzing ramp configurations that are not specifically incorporated in the program and assess the safety of these ramp configurations using other means.

By developing new SPFs for additional ramp configurations not currently incorporated within ISAT, the scope of ISAT will be increased, and the accuracy of the results will be improved. 
ISAT was programmed in such a way that it will be easy in the future to incorporate new SPFs for additional ramp configurations. 


\section{Determine Impact of Deceleration Lane Length on Safety at Freeway Ramp Junctions}

\section{Research Problem Statement}

When a driver departures a freeway onto an off-ramp, the exiting maneuver places increased demand and workload on the driver associated with navigational decision-making, speed changing, and tracking. The combination of these demands results in an increased likelihood of driver error. A deceleration lane is intended to provide sufficient distance for vehicles to slow from the speed of the major roadway to an appropriate speed before reaching the limiting design feature (e.g., horizontal curve) of the off-ramp. Such speed changes are normally made with controlled deceleration rates. Particular concerns are raised regarding heavy trucks due to their propensity to rollover on ramp curves when traveling substantially faster than the design speed of a curve. The AASHTO Green Book provides guidance on the minimum lengths of deceleration lanes for off-ramps.

\section{Literature Search Summary}

Interchanges are inherent points of conflict involving entering and exiting traffic. In particular, crash rates for off-ramps have been shown to be higher than for on-ramps. ${ }^{8}$ It has also been shown that deceleration lanes of $900 \mathrm{ft}$ or more reduce traffic friction on the through lanes and account for reduced crash rates. However, when Bauer and Harwood ${ }^{6}$ developed SPFs for speedchange lanes, they did not find a model in which deceleration lane length was a key variable in predicting crash frequency, and no other published reports have been found showing that deceleration lane is a significant predictor of crashes on off-ramps. This calls into question the actual safety benefits of incremental changes in deceleration lane lengths.

\section{Research Objective}

The objective of this research is to first determine the effect of deceleration lane length on the safety at off-ramps. Based upon research by Twomey et al. ${ }^{8}$, there is some evidence of the relative safety benefit of increasing the length of deceleration lanes; however, research by Bauer and Harwood ${ }^{6}$ indicates otherwise. It might be that driver choice of operating speed on off-ramps is not directly related to the length of deceleration lanes. Therefore, the first portion of this effort is to further investigate the safety effect of deceleration lane length. If it is determined that incremental increases in lengths of deceleration lanes improve safety, the second objective of this research is to develop SPFs for deceleration lanes which include length as a significant predictor of crash frequency. 


\section{Estimate of Problem Funding and Research Period}

Recommended Funding

$\$ 25,000$

Research Period

4 months

\section{Urgency, Payoff Potential, and Implementation}

Based upon a review of the literature, the absence of SPFs that include deceleration lane length as a key predictor variable suggests this research is of low priority. However, the fact that offramps have higher crash rates than on-ramps leads one to consider otherwise. If it can be shown that deceleration lane lengths impact safety at off-ramps, incorporating SPFs with this key variable into ISAT would improve the accuracy of the program, but based upon the best available knowledge to date, ISAT calculates predicted and expected crashes for off-ramps without considering deceleration lane length. It would be easy to incorporate SPFs with deceleration lane length as a key predictor variable for exit ramps in the next version of ISAT. 


\section{Determine Difference in Safety Effectiveness between Right- and Left-Hand Ramps}

\section{Research Problem Statement}

Design consistency is the conformance of a highway's geometric and operational features with driver expectancy. Driver expectancies are based upon their experiences in the immediate past and over their driving careers. Abrupt changes in geometric features increase driver workload because the changes go against driver expectancies and could result in undesirable driving behaviors.

The large majority of ramps are located on the right-side of the road. As such, left-hand ramps are contrary to the concept of driver expectancy when intermixed with right-hand ramps and could create uncertain operations on the mainline freeway and speed-change lane. Extreme caution should be exercised in the design of left-hand ramps.

\section{Literature Search Summary}

No recent studies have been identified which investigated the difference in safety between rightand left-hand ramps. One study conducted in the 1960s compared the general operating characteristics between right- and left-hand ramps on urban freeways. ${ }^{9}$ Using data from Chicago, Worral et al. concluded crash rates per million ramp vehicles were higher at left-hand entrances and exits than at right-hand entrances and exits. The ramp SPFs for SafetyAnalyst were developed using data for right-hand ramps only.

\section{Research Objective}

The objective of this research is to determine the relative difference in safety between right- and left-hand ramps. Due to violations with driver expectancy, it is reasonable to assume that lefthand ramps are less safe than right-hand ramps, but there is no recent research supporting this assumption.

\section{Estimate of Problem Funding and Research Period}

Recommended Funding

$\$ 20,000$

Research Period

4 months 


\section{Urgency, Payoff Potential, and Implementation}

ISAT currently assumes the same safety effect for right- and left-hand ramps. Considering that most analyses will include only right-hand ramps, ISAT will provide accurate results for most investigations. For those analyses which investigate the safety at left-hand ramps, it can be assumed that ISAT provides a conservative estimate of the crash frequency/rate.

Because most agencies discourage the use of left-hand ramps, this research is of lower priority. However, when agencies find themselves considering the design of a left-hand ramp, it is usually under extreme circumstances, and in these situations it would be desirable to know the safety tradeoffs between right- and left-hand ramps. It would be easy to incorporate the relative difference in safety between right- and left-hand ramps in the next version of ISAT. 


\section{Develop SPFs for Weaving Areas between Freeway On-and Off-ramps}

\section{Research Problem Statement}

For many years statistical techniques have been applied to predict the crash experience along roadway segments and at intersections. These statistical models are developed using crash and inventory databases, selecting appropriate functional forms for the models, and using regression techniques to estimate the values of the coefficients and parameters in the models. Historically; these models, often referred to as safety performance functions (SPFs), were developed with multiple regression techniques. More recently, Possion and negative binomial (NB) analyses have been used because theoretically they are better suited to crash data with low-frequency observations.

ISAT makes use of SPFs for predicting and/or estimating crash frequencies for individual components of an interchange and the surrounding roadway network. Safety estimates are calculated for the individual components, and these safety estimates are summed to obtain safety performance estimates for the interchange as a whole. The primary interchange components that can be included in an analysis are:

- Mainline freeway segments

- Interchange ramps and acceleration lanes

- Crossroad ramp terminals and intersections

- Crossroad roadway segments

ISAT was developed using SPFs from previous and ongoing research projects. It is important to recognize that the accuracy of output results from ISAT is only as good as the safety knowledge on which it is based.

\section{Literature Search Summary}

During the development of ISAT, a review of the technical literature on safety assessment of freeway interchanges was conducted. This review focused on quantitative information that was potentially applicable for use in ISAT. Specifically, interchange-safety-related literature was reviewed to identify quantitative SPFs which could potentially be incorporated into ISAT. The review included both engineering and statistical considerations. The primary sources of information that contained SPFs for potential incorporation in ISAT included:

- Development of Safety Performance Functions for SafetyAnalyst Interim Tools ${ }^{5}$

- $\quad$ Statistical Models for Interchange Ramps and Speed-Change Lanes ${ }^{6}$

- Safety Impact of Interchange Spacing on Urban Freeways ${ }^{3}$ 


\section{Research Objective}

The objective of this research is to develop SPFs for weaving areas between freeway on- and offramps. The SPFs currently incorporated by ISAT related to mainline freeway segments within interchange areas do not expressly consider the safety experience of weaving areas on mainline freeway segments where entering vehicles (i.e., from the crossroad) accelerating to mainline freeway speeds cross paths with exiting vehicles (i.e., from the mainline freeway) decelerating from mainline speeds to ramp speeds. The SPFs within ISAT are designed to model the safety experience upstream, adjacent, or downstream to deceleration and acceleration lanes. ISAT does not explicitly model the safety experience where the acceleration and deceleration maneuvers are occurring in the same confined areas.

\section{Estimate of Problem Funding and Research Period}

Recommended Funding

$\$ 10,000$

Research Period

2 months

\section{Urgency, Payoff Potential, and Implementation}

ISAT currently performs calculations for mainline freeway segments within interchange areas and accounts for the safety experience related to acceleration lanes. ISAT does not explicitly model weaving areas between on- and off-ramps, so as ISAT is currently designed it is recommended that weaving areas on mainline freeways be treated as mainline freeway segments within interchange areas adjacent to acceleration lanes. When treated as such, ISAT does not "crash" nor provide incorrect answers, but it should be recognized that the output is only an estimate of the given situation or design. In this respect, there is no major urgency to perform this research; however, it should be recognized that the accuracy of ISAT is only as good as the safety knowledge on which it is based. Incorporating unique SPFs for weaving areas along mainline freeway segments will improve the accuracy of the output results from ISAT when weaving areas are incorporated into the analysis area.

It would be easy to incorporate newly developed SPFs for weaving areas in the next version of ISAT. 


\section{Develop SPFs for collector-distributor roads}

\section{Research Problem Statement}

For many years statistical techniques have been applied to predict the crash experience along roadway segments and at intersections. These statistical models are developed using crash and inventory databases, selecting appropriate functional forms for the models, and using regression techniques to estimate the values of the coefficients and parameters in the models. Historically; these models, often referred to as safety performance functions (SPFs), were developed with multiple regression techniques. More recently, Possion and negative binomial (NB) analyses have been used because theoretically they are better suited to crash data with low-frequency observations.

ISAT makes use of SPFs for predicting and/or estimating crash frequencies for individual components of an interchange and the surrounding roadway network. Safety estimates are calculated for the individual components, and these safety estimates are summed to obtain safety performance estimates for the interchange as a whole. The primary interchange components that can be included in an analysis are:

- Mainline freeway segments

- Interchange ramps and acceleration lanes

- Crossroad ramp terminals and intersections

- Crossroad roadway segments

ISAT was developed using SPFs from previous and ongoing research projects. It is important to recognize that the accuracy of output results from ISAT is only as good as the safety knowledge on which it is based.

\section{Literature Search Summary}

During the development of ISAT, a review of the technical literature on safety assessment of freeway interchanges was conducted. This review focused on quantitative information that was potentially applicable for use in ISAT. Specifically, interchange-safety-related literature was reviewed to identify quantitative SPFs which could potentially be incorporated into ISAT. The review included both engineering and statistical considerations. The primary sources of information that contained SPFs for potential incorporation in ISAT included:

- Development of Safety Performance Functions for SafetyAnalyst Interim Tools ${ }^{5}$

- Statistical Models for Interchange Ramps and Speed-Change Lanes ${ }^{6}$

- Safety Impact of Interchange Spacing on Urban Freeways ${ }^{3}$ 


\section{Research Objective}

The objective of this research is to develop SPFs for collector-distributor roads used to separate entering and exiting vehicles from the mainline traffic streams at interchange locations. The SPFs currently incorporated by ISAT related to mainline freeway segments and ramp configurations do not expressly consider the safety effect of collector-distributor roads within interchange areas. ISAT only models the safety experience of vehicles leaving (or entering) the mainline freeway segments to (or from) diamond, parclo loop, free-flow loop, and directional ramps. In developing the SPFs for collector-distributor roads, the SPFs should be compatible with the current methodology which analyzes mainline freeway segments within interchange areas and ramps (i.e., ramp propers).

\section{Estimate of Problem Funding and Research Period}

Recommended Funding

$\$ 10,000$ to $\$ 25,000$

Research Period

4 months

\section{Urgency, Payoff Potential, and Implementation}

ISAT currently performs calculations for mainline freeway segments and ramps, but the methodology does not directly account for the safety experience along collector-distributor roads. By developing SPFs for collector-distributor roads within ISAT, the scope of ISAT will be increased, and the accuracy of the results will be improved.

It would be easy to incorporate newly developed SPFs for collector-distributor roads in the next version of ISAT. 


\section{RESEARCH PROBLEM STATEMENTS FOR CROSSROAD RAMP TERMINALS AND INTERSECTIONS}




\section{Develop Improved SPFs For At-Grade Crossroad Ramp Terminals}

\section{Research Problem Statement}

The intersections at crossroad ramp terminals operate differently than conventional intersections for several reasons. Because of the one-way movements from or to the ramps, unique turning movement patterns occur at certain types of crossroad ramp terminals. When crossroad ramp terminals are closely spaced, for example at tight diamond interchanges, unique interactions occur as a result of queuing and turning movements. Also, operations at single-point-urbaninterchanges (SPUI) are very much unique compared to conventional intersections due to the size and orientation of the intersection proper. Due to the difference in operations at crossroad ramp terminals compared to conventional intersections, it is reasonable to assume the safety experience at crossroad ramp terminals differs from conventional intersections as well.

\section{Literature Search Summary}

There are no publications in the open literature that specifically address safety at crossroad ramp terminals. The SPFs developed for SafetyAnalyst are for conventional intersections.

\section{Research Objective}

The objective of this research is to develop SPFs specifically for crossroad ramp terminals. Currently ISAT utilizes SPFs for conventional intersections, developed for use with SafetyAnalyst, when assessing the safety of crossroad ramp terminals. These intersections include:

- Rural three-leg intersections with minor-road STOP control

- Rural three-leg intersections with signal control

- Rural four-leg intersections with minor-road STOP control

- Rural four-leg intersections with signal control

- Urban three-leg intersections with minor-road STOP control

- Urban three-leg intersections with signal control

- Urban four-leg intersections with minor-road STOP control

- Urban four-leg intersections with signal control

Due to the unique operational differences between crossroad ramp terminals and conventional intersections, it would be desirable to develop models specifically for crossroad ramp terminals. As part of this research, models should be developed for crossroad ramp terminals at SPUI that are compatible with the diamond ramp models used in ISAT. Also, models should be developed to account for closely spaced terminals (e.g., as located at a tight diamond interchange) in a form compatible with the diamond ramp models used in ISAT. 


\section{Estimate of Problem Funding and Research Period}

Recommended Funding

$\$ 20,000$

Research Period

4 months

\section{Urgency, Payoff Potential, and Implementation}

ISAT performs calculations for crossroad ramp terminals. ISAT does not "crash" nor provide incorrect answers, but it should be recognized that the calculations are based upon SPFs for conventional intersections. For some analyses, the user currently has to make assumptions concerning which conventional intersection most closely resembles the crossroad ramp terminal to be analyzed. If SPFs were available specifically for crossroad ramp terminals, users would not have to make such assumptions, and it is likely that the safety predictions and calculations would be more accurate.

It would be easy to incorporate the SPFs developed specifically for crossroad ramp terminals in the next version of ISAT. 


\section{Develop SPFs for Acceleration Lanes and Weaving Areas on Arterial Crossroads}

\section{Research Problem Statement}

For many years statistical techniques have been applied to predict the crash experience along roadway segments and at intersections. These statistical models are developed using crash and inventory databases, selecting appropriate functional forms for the models, and using regression techniques to estimate the values of the coefficients and parameters in the models. Historically; these models, often referred to as safety performance functions (SPFs), were developed with multiple regression techniques. More recently, Possion and negative binomial (NB) analyses have been used because theoretically they are better suited to crash data with low-frequency observations.

ISAT makes use of SPFs for predicting and/or estimating crash frequencies for individual components of an interchange and the surrounding roadway network. Safety estimates are calculated for the individual components, and these safety estimates are summed to obtain safety performance estimates for the interchange as a whole. The primary interchange components that can be included in an analysis are:

- Mainline freeway segments

- Interchange ramps and acceleration lanes

- Crossroad ramp terminals and intersections

- Crossroad roadway segments

ISAT was developed using SPFs from previous and ongoing research projects. It is important to recognize that the accuracy of output results from ISAT is only as good as the safety knowledge on which it is based.

\section{Literature Search Summary}

During the development of ISAT, a review of the technical literature on safety assessment of freeway interchanges was conducted. This review focused on quantitative information that was potentially applicable for use in ISAT. Specifically, interchange-safety-related literature was reviewed to identify quantitative SPFs which could potentially be incorporated into ISAT. The review included both engineering and statistical considerations. The primary sources of information that contained SPFs for potential incorporation in ISAT included:

- Development of Safety Performance Functions for SafetyAnalyst Interim Tools ${ }^{5}$

- Statistical Models for Interchange Ramps and Speed-Change Lanes ${ }^{6}$

- Safety Impact of Interchange Spacing on Urban Freeways ${ }^{3}$ 


\section{Research Objective}

The objective of this research is to develop SPFs for acceleration lanes and weaving areas on arterial crossroads. The SPFs currently incorporated by ISAT related to at-grade crossroad ramp terminals do not expressly consider the safety effect of acceleration lanes or weaving areas on the crossroads. The at-grade crossroad ramp terminal SPFs incorporated with ISAT model the safety impacts of terminals with signal or minor-road (i.e., off-ramp) STOP control. However, in many cases crossroad ramp terminals are designed with free right-turn movements (i.e., for offramps) with extended acceleration lanes, and the SPFs within ISAT to not exactly model these cases. Similarly, weaving areas are present on many higher volume arterial crossroads, allowing for free flow movements at the arterial ramp junction, and currently there are no SPFs that model the safety experience within weaving areas along arterial crossroads at arterial ramp junctions. The SPFs should be compatible with the current methodology. It may be necessary to create new SPFs for arterial crossroad roadway segments within the interchange area (i.e., adjacent to the acceleration lane and weaving lanes).

\section{Estimate of Problem Funding and Research Period}

Recommended Funding

$\$ 25,000$

Research Period

4 months

\section{Urgency, Payoff Potential, and Implementation}

ISAT currently performs calculations for crossroad ramp terminals with signal and minor-road STOP control. ISAT does not directly account for the safety experience along acceleration lanes and weaving areas adjacent to arterial crossroads. By developing SPFs for acceleration lanes and weaving areas on arterial crossroads, the scope of ISAT will be increased, and the accuracy of the results will be improved.

It would be easy to incorporate newly developed SPFs for acceleration lanes and weaving areas in the next version of ISAT. 


\section{RESEARCH PROBLEM STATEMENTS FOR CROSSROAD ROADWAY SEGMENTS}




\section{Develop Improved SPFs For Crossroad Roadway Segments}

\section{Research Problem Statement}

For many years statistical techniques have been applied to predict the crash experience along roadway segments and at intersections. These statistical models are developed using crash and inventory databases, selecting appropriate functional forms for the models, and using regression techniques to estimate the values of the coefficients and parameters in the models. Historically; these models, often referred to as safety performance functions (SPFs), were developed with multiple regression techniques. More recently, Possion and negative binomial (NB) analyses have been used because theoretically they are better suited to crash data with low-frequency observations.

ISAT makes use of SPFs for predicting and/or estimating crash frequencies for individual components of an interchange and the surrounding roadway network. Safety estimates are calculated for the individual components, and these safety estimates are summed to obtain safety performance estimates for the interchange as a whole. The primary interchange components that can be included in an analysis are:

- Mainline freeway segments

- Interchange ramps and acceleration lanes

- Crossroad ramp terminals and intersections

- Crossroad roadway segments

ISAT was developed using SPFs from previous and ongoing research projects. It is important to recognize that the accuracy of output results from ISAT is only as good as the safety knowledge on which it is based.

\section{Literature Search Summary}

During the development of ISAT, a review of the technical literature on safety assessment of freeway interchanges was conducted. This review focused on quantitative information that was potentially applicable for use in ISAT. Specifically, interchange-safety-related literature was reviewed to identify quantitative SPFs which could potentially be incorporated into ISAT. The review included both engineering and statistical considerations. The primary sources of information that contained SPFs for potential incorporation in ISAT included:

- Development of Safety Performance Functions for SafetyAnalyst Interim Tools ${ }^{5}$

- Statistical Models for Interchange Ramps and Speed-Change Lanes ${ }^{6}$

- Safety Impact of Interchange Spacing on Urban Freeways ${ }^{3}$ 


\section{Research Objective}

The objective of this research is to develop new SPFs for crossroad roadway segments. ISAT incorporates 20 unique SPFs for crossroad roadway segments. Total and fatal and injury crashes are predicted for the following 10 crossroad roadway segment types:

- Rural two-lane highway segments (1 lane each direction)

- Rural multilane undivided highway segments (2 or 3 lanes each direction)

- Rural multilane divided highway segments (2 or 3 lanes each direction)

- Urban two-lane arterial segments (1 lane each direction)

- Urban multilane undivided arterial segments (2 or 3 lanes each direction)

- Urban multilane divided arterial segments (2 or 3 lanes each direction)

These SPFs for crossroad roadway segments were developed initially for use within SafetyAnalyst. For most of these models, the goodness of fit as represented by the FreemanTukey $\mathrm{R}^{2}$ coefficient is reasonably high (i.e., models for rural segments explain approximately 37 to 75 percent of the variability in the data). For other models, the goodness of fit is not as high (i.e., models for urban segments explain approximately 2 to 25 percent of the variability in the data). The only predictor variable in these models is traffic volume. Therefore, the objective of this research is to develop improved models for urban crossroad roadway segments, potentially including other site characteristic variables as predictors to improve the accuracy of the models.

\section{Estimate of Problem Funding and Research Period}

Recommended Funding

$\$ 20,000$

Research Period

4 months

\section{Urgency, Payoff Potential, and Implementation}

ISAT performs calculations for crossroad roadway segments. ISAT does not “crash” nor provide incorrect answers when crossroad roadway segments are included as part of the analysis area. In this respect, there is no major urgency to perform this research; however, it should be recognized that the accuracy of ISAT is only as good as the safety knowledge on which it is based.

Incorporating improved SPFs for crossroad roadway segments will improve the accuracy of the output results from ISAT. This research should be considered only after the results of NCHRP Project 17-26 have been thoroughly reviewed.

It would be easy to incorporate improved SPFs for crossroad roadway segments in the next version of ISAT. 



\section{APPENDIX B—PROCESSING ALGORITHMS OF ISAT}

This section presents the processing algorithms used for estimating the safety performance of the analysis area to be evaluated with ISAT. Processing of the safety performance calculations begins when the user clicks the Perform Calculations button on the Input-General worksheet of ISAT. Calculations are performed separately for mainline freeway segments, ramps, crossroad ramp terminals and intersections, and crossroad segments. The calculations for these interchange elements are then combined to provide summary reports for the interchange area as a whole. The algorithms to estimate the safety performance of the interchange area are shown in the following sections:

- Algorithms to estimate safety performance of mainline freeway segments

- Algorithms to estimate safety performance of ramps

- Algorithms to estimate safety performance of crossroad ramp terminals and intersections

- Algorithms to estimate safety performance of crossroad segments

- Algorithms for generating summary output reports

Tables B-1 to B-10 show the input requirements and define the terms to perform a safety analysis of an interchange with ISAT. The input tables are provided on separate worksheets within ISAT. The terms used in the processing algorithms are defined in Table B-11. The processing calculations are presented in individual steps performed within the EXCEL program.

\section{ALGORITHMS FOR MAINLINE FREEWAY SEGMENTS}

The calculations for mainline freeway segments are performed in several stages. The first stage of the calculations is performed for each individual mainline freeway segment site input by the user on the Input Mainline Freeways worksheet, and the primary output are predicted crash frequencies for TOT, FI, and PDO crash severities for each year in the analysis period and for the entire analysis period. Stage 2 calculations again are performed for each individual mainline freeway segment, and the primary purpose is to predict crash frequencies for the TOT crash severity level for each year in the crash period and for the entire crash period. If crash data are not provided for mainline freeway segments, Stage 2 and 3 calculations are skipped, and the calculations proceed from Stage 1 to Stage 4 . Stage 3 begins with calculations for each individual mainline freeway segment and culminates with calculations for all mainline freeway segments combined. The primary purpose of Stage 3 is to adjust the expected TOT crash frequency for all mainline freeways sites combined in the analysis period. Stage 4 performs calculations for each individual mainline freeway segment, and the primary purpose is to calculate EB-adjusted expected crash frequencies for each site, combining predicted crash frequencies from SPFs and observed crash data. Details of each stage are provided below. 
Table B-1. General Inputs for ISAT

\begin{tabular}{|l|l|l|l|}
\hline GI1 & Project Description & character & \\
\hline GI2 & Analyst & & \\
\hline GI3 & Date & & \\
\hline GI4 & Area type & $(\mathrm{U}, \mathrm{R})$ & \\
\hline GI5 & Beginning year of analysis & numeric & \\
\hline GI6 & Ending year of analysis & numeric & \\
\hline
\end{tabular}

\begin{tabular}{|l|l|l|l|l|l|l|}
\cline { 5 - 7 } \multicolumn{2}{c|}{} & Mainline freeways & Ramps & $\begin{array}{l}\text { Crossroad ramp terminals and } \\
\text { intersections }\end{array}$ & Crossroad segments \\
\hline GI7 & Crash data available? & $(\mathrm{Y}, \mathrm{N})$ & & & & \\
\hline GI8 & Beginning year of crash data & numeric & & & & \\
\hline GI9 & Ending year of crash data & numeric & & & & \\
\hline GI10 & Observed number of crashes & numeric & & & & \\
\hline
\end{tabular}


Table B-2. Summary of Input Variables for General Interchange Area

\begin{tabular}{|c|c|c|c|c|}
\hline Variable Name & Variable No. & Format & Definition & Type \\
\hline $\begin{array}{l}\text { Project } \\
\text { description }\end{array}$ & GI1 & Character & $\begin{array}{l}\text { Short description that describes the } \\
\text { project. }\end{array}$ & Optional \\
\hline Analyst & GI2 & Numeric & User name. & Optional \\
\hline Date & GI3 & Character & Date of analysis. & Optional \\
\hline Area type & GI4 & $\begin{array}{l}\text { Character } \\
(\mathrm{U}, \mathrm{R})\end{array}$ & $\begin{array}{l}\text { General character of land use } \\
\text { surrounding the interchange, } \\
\text { preferably based on FHWA urban } \\
\text { area boundaries: } \\
\mathrm{U}=\text { Urban } \\
\mathrm{R}=\text { Rural }\end{array}$ & Mandatory \\
\hline $\begin{array}{l}\text { Begin year of } \\
\text { analysis }\end{array}$ & GI5 & $\begin{array}{l}\text { Numeric } \\
\text { (calendar } \\
\text { year) }\end{array}$ & $\begin{array}{l}\text { Value sets the first year of the } \\
\text { period for which output reports will } \\
\text { be created. }\end{array}$ & Mandatory \\
\hline $\begin{array}{l}\text { End year of } \\
\text { analysis }\end{array}$ & GI6 & $\begin{array}{l}\text { Numeric } \\
\text { (calendar } \\
\text { year) }\end{array}$ & $\begin{array}{l}\text { Value sets the final year of the } \\
\text { period for which output reports will } \\
\text { be created. }\end{array}$ & Mandatory \\
\hline $\begin{array}{l}\text { Crash data } \\
\text { available }\end{array}$ & GI7 & $\begin{array}{l}\text { Character } \\
(\mathrm{Y}, \mathrm{N})\end{array}$ & $\begin{array}{l}\text { Field indicates whether crash data } \\
\text { are available for input on mainline } \\
\text { freeway segments, ramps, ramp } \\
\text { terminals and intersections, or } \\
\text { crossroad roadway segments, } \\
\text { respectively. }\end{array}$ & Mandatory \\
\hline $\begin{array}{l}\text { Begin year of } \\
\text { crash data }\end{array}$ & GI8 & $\begin{array}{l}\text { Numeric } \\
\text { (calendar } \\
\text { year) }\end{array}$ & $\begin{array}{l}\text { Field indicates the first year for } \\
\text { which crash data are available for } \\
\text { input for the respective interchange } \\
\text { elements. }\end{array}$ & $\begin{array}{l}\text { Mandatory, } \\
\text { if GI7 equals } \\
\text { Y }\end{array}$ \\
\hline $\begin{array}{l}\text { End year of crash } \\
\text { data }\end{array}$ & GI9 & $\begin{array}{l}\text { Numeric } \\
\text { (calendar } \\
\text { year) }\end{array}$ & $\begin{array}{l}\text { Field indicates the final year for } \\
\text { which crash data are available for } \\
\text { input for the respective interchange } \\
\text { elements. }\end{array}$ & $\begin{array}{l}\text { Mandatory, } \\
\text { if GI7 equals } \\
\text { Y }\end{array}$ \\
\hline $\begin{array}{l}\text { Observed number } \\
\text { of crashes }\end{array}$ & GI10 & Numeric & $\begin{array}{l}\text { Field indicates the total number of } \\
\text { observed crashes during the } \\
\text { specified period (i.e., GI8 through } \\
\text { GI9) across all individual mainline } \\
\text { freeway segments, ramps, ramp } \\
\text { terminals and intersections, and/or } \\
\text { crossroad roadway segment } \\
\text { included in the analysis. }\end{array}$ & $\begin{array}{l}\text { Mandatory, } \\
\text { if GI7 equals } \\
\mathrm{Y}\end{array}$ \\
\hline
\end{tabular}


Table B-3. Mainline Freeway Segments Input Data Screen

\begin{tabular}{|c|c|c|c|c|c|c|c|c|c|c|}
\hline MF1 & MF2 & MF3 & MF4 & MF5 & MF6 & MF7 & MF8 & MF9 & MF10 & MF11 \\
\hline $\begin{array}{l}\text { Segment } \\
\text { number }\end{array}$ & $\begin{array}{c}\text { Segment } \\
\text { description }\end{array}$ & $\begin{array}{c}\text { Direction of } \\
\text { travel }\end{array}$ & $\begin{array}{c}\text { Beginning } \\
\text { MP }\end{array}$ & $\begin{array}{c}\text { Ending } \\
\text { MP }\end{array}$ & $\begin{array}{l}\text { Length of } \\
\text { segment }\end{array}$ & $\begin{array}{l}\text { Number of through } \\
\text { lanes (directional) }\end{array}$ & $\begin{array}{c}\text { Mainline ADT } \\
\text { (directional) }\end{array}$ & $\begin{array}{l}\text { Mainline } \\
\text { ADT year }\end{array}$ & $\begin{array}{c}\text { ADT } \\
\text { growth } \\
\text { rate }\end{array}$ & $\begin{array}{c}\text { Within } \\
\text { interchange } \\
\text { area? }\end{array}$ \\
\hline numeric & character & $\begin{array}{l}\text { (NB, SB, } \\
\text { EB, WB) }\end{array}$ & numeric & numeric & (mi) & $(2,3,4)$ & (veh/day) & numeric & $\begin{array}{c}\text { (percent/ } \\
\text { year) }\end{array}$ & $(\mathrm{Y}, \mathrm{N})$ \\
\hline \multicolumn{11}{|l|}{1} \\
\hline \multicolumn{11}{|l|}{2} \\
\hline \multicolumn{11}{|l|}{3} \\
\hline \multicolumn{11}{|l|}{4} \\
\hline \multicolumn{11}{|l|}{5} \\
\hline \multicolumn{11}{|l|}{6} \\
\hline 7 & & & & & & & & & & \\
\hline
\end{tabular}


Table B-4. Summary of Input Variables for Mainline Freeway Segments

\begin{tabular}{|c|c|c|c|c|}
\hline Variable Name & $\begin{array}{c}\text { Variable } \\
\text { No. }\end{array}$ & Format & Definition & Type \\
\hline Segment number & MF1 & Numeric & $\begin{array}{l}\text { Each mainline freeway segment included } \\
\text { in the analysis must be identified by a } \\
\text { sequential integer, starting with 1; this } \\
\text { variable is not used in calculations but is } \\
\text { carried through onto the output report. }\end{array}$ & Mandatory \\
\hline Segment description & MF2 & Character & $\begin{array}{l}\text { This field is available to describe each } \\
\text { mainline freeway segment; a typical } \\
\text { description might be "NB mainline lanes } \\
\text { upstream of off-ramp" or "SB mainline } \\
\text { lanes between ramps"; this variable is not } \\
\text { used in calculations but is carried through } \\
\text { onto the output report. }\end{array}$ & Optional \\
\hline Direction of travel & MF3 & $\begin{array}{l}\text { Character } \\
\text { (NB, SB, EB, WB) }\end{array}$ & $\begin{array}{l}\text { This variable corresponds to the general } \\
\text { direction of travel for the individual } \\
\text { segment; this variable is not used in } \\
\text { calculations but is carried through onto } \\
\text { the output reports. }\end{array}$ & Optional \\
\hline Begin MP & MF4 & Numeric & $\begin{array}{l}\text { This is the beginning milepost or other } \\
\text { applicable coordinate for the segment; this } \\
\text { variable is not used in calculations but is } \\
\text { carried through onto the output reports. }\end{array}$ & Optional \\
\hline End MP & MF5 & Numeric & $\begin{array}{l}\text { This is the ending milepost or other } \\
\text { applicable coordinate for the segment; this } \\
\text { variable is not used in calculations but is } \\
\text { carried through onto the output reports. }\end{array}$ & Optional \\
\hline Length of segment & MF6 & $\begin{array}{l}\text { Numeric } \\
(\mathrm{mi})\end{array}$ & $\begin{array}{l}\text { This is the length of the mainline segment, } \\
\text { specified in miles, generally to the nearest } \\
\text { hundredth of a mile. }\end{array}$ & Mandatory \\
\hline $\begin{array}{l}\text { Number of through } \\
\text { lanes }\end{array}$ & MF7 & Numeric & $\begin{array}{l}\text { This variable includes all lanes on the } \\
\text { segment in a given direction [MF3] that } \\
\text { are used by through traffic. This does not } \\
\text { include auxiliary lanes. }\end{array}$ & Mandatory \\
\hline Mainline ADT & MF8 & $\begin{array}{l}\text { Numeric } \\
\text { (veh/day) }\end{array}$ & $\begin{array}{l}\text { This is the best available estimate of the } \\
\text { annual average daily traffic volume for } \\
\text { the mainline freeway segment in the given } \\
\text { direction of travel [MF3]. }\end{array}$ & Mandatory \\
\hline Mainline ADT Year & MF9 & $\begin{array}{l}\text { Numeric } \\
\text { (calendar year) }\end{array}$ & $\begin{array}{l}\text { This field indicates the year to which the } \\
\text { mainline ADT [MF8] applies. }\end{array}$ & Mandatory \\
\hline $\begin{array}{l}\text { Traffic volume } \\
\text { growth rate }\end{array}$ & MF10 & $\begin{array}{l}\text { Numeric } \\
\text { (percent/year) }\end{array}$ & $\begin{array}{l}\text { This value corresponds to the average } \\
\text { growth rate of traffic for the given } \\
\text { freeway mainline segment for the analysis } \\
\text { period. }\end{array}$ & Mandatory \\
\hline $\begin{array}{l}\text { Within interchange } \\
\text { area }\end{array}$ & MF11 & $\begin{array}{l}\text { Character } \\
(\mathrm{Y}, \mathrm{N})\end{array}$ & $\begin{array}{l}\text { This field identifies whether the segment } \\
\text { is located within an interchange area or } \\
\text { outside. } \\
\mathrm{Y}=\text { segment is located within an } \\
\text { interchange area } \\
\mathrm{N}=\text { segment is not located within an } \\
\text { interchange area }\end{array}$ & Mandatory \\
\hline
\end{tabular}


Table B-5. Ramps Input Data Screen

\begin{tabular}{|c|c|c|c|c|c|c|c|c|c|c|c|}
\hline R1 & R2 & R3 & R4 & R5 & R6 & R7 & R8 & R9 & R10 & R11 & R12 \\
\hline $\begin{array}{c}\text { Ramp } \\
\text { number }\end{array}$ & $\begin{array}{c}\text { Ramp } \\
\text { description }\end{array}$ & $\begin{array}{c}\text { Direction } \\
\text { of travel }\end{array}$ & $\begin{array}{c}\text { Ramp } \\
\text { type }\end{array}$ & $\begin{array}{c}\text { Ramp } \\
\text { configuration }\end{array}$ & $\begin{array}{l}\text { Ramp } \\
\text { length }\end{array}$ & $\begin{array}{l}\text { Ramp } \\
\text { ADT }\end{array}$ & $\begin{array}{c}\text { Ramp } \\
\text { ADT year } \\
\end{array}$ & $\begin{array}{c}\text { Ramp } \\
\text { ADT } \\
\text { growth } \\
\text { rate } \\
\end{array}$ & $\begin{array}{l}\text { Segment number } \\
\text { for adjacent } \\
\text { mainline freeway } \\
\text { segment } \\
\end{array}$ & $\begin{array}{c}\text { Acceleration } \\
\text { lane }\end{array}$ & $\begin{array}{c}\text { Acceleration } \\
\text { lane length }\end{array}$ \\
\hline numeric & character & $\begin{array}{l}\text { (NB, SB, } \\
\text { EB, WB) }\end{array}$ & $\begin{array}{l}(\mathrm{ON}, \\
\text { OFF, } \\
\text { FWY) }\end{array}$ & $\begin{array}{c}\text { (D, PL, FFL, } \\
\text { DIR) }\end{array}$ & (mi) & (veh/day) & numeric & $\begin{array}{c}\text { (percent/ } \\
\text { year) }\end{array}$ & numeric & $(\mathrm{Y}, \mathrm{N})$ & (mi) \\
\hline 1 & & & & & & & & & & & \\
\hline 2 & & & & & & & & & & & \\
\hline 3 & & & & & & & & & & & \\
\hline 4 & & & & & & & & & & & \\
\hline 5 & & & & & & & & & & & \\
\hline 6 & & & & & & & & & & & \\
\hline 7 & & & & & & & & & & & \\
\hline
\end{tabular}


Table B-6. Summary of Input Variables for Ramps

\begin{tabular}{|c|c|c|c|c|}
\hline $\begin{array}{l}\text { Variable } \\
\text { Name }\end{array}$ & $\begin{array}{l}\text { Variable } \\
\text { No. }\end{array}$ & Format & Definition & Type \\
\hline $\begin{array}{l}\text { Ramp } \\
\text { number }\end{array}$ & R1 & Numeric & $\begin{array}{l}\text { Each ramp included in the analysis must be identified by } \\
\text { a sequential integer, starting with } 1 \text {; this variable is not } \\
\text { used in calculations but is carried through onto the } \\
\text { output report. }\end{array}$ & Mandatory \\
\hline $\begin{array}{l}\text { Ramp } \\
\text { description }\end{array}$ & $\mathrm{R} 2$ & Character & $\begin{array}{l}\text { This field is available to describe each ramp; a typical } \\
\text { description might be "NB diamond off-ramp” or "SB } \\
\text { parclo on-ramp"; this variable is not used in calculations } \\
\text { but is carried through onto the output report. }\end{array}$ & Optional \\
\hline $\begin{array}{l}\text { Direction of } \\
\text { travel }\end{array}$ & R3 & $\begin{array}{l}\text { Character } \\
\text { (NB, SB, } \\
\text { EB, WB) }\end{array}$ & $\begin{array}{l}\text { This variable corresponds to the direction of travel of the } \\
\text { ramp; this variable is not used in calculations but is } \\
\text { carried through onto the output report. }\end{array}$ & Optional \\
\hline $\begin{array}{l}\text { Type of } \\
\text { ramp }\end{array}$ & R4 & $\begin{array}{l}\text { Character } \\
\text { (ON, OFF, } \\
\text { FWY) }\end{array}$ & $\begin{array}{l}\text { On-ramps service vehicles entering the mainline; off- } \\
\text { ramps service vehicles leaving the mainline; freeway-to- } \\
\text { freeway ramps service vehicles leaving one mainline } \\
\text { freeway and entering another; the type of ramps are } \\
\text { distinguished by the following codes: } \\
\text { ON = on-ramp } \\
\text { OFF = off-ramp } \\
\text { FWY = freeway-to-freeway ramp }\end{array}$ & Mandatory \\
\hline $\begin{array}{l}\text { Ramp } \\
\text { configuration }\end{array}$ & R5 & $\begin{array}{l}\text { Character } \\
\text { (D, PL, } \\
\text { FFL, DIR) }\end{array}$ & $\begin{array}{l}\text { This variable defines the basic configuration of the } \\
\text { ramp; the abbreviated codes correspond as follows: } \\
\text { D = diamond ramp } \\
\text { PL = parclo loop ramp } \\
\text { FFL = free-flow loop ramp } \\
\text { DIR = directional ramp }\end{array}$ & Mandatory \\
\hline Ramp length & R6 & $\begin{array}{l}\text { Numeric } \\
\text { (mi) }\end{array}$ & $\begin{array}{l}\text { This length is measured from the gore point at the } \\
\text { freeway ramp terminal to the crossroad ramp terminal } \\
\text { (typically measured to the nearest hundredth of a mile). }\end{array}$ & Mandatory \\
\hline Ramp ADT & R7 & $\begin{array}{l}\text { Numeric } \\
\text { (veh/day) }\end{array}$ & $\begin{array}{l}\text { This is the best available estimate of the annual average } \\
\text { daily traffic volume for the ramp proper. }\end{array}$ & Mandatory \\
\hline $\begin{array}{l}\text { Ramp ADT } \\
\text { year }\end{array}$ & R8 & Numeric & $\begin{array}{l}\text { Field indicates the year to which the ramp ADT [R7] } \\
\text { applies. }\end{array}$ & Mandatory \\
\hline $\begin{array}{l}\text { Ramp ADT } \\
\text { growth rate }\end{array}$ & R9 & $\begin{array}{l}\text { Numeric } \\
\text { (percent/ } \\
\text { year) }\end{array}$ & $\begin{array}{l}\text { Value corresponds to the average growth rate of traffic } \\
\text { for the given ramp for the analysis period. }\end{array}$ & Mandatory \\
\hline $\begin{array}{l}\text { Segment } \\
\text { number for } \\
\text { adjacent } \\
\text { mainline } \\
\text { freeway }\end{array}$ & R10 & Numeric & $\begin{array}{l}\text { The segment number (i.e., MF1) associated with the } \\
\text { freeway segment adjacent to the speed-change lane of } \\
\text { the given ramp. }\end{array}$ & Mandatory \\
\hline $\begin{array}{l}\text { Acceleration } \\
\text { lane? }\end{array}$ & R11 & $\begin{array}{l}\text { Character } \\
(\mathrm{Y}, \mathrm{N})\end{array}$ & $\begin{array}{l}\text { A code identifying whether there is an acceleration lane } \\
\text { associated with the given ramp: } \\
\mathrm{Y}=\text { yes, there is an acceleration lane attached to the } \\
\text { ramp } \\
\mathrm{N}=\text { no, there is no acceleration lane attached to the ramp }\end{array}$ & Mandatory \\
\hline $\begin{array}{l}\text { Length of } \\
\text { acceleration } \\
\text { lane }\end{array}$ & R12 & $\begin{array}{l}\text { Numeric } \\
(\mathrm{mi})\end{array}$ & $\begin{array}{l}\text { This distance is measured for the acceleration lane from } \\
\text { the gore point of the ramp to the end of the taper for an } \\
\text { acceleration lane; distances should be rounded to the } \\
\text { nearest hundredth of a mile; if no acceleration lane is } \\
\text { present, "0.00" should be entered in this field, and R11 } \\
\text { should be set equal to "N.” }\end{array}$ & $\begin{array}{l}\text { Mandatory; } \\
\text { when R11 } \\
\text { equals Y. }\end{array}$ \\
\hline
\end{tabular}


Table B-7. Crossroad Ramp Terminal and Intersection Input Data Screen

\begin{tabular}{|c|c|c|c|c|c|c|c|c|c|c|}
\hline RT1 & RT2 & RT3 & RT4 & RT5 & RT6 & RT7 & RT8 & RT9 & RT10 & RT11 \\
\hline $\begin{array}{c}\text { Terminal } \\
\text { number }\end{array}$ & $\begin{array}{c}\text { Terminal } \\
\text { description }\end{array}$ & $\begin{array}{c}\text { Type of } \\
\text { traffic } \\
\text { control } \\
\end{array}$ & \begin{tabular}{|c|} 
Number \\
of legs
\end{tabular} & $\begin{array}{c}\text { Major-road or } \\
\text { crossroad } \\
\text { segment ADT } \\
\text { (directional) }\end{array}$ & $\begin{array}{c}\begin{array}{c}\text { Major-road or } \\
\text { crossroad } \\
\text { segment ADT } \\
\text { year }\end{array} \\
\end{array}$ & $\begin{array}{c}\text { Major-road or } \\
\text { crossroad } \\
\text { segment growth } \\
\text { rate }\end{array}$ & \begin{tabular}{|c|} 
Minor-road \\
or ramp ADT \\
(directional) \\
\end{tabular} & $\begin{array}{c}\text { Minor-road } \\
\text { or ramp } \\
\text { ADT year } \\
\end{array}$ & $\begin{array}{c}\text { Minor-road or } \\
\text { ramp growth } \\
\text { rate }\end{array}$ & $\begin{array}{c}\text { Terminal } \\
\text { type }\end{array}$ \\
\hline numeric & character & $(\mathrm{SG}, \mathrm{ST})$ & $(3,4)$ & (veh/day) & numeric & (percent/year) & (veh/day) & numeric & (percent/year) & (RT, CI) \\
\hline \multicolumn{11}{|l|}{1} \\
\hline \multicolumn{11}{|l|}{2} \\
\hline \multicolumn{11}{|l|}{3} \\
\hline \multicolumn{11}{|l|}{4} \\
\hline \multicolumn{11}{|l|}{5} \\
\hline \multicolumn{11}{|l|}{6} \\
\hline 7 & & & & & & & & & & \\
\hline
\end{tabular}


Table B-8. Summary of Input Variables for Crossroad Ramp Terminals and Intersections

\begin{tabular}{|c|c|c|c|c|}
\hline Variable Name & $\begin{array}{l}\text { Variable } \\
\text { No. }\end{array}$ & Format & Definition & Type \\
\hline Terminal number & RT1 & Numeric & $\begin{array}{l}\text { Each crossroad ramp terminal and intersection } \\
\text { included in the analysis must be identified by a } \\
\text { sequential integer, starting with } 1 \text {; this variable is not } \\
\text { used in calculations but is carried through onto the } \\
\text { output reports. }\end{array}$ & Mandatory \\
\hline $\begin{array}{l}\text { Terminal } \\
\text { description }\end{array}$ & RT2 & Character & $\begin{array}{l}\text { This field is used to describe each crossroad ramp } \\
\text { terminal and intersection; a typical description might } \\
\text { be "NB diamond off-ramp/NB diamond on-ramp and } \\
\text { Main St." or "SB parclo on-ramp and 1st Ave.”; this } \\
\text { variable is not used in calculations but is carried } \\
\text { through onto the output report. }\end{array}$ & Optional \\
\hline $\begin{array}{l}\text { Type of traffic } \\
\text { control }\end{array}$ & RT3 & $\begin{array}{l}\text { Character } \\
\text { (SG, ST) }\end{array}$ & $\begin{array}{l}\text { Field is a code identifying the type of traffic control for } \\
\text { the crossroad ramp terminal or intersection: } \\
\text { SG = signalized intersection } \\
\text { ST = STOP-control on the ramp or minor roadway; no } \\
\text { control on the major crossroad }\end{array}$ & Mandatory \\
\hline Number of legs & RT4 & $\begin{array}{l}\text { Numeric } \\
(3,4)\end{array}$ & $\begin{array}{l}\text { Field is a code identifying the number of legs of the } \\
\text { crossroad ramp terminal or intersection: } \\
3=\text { three-legs } \\
4=\text { four-legs } \\
\text { NOTE: In determining the number of legs, the user } \\
\text { should consider whether it is most appropriate to treat } \\
\text { each ramp that is served by the terminal as an } \\
\text { individual leg. }\end{array}$ & Mandatory \\
\hline $\begin{array}{l}\text { Major-road or } \\
\text { crossroad segment } \\
\text { ADT (directional) }\end{array}$ & RT5 & $\begin{array}{l}\text { Numeric } \\
\text { (veh/day) }\end{array}$ & $\begin{array}{l}\text { This is the best available estimate of the annual } \\
\text { average daily traffic volume for the major-road in a } \\
\text { given direction. It is recommended that the maximum } \\
\text { directional volume of the major-road approaches be } \\
\text { entered here. }\end{array}$ & Mandatory \\
\hline $\begin{array}{l}\text { Major-road or } \\
\text { crossroad segment } \\
\text { ADT year }\end{array}$ & RT6 & Numeric & $\begin{array}{l}\text { Field indicates the year to which the major-road ADT } \\
\text { applies. }\end{array}$ & Mandatory \\
\hline $\begin{array}{l}\text { Major-road or } \\
\text { crossroad segment } \\
\text { ADT growth rate }\end{array}$ & RT7 & $\begin{array}{l}\text { Numeric } \\
\text { (percent/yr) }\end{array}$ & $\begin{array}{l}\text { Value corresponds to the average growth rate of traffic } \\
\text { for the given major-road for the analysis period. }\end{array}$ & Mandatory \\
\hline $\begin{array}{l}\text { Minor-road or } \\
\text { ramp ADT } \\
\text { (directional) }\end{array}$ & RT8 & $\begin{array}{l}\text { Numeric } \\
\text { (veh/day) }\end{array}$ & $\begin{array}{l}\text { This is the best available estimate of the annual } \\
\text { average daily traffic volume for the minor-road or } \\
\text { ramp proper. It is recommended that the maximum } \\
\text { directional volume of the minor-road (or ramp) } \\
\text { approaches be entered here. }\end{array}$ & Mandatory \\
\hline $\begin{array}{l}\text { Minor-road or } \\
\text { ramp ADT year }\end{array}$ & RT9 & Numeric & $\begin{array}{l}\text { Field indicates the year to which the minor-road or } \\
\text { ramp ADT applies. }\end{array}$ & Mandatory \\
\hline $\begin{array}{l}\text { Minor-road or } \\
\text { ramp ADT growth } \\
\text { rate }\end{array}$ & RT10 & $\begin{array}{l}\text { Numeric } \\
\text { (percent/year) }\end{array}$ & $\begin{array}{l}\text { Value corresponds to the average growth rate of traffic } \\
\text { for the given minor-road or ramp for the analysis } \\
\text { period. }\end{array}$ & Mandatory \\
\hline Terminal type & RT11 & $\begin{array}{l}\text { Character } \\
\text { (RT, CI) }\end{array}$ & $\begin{array}{l}\text { This variable distinguishes whether the terminal is a } \\
\text { ramp terminal or a conventional intersection and } \\
\text { impacts the value of the minor-road ADT entered into } \\
\text { the SPF calculations and calculation for million } \\
\text { entering vehicles (MEV). } \\
\text { RT = ramp terminal } \\
\text { CI = conventional intersection }\end{array}$ & Mandatory \\
\hline
\end{tabular}


Table B-9. Arterial Crossroad Roadway Segment Input Data Screen

\begin{tabular}{|c|c|c|c|c|c|c|c|c|c|c|}
\hline RS1 & RS2 & RS3 & RS4 & RS5 & RS6 & RS7 & RS8 & RS9 & RS10 & RS11 \\
\hline $\begin{array}{l}\text { Segment } \\
\text { number }\end{array}$ & $\begin{array}{c}\text { Segment } \\
\text { description }\end{array}$ & $\begin{array}{c}\text { Direction of } \\
\text { travel }\end{array}$ & $\begin{array}{c}\text { Beginning } \\
\text { MP }\end{array}$ & $\begin{array}{c}\text { Ending } \\
\text { MP }\end{array}$ & $\begin{array}{c}\text { Length of } \\
\text { segment }\end{array}$ & $\begin{array}{c}\text { Number of } \\
\text { through lanes } \\
\text { (directional) }\end{array}$ & $\begin{array}{c}\text { Presence of } \\
\text { median } \\
\text { (divided, } \\
\text { undivided) }\end{array}$ & $\begin{array}{c}\text { Major-road } \\
\text { ADT } \\
\text { (directional) }\end{array}$ & $\begin{array}{c}\text { Major-road } \\
\text { ADT year }\end{array}$ & $\begin{array}{c}\text { Major-road } \\
\text { ADT growth } \\
\text { rate }\end{array}$ \\
\hline numeric & character & $\begin{array}{l}\text { (NB, SB, } \\
\text { EB, WB) }\end{array}$ & numeric & numeric & (mi) & $(1,2,3)$ & $(\mathrm{D}, \mathrm{U})$ & (veh/day) & numeric & (percent/year) \\
\hline 1 & & & & & & & & & & \\
\hline 2 & & & & & & & & & & \\
\hline 3 & & & & & & & & & & \\
\hline 4 & & & & & & & & & & \\
\hline 5 & & & & & & & & & & \\
\hline 6 & & & & & & & & & & \\
\hline 7 & & & & & & & & & & \\
\hline
\end{tabular}


Table B-10. Summary of Input Variables for Crossroad Roadway Segments

\begin{tabular}{|c|c|c|c|c|}
\hline $\begin{array}{l}\text { Variable } \\
\text { Name }\end{array}$ & $\begin{array}{l}\text { Variable } \\
\text { No. }\end{array}$ & Format & Definition & Type \\
\hline $\begin{array}{l}\text { Segment } \\
\text { number }\end{array}$ & RS1 & Numeric & $\begin{array}{l}\text { Each crossroad roadway segment included in the } \\
\text { analysis must be identified by a sequential } \\
\text { integer, starting with } 1 \text {; this variable is not used } \\
\text { in calculations but is carried through onto the } \\
\text { output reports. }\end{array}$ & Mandatory \\
\hline $\begin{array}{l}\text { Segment } \\
\text { description }\end{array}$ & RS2 & Character & $\begin{array}{l}\text { This field is used to describe each crossroad } \\
\text { roadway segment; a typical description might be } \\
\text { "Main St. east of crossroad ramp terminal" or } \\
\text { "Main St. between diamond-ramp terminals"; } \\
\text { this variable is not used in calculations but is } \\
\text { carried through onto the output report. }\end{array}$ & Optional \\
\hline $\begin{array}{l}\text { Direction of } \\
\text { travel }\end{array}$ & RS3 & $\begin{array}{l}\text { Character } \\
\text { (NB, SB, EB, WB) }\end{array}$ & $\begin{array}{l}\text { This variable corresponds to the general } \\
\text { direction of travel for the individual segment; } \\
\text { this variable is not used in calculations but is } \\
\text { carried through onto the output reports. }\end{array}$ & Optional \\
\hline Begin MP & RS4 & Numeric & $\begin{array}{l}\text { This is the beginning milepost or other } \\
\text { applicable coordinate for the segment; this } \\
\text { variable is not used in calculations but is carried } \\
\text { through onto the output reports. }\end{array}$ & Optional \\
\hline End MP & RS5 & Numeric & $\begin{array}{l}\text { This is the ending milepost or other applicable } \\
\text { coordinate for the segment; this variable is not } \\
\text { used in calculations but is carried through onto } \\
\text { the output reports. }\end{array}$ & Optional \\
\hline $\begin{array}{l}\text { Length of } \\
\text { roadway } \\
\text { segment }\end{array}$ & RS6 & $\begin{array}{l}\text { Numeric } \\
(\mathrm{mi})\end{array}$ & $\begin{array}{l}\text { This is the length of the crossroad roadway } \\
\text { segment, specified in miles, generally to the } \\
\text { nearest hundredth of a mile. The length of a } \\
\text { roadway segment adjacent to a ramp terminal or } \\
\text { intersection should be measured from the center } \\
\text { of the ramp terminal or intersection; do not } \\
\text { deduct the } 250-\mathrm{ft} \text { distance referred to in the } \\
\text { crossroad ramp terminal discussion. }\end{array}$ & Mandatory \\
\hline $\begin{array}{l}\text { Number of } \\
\text { through lanes } \\
\text { (directional) }\end{array}$ & RS7 & $\begin{array}{l}\text { Numeric } \\
(1,2,3)\end{array}$ & $\begin{array}{l}\text { This variable includes all lanes used by through } \\
\text { traffic in a given direction of travel [RS3]; it } \\
\text { does not include auxiliary lanes or exclusive turn } \\
\text { lanes. }\end{array}$ & Mandatory \\
\hline $\begin{array}{l}\text { Presence of } \\
\text { median }\end{array}$ & RS8 & $\begin{array}{l}\text { Character } \\
(\mathrm{D}, \mathrm{U})\end{array}$ & $\begin{array}{l}\text { A divided roadway signifies that a raised or } \\
\text { depressed median, or a flush median at least } 4 \mathrm{ft} \\
\text { in width, is present between the lanes in } \\
\text { opposing directions of travel; all other roadways } \\
\text { should be considered undivided: } \\
\mathrm{D}=\text { divided roadway } \\
\mathrm{U}=\text { undivided roadway }\end{array}$ & Mandatory \\
\hline $\begin{array}{l}\text { Major-road } \\
\text { ADT } \\
\text { (directional) }\end{array}$ & RS9 & $\begin{array}{l}\text { Numeric } \\
\text { (veh/day) }\end{array}$ & $\begin{array}{l}\text { This is the best available estimate of the annual } \\
\text { average daily traffic volume for the given } \\
\text { direction [RS3] of the crossroad roadway } \\
\text { segment. }\end{array}$ & Mandatory \\
\hline $\begin{array}{l}\text { Major-road } \\
\text { ADT year }\end{array}$ & RS10 & Numeric & $\begin{array}{l}\text { Field indicates the year to which the crossroad } \\
\text { ADT [RS9] applies. }\end{array}$ & Mandatory \\
\hline $\begin{array}{l}\text { Major-road } \\
\text { ADT growth } \\
\text { rate }\end{array}$ & RS11 & $\begin{array}{l}\text { Numeric } \\
\text { (percent/ year) }\end{array}$ & $\begin{array}{l}\text { Value corresponds to the average growth rate of } \\
\text { traffic for the given crossroad segment for the } \\
\text { analysis period. }\end{array}$ & Mandatory \\
\hline
\end{tabular}


Table B-11. Summary of Nomenclature Used in ISAT

\begin{tabular}{|c|c|}
\hline Term & Explanation \\
\hline $\mathrm{i}$ & Subscript to represent site i \\
\hline I & Total number of sites of a given interchange element type included in the analysis \\
\hline$y$ & $\begin{array}{l}\text { Subscript to represent the analysis year } y \\
\text { - The beginning calendar year of the analysis period is BY, corresponding to } \\
y=1 \\
\text { - The ending calendar year of the analysis period is } E Y \text {, corresponding to } \\
y=Y \\
\text { - The number of years in the analysis period is } Y\end{array}$ \\
\hline $\mathrm{z}$ & $\begin{array}{l}\text { Subscript to represent the crash period year } \mathrm{z} \\
\text { - The beginning calendar year of the crash period is } B Z \text {, corresponding to } \\
\mathrm{z}=1 \\
\text { - The ending calendar year of the crash period is } E Z \text {, corresponding to } \mathrm{z}=\mathrm{Z} \\
\text { - The number of years in the crash period is } \mathrm{Z}\end{array}$ \\
\hline A & Subscript to denote analysis period years \\
\hline C & Subscript to denote crash period years \\
\hline MF & Subscript or prefix to denote mainline freeway segment \\
\hline $\mathrm{AL}$ & Subscript or prefix to denote acceleration lane \\
\hline $\mathrm{R}$ & Subscript or prefix to denote ramp \\
\hline RT & Subscript or prefix to denote ramp terminal or intersection \\
\hline RS & Subscript or prefix to denote crossroad roadway segment \\
\hline IA & Subscript or prefix to denote entire interchange area \\
\hline TOT & Subscript to denote total accidents \\
\hline $\mathrm{FI}$ & Subscript to denote fatal and injury accidents \\
\hline PDO & Subscript to denote property-damage-only accidents \\
\hline CT & Subscript to denote crash type \\
\hline $\mathrm{ADT}_{(\mathrm{i})}$ & 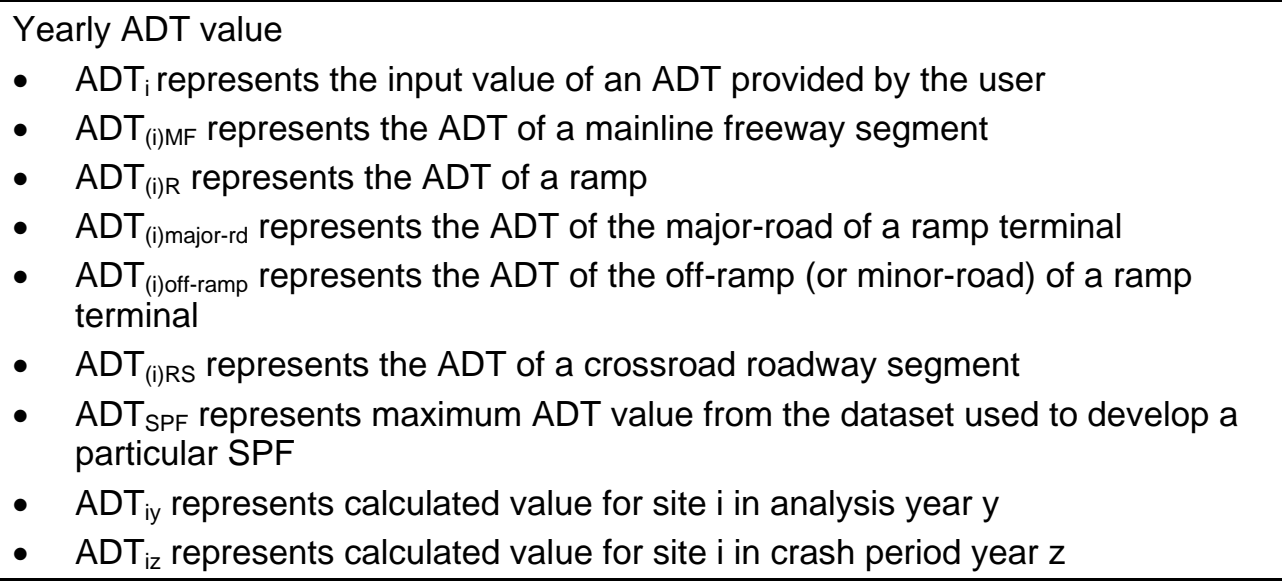 \\
\hline $\mathrm{GF}_{\mathrm{i}}$ & Input value of ADT growth factor for site i \\
\hline AY & Calendar year of inputted ADT value \\
\hline
\end{tabular}


Table B-11. Summary of Nomenclature Used in ISAT (Continued)

\begin{tabular}{|c|c|}
\hline Term & Explanation \\
\hline SL & $\begin{array}{l}\text { Segment length of a mainline freeway or crossroad roadway segment, expressed } \\
\text { in } \mathrm{mi}\end{array}$ \\
\hline $\mathrm{ALL}_{\text {Avg }}$ & Mean length of acceleration lanes used to develop the SPFs (default value $=0.1 \mathrm{mi}$ ) \\
\hline$A L L_{\text {Act }}$ & Actual length of acceleration lane being analyzed, expressed in mi \\
\hline $\mathrm{RL}$ & Ramp length, expressed in mi \\
\hline Avg & Subscript to denote calculation of average \\
\hline Act & Subscript to denote calculation using actual acceleration lane length \\
\hline $\begin{array}{l}\mathrm{SPF}_{\mathrm{TOT}}, \mathrm{SPF}_{\mathrm{FI}} \\
\mathrm{a}, \mathrm{b}, \mathrm{c}, \mathrm{d}, \mathrm{e}, \mathrm{k}\end{array}$ & $\begin{array}{l}\text { Safety Performance Function, applicable to a given type of sites. It includes the } \\
\text { following regression coefficients (on the log scale) and parameters: } \\
\text { - a - e: coefficients for intercept, ADT, and length } \\
\text { - k: dispersion parameter associated with the negative binomial regression } \\
\text { model } \\
\text { NOTE: Two SPFs are used for each type of site: SPF } \\
\text { own set of parameters. }\end{array}$ \\
\hline $\begin{array}{l}\mathrm{P}_{\mathrm{CT}(\mathrm{TOT})}, \mathrm{P}_{\mathrm{CT}(\mathrm{Fl})} \\
\mathrm{C}_{\mathrm{y}(\mathrm{TOT})}, \mathrm{C}_{\mathrm{y}(\mathrm{FI})}\end{array}$ & $\begin{array}{l}\text { - } \mathrm{P}_{\mathrm{CT}(\mathrm{TOT})} \text { : Calculated proportion of TOTAL accidents of a specified collision } \\
\text { type for all years of available data } \\
\text { - } \mathrm{P}_{\mathrm{CT(FI)}} \text { : Calculated proportion of FI accidents of a specified collision type for } \\
\text { all years of available data } \\
\text { - } \mathrm{C}_{(\mathrm{TOT})} \text { : calibration factor for TOTAL accidents } \\
\text { - } \mathrm{C}_{(\mathrm{FI})} \text { : calibration factor for FI accidents }\end{array}$ \\
\hline $\mathrm{O}_{\mathrm{MF}}, \mathrm{O}_{\mathrm{R}}, \mathrm{O}_{\mathrm{RT}}, \mathrm{O}_{\mathrm{RS}}$ & $\begin{array}{l}\text { Total number of observed crashes for a user-defined period across all } \\
\text { individual sites of the interchange element of interest (i.e., mainline freeway } \\
\text { segment, ramps, crossroad ramp terminals and intersections, or crossroad } \\
\text { segments) }\end{array}$ \\
\hline $\mathrm{N}$ & $\begin{array}{l}\text { Predicted crash frequency } \\
\text { - } \quad \mathrm{N}_{\text {iy }} \text { represents the number of crashes at site i during analysis year y } \\
\text { - } \mathrm{N}_{\mathrm{iA}} \text { represents the total number of crashes at site i for the entire analysis period } \\
\text { - } \quad \mathrm{N}_{\mathrm{A}} \text { represents the total number of crashes for all sites for the entire analysis } \\
\text { period } \\
\text { - } \quad \mathrm{N}_{\mathrm{iz}} \text { represents the number of crashes at site i during crash period year z } \\
\text { - } \quad \mathrm{N}_{\mathrm{iC}} \text { represents the total number of crashes at site i for the entire crash period } \\
\text { - } \quad \mathrm{N}_{\mathrm{C}} \text { represents the total number of crashes for all sites for the entire crash } \\
\text { period } \\
\text { - } \mathrm{N}_{\mathrm{ADT}} \text { represents the total number of crashes for the entire crash period for all } \\
\text { sites, adjusted for ADT based upon crash data period }\end{array}$ \\
\hline $\mathrm{AF}_{\mathrm{ADT}}$ & Combined ADT adjustment factor \\
\hline $\mathrm{w}_{0}$ & $\begin{array}{l}\text { A weighting factor placed on predicted accident frequency assuming accident } \\
\text { frequencies for different roadway elements are statistically independent }\end{array}$ \\
\hline $\mathrm{w}_{1}$ & $\begin{array}{l}\text { A weighting factor placed on predicted accident frequency assuming accident } \\
\text { frequencies for different roadway elements are perfectly correlated }\end{array}$ \\
\hline
\end{tabular}


Table B-11. Summary of Nomenclature Used in ISAT (Continued)

\begin{tabular}{|c|c|}
\hline Term & Explanation \\
\hline E & 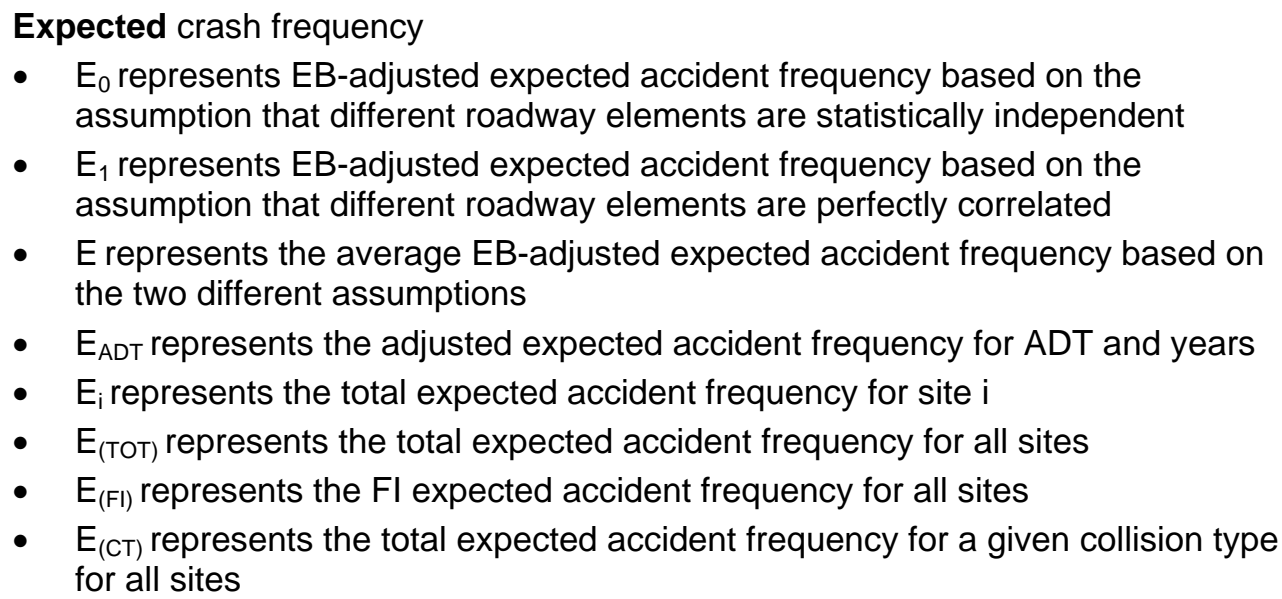 \\
\hline MVMT & Million vehicle-miles traveled \\
\hline MEV & Million entering vehicles \\
\hline
\end{tabular}

\section{Stage 1: Calculate Predicted Crash Frequencies for Analysis Period}

These calculations are performed for each individual mainline freeway segment (i.e., row) input by the user on the Input Mainline Freeways worksheet. The primary purpose of this stage is predict crash frequencies for TOT, FI, and PDO crash severities for each year in the analysis period and sum for the entire analysis period. These predicted crash frequencies are computed solely from the SPFs. Warnings can also be generated for incorrect crash proportion violations and/or exceeding Max AADT values used in calculating the SPFs.

Step 1: Determine the SPF used in predicting the safety performance of each individual site i (i.e., $\mathrm{i}=1$ to $\mathrm{I}_{\mathrm{MF}}$ ) for TOT crashes.

ISAT selects the appropriate SPF number for the site as a function of area type, interchange area, number of through lanes, and severity level. The values of the respective SPF coefficients and parameters are provided on the SPFs Mainline Freeway worksheet.

Step 2: Determine the SPF used in predicting the safety performance of each individual site i (i.e., $\mathrm{i}=1$ to $\mathrm{I}_{\mathrm{MF}}$ ) for FI crashes.

ISAT selects the appropriate SPF number for the site as a function of area type, interchange area, number of through lanes, and severity level. The values of the respective SPF coefficients and parameters are provided on the SPFs Mainline Freeway worksheet.

Step 3: Determine the crash proportions to be used for TOT and FI crashes for each individual site i (i.e., $\mathrm{i}=1$ to $\mathrm{I}_{\mathrm{MF}}$ ). 
ISAT selects the appropriate crash proportions for the site as a function of area type, severity level, and interchange area. The values of the respective crash proportions are provided on the Distributions Mainline Freeway worksheet.

Note 3A: If the sum of the crash proportions for crash types 1 to 13 do not sum to exactly 1.0, a distribution warning is provided on the output report for the site.

Step 4: Determine the number of years in the analysis period $(\mathrm{Y})$.

$$
\mathrm{Y}=\mathrm{EY}-\mathrm{BY}+1
$$

Note 4A: The maximum number of years in the analysis period permitted by the program is 20 (i.e., Max $Y=20$ ). The analysis period must be the same for all interchange elements included in the analysis.

Step 5: Determine the mainline ADT for each year (i.e., $\mathrm{y}=1,2, \ldots, \mathrm{Y}$ ).

$$
\mathrm{ADT}_{\mathrm{iy}}=\mathrm{ADT}_{\mathrm{i}} \times\left(1+\frac{\mathrm{GF}_{\mathrm{i}}}{100}\right)^{\mathrm{BY}-\mathrm{AY}_{\mathrm{i}}+\mathrm{y}-1}
$$

Step 6: Using the appropriate SPF model coefficient and parameters, compute the predicted TOT crash frequency for each year (i.e., $y=1,2, \ldots, Y$ ) in the analysis period for each site i (i.e., $\mathrm{i}=1$ to $\mathrm{I}_{\mathrm{MF}}$ ).

$$
\operatorname{MFN}_{\text {iy(Тот) }}=\mathrm{C}_{(\text {тот })} \times\left(\frac{\mathrm{e}^{\mathrm{a}} \times\left(2 \times \mathrm{ADT}_{\mathrm{iy}}\right)^{\mathrm{b}} \times \mathrm{SL}_{\mathrm{i}}}{2}\right)
$$

Note 6A: The SPFs for mainline freeways segments (developed for use within SafetyAnalyst) were modeled using an ADT for both directions of travel. Thus, the predicted crash frequency applies to both directions of travel along a mainline freeway segment. In this step, ISAT calculates the predicted crash frequency for a single direction of travel; therefore, the yearly directional ADT (i.e., input by the user) is doubled, and the whole predicted value is divided by 2.

Note 6B: The calibration factor $\left[\mathrm{C}_{(\mathrm{TOT})}\right]$ is provided in the Calibration Coefficients for Mainline Freeway Segment SPFs table on the Input Calibration worksheet. 
Step 7: Using the appropriate SPF model coefficients and parameters, compute the predicted FI crash frequency for each year (i.e., $y=1,2, \ldots, Y$ ) in the analysis period for each site i (i.e., i = 1 to $\left.\mathrm{I}_{\mathrm{MF}}\right)$.

$$
\operatorname{MFN}_{\mathrm{iy}(\mathrm{FI})}=\mathrm{C}_{(\mathrm{FI})} \times\left(\frac{\mathrm{e}^{\mathrm{a}} \times\left(2 \times \mathrm{ADT}_{\mathrm{iy}}\right)^{\mathrm{b}} \times \mathrm{SL}_{\mathrm{i}}}{2}\right)
$$

Note 7A: The SPFs for mainline freeways segments (developed for use within SafetyAnalyst) were modeled using an ADT for both directions of travel. Thus, the predicted crash frequency applies to both directions of travel along a mainline freeway segment. In this step, ISAT calculates the predicted crash frequency for a single direction of travel; therefore, the yearly directional ADT (i.e., input by the user) is doubled, and the whole predicted value is divided by 2.

Note 7B: The calibration factor $\left[\mathrm{C}_{(\mathrm{FI})}\right]$ is provided in the Calibration Coefficients for Mainline Freeway Segment SPFs table on the Input Calibration worksheet.

Step 8: Compute the predicted PDO crash frequency for each year (i.e., $\mathrm{y}=1,2, \ldots, \mathrm{Y}$ ) in the analysis period for each site i (i.e., $\mathrm{i}=1$ to $\mathrm{I}_{\mathrm{MF}}$ ).

$$
\mathrm{MFN}_{\mathrm{iy}(\mathrm{PDO})}=\mathrm{MFN}_{\mathrm{iy}(\mathrm{TOT})}-\mathrm{MFN}_{\mathrm{iy}(\mathrm{FI})}
$$

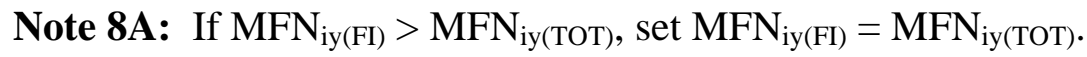

Step 9: If the mainline freeway segment site $\mathrm{i}$ is within an interchange area and is adjacent to an on-ramp with an acceleration lane, predict the TOT crash frequency associated with a mean acceleration lane length for each year (i.e., $y=1,2, \ldots, Y$ ) in the analysis period for each site i (i.e., $\mathrm{i}=1$ to $\mathrm{I}_{\mathrm{MF}}$ ).

$$
\left(A L N_{\text {iу }(\text { (TOT })}\right)_{A v g}=C \times C_{(\text {TоT })} \times e^{a} \times A D T_{i y(R)}^{b} \times e^{\left(c \times A L L_{\text {Avg }}\right)} \times A D T_{i y(M F)}{ }^{d}
$$

Otherwise

$$
\left(\mathrm{ALN}_{\text {iу (тоT })}\right)_{\mathrm{Avg}}=0
$$

Note 9A: To perform this step the program uses information input by the user on the Input Ramps worksheet.

Note 9B: ISAT selects the appropriate SPF number for the acceleration lane site as a function of area type and severity level. The values of the respective SPF coefficients and parameters are provided on the SPFs Accel Lanes worksheet.

Note 9C: $A L L_{A v g}=0.1 \mathrm{mi}$ for all acceleration lanes. This is the mean length of acceleration lanes used to develop the SPFs. 
Note 9D: The calibration factor $\left[\mathrm{C}_{(\mathrm{TOT})}\right]$ is provided in the Calibration Coefficients for Mainline Freeway Segment SPFs table on the Input Calibration worksheet.

Note 9E: The constant [C] in the SPF is provided because the SPFs for acceleration lanes were developed to predict crashes for a 3-year period. The constant scales the prediction to an annual basis. The constant also accounts for a ramp length term (i.e., the length of the ramp proper) in the original form of the SPF.

Step 10: If the mainline freeway segment site $\mathrm{i}$ is within an interchange area and is adjacent to an on-ramp with an acceleration lane, predict the TOT crash frequency associated with the actual acceleration lane length for each year (i.e., $y=1,2, \ldots, Y$ ) in the analysis period for each site $\mathrm{i}$ (i.e., $\mathrm{i}=1$ to $\mathrm{I}_{\mathrm{MF}}$ ).

$$
\left(A L N_{\text {iу (TOT })}\right)_{\text {Act }}=C \times C_{(\text {TOT })} \times e^{a} \times A D T_{i y(R)}^{b} \times e^{\left(c \times A L L_{A c t}\right)} \times A D T_{i y(M F)}^{d}
$$

Otherwise

$$
\left(\mathrm{ALN}_{\text {iу (TOT ) }}\right)_{\text {Act }}=0
$$

Note 10A: To perform this step the program uses information input by the user on the Input Ramps worksheet.

Note 10B: ISAT selects the appropriate SPF number for the acceleration lane site as a function of area type and severity level. The values of the respective SPF coefficients and parameters are provided on the SPFs Accel Lanes worksheet.

Note 10C: The calibration factor $\left[\mathrm{C}_{(\mathrm{TOT})}\right]$ is provided in the Calibration Coefficients for Mainline Freeway Segment SPFs table on the Input Calibration worksheet.

Note 10D: The constant [C] in the SPF is provided because the SPFs for acceleration lanes were developed to predict crashes for a 3-year period. The constant scales the prediction to an annual basis. The constant also accounts for a ramp length term (i.e., the length of the ramp proper) in the original form of the SPF.

Step 11: Predict the TOT crash frequency for the entire analysis period for each site i (i.e., i $=1$ to $\left.\mathrm{I}_{\mathrm{MF}}\right)$.

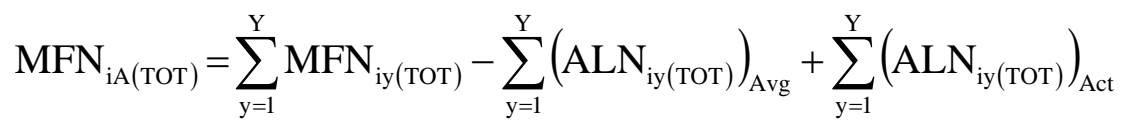

Step 12: If the mainline freeway segment site $\mathrm{i}$ is within an interchange area and is adjacent to an on-ramp with an acceleration lane, predict the FI crash frequency associated with a mean acceleration lane length for each year (i.e., $y=1,2, \ldots, Y$ ) in the analysis period for each site i (i.e., $\mathrm{i}=1$ to $\mathrm{I}_{\mathrm{MF}}$ ).

$$
\left(A L N_{i y(F I)}\right)_{A v g}=C \times C_{(F I)} \times e^{a} \times A D T_{i y(R)}^{b} \times e^{\left(c \times A L L_{A v g}\right)} \times A D T_{i y(M F)}^{d}
$$


Otherwise

$$
\left(\mathrm{ALN}_{\text {iy (FI) }}\right)_{\mathrm{Avg}}=0
$$

Note 12A: To perform this step the program uses information input by the user on the Input Ramps worksheet.

Note 12B: ISAT selects the appropriate SPF number for the acceleration lane site as a function of area type and severity level. The values of the respective SPF coefficients and parameters are provided on the SPFs Accel Lanes worksheet.

Note 12C: $A L L_{A v g}=0.1 \mathrm{mi}$ for all acceleration lanes. This is the mean length of acceleration lanes used to develop the SPFs.

Note 12D: The calibration factor $\left[\mathrm{C}_{(\mathrm{FI})}\right]$ is provided in the Calibration Coefficients for Mainline Freeway Segment SPFs table on the Input Calibration worksheet.

Note 12E: The constant [C] in the SPF is provided because the SPFs for acceleration lanes were developed to predict crashes for a 3-year period. The constant scales the prediction to an annual basis. The constant also accounts for a ramp length term (i.e., the length of the ramp proper) in the original form of the SPF.

Step 13: If the mainline freeway segment site i is within an interchange area and is adjacent to an on-ramp with an acceleration lane, predict the FI crash frequency associated with the actual acceleration lane length for each year (i.e., $\mathrm{y}=1,2, \ldots, \mathrm{Y}$ ) in the analysis period for each site i.

$$
\left(A L N_{i y(F I)}\right)_{A c t}=C \times C_{(F I)} \times e^{a} \times A D T_{i y(R)}^{b} \times e^{\left(c \times A L L_{A c t}\right)} \times A D T_{i y(M F)}^{d}
$$

Otherwise

$$
\left(\mathrm{ALN}_{\text {iy (FI })}\right)_{\mathrm{Act}}=0
$$

Note 13A: To perform this step the program uses information input by the user on the Input Ramps worksheet.

Note 13B: ISAT selects the appropriate SPF number for the acceleration lane site as a function of area type and severity level. The values of the respective SPF coefficients and parameters are provided on the SPFs Accel Lanes worksheet.

Note 13C: The calibration factor $\left[\mathrm{C}_{(\mathrm{FI})}\right]$ is provided in the Calibration Coefficients for Mainline Freeway Segment SPFs table on the Input Calibration worksheet.

Note 13D: The constant [C] in the SPF is provided because the SPFs for acceleration lanes were developed to predict crashes for a 3-year period. The constant scales the prediction to an annual basis. The constant also accounts for a ramp length term (i.e., the length of the ramp proper) in the original form of the SPF.

Note 13E: Steps 9 through 13 are performed so that the predicted crash frequencies for mainline freeway segments within interchange areas adjacent to acceleration lanes can be adjusted to more accurately account for the actual length of the acceleration lane. No adjustments are made to the predicted crash frequencies for mainline freeway segments within interchange areas adjacent to deceleration lanes due to the lack of accurate models (i.e., SPFs) for deceleration lanes that include a deceleration lane length term. 
Step 14: Predict the FI crash frequency for the entire analysis period for each site i (i.e., $\mathrm{i}=1$ to $\mathrm{I}_{\mathrm{MF}}$ ).

$$
\operatorname{MFN}_{\mathrm{iA}(\mathrm{FI})}=\sum_{\mathrm{y}=1}^{\mathrm{Y}} \mathrm{MFN}_{\mathrm{iy}(\mathrm{FI})}-\sum_{\mathrm{y}=1}^{\mathrm{Y}}\left(\mathrm{ALN}_{\mathrm{iy}(\mathrm{FI})}\right)_{\mathrm{Avg}}+\sum_{\mathrm{y}=1}^{\mathrm{Y}}\left(\mathrm{ALN}_{\mathrm{iy}(\mathrm{FI})}\right)_{\mathrm{Act}}
$$

Step 15: Predict the PDO crash frequency for the entire analysis period for each site i (i.e., $\mathrm{i}=1$ to $\left.\mathrm{I}_{\mathrm{MF}}\right)$.

$$
\mathrm{MFN}_{\mathrm{iA}(\mathrm{PDO})}=\mathrm{MFN}_{\mathrm{iA}(\mathrm{TOT})}-\mathrm{MFN}_{\mathrm{iA}(\mathrm{FI})}
$$

Step 16: Compare the max ADT for each site i (i.e., $\mathrm{i}=1$ to $\mathrm{I}_{\mathrm{MF}}$ ) for each year in the analysis period (i.e., $y=1,2, \ldots, Y$ ) to the $130 \%$ of Max ADT parameter for the respective SPF.

If

$$
\operatorname{MAX}\left(2 \times \mathrm{ADT}_{\mathrm{iy}}\right) \geq 1.3 \times \operatorname{Max} \mathrm{ADT}_{\mathrm{SPF}}
$$

then provide a violation warning for site i. Otherwise, no violation warning is necessary.

Note 16A: The value of the respective Max $\mathrm{ADT}_{\mathrm{SPF}}$ is provided on the SPFs Mainline Freeway worksheet.

\section{Stage 2: Calculate Predicted TOT Crash Frequencies for Crash Period}

These calculations are performed for each individual mainline freeway segment (i.e., row) input by the user on the Input Mainline Freeways worksheet. The primary purpose of this stage is predict crash frequencies for the TOT crash severity level for each year in the crash period and sum for the entire crash period. These predicted crash frequencies are computed solely from the SPFs. This is the first stage for incorporating crash data into the EB calculations. These calculations are only necessary when crash data are provided for mainline freeway segments on the Input-General worksheet. If crash data are not provided, proceed to step 33.

Step 17: Determine the number of years in the crash data period $\left(\mathrm{Z}_{\mathrm{MF}}\right)$.

$$
\mathrm{Z}_{\mathrm{MF}}=\mathrm{EZ}_{\mathrm{MF}}-\mathrm{BZ}_{\mathrm{MF}}+1
$$

Note 17A: The maximum allowable crash data period is 10 years (i.e., $M a x Z_{M F}=10$ ).

Step 18: Determine the mainline ADT for each year (i.e., $\mathrm{z}=1,2, \ldots, \mathrm{Z}_{\mathrm{MF}}$ ) in the crash data period for each site i.

$$
\mathrm{ADT}_{\mathrm{iz}_{\mathrm{MF}}}=\mathrm{ADT}_{\mathrm{i}} \times\left(1+\frac{\mathrm{GF}_{\mathrm{i}}}{100}\right)^{\mathrm{BZ}_{\mathrm{MF}}-\mathrm{AY}_{\mathrm{i}}+\mathrm{z}_{\mathrm{MF}}-1}
$$


Step 19: Using the appropriate SPF model coefficients and parameters, compute the predicted TOT crash frequency for each year (i.e., $\mathrm{z}=1,2, \ldots, \mathrm{Z}_{\mathrm{MF}}$ ) in the crash data period for each site $\mathrm{i}$ (i.e., $\mathrm{i}=1$ to $\mathrm{I}_{\mathrm{MF}}$ ).

$$
\operatorname{MFN}_{\mathrm{iz}(\text { TOT })}=\mathrm{C}_{(\text {TOT })} \times\left(\frac{\mathrm{e}^{\mathrm{a}} \times\left(2 \times \mathrm{ADT}_{\mathrm{iz}_{\mathrm{MF}}}\right)^{\mathrm{b}} \times \mathrm{SL}_{\mathrm{i}}}{2}\right)
$$

Step 20: Predict the TOT crash frequency for the entire crash data period for each site i (i.e., $\mathrm{i}=$ 1 to $\left.\mathrm{I}_{\mathrm{MF}}\right)$.

$$
\mathrm{MFN}_{\mathrm{iC}(\text { тот })}=\sum_{\mathrm{z}=1}^{\mathrm{Z}_{\mathrm{MF}}} \mathrm{MFN}_{\mathrm{iz}(\mathrm{TOT})}
$$

\section{Stage 3: Calculate Expected TOT Crash Frequencies for Analysis Period for all Mainline Freeway Segments Combined}

Steps 21 through 24 are performed for each individual mainline freeway segment (i.e., row) input by the user on the Input Mainline Freeways worksheet. Beginning with Step 25, data for all mainline freeway segments sites are combined to calculate an adjusted expected TOT accident frequency for all mainline freeway segment sites in the analysis period.

Step 21: Sum the predicted TOT crash frequency for all mainline freeway segment sites in the crash data period.

$$
\mathrm{MFN}_{\mathrm{C}(\mathrm{TOT})}=\sum_{\mathrm{i}=1}^{\mathrm{I}_{\mathrm{MF}}} \mathrm{MFN}_{\mathrm{iC}(\mathrm{TOT})}
$$

Step 22: Sum the predicted TOT crash frequency squared times $\mathrm{k}$ for all sites in the crash data period.

$$
\operatorname{MFN}_{C k(T O T)}=\sum_{i=1}^{I_{M F}} M F N_{i C(T O T)}^{2} \times k_{i}
$$

Step 23: Sum the predicted TOT crash frequency squared times $(\mathrm{k})^{0.5}$ for all sites in the crash data period.

$$
M F N_{C 0.5 k(\text { TOT })}=\sum_{i=1}^{I_{M F}} M F N_{i C(T O T)} \times k_{i}^{0.5}
$$

Step 24: Sum the predicted TOT crash frequency times the ADT adjustment for all sites in the analysis period.

$$
\mathrm{MFN}_{\mathrm{ADT}}=\sum_{\mathrm{i}=1}^{\mathrm{I}_{\mathrm{MF}}} \mathrm{MFN}_{\mathrm{iA}(\mathrm{TOT})} \times \frac{\frac{\mathrm{MFN}_{\mathrm{iA}(\mathrm{TOT})}}{\mathrm{Y}}}{\frac{\mathrm{MFN}_{\mathrm{iC}(\mathrm{TOT})}}{\mathrm{Z}_{\mathrm{MF}}}}
$$


Step 25: Sum the predicted TOT crash frequency for all mainline freeway sites in the analysis period.

$$
\mathrm{MFN}_{\mathrm{A}(\mathrm{TOT})}=\sum_{\mathrm{i}=1}^{\mathrm{I}_{\mathrm{MF}}} \mathrm{MFN}_{\mathrm{iA}(\mathrm{TOT})}
$$

Step 26: Compute the weighting factor $\left(w_{0(\mathrm{MF})}\right)$

$$
\mathrm{w}_{0(\mathrm{MF})}=\frac{1}{1+\frac{\mathrm{MFN}_{\mathrm{Ck}(\mathrm{TOT})}}{\mathrm{MFN}_{\mathrm{C}(\mathrm{TOT})}}}
$$

Step 27: Estimate the expected value $\left(\mathrm{MFE}_{0}\right)$

$$
\mathrm{MFE}_{0}=\left(\mathrm{w}_{0(\mathrm{MF})} \times \mathrm{MFN}_{\mathrm{C}(\mathrm{TOT})}\right)+\left(1-\mathrm{w}_{0(\mathrm{MF})}\right) \times \mathrm{O}_{\mathrm{MF}}
$$

Step 28: Compute the weighting factor $\left(w_{1(\mathrm{MF})}\right)$

$$
\mathrm{w}_{1(\mathrm{MF})}=\frac{1}{1+\frac{\mathrm{MFN}_{\mathrm{C} 0.5 \mathrm{k}(\mathrm{TOT})}}{\mathrm{MFN}_{\mathrm{C}(\mathrm{TOT})}}}
$$

Step 29: Estimate the expected value $\left(\mathrm{MFE}_{1}\right)$

$$
\mathrm{MFE}_{1}=\left(\mathrm{w}_{1(\mathrm{MF})} \times \mathrm{MFN}_{\mathrm{C}(\mathrm{TOT})}\right)+\left(1-\mathrm{w}_{1(\mathrm{MF})}\right) \times \mathrm{O}_{\mathrm{MF}}
$$

Step 30: Estimate the expected value MFE for the crash data period.

$$
\mathrm{MFE}=\frac{\mathrm{MFE}_{0}+\mathrm{MFE}_{1}}{2}
$$

Step 31: Calculate a combined ADT adjustment factor

$$
\mathrm{AF}_{\mathrm{ADT}(\mathrm{MF})}=\frac{\mathrm{MFN}_{\mathrm{ADT}}}{\mathrm{MFN}_{\mathrm{A}(\mathrm{TOT})}}
$$

Step 32: Adjust the expected TOT crash frequency for all mainline freeway sites combined in the analysis period. 


$$
\mathrm{MFE}_{\mathrm{ADT}}=\mathrm{MFE} \times \mathrm{AF}_{\mathrm{ADT}(\mathrm{MF})} \times \frac{\mathrm{Y}}{\mathrm{Z}_{\mathrm{MF}}}
$$

\section{Stage 4: Calculate EB-Adjusted Expected Crash Frequencies for Analysis Period for Each Individual Mainline Freeway Segment \\ Steps 33 through 38 are performed for each individual mainline freeway segment (i.e., row) input by the user on the Input Mainline Freeways worksheet. The primary purpose is to calculate EB-adjusted expected crash frequencies for each site, combining predicted crash frequencies from SPFs and observed crash data. If observed crash data are not provided for mainline freeway segments, the crash frequencies reflect predicted values rather than EB-adjusted expected values.}

Step 33: Calculate the adjusted expected TOT crash frequency for each mainline freeway site i (i.e., $\mathrm{i}=1$ to $\mathrm{I}_{\mathrm{MF}}$ ) for the entire analysis period.

If the user inputs that crash data are available for mainline freeway segments, then

$$
\mathrm{MFE}_{\mathrm{i}(\mathrm{TOT})}=\frac{\mathrm{MFN}_{\mathrm{ADT}} \times \mathrm{MFN}_{\mathrm{iA}(\mathrm{TOT})}}{\mathrm{MFN}_{\mathrm{A}(\mathrm{TOT})}}
$$

If the user inputs that crash data are not available for mainline freeway segments, then

$$
\mathrm{MFE}_{\mathrm{i}(\mathrm{TOT})}=\mathrm{MFN}_{\mathrm{iA}(\mathrm{TOT})}
$$

Step 34: Calculate the adjusted expected FI crash frequency for each mainline freeway site i (i.e., $\mathrm{i}=1$ to $\mathrm{I}_{\mathrm{MF}}$ ) in the entire analysis period.

If the user inputs that crash data are available for mainline freeway segments, then

$$
\mathrm{MFE}_{\mathrm{i}(\mathrm{FI})}=\mathrm{MFE}_{\mathrm{i}(\mathrm{TOT})} \times \frac{\mathrm{MFN}_{\mathrm{iA}(\mathrm{FI})}}{\mathrm{MFN}_{\mathrm{iA}(\mathrm{TOT})}}
$$

If the user inputs that crash data are not available for mainline freeway segments, then

$$
\mathrm{MFE}_{\mathrm{i}(\mathrm{FI})}=\mathrm{MFN}_{\mathrm{iA}(\mathrm{FI})}
$$

Step 35: Calculate the adjusted expected PDO crash frequency for each mainline freeway site i (i.e., $\mathrm{i}=1$ to $\mathrm{I}_{\mathrm{MF}}$ ) in the entire analysis period.

$$
\mathrm{MFE}_{\mathrm{i}(\mathrm{PDO})}=\mathrm{MFE}_{\mathrm{i}(\mathrm{TOT})}-\mathrm{MFE}_{\mathrm{i}(\mathrm{FI})}
$$


Step 36: Calculate the TOT crash frequency for each collision type (i.e., 1 through 13) for each mainline freeway site i (i.e., $\mathrm{i}=1$ to $\mathrm{I}_{\mathrm{MF}}$ ) in the entire analysis period.

$$
\mathrm{MFE}_{\mathrm{i}(\mathrm{CT} / \mathrm{TOT})}=\mathrm{MFE}_{\mathrm{i}(\mathrm{TOT})} \times \mathrm{P}_{(\mathrm{CT} / \mathrm{TOT})}
$$

Step 37: Calculate the FI crash frequency for each collision type (i.e., 1 through 13) for each mainline freeway site i (i.e., $\mathrm{i}=1$ to $\mathrm{I}_{\mathrm{MF}}$ ) in the entire analysis period.

$$
\mathrm{MFE}_{\mathrm{i}(\mathrm{CT} / \mathrm{FI})}=\mathrm{MFE}_{\mathrm{i}(\mathrm{FI})} \times \mathrm{P}_{(\mathrm{CT} / \mathrm{FI})}
$$

Step 38: Calculate the PDO crash frequency for each collision type (i.e., 1 through 13) for each mainline freeway site i (i.e., $\mathrm{i}=1$ to $\mathrm{I}_{\mathrm{MF}}$ ) in the entire analysis period.

$$
\mathrm{MFE}_{\mathrm{i}(\mathrm{CT} / \mathrm{PDO})}=\mathrm{MFE}_{\mathrm{i}(\mathrm{CT} / \mathrm{TOT})}-\mathrm{MFE}_{\mathrm{i}(\mathrm{CT} / \mathrm{FI})}
$$

Step 39: Calculate the number of TOT predicted crashes during the entire analysis period along all mainline freeway segments combined.

$$
\mathrm{MFE}_{(\mathrm{TOT})}=\sum_{\mathrm{i}=1}^{\mathrm{I}_{\mathrm{MF}}} \mathrm{MFE}_{\mathrm{i}(\mathrm{TOT})}
$$

Step 40: Calculate the number of FI predicted crashes during the entire analysis period along all mainline freeway segments combined.

$$
\operatorname{MFE}_{(\mathrm{FI})}=\sum_{\mathrm{i}=1}^{\mathrm{I}_{\mathrm{ME}}} \mathrm{MFE}_{\mathrm{i}(\mathrm{FI})}
$$

Step 41: Calculate the number of PDO predicted crashes during the entire analysis period along all mainline freeway segments combined.

$$
\mathrm{MFE}_{(\mathrm{PDO})}=\sum_{\mathrm{i}=1}^{\mathrm{I}_{\mathrm{MF}}} \mathrm{MFE}_{\mathrm{i}(\mathrm{PDO})}
$$

Step 42: Calculate the TOT crash frequency for each collision type (i.e., 1 through 13) during the entire analysis period along all mainline freeway segments combined.

$$
\operatorname{MFE}_{(\mathrm{CT} / \mathrm{TOT})}=\sum_{\mathrm{i}=1}^{\mathrm{I}_{\mathrm{MF}}} \mathrm{MFE}_{\mathrm{i}(\mathrm{CT} / \mathrm{TOT})}
$$

Step 43: Calculate the FI crash frequency for each collision type (i.e., 1 through 13) during the entire analysis period along all mainline freeway segments combined.

$$
\operatorname{MFE}_{(\mathrm{CT} / \mathrm{FI})}=\sum_{\mathrm{i}=1}^{\mathrm{I}_{\mathrm{MF}}} \mathrm{MFE}_{\mathrm{i}(\mathrm{CT} / \mathrm{FI})}
$$


Step 44: Calculate the PDO crash frequency for each collision type (i.e., 1 through 13) during the entire analysis period along all mainline freeway segments combined.

$$
\operatorname{MFE}_{(\mathrm{CT} / \mathrm{PDO})}=\sum_{\mathrm{i}=1}^{\mathrm{I}_{\mathrm{MF}}} \mathrm{MFE}_{\mathrm{i}(\mathrm{CT} / \mathrm{PDO})}
$$




\section{ALGORITHMS FOR RAMPS}

The calculations for ramps are performed in several stages. The first stage of calculations is performed for each individual ramp site input by the user on the Input Ramps worksheet, and the primary output are predicted crash frequencies for TOT, FI, and PDO crash severities for each year in the analysis period and for the entire analysis period. Stage 2 calculations again are performed for each individual ramp, and the primary purpose is to predict crash frequencies for the TOT crash severity level for each year in the crash period and for the entire crash period. If crash data are not provided for ramps, Stage 2 and 3 calculations are skipped, and the calculations proceed from Stage 1 to Stage 4 . Stage 3 begins with calculations for each individual ramp and culminates with calculations for all ramps combined. The primary purpose of Stage 3 is to adjust the expected TOT crash frequency for all ramp sites combined in the analysis period. Stage 4 performs calculations for each individual ramp, and the primary purpose is to calculate EB-adjusted expected crash frequencies for each site, combining predicted crash frequencies from SPFs and observed crash data. Details of each stage are provided below.

\section{Stage 1: Calculate Predicted Crash Frequencies for Analysis Period}

These calculations are performed for each individual ramp (i.e., row) input by the user on the Input Ramps worksheet. The primary purpose of this stage is predict crash frequencies for TOT, FI, and PDO crash severities for each year in the analysis period and sum for the entire analysis period. These predicted crash frequencies are computed solely from the SPFs. Warnings can also be generated for incorrect crash proportion violations and/or exceeding Max ADT values used in calculating the SPFs.

Step 1: Determine the SPF used in predicting the safety performance of each individual site i (i.e., $\mathrm{i}=1$ to $\mathrm{I}_{\mathrm{R}}$ ) for TOT crashes.

ISAT selects the appropriate SPF number for the site as a function of area type, ramp type, ramp configuration, and severity level. The values of the respective SPF coefficients and parameters are provided on the SPFs Ramps worksheet.

Step 2: Determine the SPF used in predicting the safety performance of each individual site i (i.e., $\mathrm{i}=1$ to $\mathrm{I}_{\mathrm{R}}$ ) for FI crashes.

ISAT selects the appropriate SPF number for the site as a function of area type, ramp type, ramp configuration, and severity level. The values of the respective SPF coefficients and parameters are provided on the SPFs Ramps worksheet.

Step 3: Determine the crash proportions to be used for TOT and FI crashes for each individual site i (i.e., $\mathrm{i}=1$ to $\mathrm{I}_{\mathrm{R}}$ ). 
ISAT selects the appropriate crash proportions for the site as a function of area type, severity level, ramp type, and ramp configuration. The values of the respective crash proportions are provided on the Distributions Ramps worksheet.

Note 3A: If the sum of the crash proportions for crash types 1 to 13 do not sum to exactly 1.0 , a distribution warning is provide on the output report for the site.

Step 4: Determine the number of years in the analysis period $(\mathrm{Y})$.

$$
\mathrm{Y}=\mathrm{EY}-\mathrm{BY}+1
$$

Note 4A: The maximum number of years in the analysis period permitted by the program is 20 (i.e., Max $Y=20$ ). The analysis period must be the same for all interchange elements included in the analysis.

Step 5: Determine the ramp ADT for each year (i.e., $\mathrm{y}=1,2, \ldots, \mathrm{Y}$ ) in the analysis period for each site i (i.e., $\mathrm{i}=1$ to $\mathrm{I}_{R}$ ).

$$
\mathrm{ADT}_{\mathrm{iy}}=\mathrm{ADT}_{\mathrm{i}} \times\left(1+\frac{\mathrm{GF}_{\mathrm{i}}}{100}\right)^{\mathrm{BY}-\mathrm{AY}_{\mathrm{i}}+\mathrm{y}-1}
$$

Step 6: Using the appropriate SPF model coefficients and parameters, compute the predicted TOT crash frequency for each year (i.e., $y=1,2, \ldots, Y$ ) in the analysis period for each site i (i.e., $\mathrm{i}=1$ to $\mathrm{I}_{\mathrm{R}}$ ).

$$
\mathrm{RN}_{\mathrm{iy}(\mathrm{TOT})}=\mathrm{C}_{(\mathrm{TOT})} \times \mathrm{e}^{\mathrm{a}} \times \mathrm{ADT}_{\mathrm{iy}}{ }^{\mathrm{b}} \times \mathrm{RL}_{\mathrm{i}}^{\mathrm{e}}
$$

Note 6A: The SPFs for ramps were developed for use within SafetyAnalyst. The SPFs predict crashes along the ramp proper.

Note 6B: The calibration factor $\left[\mathrm{C}_{(\mathrm{TOT})}\right]$ is provided in the Calibration Coefficients for Ramp SPFs table on the Input Calibration worksheet.

Step 7: Using the appropriate SPF model coefficients and parameters, compute the predicted FI crash frequency for each year (i.e., $y=1,2, \ldots, Y$ ) in the analysis period for each site i (i.e., $\mathrm{i}=1$ to $\mathrm{I}_{\mathrm{R}}$ ).

$$
\mathrm{RN}_{\mathrm{iy}(\mathrm{FI})}=\mathrm{C}_{(\mathrm{FI})} \times \mathrm{e}^{\mathrm{a}} \times \mathrm{ADT}_{\mathrm{iy}}{ }^{\mathrm{b}} \times \mathrm{RL}_{\mathrm{i}}^{\mathrm{e}}
$$

Note 7A: The SPFs for ramps were developed for use within SafetyAnalyst. The SPFs predict crashes along the ramp proper.

Note 7B: The calibration factor $\left[\mathrm{C}_{(\mathrm{FI})}\right]$ is provided in the Calibration Coefficients for Ramp SPFs table on the Input Calibration worksheet. 
Step 8: Compute the predicted PDO crash frequency for each year (i.e., $\mathrm{y}=1,2, \ldots, \mathrm{Y}$ ) in the analysis period for each site i (i.e., $\mathrm{i}=1$ to $\mathrm{I}_{\mathrm{R}}$ ).

$$
\mathrm{RN}_{\mathrm{iy}(\mathrm{PDO})}=\mathrm{RN}_{\mathrm{iy}(\mathrm{TOT})}-\mathrm{RN}_{\mathrm{iy}(\mathrm{FI})}
$$

Note 8A: If $\mathrm{RN}_{\mathrm{iy}(\mathrm{FI})}>\mathrm{RN}_{\mathrm{iy}(\mathrm{TOT})}$, set $\mathrm{RN}_{\mathrm{iy}(\mathrm{FI})}=\mathrm{RN}_{\mathrm{iy}(\mathrm{TOT})}$.

Step 9: Predict the TOT crash frequency for the entire analysis period for each site i (i.e., $\mathrm{i}=1$ to $\mathrm{I}_{\mathrm{R}}$.

$$
\mathrm{RN}_{\mathrm{iA}(\mathrm{TOT})}=\sum_{\mathrm{y}=1}^{\mathrm{Y}} \mathrm{RN}_{\mathrm{iy}(\mathrm{TOT})}
$$

Step 10: Predict the FI crash frequency for the entire analysis period for each site i (i.e., $\mathrm{i}=1$ to $\mathrm{I}_{\mathrm{R}}$ ).

$$
\mathrm{RN}_{\mathrm{iA}(\mathrm{FI})}=\sum_{\mathrm{y}=1}^{\mathrm{Y}} \mathrm{RN}_{\mathrm{iy}(\mathrm{FI})}
$$

Step 11: Predict the PDO crash frequency for the entire analysis period for each site i (i.e., $\mathrm{i}=1$ to $\left.\mathrm{I}_{\mathrm{R}}\right)$.

$$
\mathrm{RN}_{\mathrm{iA}(\mathrm{PDO})}=\mathrm{RN}_{\mathrm{iA}(\mathrm{TOT})}-\mathrm{RN}_{\mathrm{iA}(\mathrm{FI})}
$$

Step 12: Compare the max ADT for each site i (i.e., $\mathrm{i}=1$ to $\mathrm{I}_{\mathrm{R}}$ ) for each year in the analysis period (i.e., $y=1,2, \ldots, Y$ ) to the $130 \%$ of Max ADT parameter for the respective SPF.

If

$$
\operatorname{MAX}\left(2 \times \mathrm{ADT}_{\mathrm{iy}}\right) \geq 1.3 \times \operatorname{Max}_{\mathrm{ADT}}
$$

Then provide a violation warning for site i. Otherwise, no violation warning is necessary.

Note 12A: The value of the respective Max $\mathrm{ADT}_{\mathrm{SPF}}$ is provided on the SPFs Ramps worksheet.

\section{Stage 2: Calculate Predicted TOT Crash Frequencies for Crash Period}

These calculations are performed for each individual ramp (i.e., row) input by the user on the Input Ramps worksheet. The primary purpose of this stage is predict crash frequencies for the TOT crash severity level for each year in the crash period and sum for the entire crash period. These predicted crash frequencies are computed solely from the SPFs. This is the first stage for incorporating crash data into the EB calculations. These calculations are only necessary when crash data are provided for ramps on the Input-General worksheet. If crash data are not provided for ramps, proceed to step 29. 
Step 13: Determine the number of years in the crash data period $\left(\mathrm{Z}_{\mathrm{R}}\right)$.

$$
\mathrm{Z}_{\mathrm{R}}=\mathrm{EZ}_{\mathrm{R}}-\mathrm{BZ}_{\mathrm{R}}+1
$$

Note: The maximum allowable crash data period is 10 years (i.e., Max $Z_{R}=10$ ).

Step 14: Determine the ramp ADT for each year (i.e., $\mathrm{z}=1,2, \ldots, \mathrm{Z}_{\mathrm{R}}$ ) in the crash data period for each site i (i.e., $\mathrm{i}=1$ to $\mathrm{I}_{\mathrm{R}}$ ).

$$
\mathrm{ADT}_{\mathrm{i}_{\mathrm{R}}}=\mathrm{ADT}_{\mathrm{i}} \times\left(1+\frac{\mathrm{GF}_{\mathrm{i}}}{100}\right)^{\mathrm{BZ}_{\mathrm{R}}-\mathrm{AY}_{\mathrm{i}}+\mathrm{Z}_{\mathrm{R}}-1}
$$

Step 15: Using the appropriate SPF model coefficients and parameters, compute the predicted TOT crash frequency for each year (i.e., $\mathrm{z}=1,2, \ldots, \mathrm{Z}_{\mathrm{R}}$ ) in the crash data period for each site $\mathrm{i}$ (i.e., $\mathrm{i}=1$ to $\mathrm{I}_{\mathrm{R}}$ ).

$$
\mathrm{RN}_{\mathrm{iz}(\text { (TOT) }}=\mathrm{C}_{\text {(ТОT) }} \times \mathrm{e}^{\mathrm{a}} \times \mathrm{ADT}_{\mathrm{iz}_{\mathrm{R}}}{ }^{\mathrm{b}} \times \mathrm{RL}_{\mathrm{i}}{ }^{\mathrm{e}}
$$

Step 16: Predict the TOT crash frequency for the entire crash data period for each site i (i.e., $\mathrm{i}=$ 1 to $\left.\mathrm{I}_{\mathrm{R}}\right)$.

$$
\mathrm{RN}_{\mathrm{iC}(\mathrm{TOT})}=\sum_{\mathrm{z}=1}^{\mathrm{Z}_{\mathrm{R}}} \mathrm{RN} \mathrm{N}_{\mathrm{iz}(\mathrm{TOT})}
$$

\section{Stage 3: Calculate Expected TOT Crash Frequencies for Analysis Period for all Ramps Combined}

Steps 17 through 20 are performed for each individual ramp (i.e., row) input by the user on the Input Ramps worksheet. Beginning with Step 21, data for all ramps sites are combined to calculate an adjusted expected TOT accident frequency for all ramp sites in the analysis period.

Step 17: Sum the predicted TOT crash frequency for all ramp sites in the crash data period.

$$
\mathrm{RN}_{\mathrm{C}(\mathrm{TOT})}=\sum_{\mathrm{i}=1}^{\mathrm{I}_{\mathrm{R}}} \mathrm{RN}_{\mathrm{iC}(\mathrm{TOT})}
$$

Step 18: Sum the predicted TOT crash frequency squared times $\mathrm{k}$ for all sites in the crash data period.

$$
R N_{\text {Ck(TOT) }}=\sum_{i=1}^{I_{R}} R N_{i C(\mathrm{TOT})}{ }^{2} \times k_{i}
$$


Step 19: Sum the predicted TOT crash frequency squared times $(\mathrm{k})^{0.5}$ for all sites in the crash data period.

$$
R N_{\text {C0.5k(TOT) }}=\sum_{i=1}^{I_{R}} R N_{i C(T O T)} \times k_{i}^{0.5}
$$

Step 20: Sum the predicted TOT crash frequency times the ADT adjustment for all sites in the analysis period.

$$
\mathrm{RN}_{\mathrm{ADT}}=\sum_{\mathrm{i}=1}^{\mathrm{I}_{\mathrm{R}}} \mathrm{RN}_{\mathrm{iA}(\mathrm{TOT})} \times \frac{\frac{\mathrm{RN}_{\mathrm{iA}(\mathrm{TOT})}}{\mathrm{Y}}}{\frac{\mathrm{RN}_{\mathrm{iC}(\mathrm{TOT})}}{\mathrm{Z}_{\mathrm{R}}}}
$$

Step 21: Sum the predicted TOT crash frequency for all ramp sites in the analysis period.

$$
\mathrm{RN}_{\mathrm{A}(\mathrm{TOT})}=\sum_{\mathrm{i}=1}^{\mathrm{I}_{\mathrm{R}}} \mathrm{RN}_{\mathrm{iA}(\mathrm{TOT})}
$$

Step 22: Compute the weighting factor $\left(w_{0(\mathrm{R})}\right)$

$$
\mathrm{w}_{0(\mathrm{R})}=\frac{1}{1+\frac{\mathrm{RN}_{\mathrm{Ck}(\mathrm{TOT})}}{\mathrm{RN}_{\mathrm{C}(\mathrm{TOT})}}}
$$

Step 23: Estimate the expected value $\left(\mathrm{RE}_{0}\right)$

$$
\mathrm{RE}_{0}=\left(\mathrm{w}_{0(\mathrm{R})} \times \mathrm{RN}_{\mathrm{C}(\mathrm{TOT})}\right)+\left(1-\mathrm{w}_{0(\mathrm{R})}\right) \times \mathrm{O}_{\mathrm{R}}
$$

Step 24: Compute the weighting factor $\left(w_{1(\mathrm{R})}\right)$

$$
\mathrm{w}_{1(\mathrm{R})}=\frac{1}{1+\frac{\mathrm{RN}_{\mathrm{C} 0.5 \mathrm{k}(\mathrm{TOT})}}{\mathrm{RN}_{\mathrm{C}(\mathrm{TOT})}}}
$$

Step 25: Estimate the expected value $\left(\mathrm{RE}_{1}\right)$

$$
\mathrm{RE}_{1}=\left(\mathrm{w}_{1(\mathrm{R})} \times \mathrm{RN}_{\mathrm{C}(\mathrm{TOT})}\right)+\left(1-\mathrm{w}_{1(\mathrm{R})}\right) \times \mathrm{O}_{\mathrm{R}}
$$

Step 26: Estimate the expected value $\mathrm{RE}_{\mathrm{C}}$ for the crash data period.

$$
\mathrm{RE}=\frac{\mathrm{RE}_{0}+\mathrm{RE}_{1}}{2}
$$


Step 27: Calculate a combined ADT adjustment factor

$$
\mathrm{AF}_{\mathrm{ADT}(\mathrm{R})}=\frac{\mathrm{RN}_{\mathrm{ADT}}}{\mathrm{RN}_{\mathrm{A}(\mathrm{TOT})}}
$$

Step 28: Adjust the expected TOT crash frequency for all ramp sites combined in the analysis period.

$$
\mathrm{RE}_{\mathrm{ADT}}=\mathrm{RE} \times \mathrm{AF}_{\mathrm{ADT}(\mathrm{R})} \times \frac{\mathrm{Y}}{\mathrm{Z}_{\mathrm{R}}}
$$

\section{Stage 4: Calculate EB-Adjusted Expected Crash Frequencies for Analysis Period for Each} Ramp

Steps 29 through 34 are performed for each individual ramp (i.e., row) input by the user on the Input Ramps worksheet. The primary purpose is to calculate EB-adjusted expected crash frequencies for each site, combining predicted crash frequencies from SPFs and observed crash data. If observed crash data are not provided for ramps, the crash frequencies reflect predicted values rather than EB-adjusted expected values.

Step 29: Calculate the adjusted expected TOT crash frequency for each ramp site i (i.e., $\mathrm{i}=1$ to $I_{R}$ ) for the entire analysis period.

If the user inputs that crash data are available for ramps, then

$$
\mathrm{RE}_{\mathrm{i}(\mathrm{TOT})}=\frac{\mathrm{RN}_{\mathrm{ADT}} \times \mathrm{RN}_{\mathrm{iA}(\mathrm{TOT})}}{\mathrm{RN}_{\mathrm{A}(\mathrm{TOT})}}
$$

If the user inputs that crash data are not available for ramps, then

$$
\mathrm{RE}_{\mathrm{i}(\mathrm{TOT})}=\mathrm{RN}_{\mathrm{iA}(\mathrm{TOT})}
$$

Step 30: Calculate the adjusted expected FI crash frequency for each ramp site i (i.e., $\mathrm{i}=1$ to $\mathrm{I}_{\mathrm{R}}$ ) in the entire analysis period.

If the user inputs that crash data are available for ramps, then

$$
\mathrm{RE}_{\mathrm{i}(\mathrm{FI})}=\mathrm{RE}_{\mathrm{i}(\mathrm{TOT})} \times \frac{\mathrm{RN}_{\mathrm{iA}(\mathrm{FI})}}{\mathrm{RN}_{\mathrm{iA}(\mathrm{TOT})}}
$$

If the user inputs that crash data are not available for ramps, then

$$
\mathrm{RE}_{\mathrm{i}(\mathrm{FI})}=\mathrm{RN}_{\mathrm{iA}(\mathrm{FI})}
$$


Step 31: Calculate the adjusted expected PDO crash frequency for each ramp site i (i.e., $\mathrm{i}=1$ to $\left.I_{R}\right)$ in the entire analysis period.

$$
\mathrm{RE}_{\mathrm{i}(\mathrm{PDO})}=\mathrm{RE}_{\mathrm{i}(\mathrm{TOT})}-\mathrm{RE}_{\mathrm{i}(\mathrm{PI})}
$$

Step 32: Calculate the TOT crash frequency by collision type for each ramp site i (i.e., $\mathrm{i}=1$ to $\left.I_{R}\right)$ in the entire analysis period.

$$
\mathrm{RE}_{\mathrm{i}(\mathrm{CT} / \mathrm{TOT})}=\mathrm{RE}_{\mathrm{i}(\mathrm{TOT})} \times \mathrm{P}_{(\mathrm{CT} / \mathrm{TOT})}
$$

Step 33: Calculate the FI crash frequency by collision type for each ramp site i (i.e., $\mathrm{i}=1$ to $\mathrm{I}_{\mathrm{R}}$ ) in the entire analysis period.

$$
\mathrm{RE}_{\mathrm{i}(\mathrm{CT} / \mathrm{FI})}=\mathrm{RE}_{\mathrm{i}(\mathrm{FI})} \times \mathrm{P}_{(\mathrm{CT} / \mathrm{FI})}
$$

Step 34: Calculate the PDO crash frequency by collision type for each ramp site i (i.e., $\mathrm{i}=1$ to $\left.I_{R}\right)$ in the entire analysis period.

$$
\mathrm{RE}_{\mathrm{i}(\mathrm{CT} / \mathrm{PDO})}=\mathrm{RE}_{\mathrm{i}(\mathrm{CT} / \mathrm{TOT})}-\mathrm{RE}_{\mathrm{i}(\mathrm{CT} / \mathrm{FI})}
$$

Step 35: Calculate the number of TOT predicted crashes during the entire analysis period along all ramps combined.

$$
\mathrm{RE}_{\text {(ТОT) }}=\sum_{\mathrm{i}=1}^{\mathrm{I}_{\mathrm{R}}} \mathrm{RE}_{\mathrm{i}(\mathrm{TOT})}
$$

Step 36: Calculate the number of FI predicted crashes during the entire analysis period along all ramps combined.

$$
\mathrm{RE}_{(\mathrm{FI})}=\sum_{\mathrm{i}=1}^{\mathrm{I}_{\mathrm{R}}} \mathrm{RE}_{\mathrm{i}(\mathrm{FI})}
$$

Step 37: Calculate the number of PDO predicted crashes during the entire analysis period along all ramps combined.

$$
\mathrm{RE}_{(\mathrm{PDO})}=\sum_{\mathrm{i}=1}^{\mathrm{I}_{\mathrm{R}}} \mathrm{RE}_{\mathrm{i}(\mathrm{PDO})}
$$


Step 38: Calculate the TOT crash frequency for each collision type (i.e., 1 through 13) during the entire analysis period along all ramps combined.

$$
\mathrm{RE}_{(\mathrm{CT} / \mathrm{TOT})}=\sum_{\mathrm{i}=1}^{\mathrm{I}_{\mathrm{R}}} \mathrm{RE}_{\mathrm{i}(\mathrm{CT} / \mathrm{TOT})}
$$

Step 39: Calculate the FI crash frequency for each collision type (i.e., 1 through 13) during the entire analysis period along all ramps combined.

$$
\mathrm{RE}_{(\mathrm{CT} / \mathrm{FI})}=\sum_{\mathrm{i}=1}^{\mathrm{I}_{\mathrm{R}}} \mathrm{RE}_{\mathrm{i}(\mathrm{CT} / \mathrm{FI})}
$$

Step 40: Calculate the PDO crash frequency for each collision type (i.e., 1 through 13) during the entire analysis period along all ramps combined.

$$
\mathrm{RE}_{(\mathrm{CT} / \mathrm{PDO})}=\sum_{\mathrm{i}=1}^{\mathrm{I}_{\mathrm{R}}} \mathrm{RE}_{\mathrm{i}(\mathrm{CT} / \mathrm{PDO})}
$$




\section{ALGORITHMS FOR CROSSROAD RAMP TERMINALS AND INTERSECTIONS}

The calculations for crossroad ramp terminals and intersections are performed in several stages. The first stage of calculations is performed for each individual crossroad ramp terminal or intersection site input by the user on the Input Ramp Terminals worksheet, and the primary output are predicted crash frequencies for TOT, FI, and PDO crash severities for each year in the analysis period and for the entire analysis period. Stage 2 calculations again are performed for each individual ramp terminal or intersection, and the primary purpose is to predict crash frequencies for the TOT crash severity level for each year in the crash period and for the entire crash period. If crash data are not provided for crossroad ramp terminals and intersections, Stage 2 and 3 calculations are skipped, and the calculations proceed from Stage 1 to Stage 4. Stage 3 begins with calculations for each individual crossroad ramp terminal and intersection and culminates with calculations for all ramp terminals and intersections combined. The primary purpose of Stage 3 is to adjust the expected TOT crash frequency for all ramp terminal and intersection sites combined in the analysis period. Stage 4 performs calculations for each individual crossroad ramp and intersection, and the primary purpose is to calculate EB-adjusted expected crash frequencies for each site, combining predicted crash frequencies from SPFs and observed crash data. Details of each stage are provided below.

\section{Stage 1: Calculate Predicted Crash Frequencies for Analysis Period}

These calculations are performed for each individual crossroad ramp terminal and intersection (i.e., row) input by the user on the Input Ramp Terminals worksheet. The primary purpose of this stage is predict crash frequencies for TOT, FI, and PDO crash severities for each year in the analysis period and sum for the entire analysis period. These predicted crash frequencies are computed solely from the SPFs. Warnings can also be generated for incorrect crash proportion violations and/or exceeding Max ADT values used in calculating the SPFs.

Step 1: Determine the SPF used in predicting the safety performance of each individual site i (i.e., $\mathrm{i}=1$ to $\mathrm{I}_{\mathrm{RT}}$ ) for TOT crashes.

ISAT selects the appropriate SPF number for the site as a function of area type, type of traffic control, number of legs, and severity level. The values of the respective SPF coefficients and parameters are provided on the SPFs Ramp Terminals worksheet.

Step 2: Determine the SPF used in predicting the safety performance of each individual site i (i.e., $\mathrm{i}=1$ to $\mathrm{I}_{\mathrm{RT}}$ ) for FI crashes.

ISAT selects the appropriate SPF number for the site as a function of area type, type of traffic control, number of legs, and severity level. The values of the respective SPF coefficients and parameters are provided on the SPFs Ramp Terminals worksheet. 
Step 3: Determine the crash proportions to be used for TOT and FI crashes for each individual site i (i.e., $\mathrm{i}=1$ to $\mathrm{I}_{\mathrm{RT}}$ ).

ISAT selects the appropriate crash proportions for the site as a function of area type, severity level, type of traffic control, and number of legs. The values of the respective crash proportions are provided on the Distributions Ramp Terminals worksheet.

Note 3A: If the sum of the crash proportions for crash types 1 to 13 do not sum to exactly 1.0, a distribution warning is provide on the output report for the site.

Step 4: Determine the number of years in the analysis period (Y).

$$
\mathrm{Y}=\mathrm{EY}-\mathrm{BY}+1
$$

Note 4A: The maximum number of years in the analysis period is 20 (i.e., Max $Y=20$ ). The analysis period must be the same for all interchange elements included in the analysis.

Step 5: Determine the ADT for the major rd crossroad for each year (i.e., $\mathrm{y}=1,2, \ldots, \mathrm{Y}$ ) in the analysis period for each site i (i.e., $\mathrm{i}=1$ to $\mathrm{I}_{\mathrm{RT}}$ ).

$$
A D T_{i y(\text { major } r d)}=A D T_{i(\text { major } r d)} \times\left(1+\frac{G F_{i}}{100}\right)^{B Y-A Y_{i}+y-1}
$$

Step 6: Determine the ADT for the off-ramp (or minor rd) for each year (i.e., $\mathrm{y}=1,2, \ldots, \mathrm{Y}$ ) in the analysis period for each site i (i.e., $\mathrm{i}=1$ to $\mathrm{I}_{\mathrm{RT}}$ ).

$$
\mathrm{ADT}_{\mathrm{iy}(\text { off-ramp) }}=\mathrm{ADT}_{\mathrm{i}(\text { off-ramp })} \times\left(1+\frac{\mathrm{GF}_{\mathrm{i}}}{100}\right)^{\mathrm{BY}-\mathrm{AY}_{\mathrm{i}}+\mathrm{y}-1}
$$

Step 7: Using the appropriate SPF model coefficients and parameters, compute the predicted TOT crash frequency for each year (i.e., $\mathrm{y}=1,2, \ldots, \mathrm{Y}$ ) in the analysis period for each site i (i.e., $\mathrm{i}=1$ to $\mathrm{I}_{\mathrm{RT}}$ ).

If the site is a conventional intersection (CI), then

$$
R T N_{\text {iy (TOT) }}=C_{(\text {TOT })} \times e^{a} \times\left(2 \times A D T_{\text {iy(major rd })}\right)^{b} \times\left(2 \times A D T_{\text {iy (off -ramp }}\right)^{c}
$$

If the site is a ramp terminal (RT), then

$$
R T N_{i y(T O T)}=C_{(T O T)} \times e^{a} \times\left(2 \times A D T_{i y(\text { major rd })}\right)^{b} \times\left(A D T_{i y(\text { off }- \text { ramp }}\right)^{c}
$$


Note 7A: The SPFs for crossroad ramp terminals and intersections were developed for use within SafetyAnalyst. Because the SPFs were developed using data from conventional intersections only, the ADTs are adjusted accordingly to account for the difference in directional usage between conventional intersections and intersections at crossroad ramp terminals.

Note 7B: The calibration factor $\left[\mathrm{C}_{(\mathrm{TOT})}\right]$ is provided in the Calibration Coefficients for Crossroad Ramp Terminal and Intersection SPFs table on the Input Calibration worksheet.

Note 7C: If the site is a conventional intersection, the $\mathrm{ADT}_{\text {(off-ramp) }}$ will be the ADT of the minor-rd.

Step 8: Using the appropriate SPF model coefficients and parameters, compute the predicted FI crash frequency for each year (i.e., $\mathrm{y}=1,2, \ldots, \mathrm{Y}$ ) in the analysis period for each site i (i.e., $\mathrm{i}=1$ to $\left.\mathrm{I}_{\mathrm{RT}}\right)$.

If the site is a conventional intersection (CI), then

$$
R T N_{i y(F I)}=C_{(F I)} \times e^{a} \times\left(2 \times A D T_{i y(\text { major } r d)}\right)^{b} \times\left(2 \times A D T_{i y(\text { off -ramp })}\right)^{c}
$$

If the site is a ramp terminal (RT), then

$$
R T N_{i y(F I)}=C_{(F I)} \times e^{a} \times\left(2 \times A D T_{i y(\text { major rd })}\right)^{b} \times\left(A D T_{i y(\text { off }- \text { ramp })}\right)^{c}
$$

Note 8A: The SPFs for crossroad ramp terminals and intersections were developed for use within SafetyAnalyst. Because the SPFs were developed using data from conventional intersections only, the ADTs are adjusted accordingly to account for the difference in directional usage between conventional intersections and intersections at crossroad ramp terminals.

Note 8B: The calibration factor $\left[\mathrm{C}_{(\mathrm{FI})}\right]$ is provided in the Calibration Coefficients for Crossroad Ramp Terminal and Intersection SPFs table on the Input Calibration worksheet.

Note 8C: If the site is a conventional intersection, the $\mathrm{ADT}_{\text {(off-ramp) }}$ will be the $\mathrm{ADT}$ of the minor rd.

Step 9: Compute the predicted PDO crash frequency for each year (i.e., $\mathrm{y}=1,2, \ldots, \mathrm{Y}$ ) in the analysis period for each site i (i.e., $\mathrm{i}=1$ to $\mathrm{I}_{\mathrm{RT}}$ ).

$$
\mathrm{RTN}_{\mathrm{iy}(\mathrm{PDO})}=\mathrm{RTN}_{\mathrm{iy}(\mathrm{TOT})}-\mathrm{RTN}_{\mathrm{iy}(\mathrm{FI})}
$$

Note 9A: If $\mathrm{RTN}_{\mathrm{iy}(\mathrm{FI})}>\mathrm{RTN}_{\mathrm{iy}(\mathrm{TOT})}$, set $\mathrm{RTN}_{\mathrm{iy}(\mathrm{FI})}=\mathrm{RTN}_{\mathrm{iy}(\mathrm{TOT})}$.

Step 10: Predict the TOT crash frequency for the entire analysis period for each site i (i.e., $\mathrm{i}=1$ to $\mathrm{I}_{\mathrm{RT}}$ ).

$$
\mathrm{RTN}_{\mathrm{iA(TOT)}}=\sum_{\mathrm{y}=1}^{\mathrm{Y}} \mathrm{RTN}_{\mathrm{iy}(\mathrm{TOT})}
$$


Step 11: Predict the FI crash frequency for the entire analysis period for each site i (i.e., $\mathrm{i}=1$ to $\mathrm{I}_{\mathrm{RT}}$ ).

$$
\mathrm{RTN}_{\mathrm{iA}(\mathrm{FI})}=\sum_{\mathrm{y}=1}^{\mathrm{Y}} \mathrm{RTN}_{\mathrm{iy}(\mathrm{FI})}
$$

Step 12: Predict the PDO crash frequency for the entire analysis period for each site i (i.e., $\mathrm{i}=1$ to $\mathrm{I}_{\mathrm{RT}}$ ).

$$
\mathrm{RTN}_{\mathrm{iA}(\mathrm{PDO})}=\mathrm{RTN}_{\mathrm{iA}(\mathrm{TOT})}-\mathrm{RTN}_{\mathrm{iA}(\mathrm{FI})}
$$

Step 13: Compare the max ADT from the major rd for each site i (i.e., $\mathrm{i}=1$ to $\mathrm{I}_{\mathrm{RT}}$ ) for each year

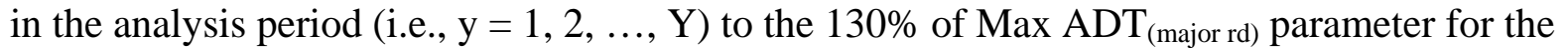
respective SPF.

If

$$
\operatorname{MAX}\left(2 \times A D T_{i y(m a j o r ~ r d)}\right) \geq 1.3 \times \operatorname{Max} A D T_{S P F(\text { major } r d)}
$$

then provide a violation warning for site i. Otherwise, no violation warning is necessary.

Note 13A: The value of the respective Max $\mathrm{ADT}_{\mathrm{SPF} \text { (major rd) }}$ is provided on the SPFs Ramp Terminals worksheet.

Step 14: Compare the max ADT from the off-ramp (or minor rd) for each site i (i.e., $\mathrm{i}=1$ to $\mathrm{I}_{\mathrm{RT}}$ ) for each year in the analysis period (i.e., $\mathrm{y}=1,2, \ldots, \mathrm{Y}$ ) to the $130 \%$ of $\mathrm{Max}_{\mathrm{ADT}} \mathrm{T}_{\text {(off-ramp) }}$ parameter for the respective SPF.

If

$$
\operatorname{MAX}\left(2 \times \mathrm{ADT}_{\text {iy (off-ramp) }}\right) \geq 1.3 \times \operatorname{Max} \mathrm{ADT}_{\mathrm{SPF}(\text { off-ramp) }}
$$

then provide a violation warning for site i. Otherwise, no violation warning is necessary.

Note 14A: The value of the respective Max $\mathrm{ADT}_{\mathrm{SPF}(\text { off-ramp) }}$ is provided on the SPFs Ramp Terminals worksheet. 


\section{Stage 2: Calculate Predicted TOT Crash Frequencies for Crash Period}

These calculations are performed for each individual crossroad ramp terminal and intersection (i.e., row) input by the user on the Input Ramp Terminals worksheet. The primary purpose of this stage is predict crash frequencies for the TOT crash severity level for each year in the crash period and sum for the entire crash period. These predicted crash frequencies are computed solely from the SPFs. This is the first stage for incorporating crash data into the EB calculations. These calculations are only necessary when crash data are provided for ramps on the InputGeneral worksheet. If crash data are not provided for crossroad ramp terminals and intersections, proceed to step 32.

Step 15: Determine the number of years in the crash data period $\left(\mathrm{Z}_{\mathrm{RT}}\right)$.

$$
\mathrm{Z}_{\mathrm{RT}}=\mathrm{EZ}_{\mathrm{RT}}-\mathrm{BZ}_{\mathrm{RT}}+1
$$

Note: The maximum allowable crash data period is 10 years (i.e., Max $\mathrm{Z}_{\mathrm{RT}}=10$ ).

Step 16: Determine the ADT for the major rd crossroad for each year (i.e., $\mathrm{z}=1,2, \ldots, \mathrm{Z}_{\mathrm{RT}}$ ) in the crash data period for each site i (i.e., $\mathrm{i}=1$ to $\mathrm{I}_{\mathrm{RT}}$ ).

$$
A D T_{i_{R T}(\text { major rd })}=A D T_{i(\text { major rd })} \times\left(1+\frac{G F_{i}}{100}\right)^{B Z_{R T}-A Y_{i}+Z_{R T}-1}
$$

Step 17: Determine the ADT for the off-ramp (or minor rd) for each year (i.e., $\mathrm{z}=1,2, \ldots, \mathrm{Z}_{\mathrm{RT}}$ ) in the crash data period for each site i (i.e., $\mathrm{i}=1$ to $\mathrm{I}_{\mathrm{RT}}$ ).

$$
\mathrm{ADT}_{\mathrm{iz}_{\mathrm{RT}} \text { (off-ramp) }}=\mathrm{ADT}_{\mathrm{i}(\text { off-ramp) }} \times\left(1+\frac{\mathrm{GF}_{\mathrm{i}}}{100}\right)^{\mathrm{BZ}_{\mathrm{RT}}-\mathrm{AY}_{\mathrm{i}}+\mathrm{Z}_{\mathrm{RT}}-1}
$$

Step 18: Using the appropriate SPF model coefficients and parameters, compute the predicted TOT crash frequency for each year (i.e., $\mathrm{z}=1,2, \ldots, \mathrm{Z}_{\mathrm{RT}}$ ) in the crash data period for each site $\mathrm{i}$ (i.e., $\mathrm{i}=1$ to $\mathrm{I}_{\mathrm{RT}}$ ).

If the site is a conventional intersection (CI), then

$$
R T N_{i z(T O T)}=C_{(\text {TOT })} \times e^{a} \times\left(2 \times A D T_{i y(\text { major rd })}\right)^{b} \times\left(2 \times A D T_{i y(\text { off-ramp }}\right)^{c}
$$

If the site is a ramp terminal (RT), then

$$
R T N_{i z(T O T)}=C_{(\text {TOT })} \times e^{a} \times\left(2 \times A D T_{i y(\text { major } r d)}\right)^{b} \times\left(A D T_{i y(\text { off }- \text { ramp }}\right)^{c}
$$


Step 19: Predict the TOT crash frequency for the entire crash data period for each site i (i.e., $\mathrm{i}=$ 1 to $\mathrm{I}_{\mathrm{RT}}$ ).

$$
\operatorname{RTN}_{\mathrm{iC}(\mathrm{TOT})}=\sum_{\mathrm{z}=1}^{Z_{\mathrm{RT}}} \mathrm{RTN}_{\mathrm{iz}(\mathrm{TOT})}
$$

\section{Stage 3: Calculate Expected TOT Crash Frequencies for Analysis Period for all Crossroad Ramp Terminals and Intersections Combined}

Steps 20 through 23 are performed for each individual crossroad ramp and intersection (i.e., row) input by the user on the Input Ramp Terminals worksheet. Beginning with Step 24, data for all crossroad ramp terminal and intersection sites are combined to calculate an adjusted expected TOT accident frequency for all ramp terminal and intersection sites in the analysis period.

Step 20: Sum the predicted TOT crash frequency for all ramp terminal and intersection sites in the crash data period.

$$
\mathrm{RTN}_{\mathrm{C}(\mathrm{TOT})}=\sum_{\mathrm{i}=1}^{\mathrm{I}_{\mathrm{RT}}} \mathrm{RTN}_{\mathrm{iC}(\mathrm{TOT})}
$$

Step 21: Sum the predicted TOT crash frequency squared times $k$ for all sites in the crash data period.

$$
R T N_{C k(T O T)}=\sum_{i=1}^{I_{R T}} R T N_{i C(T O T)}^{2} \times k_{i}
$$

Step 22: Sum the predicted TOT crash frequency squared times $(\mathrm{k})^{0.5}$ for all sites in the crash data period.

$$
R T N_{C 0.5 k(T O T)}=\sum_{i=1}^{I_{R T}} R T N_{i C(T O T)} \times k_{i}^{0.5}
$$

Step 23: Sum the predicted TOT crash frequency times the ADT adjustment for all sites in the analysis period.

$$
\mathrm{RTN}_{\mathrm{ADT}}=\sum_{\mathrm{i}=1}^{\mathrm{I}_{\mathrm{RT}}} \mathrm{RTN}_{\mathrm{iA}(\mathrm{TOT})} \times \frac{\frac{\mathrm{RTN}_{\mathrm{iA}(\mathrm{TOT})}}{\mathrm{Y}}}{\frac{\mathrm{RTN}_{\mathrm{iC}(\mathrm{TOT})}}{\mathrm{Z}_{\mathrm{RT}}}}
$$

Step 24: Sum the predicted TOT crash frequency for all ramp terminal and intersection sites in the analysis period.

$$
\operatorname{RTN}_{\mathrm{A}(\mathrm{TOT})}=\sum_{\mathrm{i}=1}^{\mathrm{I}_{\mathrm{RT}}} \mathrm{RTN}_{\mathrm{iA}(\mathrm{TOT})}
$$


Step 25: Compute the weighting factor $\left(w_{0(\mathrm{RT})}\right)$

$$
\mathrm{w}_{0(\mathrm{RT})}=\frac{1}{1+\frac{\mathrm{RTN}_{\mathrm{Ck}(\mathrm{TOT})}}{\mathrm{RTN}_{\mathrm{C}(\mathrm{TOT})}}}
$$

Step 26: Estimate the expected value $\left(\mathrm{RTE}_{0}\right)$

$$
\mathrm{RTE}_{0}=\left(\mathrm{w}_{0(\mathrm{RT})} \times \mathrm{RTN}_{\mathrm{C}(\mathrm{TOT})}\right)+\left(1-\mathrm{w}_{\mathrm{O(RT)}}\right) \times \mathrm{O}_{\mathrm{RT}}
$$

Step 27: Compute the weighting factor $\left(w_{1(\mathrm{RT})}\right)$

$$
\mathrm{w}_{1(\mathrm{RT})}=\frac{1}{1+\frac{\mathrm{RTN}_{\mathrm{C} 0.5 \mathrm{k}(\mathrm{TOT})}}{\mathrm{RTN}_{\mathrm{C}(\mathrm{TOT})}}}
$$

Step 28: Estimate the expected value $\left(\mathrm{RTE}_{1}\right)$

$$
\mathrm{RTE}_{1}=\left(\mathrm{w}_{1(\mathrm{RT})} \times \mathrm{RTN}_{\mathrm{C}(\mathrm{TOT})}\right)+\left(1-\mathrm{w}_{1(\mathrm{RT})}\right) \times \mathrm{O}_{\mathrm{RT}}
$$

Step 29: Estimate the expected value RTE for the crash data period.

$$
\mathrm{RTE}=\frac{\mathrm{RTE}_{0}+\mathrm{RTE}_{1}}{2}
$$

Step 30: Calculate a combined ADT adjustment factor

$$
\mathrm{AF}_{\mathrm{ADT}(\mathrm{RT})}=\frac{\mathrm{RTN}_{\mathrm{ADT}}}{\mathrm{RTN}_{\mathrm{A}(\mathrm{TOT})}}
$$

Step 31: Adjust the expected TOT crash frequency for all ramp terminal and intersection sites combined in the analysis period.

$$
\mathrm{RTE}_{\mathrm{ADT}}=\mathrm{RTE} \times \mathrm{AF}_{\mathrm{ADT}(\mathrm{RT})} \times \frac{\mathrm{Y}}{\mathrm{Z}_{\mathrm{RT}}}
$$


Stage 4: Calculate EB-Adjusted Expected Crash Frequencies for Analysis Period for Each Crossroad Ramp Terminal and Intersection

Steps 32 through 37 are performed for each individual crossroad ramp and intersection (i.e., row) input by the user on the Input Ramp Terminals worksheet. The primary purpose is to calculate EB-adjusted expected crash frequencies for each site, combining predicted crash frequencies from SPFs and observed crash data. If observed crash data are not provided for crossroad ramp terminals and intersections, the crash frequencies reflect predicted values rather than EB-adjusted expected values.

Step 32: Calculate the adjusted expected TOT crash frequency for each crossroad ramp terminal and intersection site i (i.e., $\mathrm{i}=1$ to $\mathrm{I}_{\mathrm{RT}}$ ) for the entire analysis period.

If the user inputs that crash data are available for crossroad ramp terminals and intersections, then

$$
\mathrm{RTE}_{\mathrm{i}(\mathrm{TOT})}=\frac{\mathrm{RTN}_{\mathrm{ADT}} \times \mathrm{RTN}_{\mathrm{iA(TOT)}}}{\mathrm{RTN}_{\mathrm{A}(\mathrm{TOT})}}
$$

If the user inputs that crash data are not available for crossroad ramp terminals and intersections, then

$$
\mathrm{RTE}_{\mathrm{i}(\mathrm{TOT})}=\mathrm{RTN}_{\mathrm{iA}(\mathrm{TOT})}
$$

Step 33: Calculate the adjusted expected FI crash frequency for each crossroad ramp terminal and intersection site i (i.e., $\mathrm{i}=1$ to $\mathrm{I}_{\mathrm{RT}}$ ) in the entire analysis period.

If the user inputs that crash data are available for crossroad ramp terminals and intersections, then

$$
\mathrm{RTE}_{\mathrm{i}(\mathrm{FI})}=\mathrm{RTE}_{\mathrm{i}(\mathrm{TOT})} \times \frac{\mathrm{RTN}_{\mathrm{iA}(\mathrm{FI})}}{\mathrm{RTN}_{\mathrm{iA}(\mathrm{TOT})}}
$$

If the user inputs that crash data are not available for crossroad ramp terminals and intersections, then

$$
\mathrm{RTE}_{\mathrm{i}(\mathrm{FI})}=\mathrm{RTN}_{\mathrm{iA}(\mathrm{FI})}
$$

Step 34: Calculate the adjusted expected PDO crash frequency for each crossroad ramp terminal and intersection site $\mathrm{i}$ (i.e., $\mathrm{i}=1$ to $\mathrm{I}_{\mathrm{RT}}$ ) in the entire analysis period.

$$
\mathrm{RTE}_{\mathrm{i}(\mathrm{PDO})}=\mathrm{RTE}_{\mathrm{i}(\mathrm{TOT})}-\mathrm{RTE}_{\mathrm{i}(\mathrm{FI})}
$$


Step 35: Calculate the TOT crash frequency by collision type for each crossroad ramp terminal and intersection site i (i.e., $\mathrm{i}=1$ to $\mathrm{I}_{\mathrm{RT}}$ ) in the entire analysis period.

$$
\mathrm{RTE}_{\mathrm{i}(\mathrm{CT} / \mathrm{TOT})}=\mathrm{RTE}_{\mathrm{i}(\mathrm{TOT})} \times \mathrm{P}_{(\mathrm{CT} / \mathrm{TOT})}
$$

Step 36: Calculate the FI crash frequency by collision type for each crossroad ramp terminal and intersection site i (i.e., $\mathrm{i}=1$ to $\mathrm{I}_{\mathrm{RT}}$ ) in the entire analysis period.

$$
\mathrm{RTE}_{\mathrm{i}(\mathrm{CT} / \mathrm{FI})}=\mathrm{RTE}_{\mathrm{i}(\mathrm{FI})} \times \mathrm{P}_{(\mathrm{CT} / \mathrm{FI})}
$$

Step 37: Calculate the PDO crash frequency by collision type for each crossroad ramp terminal and intersection site i (i.e., $\mathrm{i}=1$ to $\mathrm{I}_{\mathrm{RT}}$ ) in the entire analysis period.

$$
\mathrm{RTE}_{\mathrm{i}(\mathrm{CT} / \mathrm{PDO})}=\mathrm{RTE}_{\mathrm{i}(\mathrm{CT} / \mathrm{TOT})}-\mathrm{RTE}_{\mathrm{i}(\mathrm{CT} / \mathrm{FI})}
$$

Step 38: Calculate the number of TOT predicted crashes during the entire analysis period at all crossroad ramp terminals and intersections combined.

$$
\mathrm{RTE}_{(\mathrm{TOT})}=\sum_{\mathrm{i}=1}^{\mathrm{I}_{\mathrm{RT}}} \mathrm{RTE}_{\mathrm{i}(\mathrm{TOT})}
$$

Step 39: Calculate the number of FI predicted crashes during the entire analysis period at all crossroad ramp terminals and intersections combined.

$$
\mathrm{RTE}_{(\mathrm{FI})}=\sum_{\mathrm{i}=1}^{\mathrm{I}_{\mathrm{RT}}} \mathrm{RTE}_{\mathrm{i}(\mathrm{Fi})}
$$

Step 40: Calculate the number of PDO predicted crashes during the entire analysis period at all crossroad ramp terminals and intersections combined.

$$
\mathrm{RTE}_{(\mathrm{PDO})}=\sum_{\mathrm{i}=1}^{\mathrm{I}_{\mathrm{RT}}} \mathrm{RTE}_{\mathrm{i}(\mathrm{PDO})}
$$

Step 41: Calculate the TOT crash frequency for each collision type (i.e., 1 through 13) during the entire analysis period at all crossroad ramp terminals and intersections combined.

$$
\operatorname{RTE}_{(\mathrm{CT} / \mathrm{TOT})}=\sum_{\mathrm{i}=1}^{\mathrm{I}_{\mathrm{RT}}} \mathrm{RTE}_{\mathrm{i}(\mathrm{CT} / \mathrm{TOT})}
$$

Step 42: Calculate the FI crash frequency for each collision type (i.e., 1 through 13) during the entire analysis period at all crossroad ramp terminals and intersections combined.

$$
\operatorname{RTE}_{(\mathrm{CT} / \mathrm{FI})}=\sum_{\mathrm{i}=1}^{\mathrm{I}_{\mathrm{RT}}} \mathrm{RTE}_{\mathrm{i}(\mathrm{CT} / \mathrm{FI})}
$$


Step 43: Calculate the PDO crash frequency for each collision type (i.e., 1 through 13) during the entire analysis period at all crossroad ramp terminals and intersections combined.

$$
\operatorname{RTE}_{(\mathrm{CT} / \mathrm{PDO})}=\sum_{\mathrm{i}=1}^{\mathrm{I}_{\mathrm{RT}}} \mathrm{RTE}_{\mathrm{i}(\mathrm{CT} / \mathrm{PDO})}
$$




\section{ALGORITHMS FOR CROSSROAD ROADWAY SEGMENTS}

The calculations for crossroad roadway segments are performed in several stages. The first stage of calculations is performed for each individual crossroad roadway segment site input by the user on the Input Crossroad Segments worksheet, and the primary output are predicted crash frequencies for TOT, FI, and PDO crash severities for each year in the analysis period and for the entire analysis period. Stage 2 calculations, again, are performed for each individual crossroad roadway segment, and the primary purpose is to predict crash frequencies for the TOT crash severity level for each year in the crash period and for the entire crash period. If crash data are not provided for crossroad roadway segments, Stage 2 and 3 calculations are skipped, and the calculations proceed from Stage 1 to Stage 4. Stage 3 begins with calculations for each individual crossroad roadway segment and culminates with calculations for all crossroad roadway segments combined. The primary purpose of Stage 3 is to adjust the expected TOT crash frequency for all crossroad roadway segment sites combined in the analysis period. Stage 4 performs calculations for each individual crossroad roadway segment, and the primary purpose is to calculate EB-adjusted expected crash frequencies for each site, combining predicted crash frequencies from SPFs and observed crash data. Details of each stage are provided below.

\section{Stage 1: Calculate Predicted Crash Frequencies for Analysis Period}

These calculations are performed for each individual crossroad roadway segment (i.e., row) input by the user on the Input Crossroad Segments worksheet. The primary purpose of this stage is predict crash frequencies for TOT, FI, and PDO crash severities for each year in the analysis period and sum for the entire analysis period. These predicted crash frequencies are computed solely from the SPFs. Warnings can also be generated for incorrect crash proportion violations and/or exceeding Max ADT values used in calculating the SPFs.

Step 1: Determine the SPF used in predicting the safety performance of each individual site i (i.e., $\mathrm{i}=1$ to $\mathrm{I}_{\mathrm{RS}}$ ) for TOT crashes.

ISAT selects the appropriate SPF number for the site as a function of area type, number of through lanes, median type, and severity level. The values of the respective SPF coefficients and parameters are provided on the SPFs Crossroad Segments worksheet.

Step 2: Determine the SPF used in predicting the safety performance of each individual site i (i.e., $\mathrm{i}=1$ to $\mathrm{I}_{\mathrm{RS}}$ ) for FI crashes.

ISAT selects the appropriate SPF number for the site as a function of area type, number of through lanes, median type, and severity level. The values of the respective SPF coefficients and parameters are provided on the SPFs Crossroad Segments worksheet.

Step 3: Determine the crash proportions to be used for TOT and FI crashes for each individual site i (i.e., $\mathrm{i}=1$ to $\mathrm{I}_{\mathrm{RS}}$ ). 
ISAT selects the appropriate crash proportions for the site as a function of area type, severity level, number of through lanes, and median type. The values of the respective crash proportions are provided on the Distributions Crossroad Segments worksheet.

Note 3A: If the sum of the crash proportions for crash types 1 to 13 do not sum to exactly 1.0, a distribution warning is provide on the output report for the site.

Step 4: Determine the number of years in the analysis period $(\mathrm{Y})$.

$$
\mathrm{Y}=\mathrm{EY}-\mathrm{BY}+1
$$

Note 4A: The maximum number of years in the analysis period is 20 (i.e., Max $Y=20$ ). The analysis period must be the same for all interchange elements included in the analysis.

Step 5: Determine the mainline ADT for each year (i.e., $\mathrm{y}=1,2, \ldots, \mathrm{Y}$ ) in the analysis period for each site i (i.e., $\mathrm{i}=1$ to $\mathrm{I}_{\mathrm{RS}}$ ).

$$
\mathrm{ADT}_{\text {iy }}=\mathrm{ADT}_{\mathrm{i}} \times\left(1+\frac{\mathrm{GF}_{\mathrm{i}}}{100}\right)^{\mathrm{BY}-\mathrm{AY}_{\mathrm{i}}+\mathrm{y}-1}
$$

Step 6: Using the appropriate SPF model coefficient and parameters, compute the predicted TOT crash frequency for each year (i.e., $\mathrm{y}=1,2, \ldots, \mathrm{Y}$ ) in the analysis period for each site i (i.e., $\mathrm{i}=1$ to $\left.\mathrm{I}_{\mathrm{RS}}\right)$.

$$
\mathrm{RSN}_{\text {iу }(\text { ТоT })}=\mathrm{C}_{(\text {ТОT })} \times\left(\frac{\mathrm{e}^{\mathrm{a}} \times\left(2 \times \mathrm{ADT}_{\mathrm{iy}}\right)^{\mathrm{b}} \times \mathrm{SL}_{\mathrm{i}}}{2}\right)
$$

Note 6A: The SPFs for crossroad roadway segments (developed for use within SafetyAnalyst) were modeled using an ADT for both directions of travel. Thus, the predicted crash frequency applies to both directions of travel along an arterial roadway segment. In this step, ISAT calculates the predicted crash frequency for a single direction of travel; therefore, the yearly directional ADT (i.e., input by the user) is doubled, and the whole predicted value is divided by 2.

Note 6B: The calibration factor $\left[\mathrm{C}_{(\mathrm{TOT})}\right]$ is provided in the Calibration Coefficients for Arterial Crossroad Roadway Segment SPFs table on the Input Calibration worksheet.

Step 7: Using the appropriate SPF model coefficients and parameters, compute the predicted FI crash frequency for each year (i.e., $\mathrm{y}=1,2, \ldots, \mathrm{Y}$ ) in the analysis period for each site i (i.e., $\mathrm{i}=1$ to $\left.\mathrm{I}_{\mathrm{RS}}\right)$.

$$
\operatorname{RSN}_{\mathrm{iy}(\mathrm{FI})}=\mathrm{C}_{(\mathrm{FI})} \times\left(\frac{\mathrm{e}^{\mathrm{a}} \times\left(2 \times \mathrm{ADT}_{\mathrm{iy}}\right)^{\mathrm{b}} \times \mathrm{SL}_{\mathrm{i}}}{2}\right)
$$


Note 7A: The SPFs for crossroad roadway segments (developed for use within SafetyAnalyst) were modeled using an ADT for both directions of travel. Thus, the predicted crash frequency applies to both directions of travel along a mainline freeway segment. In this step, ISAT calculates the predicted crash frequency for a single direction of travel; therefore, the yearly directional ADT (i.e., input by the user) is doubled, and the whole predicted value is divided by 2.

Note 7B: The calibration factor $\left[\mathrm{C}_{(\mathrm{FI})}\right]$ is provided in the Calibration Coefficients for Arterial Crossroad Roadway Segment SPFs table on the Input Calibration worksheet.

Step 8: Compute the predicted PDO crash frequency for each year (i.e., $\mathrm{y}=1,2, \ldots, \mathrm{Y}$ ) in the analysis period for each site i (i.e., $\mathrm{i}=1$ to $\mathrm{I}_{\mathrm{RS}}$ ).

$$
\mathrm{RSN}_{\mathrm{iy}(\mathrm{PDO})}=\mathrm{RSN}_{\mathrm{iy}(\mathrm{TOT})}-\mathrm{RSN}_{\mathrm{iy}(\mathrm{FI})}
$$

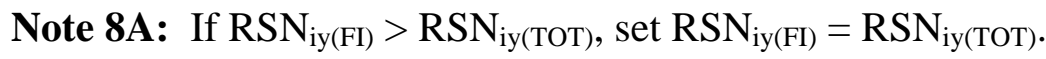

Step 9: Predict the TOT crash frequency for the entire analysis period for each site i (i.e., $\mathrm{i}=1$ to $\mathrm{I}_{\mathrm{RS}}$ ).

$$
\mathrm{RSN}_{\mathrm{iA}(\mathrm{TOT})}=\sum_{\mathrm{y}=1}^{\mathrm{Y}} \mathrm{RSN}_{\mathrm{iy}(\mathrm{TOT})}
$$

Step 10: Predict the FI crash frequency for the entire analysis period for each site i (i.e., $\mathrm{i}=1$ to $\mathrm{I}_{\mathrm{RS}}$ ).

$$
\mathrm{RSN}_{\mathrm{iA}(\mathrm{FI})}=\sum_{\mathrm{y}=1}^{\mathrm{Y}} \mathrm{RSN}_{\mathrm{iy}(\mathrm{FI})}
$$

Step 11: Predict the PDO crash frequency for the entire analysis period for each site i (i.e., $\mathrm{i}=1$ to $\left.\mathrm{I}_{\mathrm{RS}}\right)$.

$$
\mathrm{RSN}_{\mathrm{iA}(\mathrm{PDO})}=\mathrm{RSN}_{\mathrm{iA}(\mathrm{TOT})}-\mathrm{RSN}_{\mathrm{iA}(\mathrm{FI})}
$$

Step 12: Compare the max ADT for each site i (i.e., $\mathrm{i}=1$ to $\mathrm{I}_{\mathrm{RS}}$ ) for each year in the analysis period (i.e., $y=1,2, \ldots, Y$ ) to the $130 \%$ of Max ADT parameter for the respective SPF.

If

$$
\operatorname{MAX}\left(2 \times \mathrm{ADT}_{\mathrm{iy}}\right) \geq 1.3 \times \operatorname{Max} \mathrm{ADT}_{\mathrm{SPF}}
$$

Then provide a violation warning for site i. Otherwise, no violation warning is necessary.

Note 12A: The value of the respective Max $\mathrm{ADT}_{\mathrm{SPF}}$ is provided on the SPFs Crossroad Segments worksheet. 


\section{Stage 2: Calculate Predicted TOT Crash Frequencies for Crash Period}

These calculations are performed for each individual crossroad roadway segment (i.e., row) input by the user on the Input Crossroad Segments worksheet. The primary purpose of this stage is to predict crash frequencies for the TOT crash severity level for each year in the crash period and for the entire crash period. These predicted crash frequencies are computed solely from the SPFs. This is the first stage for incorporating crash data into the EB calculations. These calculations are only necessary when crash data are provided for crossroad roadway segments on the InputGeneral worksheet. If crash data are not provided, proceed to step 29.

Step 13: Determine the number of years in the crash data period $\left(\mathrm{Z}_{\mathrm{RS}}\right)$.

$$
\mathrm{Z}_{\mathrm{RS}}=\mathrm{EZ}_{\mathrm{RS}}-\mathrm{BZ}_{\mathrm{RS}}+1
$$

Note 13A: The maximum allowable crash data period is 10 years (i.e., $\operatorname{Max} \mathrm{Z}_{\mathrm{RS}}=10$ ).

Step 14: Determine the crossroad roadway segment ADT for each year (i.e., $\mathrm{z}=1,2, \ldots, \mathrm{Z}_{\mathrm{RS}}$ ) in the crash data period for each site i (i.e., $\mathrm{i}=1$ to $\mathrm{I}_{\mathrm{RS}}$ ).

$$
\mathrm{ADT}_{\mathrm{iz}_{\mathrm{RS}}}=\mathrm{ADT}_{\mathrm{i}} \times\left(1+\frac{\mathrm{GF}_{\mathrm{i}}}{100}\right)^{\mathrm{BZ}_{\mathrm{RS}}-\mathrm{AY}_{\mathrm{i}}+\mathrm{Z}_{\mathrm{RS}}-1}
$$

Step 15: Using the appropriate SPF model coefficients and parameters, compute the predicted TOT crash frequency for each year (i.e., $\mathrm{z}=1,2, \ldots, \mathrm{Z}_{\mathrm{RS}}$ ) in the crash data period for each site i (i.e., $\mathrm{i}=1$ to $\mathrm{I}_{\mathrm{RS}}$ ).

$$
\operatorname{RSN}_{\mathrm{iz}(\mathrm{TOT})}=\mathrm{C}_{(\mathrm{TOT})} \times\left(\frac{\mathrm{e}^{\mathrm{a}} \times\left(2 \times \mathrm{ADT}_{\mathrm{i}_{\mathrm{RS}}}\right)^{\mathrm{b}} \times \mathrm{SL}_{\mathrm{i}}}{2}\right)
$$

Step 16: Predict the TOT crash frequency for the entire crash data period for each site i (i.e., $\mathrm{i}=1$ to $\mathrm{I}_{\mathrm{RS}}$ ).

$$
\operatorname{RSN}_{\mathrm{iC}(\mathrm{TOT})}=\sum_{\mathrm{z}=1}^{\mathrm{Z}_{\mathrm{RS}}} \mathrm{RSN}_{\mathrm{iz}(\mathrm{TOT})}
$$

\section{Stage 3: Calculate Expected TOT Crash Frequencies for Analysis Period for all Crossroad Roadway Segments Combined}

Steps 17 through 20 are performed for each individual crossroad roadway segment (i.e., row) input by the user on the Input Crossroad Segments worksheet. Beginning with Step 21, data for all crossroad roadway segments sites are combined to calculate an adjusted expected TOT accident frequency for all crossroad roadway segment sites in the analysis period. 
Step 17: Sum the predicted TOT crash frequency for all crossroad roadway segment sites in the crash data period.

$$
\mathrm{RSN}_{\mathrm{C}(\mathrm{TOT})}=\sum_{\mathrm{i}=1}^{\mathrm{I}_{\mathrm{RS}}} \mathrm{RSN}_{\mathrm{iC}(\mathrm{TOT})}
$$

Step 18: Sum the predicted TOT crash frequency squared times $\mathrm{k}$ for all sites in the crash data period.

$$
R S N_{C k(T O T)}=\sum_{i=1}^{I_{R S}} R S N_{i C(T O T)}^{2} \times k_{i}
$$

Step 19: Sum the predicted TOT crash frequency squared times $(\mathrm{k})^{0.5}$ for all sites in the crash data period.

$$
R S N_{C 0.5 k(T O T)}=\sum_{i=1}^{I_{R S}} R S N_{\text {CC(TOT })} \times k_{i}^{0.5}
$$

Step 20: Sum the predicted TOT crash frequency times the ADT adjustment for all sites in the analysis period.

$$
\operatorname{RSN}_{\mathrm{ADT}}=\sum_{\mathrm{i}=1}^{\mathrm{I}_{\mathrm{RS}}} \mathrm{RSN}_{\mathrm{iA}(\mathrm{TOT})} \times \frac{\frac{\mathrm{RSN}_{\mathrm{iA}(\mathrm{TOT})}}{\mathrm{Y}}}{\frac{\mathrm{RSN}_{\mathrm{iC}(\mathrm{TOT})}}{\mathrm{Z}_{\mathrm{RS}}}}
$$

Step 21: Sum the predicted TOT crash frequency for all crossroad roadway segment sites in the analysis period.

$$
\mathrm{RSN}_{\mathrm{A}(\mathrm{TOT})}=\sum_{\mathrm{i}=1}^{\mathrm{I}_{\mathrm{RS}}} \mathrm{RSN}_{\mathrm{iA}(\mathrm{TOT})}
$$

Step 22: Compute the weighting factor $\left(w_{0(\mathrm{RS})}\right)$

$$
\mathrm{w}_{\mathrm{0}(\mathrm{RS})}=\frac{1}{1+\frac{\mathrm{RSN}_{\mathrm{Ck}(\mathrm{TOT})}}{\mathrm{RSN}_{\mathrm{C}(\mathrm{TOT})}}}
$$

Step 23: Estimate the expected value $\left(\mathrm{RSE}_{0}\right)$

$$
\operatorname{RSE}_{0}=\left(\mathrm{w}_{0(\mathrm{RS})} \times \mathrm{RSN}_{\mathrm{C}(\mathrm{TOT})}\right)+\left(1-\mathrm{w}_{0(\mathrm{RS})}\right) \times \mathrm{O}_{\mathrm{RS}}
$$


Step 24: Compute the weighting factor $\left(w_{1(\mathrm{RS})}\right)$

$$
\mathrm{W}_{1(\mathrm{RS})}=\frac{1}{1+\frac{\mathrm{RSN}_{\mathrm{C} 0.5 \mathrm{k}(\mathrm{TOT})}}{\mathrm{RSN}_{\mathrm{C}(\mathrm{TOT})}}}
$$

Step 25: Estimate the expected value $\left(\mathrm{RSE}_{1}\right)$

$$
\mathrm{RSE}_{1}=\left(\mathrm{w}_{1(\mathrm{RS})} \times \mathrm{RSN}_{\mathrm{C}(\mathrm{TOT})}\right)+\left(1-\mathrm{w}_{1(\mathrm{RS})}\right) \times \mathrm{O}_{\mathrm{RS}}
$$

Step 26: Estimate the expected value RSE for the crash data period.

$$
\mathrm{RSE}=\frac{\mathrm{RSE}_{0}+\mathrm{RSE}_{1}}{2}
$$

Step 27: Calculate a combined ADT adjustment factor

$$
\mathrm{AF}_{\mathrm{ADT}(\mathrm{RS})}=\frac{\mathrm{RSN}_{\mathrm{ADT}}}{\mathrm{RSN}_{\mathrm{A}(\mathrm{TOT})}}
$$

Step 28: Adjust the expected TOT crash frequency for all crossroad roadway segment sites combined in the analysis period.

$$
\mathrm{RSE}_{\mathrm{ADT}}=\mathrm{RSE} \times \mathrm{AF}_{\mathrm{ADT}(\mathrm{RS})} \times \frac{\mathrm{Y}}{\mathrm{Z}_{\mathrm{RS}}}
$$

Stage 4: Calculate EB-Adjusted Expected Crash Frequencies for Analysis Period for Each
Individual Crossroad Roadway Segment
Steps 29 through 34 are performed for each individual crossroad roadway segment (i.e., row)
input by the user on the Input Crossroad Segments worksheet. The primary purpose is to
calculate EB-adjusted expected crash frequencies for each site, combining predicted crash
frequencies from SPFs and observed crash data. If observed crash data are not provided for
crossroad roadway segments, the crash frequencies reflect predicted values rather than EB-
adjusted expected values.

Step 29: Calculate the adjusted expected TOT crash frequency for each crossroad roadway segment site i (i.e., $\mathrm{i}=1$ to $\mathrm{I}_{\mathrm{RS}}$ ) for the entire analysis period.

If the user inputs that crash data are available for crossroad roadway segments, then

$$
\operatorname{RSE}_{\mathrm{i}(\mathrm{TOT})}=\frac{\mathrm{RSN}_{\mathrm{ADT}} \times \mathrm{RSN}_{\mathrm{iA}(\mathrm{TOT})}}{\mathrm{RSN}_{\mathrm{A}(\mathrm{TOT})}}
$$


If the user inputs that crash data are not available for crossroad roadway segments, then

$$
\mathrm{RSE}_{\mathrm{i}(\mathrm{TOT})}=\mathrm{RSN}_{\mathrm{iA}(\mathrm{TOT})}
$$

Step 30: Calculate the adjusted expected FI crash frequency for each crossroad roadway segment site i (i.e., $\mathrm{i}=1$ to $\mathrm{I}_{\mathrm{RS}}$ ) in the entire analysis period.

If the user inputs that crash data are available for crossroad roadway segments, then

$$
\mathrm{RSE}_{\mathrm{i}(\mathrm{FI})}=\mathrm{RSE}_{\mathrm{i}(\mathrm{TOT})} \times \frac{\mathrm{RSN}_{\mathrm{iA}(\mathrm{FI})}}{\mathrm{RSN}_{\mathrm{iA}(\mathrm{TOT})}}
$$

If the user inputs that crash data are not available for crossroad roadway segments, then

$$
\mathrm{RSE}_{\mathrm{i}(\mathrm{FI})}=\mathrm{RSN}_{\mathrm{iA}(\mathrm{FI})}
$$

Step 31: Calculate the adjusted expected PDO crash frequency for each crossroad roadway segment site i (i.e., $\mathrm{i}=1$ to $\mathrm{I}_{\mathrm{RS}}$ ) in the entire analysis period.

$$
\mathrm{RSE}_{\mathrm{i}(\mathrm{PDO})}=\mathrm{RSE}_{\mathrm{i}(\mathrm{TOT})}-\mathrm{RSE}_{\mathrm{i}(\mathrm{FI})}
$$

Step 32: Calculate the TOT crash frequency by collision type for each crossroad roadway segment site i (i.e., $\mathrm{i}=1$ to $\mathrm{I}_{\mathrm{RS}}$ ) in the entire analysis period.

$$
\mathrm{RSE}_{\mathrm{i}(\mathrm{CT} / \mathrm{TOT})}=\mathrm{RSE}_{\mathrm{i}(\text { (ТОT })} \times \mathrm{P}_{(\mathrm{CT} / \mathrm{TOT})}
$$

Step 33: Calculate the FI crash frequency by collision type for each crossroad roadway segment site $\mathrm{i}$ (i.e., $\mathrm{i}=1$ to $\mathrm{I}_{\mathrm{RS}}$ ) in the entire analysis period.

$$
\operatorname{RSE}_{\mathrm{i}(\mathrm{CT} / \mathrm{FI})}=\mathrm{RSE}_{\mathrm{i}(\mathrm{FI})} \times \mathrm{P}_{(\mathrm{CT} / \mathrm{FI})}
$$

Step 34: Calculate the PDO crash frequency by collision type for each crossroad roadway segment site i (i.e., $\mathrm{i}=1$ to $\mathrm{I}_{\mathrm{RS}}$ ) in the entire analysis period.

$$
\mathrm{RSE}_{\mathrm{i}(\mathrm{CT} / \mathrm{PDO})}=\mathrm{RSE}_{\mathrm{i}(\mathrm{CT} / \mathrm{TOT})}-\mathrm{RSE}_{\mathrm{i}(\mathrm{CT} / \mathrm{FI})}
$$


Step 35: Calculate the number of TOT predicted crashes during the entire analysis period at all crossroad roadway segments combined.

$$
\mathrm{RSE}_{(\mathrm{TOT})}=\sum_{\mathrm{i}=1}^{\mathrm{I}_{\mathrm{RS}}} \mathrm{RSE}_{\mathrm{i}(\mathrm{TOT})}
$$

Step 36: Calculate the number of FI predicted crashes during the entire analysis period at all crossroad roadway segments combined.

$$
\operatorname{RSE}_{(\mathrm{FI})}=\sum_{\mathrm{i}=1}^{\mathrm{I}_{\mathrm{RS}}} \mathrm{RSE}_{\mathrm{i}(\mathrm{Fi})}
$$

Step 37: Calculate the number of PDO predicted crashes during the entire analysis period at all crossroad roadway segments combined.

$$
\mathrm{RSE}_{(\mathrm{PDO})}=\sum_{\mathrm{i}=1}^{\mathrm{I}_{\mathrm{RS}}} \mathrm{RSE}_{\mathrm{i}(\mathrm{PDO})}
$$

Step 38: Calculate the TOT crash frequency for each collision type (i.e., 1 through 13) during the entire analysis period at all crossroad roadway segments combined.

$$
\operatorname{RSE}_{(\mathrm{CT} / \mathrm{TOT})}=\sum_{\mathrm{i}=1}^{\mathrm{I}_{\mathrm{RS}}} \mathrm{RSE}_{\mathrm{i}(\mathrm{CT} / \mathrm{TOT})}
$$

Step 39: Calculate the FI crash frequency for each collision type (i.e., 1 through 13) during the entire analysis period at all crossroad roadway segments combined.

$$
\operatorname{RSE}_{(\mathrm{CT} / \mathrm{FI})}=\sum_{\mathrm{i}=1}^{\mathrm{I}_{\mathrm{RS}}} \mathrm{RSE}_{\mathrm{i}(\mathrm{CT} / \mathrm{FI})}
$$

Step 40: Calculate the PDO crash frequency for each collision type (i.e., 1 through 13) during the entire analysis period at all crossroad roadway segments combined.

$$
\mathrm{RSE}_{(\mathrm{CT} / \mathrm{PDO})}=\sum_{\mathrm{i}=1}^{\mathrm{I}_{\mathrm{RS}}} \mathrm{RSE}_{\mathrm{i}(\mathrm{CT} / \mathrm{PDO})}
$$




\section{ALGORITHMS FOR GENERAL OUTPUT REPORTS}

This section presents the algorithms used to generate the summary output reports of an analysis. The previous sections in this appendix describe the basic algorithms for the different interchange elements. From these algorithms data are summarized and/or aggregated to generate output reports. On the general output report results are summarized in the following manner:

- Number of predicted crashes for entire interchange area

- Number of predicted crashes by interchange element type

- Number of predicted crashes by year

- Number of predicted crashes by collision type

Separate output worksheets are also generated for each type of interchange element (i.e., mainline freeway segments, ramps, crossroad ramp terminals and intersections, and crossroad segments). On these output reports, the number of predicted crashes by collision type and severity level is summed across the individual components of the respective interchange elements, and results are provided for the individual components of the respective interchange elements.

\section{Number of Predicted Crashes for Entire Interchange Area}

Table B-12 shows the number of predicted crashes during the analysis period for the entire analysis area and shows the average number of predicted crashes per year during the analysis period. These values are provided for TOT, FI, and PDO severity levels. The algorithms for filling in this table are presented below.

Table B-12. Number of Predicted Crashes for Entire Interchange Area

\begin{tabular}{|c|c|c|c|c|c|}
\hline \multicolumn{2}{|c|}{ Number of predicted crashes during analysis } & \multicolumn{3}{|c|}{$\begin{array}{c}\text { Average number of predicted crashes per year } \\
\text { during analysis period }\end{array}$} \\
\hline Total & FI & PDO & Total & FI & PDO \\
\hline & & & & & \\
\hline
\end{tabular}

Step 1: Number of TOT predicted crashes for the entire interchange area during entire analysis period:

$$
\mathrm{IAE}_{(\mathrm{TOT})}=\mathrm{MFE}_{\text {(ТоT) }}+\mathrm{RE}_{(\mathrm{TOT})}+\mathrm{RTE}_{(\mathrm{TOT})}+\mathrm{RSE}_{(\mathrm{TOT})}
$$


Step 2: Number of FI predicted crashes for the entire interchange area during entire analysis period:

$$
\mathrm{IAE}_{(\mathrm{FI})}=\mathrm{MFE}_{(\mathrm{FI})}+\mathrm{RE}_{(\mathrm{FI})}+\mathrm{RTE}_{(\mathrm{FI})}+\mathrm{RSE}_{(\mathrm{FI})}
$$

Step 3: Number of PDO predicted crashes for the entire interchange area during entire analysis period:

$$
\mathrm{IAE}_{(\mathrm{PDO})}=\mathrm{MFE}_{(\mathrm{PDO})}+\mathrm{RE}_{(\mathrm{PDO})}+\mathrm{RTE}_{(\mathrm{PDO})}+\mathrm{RSE}_{(\mathrm{PDO})}
$$

Step 4: Average number of TOT predicted crashes for the entire interchange area per year during the analysis period:

$$
\operatorname{AVG}\left(\operatorname{IAE}_{(\text {TOT) }}\right)=\frac{\operatorname{IAE}_{(\text {(Оо) }}}{Y}
$$

Step 5: Average number of FI predicted crashes for the entire interchange area per year during the analysis period:

$$
\operatorname{AVG}\left(\operatorname{IAE}_{(\mathrm{FI})}\right)=\frac{\operatorname{IAE}_{(\mathrm{FI})}}{\mathrm{Y}}
$$

Step 6: Average number of PDO predicted crashes for the entire interchange area per year during the analysis period:

$$
\operatorname{AVG}\left(\operatorname{IAE}_{(\mathrm{PDO})}\right)=\frac{\operatorname{IAE}_{(\mathrm{PDO})}}{\mathrm{Y}}
$$

\section{Number of Predicted Crashes by Interchange Element Type}

Table B-13 summarizes the crash predictions by interchange element types. This table shows the number of sites included in the analysis area for the four interchange elements. The table also shows the number of crashes by severity type that are expected to occur on each type of interchange element. Million vehicle-miles traveled (MVMT) are displayed for mainline freeway segments, ramps, and crossroad segments based upon the traffic volumes and lengths of these interchange elements. For crossroad ramp terminals and intersections, million entering vehicles (MEV) is displayed. The last column of the table displays the crash rates across each of the interchange elements, either based upon MVMT or MEV. The last row of the table shows totals for the entire interchange area. The crash rate in this last row is calculated using total crashes and total MVMT. The algorithms for filling in this table are presented below. 
Table B-13. Number of Predicted Crashes by Interchange Element Type

\begin{tabular}{|c|c|c|c|c|c|c|c|}
\hline \multirow{2}{*}{$\begin{array}{c}\text { Interchange element } \\
\text { type }\end{array}$} & \multirow{2}{*}{$\begin{array}{c}\text { Number } \\
\text { of sites }\end{array}$} & \multicolumn{3}{|c|}{$\begin{array}{c}\text { Number of predicted crashes } \\
\text { during analysis period }\end{array}$} & \multirow[b]{2}{*}{ MVMT } & \multirow[b]{2}{*}{ MEV } & \multirow{2}{*}{$\begin{array}{l}\text { Crash rate } \\
\text { (per MVMT } \\
\text { or MEV) }\end{array}$} \\
\hline & & Total & FI & PDO & & & \\
\hline \multicolumn{8}{|l|}{$\begin{array}{l}\text { Mainline freeway } \\
\text { segments }\end{array}$} \\
\hline \multirow{3}{*}{\multicolumn{8}{|c|}{$\begin{array}{l}\text { Ramps } \\
\text { Crossroad ramp } \\
\text { terminals \& ints } \\
\text { Crossroad segments }\end{array}$}} \\
\hline & & & & & & & \\
\hline & & & & & & & \\
\hline Total & & & & & & & \\
\hline
\end{tabular}

Step 1: Number of sites for mainline freeway segments.

$$
\text { Number of sites (mainline freeway segments) }=\mathrm{I}_{\mathrm{MF}}
$$

Step 2: Number of sites for ramps.

$$
\text { Number of sites (ramps) }=I_{R}
$$

Step 3: Number of sites for crossroad ramp terminals and intersections.

$$
\text { Number of sites (crossroad ramp terminals and intersections) }=I_{R T}
$$

Step 4: Number of sites for crossroad segments.

$$
\text { Number of sites (crossroad segments) }=\mathrm{I}_{\mathrm{RS}}
$$

Step 5: Total number of sites for entire interchange area.

$$
\text { Number of sites (total) }=I_{M F}+I_{R}+I_{R T}+I_{R S}
$$

Step 6: Number of TOT predicted crashes during entire analysis period along mainline freeway segments.

$$
\operatorname{MFE}_{(\mathrm{TOT})}=\sum_{\mathrm{i}=1}^{\mathrm{I}_{\mathrm{MF}}} \mathrm{MFE}_{\mathrm{i}(\mathrm{TOT})}
$$

Step 7: Number of TOT predicted crashes during entire analysis period along ramps.

$$
\mathrm{RE}_{\text {(ТОT) }}=\sum_{\mathrm{i}=1}^{\mathrm{I}_{\mathrm{R}}} \mathrm{RE}_{\mathrm{i}(\text { (ТОT) }}
$$


Step 8: Number of TOT predicted crashes during entire analysis period at crossroad ramp terminals and intersections.

$$
\mathrm{RTE}_{(\mathrm{TOT})}=\sum_{\mathrm{i}=1}^{\mathrm{I}_{\mathrm{RT}}} \mathrm{RTE}_{\mathrm{i}(\mathrm{TOT})}
$$

Step 9: Number of TOT predicted crashes during entire analysis period at crossroad roadway segments.

$$
\mathrm{RSE}_{(\mathrm{TOT})}=\sum_{\mathrm{i}=1}^{\mathrm{I}_{\mathrm{RS}}} \mathrm{RSE}_{\mathrm{i}(\mathrm{TOT})}
$$

Step 10: Number of TOT predicted crashes during entire analysis period for the entire interchange area.

$$
\mathrm{IAE}_{\text {(тот) }}=\mathrm{MFE}_{\text {(тот) }}+\mathrm{RE}_{\text {(тот) }}+\mathrm{RTE}_{\text {(тот) }}+\mathrm{RSE}_{\text {(тот) }}
$$

Step 11: Number of FI predicted crashes during entire analysis period along mainline freeway segments.

$$
\operatorname{MFE}_{(\mathrm{FI})}=\sum_{\mathrm{i}=1}^{\mathrm{I}_{\mathrm{ME}}} \mathrm{MFE}_{\mathrm{i}(\mathrm{FI})}
$$

Step 12: Number of FI predicted crashes during entire analysis period along ramps.

$$
\mathrm{RE}_{(\mathrm{FI})}=\sum_{\mathrm{i}=1}^{\mathrm{I}_{\mathrm{R}}} \mathrm{RE}_{\mathrm{i}(\mathrm{FI})}
$$

Step 13: Number of FI predicted crashes during entire analysis period at crossroad ramp terminals and intersections.

$$
\mathrm{RTE}_{(\mathrm{FI})}=\sum_{\mathrm{i}=1}^{\mathrm{I}_{\mathrm{BT}}} \mathrm{RTE}_{\mathrm{i}(\mathrm{FI})}
$$

Step 14: Number of FI predicted crashes during entire analysis period at crossroad roadway segments.

$$
\operatorname{RSE}_{(\mathrm{FI})}=\sum_{\mathrm{i}=1}^{\mathrm{I}_{\mathrm{RS}}} \mathrm{RSE}_{\mathrm{i}(\mathrm{FI})}
$$

Step 15: Number of FI predicted crashes during entire analysis period for the entire interchange area.

$$
\mathrm{IAE}_{(\mathrm{FI})}=\mathrm{MFE}_{(\mathrm{FI})}+\mathrm{RE}_{(\mathrm{FI})}+\mathrm{RTE}_{(\mathrm{FI})}+\mathrm{RSE}_{(\mathrm{FI})}
$$


Step 16: Number of PDO predicted crashes during entire analysis period along mainline freeway segments.

$$
\mathrm{MFE}_{(\mathrm{PDO})}=\sum_{\mathrm{i}=1}^{\mathrm{I}_{\mathrm{MF}}} \mathrm{MFE}_{\mathrm{i}(\mathrm{PDO})}
$$

Step 17: Number of PDO predicted crashes during entire analysis period along ramps.

$$
\mathrm{RE}_{(\mathrm{PDO})}=\sum_{\mathrm{i}=1}^{\mathrm{I}_{\mathrm{R}}} \mathrm{RE}_{\mathrm{i}(\mathrm{PDO})}
$$

Step 18: Number of PDO predicted crashes during entire analysis period at crossroad ramp terminals and intersections.

$$
\mathrm{RTE}_{(\mathrm{PDO})}=\sum_{\mathrm{i}=1}^{\mathrm{I}_{\mathrm{RT}}} \mathrm{RTE}_{\mathrm{i}(\mathrm{PDO})}
$$

Step 19: Number of PDO predicted crashes during entire analysis period at crossroad roadway segments.

$$
\operatorname{RSE}_{(\mathrm{PDO})}=\sum_{\mathrm{i}=1}^{\mathrm{I}_{\mathrm{RS}}} \mathrm{RSE}_{\mathrm{i}(\mathrm{PDO})}
$$

Step 20: Number of PDO predicted crashes during entire analysis period for the entire interchange area.

$$
\mathrm{IAE}_{(\mathrm{PDO})}=\mathrm{MFE}_{(\mathrm{PDO})}+\mathrm{RE}_{(\mathrm{PDO})}+\mathrm{RTE}_{(\mathrm{PDO})}+\mathrm{RSE}_{(\mathrm{PDO})}
$$

Step 21: Million vehicle-miles traveled (MVMT) along mainline freeway segments.

$$
\operatorname{MVMT}_{\mathrm{MF}}=\sum_{\mathrm{i}=1}^{\mathrm{I}_{\mathrm{MF}}} \sum_{\mathrm{y}=1}^{\mathrm{Y}} \frac{\mathrm{SL}_{\text {iy }} \times \mathrm{ADT}_{\mathrm{iy}} \times 365}{1,000,000}
$$

Step 22: Million vehicle-miles traveled (MVMT) along ramps.

$$
\operatorname{MVMT}_{\mathrm{R}}=\sum_{\mathrm{i}=1}^{\mathrm{I}_{\mathrm{R}}} \sum_{\mathrm{y}=1}^{\mathrm{Y}} \frac{\mathrm{RL}_{\text {iy }} \times \mathrm{ADT}_{\text {iy }} \times 365}{1,000,000}
$$


Step 23: Million vehicle-miles traveled (MVMT) along crossroad segments.

$$
\mathrm{MVMT}_{\mathrm{RS}}=\sum_{\mathrm{i}=1}^{\mathrm{I}_{\mathrm{RS}}} \sum_{\mathrm{y}=1}^{\mathrm{Y}} \frac{\mathrm{SL}_{\text {iy }} \times \mathrm{ADT}_{\text {iy }} \times 365}{1,000,000}
$$

Step 24: Million vehicle-miles traveled (MVMT) along entire interchange area.

$$
\mathrm{MVMT}_{\mathrm{IA}}=\mathrm{MVMT}_{\mathrm{MF}}+\mathrm{MVMT}_{\mathrm{R}}+\mathrm{MVMT}_{\mathrm{RS}}
$$

Step 25: Million entering-vehicles (MEV) at crossroad ramp terminals and intersections.

If the site is a conventional intersection (CI), then

$$
M E V_{R T(C I)}=\sum_{i=1}^{I_{R T C(C)}} \sum_{y=1}^{Y} \frac{\left(\left(2 \times A D T_{i y(\text { major rd })}\right)+\left(2 \times A D T_{i y(\text { off }- \text { ramp })}\right)\right) \times 365}{1,000,000}
$$

If the site is a ramp terminal (RT), then

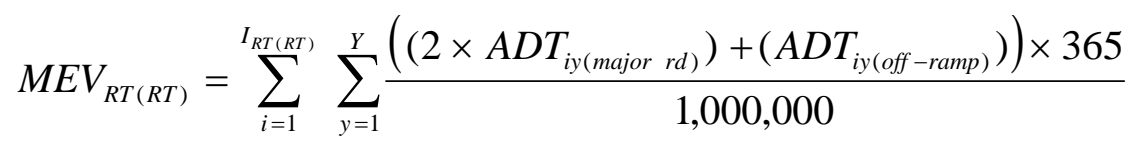

The total MEV for all crossroad ramp terminals and intersections is

$$
\mathrm{MEV}_{\mathrm{RT}}=\mathrm{MEV}_{\mathrm{RT}(\mathrm{RT})}+\mathrm{MEV}_{\mathrm{RT}(\mathrm{CI})}
$$

Step 26: Crash rate of TOT predicted crashes during entire analysis period along mainline freeway segments.

$$
\text { Crash Rate }_{\mathrm{MF}(\mathrm{TOT})}=\frac{\mathrm{MFE}_{(\mathrm{TOT})}}{\mathrm{MVMT}_{\mathrm{MF}}}
$$

Step 27: Crash rate of TOT predicted crashes during entire analysis period along ramps.

$$
\text { Crash Rate }_{\mathrm{R}(\mathrm{TOT})}=\frac{\mathrm{RE}_{(\mathrm{TOT})}}{\mathrm{MVMT}_{\mathrm{R}}}
$$

Step 28: Crash rate of TOT predicted crashes during entire analysis period at crossroad ramp terminals and intersections.

$$
\text { Crash Rate }_{\mathrm{RT}(\mathrm{TOT})}=\frac{\mathrm{RTE}_{(\mathrm{TOT})}}{\mathrm{MEV}_{\mathrm{RT}}}
$$


Step 29: Crash rate of TOT predicted crashes during entire analysis period at crossroad roadway segments.

$$
\text { Crash Rate }_{\mathrm{RS}(\mathrm{TOT})}=\frac{\mathrm{RSE}_{(\mathrm{TOT})}}{\mathrm{MVMT}_{\mathrm{RS}}}
$$

Step 30: Crash rate of TOT predicted crashes during entire analysis period for the entire interchange area.

$$
\text { Crash Rate }_{\mathrm{IA}(\mathrm{TOT})}=\frac{\mathrm{IAE}_{\text {(TOT) }}}{\mathrm{MVMT}_{\mathrm{MF}}+\mathrm{MVMT}_{\mathrm{R}}+\mathrm{MVMT}_{\mathrm{RS}}}
$$

\section{Number of Predicted Crashes by Year}

Table B-14 displays the predicted number of crashes for each year of the analysis period by severity level. The number of columns in this table is based upon the number of years in the analysis period. The top row of this table displays each calendar year of the analysis period, beginning with the first year (BY) and ending with the final year (BY + EY -1). Predicted crash totals for the entire analysis period are also summarized by severity level in the second column of the table. The algorithms for filling in this table are presented below.

Table B-14. Number of Predicted Crashes by Year

\begin{tabular}{|l|l|l|l|l|l|l|}
\hline & Total & $\mathbf{( B Y})$ & $\mathbf{B Y}+\mathbf{1}$ & $\ldots$ & & $(\mathbf{B Y}+\mathbf{E Y}-\mathbf{1})$ \\
\hline Total Crashes & & & & $\ldots$ & & \\
\hline FI Crashes & & & & $\ldots$ & & \\
\hline PDO Crashes & & & & $\ldots$ & & \\
\hline
\end{tabular}

Step 1: Number of TOT predicted crashes for the entire interchange area during entire analysis period:

$$
\mathrm{IAE}_{\text {(ТОT) }}=\mathrm{MFE}_{\text {(ТоT) }}+\mathrm{RE}_{\text {(ТоT) }}+\mathrm{RTE}_{(\mathrm{TOT})}+\mathrm{RSE}_{(\mathrm{TOT})}
$$

Step 2: Number of FI predicted crashes for the entire interchange area during entire analysis period:

$$
\mathrm{IAE}_{(\mathrm{FI})}=\mathrm{MFE}_{(\mathrm{FI})}+\mathrm{RE}_{(\mathrm{FI})}+\mathrm{RTE}_{(\mathrm{FI})}+\mathrm{RSE}_{(\mathrm{FI})}
$$

Step 3: Number of PDO predicted crashes for the entire interchange area during entire analysis period:

$$
\mathrm{IAE}_{(\mathrm{PDO})}=\mathrm{MFE}_{(\mathrm{PDO})}+\mathrm{RE}_{(\mathrm{PDO})}+\mathrm{RTE}_{(\mathrm{PDO})}+\mathrm{RSE}_{(\mathrm{PDO})}
$$


Step 4: Number of TOT predicted crashes for the entire interchange area during $\mathrm{y}=1$ of the analysis period:

$$
\mathrm{IAE}_{1(\mathrm{TOT})}=\left(\frac{\sum_{\mathrm{i}=1}^{\mathrm{I}_{\mathrm{MF}}} \mathrm{MFN}_{\mathrm{iA}=1(\mathrm{TOT})}+\sum_{\mathrm{i}=1}^{\mathrm{I}_{\mathrm{R}}} \mathrm{RN}_{\mathrm{iA}=1(\mathrm{TOT})}+\sum_{\mathrm{i}=1}^{\mathrm{I}_{\mathrm{RT}}} \mathrm{RTN}_{\mathrm{iA}=1(\mathrm{TOT})}+\sum_{\mathrm{i}=1}^{\mathrm{I}_{\mathrm{RS}}} \mathrm{RSN}_{\mathrm{iA}=1(\mathrm{TOT})}}{\mathrm{MFN}_{\mathrm{A}(\mathrm{TOT})}+\mathrm{RN}_{\mathrm{A}(\mathrm{TOT})}+\mathrm{RTN}_{\mathrm{A}(\mathrm{TOT})}+\mathrm{RSN}_{\mathrm{A}(\mathrm{TOT})}}\right) \times \mathrm{IAE}_{(\mathrm{TOT})}
$$

Step 5: Number of FI predicted crashes for the entire interchange area during $\mathrm{y}=1$ of the analysis period:

$$
\mathrm{IAE}_{1(\mathrm{FI})}=\left(\frac{\sum_{\mathrm{i}=1}^{\mathrm{I}_{\mathrm{MF}}} \mathrm{MFN}_{\mathrm{iA}=1(\mathrm{FI})}+\sum_{\mathrm{i}=1}^{\mathrm{I}_{\mathrm{R}}} \mathrm{RN}_{\mathrm{iA}=1(\mathrm{FI})}+\sum_{\mathrm{i}=1}^{\mathrm{I}_{\mathrm{RT}}} \mathrm{RTN}_{\mathrm{iA}=1(\mathrm{FI})}+\sum_{\mathrm{i}=1}^{\mathrm{I}_{\mathrm{RS}}} \mathrm{RSN}_{\mathrm{iA}=1(\mathrm{FI})}}{\mathrm{MFN}_{\mathrm{A}(\mathrm{FI})}+\mathrm{RN}_{\mathrm{A}(\mathrm{FI})}+\mathrm{RTN}_{\mathrm{A}(\mathrm{FI})}+\mathrm{RSN}_{\mathrm{A}(\mathrm{FI})}}\right) \times \mathrm{IAE}_{(\mathrm{FI})}
$$

Step 6: Number of PDO predicted crashes for the entire interchange area during $\mathrm{y}=1$ of the analysis period:

$$
\mathrm{IAE}_{1(\mathrm{PDO})}=\left(\frac{\sum_{\mathrm{i}=1}^{\mathrm{I}_{\mathrm{MF}}} \mathrm{MFN}_{\mathrm{iA}=1(\mathrm{PDO})}+\sum_{\mathrm{i}=1}^{\mathrm{I}_{\mathrm{R}}} \mathrm{RN}_{\mathrm{iA}=1(\mathrm{PDO})}+\sum_{\mathrm{i}=1}^{\mathrm{I}_{\mathrm{RT}}} \mathrm{RTN}_{\mathrm{iA}=1(\mathrm{PDO})}+\sum_{\mathrm{i}=1}^{\mathrm{I}_{\mathrm{RS}}} \mathrm{RSN}_{\mathrm{iA}=1(\mathrm{PDO})}}{\mathrm{MFN}_{\mathrm{A}(\mathrm{PDO})}+\mathrm{RN}_{\mathrm{A}(\mathrm{PDO})}+\mathrm{RTN}_{\mathrm{A}(\mathrm{PDO})}+\mathrm{RSN}_{\mathrm{A}(\mathrm{PDO})}}\right) \times \mathrm{IAE}_{(\mathrm{PDO})}
$$

Steps 4 through 6 are repeated for each year in the analysis period.

\section{Number of Predicted Crashes by Collision Type}

Table B-15 shows the number and percentage of predicted crashes by collision type and severity level. Subtotals are also provided for all single-vehicle crashes and all multiple-vehicle crashes. The algorithms for filling in this table are presented below. 
Table B-15. Number of Predicted Crashes by Collision Type

\begin{tabular}{|c|c|c|c|c|c|c|}
\hline \multirow[b]{3}{*}{ Collision type } & \multicolumn{6}{|c|}{$\begin{array}{l}\text { Number and percentage of predicted crashes } \\
\text { by collision type }\end{array}$} \\
\hline & \multicolumn{2}{|c|}{ Total } & \multicolumn{2}{|c|}{ FI } & \multicolumn{2}{|c|}{ PDO } \\
\hline & No. & $\%$ & No. & $\%$ & No. & $\%$ \\
\hline \multicolumn{7}{|l|}{ All collision types } \\
\hline \multicolumn{7}{|l|}{ Single vehicle } \\
\hline \multicolumn{7}{|l|}{ Fixed object } \\
\hline \multicolumn{7}{|l|}{ Animal } \\
\hline \multicolumn{7}{|l|}{$\begin{array}{l}\text { Pedestrian } \\
\text { Bicyclist }\end{array}$} \\
\hline \multicolumn{7}{|l|}{ Bicyclist } \\
\hline \multicolumn{7}{|l|}{ Parked car } \\
\hline \multicolumn{7}{|l|}{ Noncollision } \\
\hline \multicolumn{7}{|l|}{ Other single-vehicle } \\
\hline \multicolumn{7}{|l|}{ Multiple vehicle } \\
\hline \multicolumn{7}{|l|}{ Rear-end } \\
\hline \multicolumn{7}{|l|}{ Head-on } \\
\hline \multicolumn{7}{|l|}{ Angle } \\
\hline \multicolumn{7}{|l|}{ Sideswipe, same direction } \\
\hline \multirow{2}{*}{\multicolumn{7}{|c|}{ Sideswipe, opposite direction }} \\
\hline & & & & & & \\
\hline
\end{tabular}

Step 1: Number of TOT predicted crashes for a given collision type for the entire interchange area during entire analysis period:

$$
\mathrm{IAE}_{(\mathrm{CT} / \mathrm{TOT})}=\mathrm{MFE}_{(\mathrm{CT} / \mathrm{TOT})}+\mathrm{RE}_{(\mathrm{CT} / \mathrm{TOT})}+\mathrm{RTE}_{(\mathrm{CT} / \mathrm{TOT})}+\mathrm{RSE}_{(\mathrm{CT} / \mathrm{TOT})}
$$

Step 2: Percentage of TOT predicted crashes for a given collision type for the entire interchange area during entire analysis period:

$$
\text { Percent }\left(\mathrm{IAE}_{(\mathrm{CT} / \mathrm{TOT})}\right)=\frac{\mathrm{IAE}_{(\mathrm{CT} / \mathrm{TOT})}}{\mathrm{IAE}_{(\text {TOT })}}
$$

Step 3: Number of FI predicted crashes for a given collision type for the entire interchange area during entire analysis period:

$$
\mathrm{IAE}_{(\mathrm{CT} / \mathrm{FI})}=\mathrm{MFE}_{(\mathrm{CT} / \mathrm{FI})}+\mathrm{RE}_{(\mathrm{CT} / \mathrm{FI})}+\mathrm{RTE}_{(\mathrm{CT} / \mathrm{FI})}+\mathrm{RSE}_{(\mathrm{CT} / \mathrm{FI})}
$$

Step 4: Percentage of FI predicted crashes for a given collision type for the entire interchange area during entire analysis period:

$$
\operatorname{Percent}\left(\mathrm{IAE}_{(\mathrm{CT} / \mathrm{FI})}\right)=\frac{\mathrm{IAE}_{(\mathrm{CT} / \mathrm{FI})}}{\mathrm{IAE}_{(\mathrm{FI})}}
$$


Step 5: Number of PDO predicted crashes for a given collision type for the entire interchange area during entire analysis period:

$$
\mathrm{IAE}_{(\mathrm{CT} / \mathrm{PDO})}=\mathrm{MFE}_{(\mathrm{CT} / \mathrm{PDO})}+\mathrm{RE}_{(\mathrm{CT} / \mathrm{PDO})}+\mathrm{RTE}_{(\mathrm{CT} / \mathrm{PDO})}+\mathrm{RSE}_{(\mathrm{CT} / \mathrm{PDO})}
$$

Step 6: Percentage of PDO predicted crashes for a given collision type for the entire interchange area during entire analysis period:

$$
\text { Percent }\left(\mathrm{IAE}_{(\mathrm{CT} / \mathrm{PDO})}\right)=\frac{\mathrm{IAE}_{(\mathrm{CT} / \mathrm{PDO})}}{\mathrm{IAE}_{(\mathrm{PDO})}}
$$

Steps 1 through 6 are repeated for all collision types 1 through 13 . Subtotals for all single vehicle and all multiple vehicle collisions are provided by summing the numbers and percentages for all single vehicle collision types and all multiple vehicle collision types, respectively. The first row of the table displays the number and percentage for all collision types. Again, these values are simply the sums of the numbers and percentages for all collision types 1 through 13.

\section{ALGORITHMS FOR OUTPUT REPORTS FOR MAINLINE FREEWAY SEGMENTS}

Output results for mainline freeway segments are provided in two tables. The first table shows the number of predicted crashes by collision type for all mainline freeway segments combined. The second table shows the number of predicted crashes for each individual mainline freeway segment.

\section{Number of Predicted Crashes by Collision Type for All Mainline Freeway Segments Combined}

Table B-16 shows the number of predicted crashes by collision type for all mainline freeway segments combined. These crashes are categorized by the 13 collision types and by severity level. The algorithms for filling in this table are presented below. 
Table B-16. Number of Predicted Crashes by Collision Type for all Mainline Freeway Segments Combined

\begin{tabular}{|c|c|c|c|c|c|c|}
\hline \multirow[b]{3}{*}{ Collision type } & \multicolumn{6}{|c|}{ Number and percentage of predicted crashes by collision type } \\
\hline & \multicolumn{2}{|c|}{ Total } & \multicolumn{2}{|c|}{ FI } & \multicolumn{2}{|c|}{ PDO } \\
\hline & No. & $\%$ & No. & $\%$ & No. & $\%$ \\
\hline \multicolumn{7}{|l|}{ All collision types } \\
\hline \multicolumn{7}{|l|}{ Single vehicle } \\
\hline \multicolumn{7}{|l|}{ Fixed object } \\
\hline \multicolumn{7}{|l|}{ Animal } \\
\hline \multicolumn{7}{|l|}{ Pedestrian } \\
\hline \multicolumn{7}{|l|}{ Bicyclist } \\
\hline \multicolumn{7}{|l|}{ Parked car } \\
\hline \multicolumn{7}{|l|}{ Noncollision } \\
\hline \multicolumn{7}{|l|}{ Other single-vehicle } \\
\hline \multicolumn{7}{|l|}{ Multiple vehicle } \\
\hline \multicolumn{7}{|l|}{ Rear-end } \\
\hline \multicolumn{7}{|l|}{ Head-on } \\
\hline \multicolumn{7}{|l|}{ Angle } \\
\hline \multicolumn{7}{|l|}{ Sideswipe, same direction } \\
\hline \multicolumn{7}{|l|}{ Sideswipe, opposite direction } \\
\hline Other multiple-vehicle & & & & & & \\
\hline
\end{tabular}

Step 1: Number of TOT predicted crashes for a given collision type for all mainline freeway segments combined during entire analysis period:

$$
\operatorname{MFE}_{(\mathrm{CT} / \mathrm{TOT})}=\sum_{\mathrm{i}=1}^{\mathrm{I}_{\mathrm{MF}}} \mathrm{MFE}_{\mathrm{i}(\mathrm{CT} / \mathrm{TOT})}
$$

Step 2: Percentage of TOT predicted crashes for a given collision type for all mainline freeway segments combined during entire analysis period:

$$
\operatorname{Percent}\left(\mathrm{MFE}_{(\mathrm{CT} / \mathrm{TOT})}\right)=\frac{\operatorname{MFE}_{(\mathrm{CT} / \mathrm{TOT})}}{\mathrm{MFE}_{(\mathrm{TOT})}}
$$

Step 3: Number of FI predicted crashes for a given collision type for all mainline freeway segments combined during entire analysis period:

$$
\mathrm{MFE}_{(\mathrm{CT} / \mathrm{FI})}=\sum_{\mathrm{i}=1}^{\mathrm{I}_{\mathrm{MF}}} \mathrm{MFE}_{\mathrm{i}(\mathrm{CT} / \mathrm{FI})}
$$

Step 4: Percentage of FI predicted crashes for a given collision type for all mainline freeway segments combined during entire analysis period:

$$
\operatorname{Percent}\left(\mathrm{MFE}_{(\mathrm{CT} / \mathrm{FI})}\right)=\frac{\mathrm{MFE}_{(\mathrm{CT} / \mathrm{Fi})}}{\mathrm{MFE}_{(\mathrm{FI})}}
$$


Step 5: Number of PDO predicted crashes for a given collision type for all mainline freeway segments combined during entire analysis period:

$$
\operatorname{MFE}_{(\mathrm{CT} / \mathrm{PDO})}=\sum_{\mathrm{i}=1}^{\mathrm{I}_{\mathrm{MF}}} \mathrm{MFE}_{\mathrm{i}(\mathrm{CT} / \mathrm{PDO})}
$$

Step 6: Percentage of PDO predicted crashes for a given collision type for all mainline freeway segments combined during entire analysis period:

$$
\operatorname{Percent}\left(\mathrm{MFE}_{(\mathrm{CT} / \mathrm{PDO})}\right)=\frac{\mathrm{MFE}_{(\mathrm{CT} / \mathrm{PDO})}}{\mathrm{MFE}_{(\mathrm{PDO})}}
$$

Steps 1 through 6 are repeated for all collision types 1 through 13 . Subtotals for all single vehicle and all multiple vehicle collisions are provided by summing the numbers and percentages for all single vehicle collision types and all multiple vehicle collision types, respectively. The first row of the table displays the number and percentage for all collision types. Again, these values are simply the sums of the numbers and percentages for all collision types 1 through 13.

\section{Number of Predicted Crashes for Individual Mainline Freeway Segments}

Table B-17 shows the segment number, segment description, direction of travel, beginning milepost, ending milepost, and segment length for each individual site. For each individual site, the number of predicted crashes during the analysis period is provided by severity level. The average daily traffic (ADT) for each site is given for the entire analysis period along with MVMT, crashes per mile per year, and crash rate per MVMT. Totals are provided in the first row for segment length, number of predicted crashes during analysis period, ADT, MVMT, crashes per mile per year, and crash rate per MVMT. Several columns in table B-17 are also provided to serve as warnings to users when interpreting the output. One warning is associated with the ADT of a given site. As indicated earlier, SPFs are used in predicting the number of accidents at a given site. Each SPF was calibrated/calculated using data from actual sites. The maximum ADT used in calibrating/calculating each SPF is one of the parameters included on the SPF worksheets. If the ADT at a given site for any year in the analysis period exceeds the maximum ADT used to calibrate the SPF, which is used in predicting crashes for the respective site, this is indicted to the user by showing a "YES" in the respective row under the column headed "Max ADT for SPF exceeded". A "YES" is also provided in the first row of the table under the same column. These "YES" values serve as a warning to the user to view the predictions for the given site with caution. Because the ADT for the given site is beyond the limits for which the SPF was calibrated, there is less certainty associated with the predictions for the given site. A second warning is associated with the crash distributions. For a given group of crash types (i.e., 13 crash types) and subtype, the sum of the proportions should equal 1.00. If the sum of the proportions does not equal exactly 1.00, erroneous results will be calculated for the collision types. A "YES" value in the respective row under the column headed "Incorrect collision distribution" indicates that crash distributions used in the calculations for the given site were incorrect (i.e., did not sum to 1.00). The algorithms for filling in this table are presented below. Information on segment 
description, direction of travel, beginning MP, ending MP, and segment length are the same as input by the user on the Input Mainline Freeways worksheet.

Step 1: Total segment length:

$$
\mathrm{SL}_{(\mathrm{MF})}=\sum_{\mathrm{i}=1}^{\mathrm{I}_{\mathrm{MF}}} \mathrm{SL}_{\mathrm{i}}
$$

Step 2: Number of TOT predicted crashes during analysis period for each site i (i.e., $\mathrm{i}=1$ to $\left.\mathrm{I}_{\mathrm{MF}}\right)$.

$$
\mathrm{MFE}_{\mathrm{i}(\mathrm{TOT})}
$$

Step 3: Number of FI predicted crashes during analysis period for each site i (i.e., $\mathrm{i}=1$ to $\mathrm{I}_{\mathrm{MF}}$ ).

$$
\mathrm{MFE}_{\mathrm{i}(\mathrm{FI})}
$$

Step 4: Number of PDO predicted crashes during analysis period for each site i (i.e., $\mathrm{i}=1$ to $\left.\mathrm{I}_{\mathrm{MF}}\right)$.

$$
\mathrm{MFE}_{\mathrm{i}(\mathrm{PDO})}
$$

Step 5: Number of TOT predicted crashes during the entire analysis period along all mainline freeway segments combined.

$$
\mathrm{MFE}_{(\mathrm{TOT})}=\sum_{\mathrm{i}=1}^{\mathrm{I}_{\mathrm{MF}}} \mathrm{MFE}_{\mathrm{i}(\mathrm{TOT})}
$$

Step 6: Number of FI predicted crashes during the entire analysis period along all mainline freeway segments combined.

$$
\mathrm{MFE}_{(\mathrm{FI})}=\sum_{\mathrm{i}=1}^{\mathrm{I}_{\mathrm{MF}}} \mathrm{MFE}_{\mathrm{i}(\mathrm{FI})}
$$

Step 7: Number of PDO predicted crashes during the entire analysis period along all mainline freeway segments combined.

$$
\mathrm{MFE}_{(\mathrm{PDO})}=\sum_{\mathrm{i}=1}^{\mathrm{I}_{\mathrm{MF}}} \mathrm{MFE}_{\mathrm{i}(\mathrm{PDO})}
$$


Step 8: Average ADT during analysis period for each site i (i.e., $\mathrm{i}=1$ to $\mathrm{I}_{\mathrm{MF}}$ ).

$$
\operatorname{AVG}\left(\mathrm{ADT}_{\mathrm{i}(\mathrm{MF})}\right)=\frac{\sum_{\mathrm{y}=1}^{\mathrm{Y}} \mathrm{ADT}_{\mathrm{iy}}}{\mathrm{Y}}
$$

Step 9: Average ADT during analysis period along all mainline freeway segments combined.

$$
\operatorname{AVG}\left(\mathrm{ADT}_{\mathrm{MF}}\right)=\frac{\mathrm{MVMT}_{\mathrm{MF}} \times 1,000,000}{\sum_{\mathrm{i}=1}^{I_{\mathrm{MF}}} \mathrm{SL}_{\mathrm{i}} \times 365 \times \mathrm{Y}}
$$

Step 10: Max ADT SPF exceeded for each site i (i.e., $\mathrm{i}=1$ to $\mathrm{I}_{\mathrm{MF}}$ ).

Report violation as determined in Step 16 under algorithms for mainline freeway segments.

Step 11: MVMT for each site i (i.e., $\mathrm{i}=1$ to $\mathrm{I}_{\mathrm{MF}}$ )

$$
\operatorname{MVMT}_{\mathrm{i}(\mathrm{MF})}=\sum_{\mathrm{y}=1}^{\mathrm{Y}} \frac{\mathrm{SL}_{\mathrm{iy}} \times \mathrm{ADT}_{\mathrm{iy}} \times 365}{1,000,000}
$$

Step 12: Million vehicle-miles traveled (MVMT) along mainline freeway segments.

$$
\mathrm{MVMT}_{\mathrm{MF}}=\sum_{\mathrm{i}=1}^{\mathrm{I}_{\mathrm{MF}}} \sum_{\mathrm{y}=1}^{\mathrm{Y}} \frac{\mathrm{SL}_{\mathrm{iy}} \times \mathrm{ADT}_{\mathrm{iy}} \times 365}{1,000,000}
$$

Step 13: Crashes per mile per year for each site i (i.e., $\mathrm{i}=1$ to $\mathrm{I}_{\mathrm{MF}}$ ).

$$
\text { (Crashes } / \mathrm{mi} / \mathrm{yr})_{\mathrm{i}(\mathrm{MF})}=\frac{\mathrm{MFE}_{\mathrm{i}(\mathrm{TOT})}}{\mathrm{SL}_{\mathrm{i}} \times \mathrm{Y}}
$$

Step 14: Crashes per mile per year along all mainline freeway segments combined.

$$
\text { (Crashes } / \mathrm{mi} / \mathrm{yr})_{(\mathrm{MF})}=\frac{\mathrm{MFE}_{(\mathrm{TOT})}}{\sum_{\mathrm{i}=1}^{\mathrm{I}_{\mathrm{MF}}} \mathrm{SL}_{\mathrm{i}} \times \mathrm{Y}}
$$


Table B-17. Number of Predicted Crashes for Individual Mainline Freeway Segments

\begin{tabular}{|c|c|c|c|c|c|c|c|c|c|c|c|c|c|c|}
\hline \multirow{2}{*}{$\begin{array}{l}\text { Segment } \\
\text { number }\end{array}$} & \multirow{2}{*}{$\begin{array}{c}\text { Segment } \\
\text { description }\end{array}$} & \multirow{2}{*}{$\begin{array}{l}\text { Direction } \\
\text { of travel }\end{array}$} & \multirow{2}{*}{$\begin{array}{c}\text { Beginning } \\
\text { MP }\end{array}$} & \multirow{2}{*}{$\begin{array}{c}\text { Ending } \\
\text { MP }\end{array}$} & \multirow{2}{*}{$\begin{array}{c}\text { Segment } \\
\text { length } \\
\text { (mi) }\end{array}$} & \multicolumn{3}{|c|}{$\begin{array}{c}\text { Number of } \\
\text { predicted crashes } \\
\text { during analysis } \\
\text { period } \\
\end{array}$} & \multirow{2}{*}{$\begin{array}{c}\text { ADT } \\
\text { (veh/day) }\end{array}$} & \multirow{2}{*}{$\begin{array}{c}\text { Max ADT } \\
\text { for SPF } \\
\text { exceeded }\end{array}$} & \multirow[b]{2}{*}{ MVMT } & \multirow{2}{*}{$\begin{array}{l}\text { Crashes } \\
\text { per mile } \\
\text { per year }\end{array}$} & \multirow{2}{*}{$\begin{array}{c}\text { Crash } \\
\text { rate per } \\
\text { MVMT }\end{array}$} & \multirow{2}{*}{$\begin{array}{c}\text { Incorrect } \\
\text { collision } \\
\text { distribution }\end{array}$} \\
\hline & & & & & & Total & FI & PDO & & & & & & \\
\hline \multicolumn{15}{|l|}{ Total } \\
\hline \multicolumn{15}{|c|}{1} \\
\hline \multicolumn{15}{|l|}{2} \\
\hline : & & & & & & & & & & & & & & \\
\hline \multicolumn{15}{|c|}{$:$} \\
\hline \multicolumn{15}{|c|}{ : } \\
\hline : & & & & & & & & & & & & & & \\
\hline \multicolumn{15}{|l|}{48} \\
\hline \multicolumn{15}{|c|}{49} \\
\hline 50 & & & & & & & & & & & & & & \\
\hline
\end{tabular}


Step 15: Crash rate per MVMT for each site i (i.e., $\mathrm{i}=1$ to $\mathrm{I}_{\mathrm{MF}}$ ).

$$
\text { Crash Rate }_{\mathrm{i}(\mathrm{MF})}=\frac{\mathrm{MFE}_{\mathrm{i}(\mathrm{TOT})}}{\operatorname{MVMT}_{\mathrm{i}(\mathrm{MF})}}
$$

Step 16: Crash rate per MVMT along all mainline freeway segments combined.

$$
\text { Crash Rate }_{\mathrm{MF}}=\frac{\mathrm{MFE}_{(\mathrm{TOT})}}{\mathrm{MVMT}_{\mathrm{MF}}}
$$

Step 17: Incorrect collision distribution for each site i (i.e., $\mathrm{i}=1$ to $\mathrm{I}_{\mathrm{MF}}$ ).

Report violation as determined in Step 3 under algorithms for mainline freeway segments, if the sum of the crash proportions for crash types 1 to 13 do not sum to exactly 1.0.

\section{ALGORITHMS FOR OUTPUT REPORTS FOR RAMPS}

Output results for ramps are provided in two tables. The first table shows the number of predicted crashes by collision type for all ramps combined. The second table shows the number of predicted crashes for each individual ramp.

\section{Number of Predicted Crashes by Collision Type for All Ramps Combined}

Table B-18 shows the number of predicted crashes by collision type for all ramps combined. These crashes are categorized by the 13 collision types and by severity level. The algorithms for filling in this table are presented below. 
Table B-18. Number of Predicted Crashes by Collision Type for all Ramps Combined

\begin{tabular}{|c|c|c|c|c|c|c|}
\hline \multirow[b]{3}{*}{ Collision type } & \multicolumn{6}{|c|}{ Number and percentage of predicted crashes by collision type } \\
\hline & \multicolumn{2}{|c|}{ Total } & \multicolumn{2}{|c|}{ FI } & \multicolumn{2}{|c|}{ PDO } \\
\hline & No. & $\%$ & No. & $\%$ & No. & $\%$ \\
\hline \multicolumn{7}{|l|}{ All collision types } \\
\hline \multicolumn{7}{|l|}{ Single vehicle } \\
\hline \multicolumn{7}{|l|}{ Fixed object } \\
\hline \multicolumn{7}{|l|}{ Animal } \\
\hline \multicolumn{7}{|l|}{ Pedestrian } \\
\hline \multicolumn{7}{|l|}{ Bicyclist } \\
\hline \multicolumn{7}{|l|}{ Parked car } \\
\hline \multicolumn{7}{|l|}{ Noncollision } \\
\hline \multicolumn{7}{|l|}{$\begin{array}{l}\text { Other single-vehicle } \\
\text { Multinle vehicle }\end{array}$} \\
\hline Multiple vehicle & & & & & & \\
\hline \multicolumn{7}{|l|}{ Rear-end } \\
\hline \multicolumn{7}{|l|}{ Head-on } \\
\hline \multicolumn{7}{|l|}{ Angle } \\
\hline \multicolumn{7}{|l|}{ Sideswipe, same direction } \\
\hline \multicolumn{7}{|l|}{ Sideswipe, opposite direction } \\
\hline Other multiple-vehicle & & & & & & \\
\hline
\end{tabular}

Step 1: Number of TOT predicted crashes for a given collision type for all ramps combined during entire analysis period:

$$
\mathrm{RE}_{(\mathrm{CT} / \mathrm{TOT})}=\sum_{\mathrm{i}=1}^{\mathrm{I}_{\mathrm{R}}} \mathrm{RE}_{\mathrm{i}(\mathrm{CT} / \mathrm{TOT})}
$$

Step 2: Percentage of TOT predicted crashes for a given collision type for all ramps combined during entire analysis period:

$$
\operatorname{Percent}\left(\mathrm{RE}_{(\mathrm{CT} / \mathrm{TOT})}\right)=\frac{\mathrm{RE}_{(\mathrm{CT} / \mathrm{TOT})}}{\mathrm{RE}_{(\mathrm{TOT})}}
$$

Step 3: Number of FI predicted crashes for a given collision type for all ramps combined during entire analysis period:

$$
\mathrm{RE}_{(\mathrm{CT} / \mathrm{FI})}=\sum_{\mathrm{i}=1}^{\mathrm{I}_{\mathrm{R}}} \mathrm{RE}_{\mathrm{i}(\mathrm{CT} / \mathrm{FI})}
$$

Step 4: Percentage of FI predicted crashes for a given collision type for all ramps combined during entire analysis period:

$$
\operatorname{Percent}\left(\mathrm{RE}_{(\mathrm{CT} / \mathrm{FI})}\right)=\frac{\mathrm{RE}_{(\mathrm{CT} / \mathrm{FI})}}{\mathrm{RE}_{(\mathrm{FI})}}
$$


Step 5: Number of PDO predicted crashes for a given collision type for all ramps combined during entire analysis period:

$$
\mathrm{RE}_{(\mathrm{CT} / \mathrm{PDO})}=\sum_{\mathrm{i}=1}^{\mathrm{I}_{\mathrm{R}}} \mathrm{RE}_{\mathrm{i}(\mathrm{CT} / \mathrm{PDO})}
$$

Step 6: Percentage of PDO predicted crashes for a given collision type for all ramps combined during entire analysis period:

$$
\operatorname{Percent}\left(\mathrm{RE}_{(\mathrm{CT} / \mathrm{PDO})}\right)=\frac{\mathrm{RE}_{(\mathrm{CT} / \mathrm{PDO})}}{\mathrm{RE}_{(\mathrm{PDO})}}
$$

Steps 1 through 6 are repeated for all collision types 1 through 13 . Subtotals for all single vehicle and all multiple vehicle collisions are provided by summing the numbers and percentages for all single vehicle collision types and all multiple vehicle collision types, respectively. The first row of the table displays the number and percentage for all collision types. Again, these values are simply the sums of the numbers and percentages for all collision types 1 through 13.

\section{Number of Predicted Crashes for Individual Ramps}

Table B-19 shows the ramp number, ramp description, and ramp length for each individual site. For each individual site, the number of predicted crashes during the analysis period is provided by severity level. The average daily traffic (ADT) for each site is given for the entire analysis period along with MVMT and crash rate per MVMT. Totals are provided in the first row for ramp length, number of predicted crashes during analysis period, ADT, MVMT, and crash rate per MVMT. Several columns in table B-19 are also provided to serve as warnings to users when interpreting the output. One warning is associated with the ADT of a given site. A second warning is associated with the crash distributions. The algorithms for filling in this table are presented below. Information on ramp description and ramp length are the same as input by the user on the Input Ramps worksheet.

Step 1: Total ramp length:

$$
\mathrm{RL}=\sum_{\mathrm{i}=1}^{\mathrm{I}_{\mathrm{R}}} \mathrm{RL_{ \textrm {i } }}
$$

Step 2: Number of TOT predicted crashes during analysis period for each site i (i.e., $\mathrm{i}=1$ to $\mathrm{I}_{\mathrm{R}}$ ).

$$
\mathrm{RE}_{\mathrm{i}(\mathrm{TOT})}
$$


Step 3: Number of FI predicted crashes during analysis period for each site i (i.e., $\mathrm{i}=1$ to $\mathrm{I}_{\mathrm{R}}$ ).

$$
\mathrm{RE}_{\mathrm{i}(\mathrm{FI})}
$$

Step 4: Number of PDO predicted crashes during analysis period for each site i (i.e., $\mathrm{i}=1$ to $\mathrm{I}_{\mathrm{R}}$ ).

$$
\mathrm{RE}_{\mathrm{i}(\mathrm{PDO})}
$$

Step 5: Number of TOT predicted crashes during the entire analysis period along all ramps combined.

$$
\mathrm{RE}_{\text {(TOT) }}=\sum_{\mathrm{i}=1}^{\mathrm{I}_{\mathrm{R}}} \mathrm{RE}_{\mathrm{i}(\mathrm{TOT})}
$$

Step 6: Number of FI predicted crashes during the entire analysis period along all ramps combined.

$$
\mathrm{RE}_{(\mathrm{FI})}=\sum_{\mathrm{i}=1}^{\mathrm{I}_{\mathrm{R}}} \mathrm{RE}_{\mathrm{i}(\mathrm{FI})}
$$

Step 7: Number of PDO predicted crashes during the entire analysis period along all ramps combined.

$$
\mathrm{RE}_{(\mathrm{PDO})}=\sum_{\mathrm{i}=1}^{\mathrm{I}_{\mathrm{R}}} \mathrm{RE}_{\mathrm{i}(\mathrm{PDO})}
$$

Step 8: Average ADT during analysis period for each site i (i.e., $\mathrm{i}=1$ to $\mathrm{I}_{\mathrm{R}}$ ).

$$
\operatorname{AVG}\left(\mathrm{ADT}_{\mathrm{i}(\mathrm{R})}\right)=\frac{\sum_{\mathrm{y}=1}^{\mathrm{Y}} \mathrm{ADT}_{\mathrm{iy}}}{\mathrm{Y}}
$$

Step 9: Average ADT during analysis period along all ramps combined.

$$
\operatorname{AVG}\left(\mathrm{ADT}_{\mathrm{R}}\right)=\frac{\mathrm{MVMT}_{\mathrm{R}} \times 1,000,000}{\sum_{\mathrm{i}=1}^{I_{R}} \mathrm{RL}_{\mathrm{i}} \times 365 \times \mathrm{Y}}
$$

Step 10: Max ADT SPF exceeded for each site i (i.e., $\mathrm{i}=1$ to $\mathrm{I}_{\mathrm{R}}$ ).

Report violation as determined in Step 12 under algorithms for ramps. 
Step 11: MVMT for each site i (i.e., $\mathrm{i}=1$ to $\mathrm{I}_{\mathrm{R}}$ ).

$$
\operatorname{MVMT}_{i(\mathrm{R})}=\sum_{\mathrm{y}=1}^{\mathrm{Y}} \frac{\mathrm{RL}_{\mathrm{iy}} \times \mathrm{ADT}_{\mathrm{iy}} \times 365}{1,000,000}
$$

Step 12: Million vehicle-miles traveled (MVMT) along all ramps combined.

$$
\operatorname{MVMT}_{\mathrm{R}}=\sum_{\mathrm{i}=1}^{\mathrm{I}_{\mathrm{R}}} \sum_{\mathrm{y}=1}^{\mathrm{Y}} \frac{\mathrm{RL}_{\mathrm{iy}} \times \mathrm{ADT}_{\mathrm{iy}} \times 365}{1,000,000}
$$

Step 13: Crash rate per MVMT for each site i (i.e., $\mathrm{i}=1$ to $\mathrm{I}_{\mathrm{R}}$ ).

$$
\text { Crash Rate }_{\mathrm{i}(\mathrm{R})}=\frac{\mathrm{RE}_{\mathrm{i}(\mathrm{TOT})}}{\mathrm{MVMT}_{\mathrm{i}(\mathrm{R})}}
$$

Step 14: Crash rate per MVMT along all ramps combined.

$$
\text { Crash Rate }{ }_{\mathrm{R}}=\frac{\mathrm{RE}_{(\mathrm{TOT})}}{\mathrm{MVMT}_{\mathrm{R}}}
$$

Step 15: Incorrect collision distribution for each site i (i.e., $\mathrm{i}=1$ to $\mathrm{I}_{\mathrm{R}}$ ).

Report violation as determined in Step 3 under algorithms for ramps, if the sum of the crash proportions for crash types 1 to 13 do not sum to exactly 1.0. 
Table B-19. Number of Predicted Crashes for Individual Ramps

\begin{tabular}{|c|c|c|c|c|c|c|c|c|c|c|}
\hline \multirow{2}{*}{$\begin{array}{c}\text { Ramp } \\
\text { number }\end{array}$} & \multirow{2}{*}{$\begin{array}{c}\text { Ramp } \\
\text { description }\end{array}$} & \multirow{2}{*}{$\begin{array}{c}\text { Ramp } \\
\text { length } \\
\text { (mi) }\end{array}$} & \multicolumn{3}{|c|}{$\begin{array}{c}\text { Number of predicted crashes during analysis } \\
\text { period }\end{array}$} & \multirow{2}{*}{$\begin{array}{c}\text { ADT } \\
\text { (veh/day) }\end{array}$} & \multirow{2}{*}{$\begin{array}{l}\text { Max ADT for } \\
\text { SPF exceeded }\end{array}$} & \multirow[b]{2}{*}{ MVMT } & \multirow{2}{*}{$\begin{array}{c}\text { Crash rate } \\
\text { per } \\
\text { MVMT }\end{array}$} & \multirow{2}{*}{$\begin{array}{c}\text { Incorrect } \\
\text { collision } \\
\text { distribution }\end{array}$} \\
\hline & & & Total & FI & PDO & & & & & \\
\hline \multicolumn{11}{|l|}{ Total } \\
\hline \multicolumn{11}{|l|}{1} \\
\hline \multicolumn{11}{|l|}{2} \\
\hline \multicolumn{11}{|l|}{$:$} \\
\hline \multicolumn{11}{|l|}{ : } \\
\hline \multicolumn{11}{|l|}{ : } \\
\hline \multicolumn{11}{|l|}{ : } \\
\hline \multicolumn{11}{|l|}{48} \\
\hline \multicolumn{11}{|l|}{49} \\
\hline 50 & & & & & & & & & & \\
\hline
\end{tabular}




\section{ALGORITHMS FOR OUTPUT REPORTS FOR CROSSROAD RAMP TERMINALS AND INTERSECTIONS}

Output results for crossroad ramp terminals and intersections are provided in two tables. The first table shows the number of predicted crashes by collision type for all crossroad ramp terminals and intersections combined. The second table shows the number of predicted crashes for each individual crossroad ramp terminal and intersection.

\section{Number of Predicted Crashes by Collision Type for All Crossroad Ramp Terminals and Intersections Combined}

Table B-20 shows the number of predicted crashes by collision type for all crossroad ramp terminals and intersections combined. These crashes are categorized by the 13 collision types and by severity level. The algorithms for filling in this table are presented below.

Table B-20. Number of Predicted Crashes by Collision Type for all Crossroad Ramp Terminals and Intersections Combined

\begin{tabular}{|c|c|c|c|c|c|c|}
\hline \multirow[b]{3}{*}{ Collision type } & \multicolumn{6}{|c|}{ Number and percentage of predicted crashes by collision type } \\
\hline & \multicolumn{2}{|c|}{ Total } & \multicolumn{2}{|c|}{ FI } & \multicolumn{2}{|c|}{ PDO } \\
\hline & No. & $\%$ & No. & $\%$ & No. & $\%$ \\
\hline \multicolumn{7}{|l|}{ All collision types } \\
\hline \multicolumn{7}{|l|}{ Single vehicle } \\
\hline \multicolumn{7}{|l|}{ Fixed object } \\
\hline \multicolumn{7}{|l|}{ Animal } \\
\hline \multicolumn{7}{|l|}{ Pedestrian } \\
\hline \multicolumn{7}{|l|}{ Bicyclist } \\
\hline \multicolumn{7}{|l|}{ Parked car } \\
\hline \multicolumn{7}{|l|}{ Noncollision } \\
\hline \multicolumn{7}{|l|}{ Other single-vehicle } \\
\hline \multicolumn{7}{|l|}{ Multiple vehicle } \\
\hline \multicolumn{7}{|l|}{ Rear-end } \\
\hline \multicolumn{7}{|l|}{ Head-on } \\
\hline \multicolumn{7}{|l|}{ Angle } \\
\hline \multicolumn{7}{|l|}{ Sideswipe, same direction } \\
\hline Sideswipe, opposite direction & & & & & & \\
\hline Other multiple-vehicle & & & & & & \\
\hline
\end{tabular}


Step 1: Number of TOT predicted crashes for a given collision type for all crossroad ramp terminals and intersections combined during entire analysis period:

$$
\mathrm{RTE}_{(\mathrm{CT} / \mathrm{TOT})}=\sum_{\mathrm{i}=1}^{\mathrm{I}_{\mathrm{RT}}} \mathrm{RTE}_{\mathrm{i}(\mathrm{CT} / \mathrm{TOT})}
$$

Step 2: Percentage of TOT predicted crashes for a given collision type for all crossroad ramp terminals and intersections combined during entire analysis period:

$$
\operatorname{Percent}\left(\mathrm{RTE}_{(\mathrm{CT} / \mathrm{TOT})}\right)=\frac{\operatorname{RTE}_{(\mathrm{CT} / \mathrm{TOT})}}{\operatorname{RTE}_{(\mathrm{TOT})}}
$$

Step 3: Number of FI predicted crashes for a given collision type for all crossroad ramp terminals and intersections combined during entire analysis period:

$$
\operatorname{RTE}_{(\mathrm{CT} / \mathrm{FI})}=\sum_{\mathrm{i}=1}^{\mathrm{I}_{\mathrm{RT}}} \mathrm{RTE}_{\mathrm{i}(\mathrm{CT} / \mathrm{FI})}
$$

Step 4: Percentage of FI predicted crashes for a given collision type for all crossroad ramp terminals and intersections combined during entire analysis period:

$$
\operatorname{Percent}\left(\mathrm{RTE}_{(\mathrm{CT} / \mathrm{FI})}\right)=\frac{\mathrm{RTE}_{(\mathrm{CT} / \mathrm{FI})}}{\mathrm{RTE}_{(\mathrm{FI})}}
$$

Step 5: Number of PDO predicted crashes for a given collision type for all crossroad ramp terminals and intersections combined during entire analysis period:

$$
\operatorname{RTE}_{(\mathrm{CT} / \mathrm{PDO})}=\sum_{\mathrm{i}=1}^{\mathrm{I}_{\mathrm{RT}}} \mathrm{RTE}_{\mathrm{i}(\mathrm{CT} / \mathrm{PDO})}
$$

Step 6: Percentage of PDO predicted crashes for a given collision type for all crossroad ramp terminals and intersections combined during entire analysis period:

$$
\operatorname{Percent}\left(\mathrm{RTE}_{(\mathrm{CT} / \mathrm{PDO})}\right)=\frac{\mathrm{RTE}_{(\mathrm{CT} / \mathrm{PDO})}}{\mathrm{RTE}_{(\mathrm{PDO})}}
$$

Steps 1 through 6 are repeated for all collision types 1 through 13 . Subtotals for all single vehicle and all multiple vehicle collisions are provided by summing the numbers and percentages for all single vehicle collision types and all multiple vehicle collision types, respectively. The first row of the table displays the number and percentage for all collision types. Again, these values are simply the sums of the numbers and percentages for all collision types 1 through 13. 


\section{Number of Predicted Crashes for Individual Crossroad Ramp Terminals and Intersections}

Table B-21 shows the terminal number and terminal description for each individual site. For each individual site, the number of predicted crashes during the analysis period is provided by severity level along with MEV, crashes per year, and crash rate per MEV. Totals are provided in the first row for number of predicted crashes during analysis period, $\mathrm{MEV}$, crashes per year, and crash rate per MEV. Several columns in table B-21 are also provided to serve as warnings to users when interpreting the output. One warning is associated with the ADT of a given site. A second warning is associated with the crash distributions. The algorithms for filling in this table are presented below. Information on terminal description is the same as input by the user on the Input Ramp Terminals worksheet.

Step 1: Number of TOT predicted crashes during analysis period for each site i (i.e., $\mathrm{i}=1$ to $\mathrm{I}_{\mathrm{RT}}$ ).

$$
\mathrm{RTE}_{\mathrm{i}(\mathrm{TOT})}
$$

Step 2: Number of FI predicted crashes during analysis period for each site i (i.e., $\mathrm{i}=1$ to $\mathrm{I}_{\mathrm{RT}}$ ).

$$
\mathrm{RTE}_{\mathrm{i}(\mathrm{FI})}
$$

Step 3: Number of PDO predicted crashes during analysis period for each site i (i.e., $\mathrm{i}=1$ to $\left.\mathrm{I}_{\mathrm{RT}}\right)$.

$$
\mathrm{RTE}_{\mathrm{i}(\mathrm{PDO})}
$$

Step 4: Number of TOT predicted crashes during the entire analysis period along all crossroad ramp terminals and intersections combined.

$$
\mathrm{RTE}_{(\mathrm{TOT})}=\sum_{\mathrm{i}=1}^{\mathrm{I}_{\mathrm{RT}}} \mathrm{RTE}_{\mathrm{i}(\mathrm{TOT})}
$$

Step 5: Number of FI predicted crashes during the entire analysis period along all crossroad ramp terminals and intersections combined.

$$
\mathrm{RTE}_{(\mathrm{FI})}=\sum_{\mathrm{i}=1}^{\mathrm{I}_{\mathrm{RT}}} \mathrm{RTE}_{\mathrm{i}(\mathrm{FI})}
$$

Step 6: Number of PDO predicted crashes during the entire analysis period along all crossroad ramp terminals and intersections combined.

$$
\mathrm{RTE}_{(\mathrm{PDO})}=\sum_{\mathrm{i}=1}^{\mathrm{I}_{\mathrm{RT}}} \mathrm{RTE}_{\mathrm{i}(\mathrm{PDO})}
$$


Step 7: Max ADT SPF exceeded for each site i (i.e., $\mathrm{i}=1$ to $\mathrm{I}_{\mathrm{RT}}$ ).

Report violation as determined in Steps 13 and 14 under algorithms for crossroad ramp terminals and intersections.

Step 8: $\mathrm{MEV}$ for each site i (i.e., $\mathrm{i}=1$ to $\mathrm{I}_{\mathrm{RT}}$ ).

If the site is a conventional intersection (CI), then

$$
M E V_{i[R T(C I)]}=\sum_{y=1}^{Y} \frac{\left(\left(2 \times A D T_{i y(\text { major } r d)}\right)+\left(2 \times A D T_{i y(\text { off-ramp })}\right)\right) \times 365}{1,000,000}
$$

If the site is a ramp terminal (RT), then

$$
M E V_{i[R T(R T)]}=\sum_{y=1}^{Y} \frac{\left(\left(2 \times A D T_{i y(\text { major } r d)}\right)+\left(A D T_{i y(\text { off-ramp })}\right)\right) \times 365}{1,000,000}
$$

Step 9: MEV for all crossroad ramp terminals and intersections combined.

The total MEV for all crossroad ramp terminals and intersections is

$$
\mathrm{MEV}_{\mathrm{RT}}=\mathrm{MEV}_{\mathrm{RT}(\mathrm{RT})}+\mathrm{MEV}_{\mathrm{RT}(\mathrm{CI})}
$$

for all $i=1$ to $I_{R T}$

Step 10: Crashes per year for each site i (i.e., $\mathrm{i}=1$ to $\mathrm{I}_{\mathrm{RT}}$ ).

$$
(\text { Crashes } / \mathrm{yr})_{\mathrm{i}(\mathrm{RT})}=\frac{\mathrm{RTE}_{\mathrm{i}(\mathrm{TOT})}}{\mathrm{Y}}
$$

Step 11: Crashes per year for all crossroad ramp terminals and intersections combined.

$$
(\text { Crashes } / \mathrm{yr})_{(\mathrm{RT})}=\frac{\sum_{\mathrm{i}=1}^{\mathrm{I}_{\mathrm{RT}}} \mathrm{RTE}_{\mathrm{i}(\mathrm{TOT})}}{\mathrm{Y}}
$$

Step 12: Crash rate per MEV for each site i (i.e., $\mathrm{i}=1$ to $\mathrm{I}_{\mathrm{RT}}$ ).

$$
\text { Crash Rate }_{i(R T)}=\frac{\operatorname{RTE}_{\mathrm{i}(\mathrm{TOT})}}{\operatorname{MEV}_{\mathrm{i}(\mathrm{RT})}}
$$


Step 13: Crash rate per MEV for all crossroad ramp terminals and intersections combined.

$$
\text { Crash Rate }_{\mathrm{RT}}=\frac{\text { RTE }_{(\mathrm{TOT})}}{\mathrm{MEV}_{\mathrm{RT}}}
$$

Step 14: Incorrect collision distribution for each site i (i.e., $\mathrm{i}=1$ to $\mathrm{I}_{\mathrm{RT}}$ ).

Report violation as determined in Step 3 under algorithms for crossroad ramp terminals and intersections, if the sum of the crash proportions for crash types 1 to 13 do not sum to exactly 1.0 . 
Table B-21. Number of Predicted Crashes for Individual Crossroad Ramp Terminals and Intersections

\begin{tabular}{|c|c|c|c|c|c|c|c|c|c|}
\hline \multirow{2}{*}{$\begin{array}{l}\text { Terminal } \\
\text { number }\end{array}$} & \multirow{2}{*}{$\begin{array}{l}\text { Terminal } \\
\text { description }\end{array}$} & \multicolumn{3}{|c|}{$\begin{array}{c}\text { Number of predicted crashes during } \\
\text { analysis period }\end{array}$} & \multirow{2}{*}{$\begin{array}{l}\text { Max ADT } \\
\text { for SPF } \\
\text { exceeded }\end{array}$} & \multirow[b]{2}{*}{ MEV } & \multirow{2}{*}{$\begin{array}{l}\text { Crashes } \\
\text { per year }\end{array}$} & \multirow{2}{*}{$\begin{array}{l}\text { Crash rate } \\
\text { per MEV }\end{array}$} & \multirow{2}{*}{$\begin{array}{l}\text { Incorrect } \\
\text { collision } \\
\text { distribution }\end{array}$} \\
\hline & & Total & FI & PDO & & & & & \\
\hline \multicolumn{10}{|l|}{ Total } \\
\hline \multicolumn{10}{|l|}{$\frac{1}{2}$} \\
\hline \multicolumn{10}{|l|}{2} \\
\hline \multicolumn{10}{|l|}{$:$} \\
\hline \multicolumn{10}{|l|}{ : } \\
\hline \multicolumn{10}{|l|}{ : } \\
\hline \multicolumn{10}{|l|}{ : } \\
\hline \multicolumn{10}{|l|}{48} \\
\hline \multicolumn{10}{|l|}{49} \\
\hline 50 & & & & & & & & & \\
\hline
\end{tabular}




\section{ALGORITHMS FOR OUTPUT REPORTS FOR CROSSROAD ROADWAY SEGMENTS}

Output results for crossroad roadway segments are provided in two tables. The first table shows the number of predicted crashes by collision type for all crossroad roadway segments combined. The second table shows the number of predicted crashes for each individual crossroad roadway segment.

\section{Number of Predicted Crashes by Collision Type for All Arterial Crossroad Roadway Segments Combined}

Table B-22 shows the number of predicted crashes by collision type for all crossroad roadway segments combined. These crashes are categorized by the 13 collision types and by severity level. The algorithms for filling in this table are presented below.

Table B-22. Number of Predicted Crashes by Collision Type for all Arterial Crossroad Roadway Segments Combined

\begin{tabular}{|c|c|c|c|c|c|c|}
\hline \multirow[b]{3}{*}{ Collision type } & \multicolumn{6}{|c|}{ Number and percentage of predicted crashes by collision type } \\
\hline & \multicolumn{2}{|c|}{ Total } & \multicolumn{2}{|c|}{ FI } & \multicolumn{2}{|c|}{ PDO } \\
\hline & No. & $\%$ & No. & $\%$ & No. & $\%$ \\
\hline \multicolumn{7}{|l|}{ All collision types } \\
\hline \multicolumn{7}{|l|}{ Single vehicle } \\
\hline \multicolumn{7}{|l|}{ Fixed object } \\
\hline \multicolumn{7}{|l|}{ Animal } \\
\hline \multicolumn{7}{|l|}{ Pedestrian } \\
\hline \multicolumn{7}{|l|}{ Bicyclist } \\
\hline \multicolumn{7}{|l|}{ Parked car } \\
\hline \multicolumn{7}{|l|}{ Noncollision } \\
\hline \multicolumn{7}{|l|}{ Other single-vehicle } \\
\hline \multicolumn{7}{|l|}{ Multiple vehicle } \\
\hline \multicolumn{7}{|l|}{ Rear-end } \\
\hline \multicolumn{7}{|l|}{ Head-on } \\
\hline \multicolumn{7}{|l|}{ Angle } \\
\hline \multicolumn{7}{|l|}{ Sideswipe, same direction } \\
\hline \multicolumn{7}{|l|}{ Sideswipe, opposite direction } \\
\hline Other multiple-vehicle & & & & & & \\
\hline
\end{tabular}

Step 1: Number of TOT predicted crashes for a given collision type for all crossroad roadway segments combined during entire analysis period:

$$
\operatorname{RSE}_{(\mathrm{CT} / \mathrm{TOT})}=\sum_{\mathrm{i}=1}^{\mathrm{I}_{\mathrm{RS}}} \mathrm{RSE}_{\mathrm{i}(\mathrm{CT} / \mathrm{TOT})}
$$


Step 2: Percentage of TOT predicted crashes for a given collision type for all crossroad roadway segments combined during entire analysis period:

$$
\text { Percent }\left(\operatorname{RSE}_{(\mathrm{CT} / \mathrm{TOT})}\right)=\frac{\operatorname{RSE}_{(\mathrm{CT} / \mathrm{TOT})}}{\operatorname{RSE}_{(\mathrm{TOT})}}
$$

Step 3: Number of FI predicted crashes for a given collision type for all crossroad roadway segments combined during entire analysis period:

$$
\operatorname{RSE}_{(\mathrm{CT} / \mathrm{FI})}=\sum_{\mathrm{i}=1}^{\mathrm{I}_{\mathrm{RS}}} \mathrm{RSE}_{\mathrm{i}(\mathrm{CT} / \mathrm{FI})}
$$

Step 4: Percentage of FI predicted crashes for a given collision type for all crossroad roadway segments combined during entire analysis period:

$$
\operatorname{Percent}\left(\mathrm{RSE}_{(\mathrm{CT} / \mathrm{FI})}\right)=\frac{\mathrm{RSE}_{(\mathrm{CT} / \mathrm{FI})}}{\operatorname{RSE}_{(\mathrm{FI})}}
$$

Step 5: Number of PDO predicted crashes for a given collision type for all crossroad roadway segments combined during entire analysis period:

$$
\operatorname{RSE}_{(\mathrm{CT} / \mathrm{PDO})}=\sum_{\mathrm{i}=1}^{\mathrm{I}_{\mathrm{RS}}} \mathrm{RSE}_{\mathrm{i}(\mathrm{CT} / \mathrm{PDO})}
$$

Step 6: Percentage of PDO predicted crashes for a given collision type for all crossroad roadway segments combined during entire analysis period:

$$
\operatorname{Percent}\left(\mathrm{RSE}_{(\mathrm{CT} / \mathrm{PDO})}\right)=\frac{\operatorname{RSE}_{(\mathrm{CT} / \mathrm{PDO})}}{\operatorname{RSE}_{(\mathrm{PDO})}}
$$

Steps 1 through 6 are repeated for all collision types 1 through 13. Subtotals for all single vehicle and all multiple vehicle collisions are provided by summing the numbers and percentages for all single vehicle collision types and all multiple vehicle collision types, respectively. The first row of the table displays the number and percentage for all collision types. Again, these values are simply the sums of the numbers and percentages for all collision types 1 through 13.

\section{Number of Predicted Crashes for Individual Crossroad roadway Segments}

Table B-23 shows the segment number, segment description, direction of travel, beginning milepost, ending milepost, and segment length for each individual site. For each individual site, the number of predicted crashes during the analysis period is provided by severity level. The 
average daily traffic (ADT) for each site is given for the entire analysis period along with MVMT, crashes per mile per year, and crash rate per MVMT. Totals are provided in the first row for segment length, number of predicted crashes during analysis period, ADT, MVMT, crashes per mile per year, and crash rate per MVMT. Several columns in table B-23 are also provided to serve as warnings to users when interpreting the output. One warning is associated with the ADT of a given site. A second warning is associated with the crash distributions. The algorithms for filling in this table are presented below. Information on segment description, direction of travel, beginning MP, ending MP, and segment length are the same as input by the user on the Input Crossroad Segments worksheet.

Step 1: Total segment length:

$$
\mathrm{SL}_{(\mathrm{RS})}=\sum_{\mathrm{i}=1}^{\mathrm{I}_{\mathrm{RS}}} \mathrm{SL}_{\mathrm{i}}
$$

Step 2: Number of TOT predicted crashes during analysis period for each site i (i.e., $\mathrm{i}=1$ to $\mathrm{I}_{\mathrm{RS}}$ ).

$$
\mathrm{RSE}_{\mathrm{i}(\mathrm{TOT})}
$$

Step 3: Number of FI predicted crashes during analysis period for each site i (i.e., $\mathrm{i}=1$ to $\mathrm{I}_{\mathrm{RS}}$ ).

$$
\mathrm{RSE}_{\mathrm{i}(\mathrm{FI})}
$$

Step 4: Number of PDO predicted crashes during analysis period for each site i (i.e., $\mathrm{i}=1$ to $\mathrm{I}_{\mathrm{RS}}$ ).

$$
\mathrm{RSE}_{\mathrm{i}(\mathrm{PDO})}
$$

Step 5: Number of TOT predicted crashes during the entire analysis period along all crossroad roadway segments combined.

$$
\operatorname{RSE}_{(\text {TOT) }}=\sum_{\mathrm{i}=1}^{\mathrm{I}_{\mathrm{RS}}} \mathrm{RSE}_{\mathrm{i}(\mathrm{TOT})}
$$

Step 6: Number of FI predicted crashes during the entire analysis period along all crossroad roadway segments combined.

$$
\operatorname{RSE}_{(\mathrm{FI})}=\sum_{\mathrm{i}=1}^{\mathrm{I}_{\mathrm{RS}}} \mathrm{RSE}_{\mathrm{i}(\mathrm{FI})}
$$

Step 7: Number of PDO predicted crashes during the entire analysis period along all crossroad roadway segments combined.

$$
\mathrm{RSE}_{(\mathrm{PDO})}=\sum_{\mathrm{i}=1}^{\mathrm{I}_{\mathrm{RS}}} \mathrm{RSE}_{\mathrm{i}(\mathrm{PDO})}
$$


Step 8: Average ADT during analysis period for each site i (i.e., $\mathrm{i}=1$ to $\mathrm{I}_{\mathrm{RS}}$ ).

$$
\operatorname{AVG}\left(\mathrm{ADT}_{\mathrm{i}(\mathrm{RS})}\right)=\frac{\sum_{\mathrm{y}=1}^{\mathrm{Y}} \mathrm{ADT}_{\mathrm{iy}}}{\mathrm{Y}}
$$

Step 9: Average ADT during analysis period along all crossroad roadway segments combined.

$$
\operatorname{AVG}\left(\mathrm{ADT}_{\mathrm{RS}}\right)=\frac{\mathrm{MVMT}_{\mathrm{RS}} \times 1,000,000}{\sum_{\mathrm{i}=1}^{\mathrm{I}_{\mathrm{RS}}} \mathrm{SL}_{\mathrm{i}} \times 365 \times \mathrm{Y}}
$$

Step 10: Max ADT SPF exceeded for each site i (i.e., $\mathrm{i}=1$ to $\mathrm{I}_{\mathrm{RS}}$ ).

Report violation as determined in Step 12 under algorithms for crossroad roadway segments.

Step 11: MVMT for each site i (i.e., $\mathrm{i}=1$ to $\mathrm{I}_{\mathrm{RS}}$ ).

$$
\operatorname{MVMT}_{\mathrm{i}(\mathrm{RS})}=\sum_{\mathrm{y}=1}^{\mathrm{Y}} \frac{\mathrm{SL}_{\mathrm{iy}} \times \mathrm{ADT}_{\mathrm{iy}} \times 365}{1,000,000}
$$

Step 12: Million vehicle-miles traveled (MVMT) along crossroad roadway segments.

$$
\operatorname{MVMT}_{\mathrm{RS}}=\sum_{\mathrm{i}=1}^{\mathrm{I}_{\mathrm{RS}}} \sum_{\mathrm{y}=1}^{\mathrm{Y}} \frac{\mathrm{SL}_{\mathrm{iy}} \times \mathrm{ADT}_{\mathrm{iy}} \times 365}{1,000,000}
$$

Step 13: Crashes per mile per year for each site i (i.e., $\mathrm{i}=1$ to $\mathrm{I}_{\mathrm{RS}}$ ).

$$
(\text { Crashes } / \mathrm{mi} / \mathrm{yr})_{\mathrm{i}(\mathrm{RS})}=\frac{\mathrm{RSE}_{\mathrm{i}(\mathrm{TOT})}}{\mathrm{SL}_{\mathrm{i}} \times \mathrm{Y}}
$$

Step 14: Crashes per mile per year along all crossroad roadway segments combined.

$$
(\text { Crashes } / \mathrm{mi} / \mathrm{yr})_{(\mathrm{RS})}=\frac{\mathrm{RSE}_{(\mathrm{TOT})}}{\sum_{\mathrm{i}=1}^{\mathrm{RSS}} \mathrm{SL}_{\mathrm{i}} \times \mathrm{Y}}
$$

Step 15: Crash rate per MVMT for each site i (i.e., $\mathrm{i}=1$ to $\mathrm{I}_{\mathrm{RS}}$ ).

$$
\text { Crash Rate }_{\mathrm{i}(\mathrm{RS})}=\frac{\operatorname{RSE}_{\mathrm{i}(\mathrm{TOT})}}{\operatorname{MVMT}_{\mathrm{i}(\mathrm{RS})}}
$$


Step 16: Crash rate per MVMT along all crossroad roadway segments combined.

$$
\text { Crash Rate } \mathrm{RS}=\frac{\mathrm{RSE}_{(\mathrm{TOT})}}{\mathrm{MVMT}_{\mathrm{RS}}}
$$

Step 17: Incorrect collision distribution for each site i (i.e., $\mathrm{i}=1$ to $\mathrm{I}_{\mathrm{RS}}$ ).

Report violation as determined in Step 3 under algorithms for crossroad roadway segments, if the sum of the crash proportions for crash types 1 to 13 do not sum to exactly 1.0. 
Table B-23. Number of Predicted Crashes for Individual Arterial Crossroad Roadway Segments

\begin{tabular}{|c|c|c|c|c|c|c|c|c|c|c|c|c|c|c|}
\hline \multirow{2}{*}{$\begin{array}{l}\text { Segment } \\
\text { number }\end{array}$} & \multirow{2}{*}{$\begin{array}{c}\text { Segment } \\
\text { description }\end{array}$} & \multirow{2}{*}{$\begin{array}{c}\text { Direction } \\
\text { of travel }\end{array}$} & \multirow{2}{*}{\begin{tabular}{|c} 
Beginning \\
MP
\end{tabular}} & \multirow{2}{*}{$\begin{array}{c}\text { Ending } \\
\text { MP }\end{array}$} & \multirow{2}{*}{$\begin{array}{c}\text { Segment } \\
\text { length } \\
\text { (mi) }\end{array}$} & \multicolumn{3}{|c|}{\begin{tabular}{|c|} 
Number of \\
predicted crashes \\
during analysis \\
period
\end{tabular}} & \multirow{2}{*}{$\begin{array}{c}\text { ADT } \\
\text { (veh/day) }\end{array}$} & \multirow{2}{*}{$\begin{array}{c}\text { Max ADT } \\
\text { for SPF } \\
\text { exceeded }\end{array}$} & \multirow[b]{2}{*}{ MVMT } & \multirow{2}{*}{$\begin{array}{l}\text { Crashes } \\
\text { per mile } \\
\text { per year }\end{array}$} & \multirow{2}{*}{$\begin{array}{c}\text { Crash } \\
\text { rate per } \\
\text { MVMT }\end{array}$} & \multirow{2}{*}{$\begin{array}{l}\text { Incorrect } \\
\text { collision } \\
\text { distribution }\end{array}$} \\
\hline & & & & & & \begin{tabular}{|l|} 
Total \\
\end{tabular} & FI & PDO & & & & & & \\
\hline \multicolumn{15}{|l|}{ Total } \\
\hline \multicolumn{15}{|c|}{1} \\
\hline \multicolumn{15}{|l|}{2} \\
\hline \multirow{2}{*}{\multicolumn{15}{|c|}{ : }} \\
\hline & & & & & & & & & & & & & & \\
\hline : & & & & & & & & & & & & & & \\
\hline \multicolumn{15}{|c|}{ 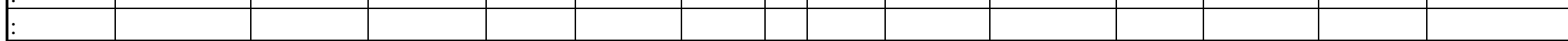 } \\
\hline \multicolumn{15}{|l|}{48} \\
\hline \multicolumn{15}{|l|}{49} \\
\hline 50 & & & & & & & & & & & & & & \\
\hline
\end{tabular}

